

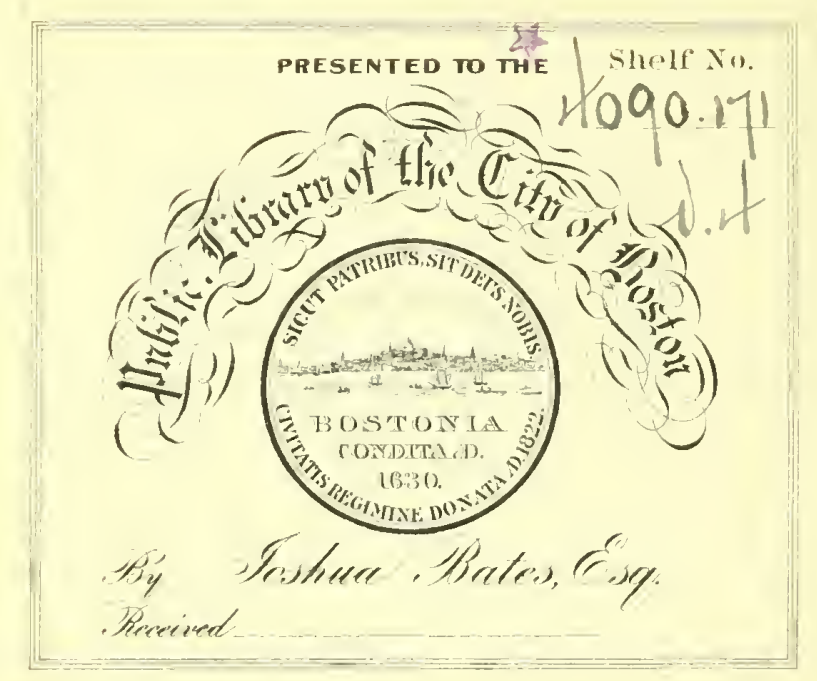




FORSCHUNGEN ZUR ISLAMISCHEN KUNST HERAUSGEGEBEN VON FRIEDRICH SARRE I

\author{
F. SARRE UND E. HERZFELD
}

ARCHÄOLOGISCHE REISE IM EUPHRAT- UND

TIGRIS-GEBIET

BAND IV 
Digitized by the Internet Archive in 2016 


\section{ArchäOlogische Reise im Euphrat- und TigRIS-GeBIET VON}

FRIEDRICH SARRE UND ERNST HERZFELD

IN VIER BÄNDEN

BAND IV

MIT 22 TEXTABBILDUNGEN UND 28 TAFELN

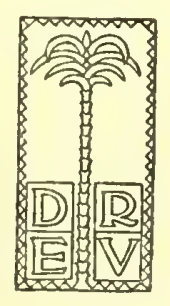

BERLIN 1920

VERLAG VON DIETRICH REIMER/ERNST VOHSEN/A.-G. 
ALLE RECHTE VORBEHALTEN 


\section{INHALTSVERZEICHNIS}

KAPITEL XI. DIE KERAMIK IM EUPHRAT- UND TIGRIS-GEBIET VON FRIEDRICH SARRE Keramik altorientalischer und hellenistischer Zeit . . . . . . . . . . . . . . 1 parthisch-sassanidischer Zeit . . . . . . . . . . . . . . . . . 4 Unglasierte Keramik mit Gravierung und aufgelegten Verzierungen . . . . . . . . . 9 Stempelkeramik . . . . . . . . . . . . . . . . . . . . . . . . . . . 10 Die Barbotin-Keramik . . . . . . . . . . . . . . . . . . . . . . . . 13 Frühislamische Keramik mit farbiger Malerei unter der Glasur . . . . . . . . . . 17 Keramik mit farbiger Malerei und geritzter Zeichnung unter der Glasur . . . . . . . 19 Die Keramik von Raqqah . . . . . . . . . . . . . . . . . . . . . . . 20 Andere Kleinfunde aus Raqqah . . . . . . . . . . . . . . . . . . . . . 25

ANHANG. HERBARAUFNAHMEN von ERNST HERZFELD . . . . . . . . . . . . . . . 26

Register der arabischen Namen

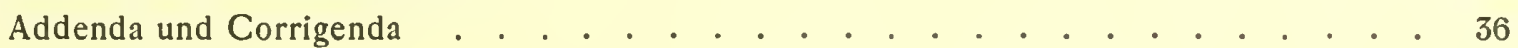
Allgemeiner Index . . . . . . . . . . . . . . . . . . . . . . . . . . 38

I. Geographischer Index . . . . . . . . . . . . . . . . . . . 38

II. Historischer Index . . . . . . . . . . . . . . . . . . . . . . 52

III. Technischer Index . . . . . . . . . . . . . . . . . . . . . . 56

\section{VERZEICHNIS DER ABBILDUNGEN}

Abb. 378. Altassyrische Keramik aus Tulūl 'Aqr. . . . . . . . . . . . . . . . . . . . 2

379. Assyrische Keramik aus Nimrud . . . . . . . . . . . . . . . . . . . . . 2

"380. Antike Scherben mit Malerei . . . . . . . . . . . . . . . . . . . . . . 3

"381. Halsstück eines eines glasierten Kruges aus Tābūs . . . . . . . . . . . . . . . . . . . . . 6

, 382. Bruchstück einer Terakottafigur aus Quraiyah und Widderköpfchen aus Baghdad . . . . 7

383. Bruchstücke bemalter unglasierter Gefäße aus Sūriyyah . . . . . . . . . . . . . 8

384. Scherben unglasierter Keramik aus Sudēre und Kushāf . . . . . . . . . . . . . 9

385. Unglasierte Keramik mit Gravierung aus Raqqah und Baghdad . . . . . . . . . . 9

386. Stempelkeramik verschiedener Herkunft . . . . . . . . . . . . . . . . . . 10

387. Stempelkeramik aus Takrīt . . . . . . . . . . . . . . . . . . . . . . 10

388. Keramische Stempel . . . . . . . . . . . . . . . . . . . . . 11

389. Figürliche Stempelkeramik aus Takrīt . . . . . . . . . . . . . . . . . . . 11

390. Figürliche Stempelkeramik verschiedener Herkunft . . . . . . . . . . . . . . 11

391. Tonmodell für die Dekoration eines unglasierten Gefäßes . . . . . . . . . . . . 12

392. Großer Wasserkrug aus Takrīt . . . . . . . . . . . . . . . . . 14

393. Topfmarkt in Mosul . . . . . . . . . . . . . . . . . . . . . . . 15

394. Bruchstück eines unglasierten Tongefäßes aus Tell Husain . . . . . . . . . . . . 16

395. " " " " "Takrīt . . . . . . . . . . . . . 16

396. „ einer glasierten Schüssel aus Nīliyyah . . . . . . . . . . . . . . . 18

397. " eines glasierten Tellers aus Baghdad . . . . . . . . . . . . . . . 18

398. " " " "Raqqah . . . . . . . . . . . . . . . 23

"399. Figürchen aus glasiertem Ton aus Raqqah . . . . . . . . . . . . . . . . . . 24

\section{TAFELVERZEICHNIS}

Tafel CXXI. Ruṣāah, Gesamtplan

" CXXII. Rușāfah, Basilika; Korykos; Zohāg, Rotes Kloster;

Zohag, Rotes Kloster, Restaurationsversuch;

Alahan Monastyr 
Tafel CXXIII. Seleukeia, al-Sür

" Qaṣr bint al-Qāọī

" CXXIV. Ktesiphon, Ṭāq i Kisrā, Rückseite

" CXXV. " " Widerlager

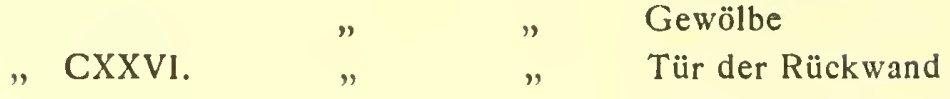

" $\quad$ (1908) Blick durch Seitentür

" CXXVII. Dastagerd, Wehrgang der Stadtmauer

Ktesiphon, Ṭāq i Kisrā, Galerie der Rückseite der Front

"CXXVIII. Dastagerd, das Zindān von Osten

CXXIX. Baghdad, die Mustanșiriyyah

" Dekoration im nördlichen Īwān der Mustanșiriyyah

" CXXX. " " Inschrift an der Außenmauer der Mustanșiriyyah

, Detail derselben Inschrift

" CXXXI. " Bāb al-Wastānī von außen

" Inneres des Bāb al-Wastān̄ī

" CXXXII. " $\quad$ Kuppel der Mirdjāniyyah

" Hof und Minaret der Mirdjāniyyah

, Inschrift am Nordportal des Khän Ortmah

" CXXXI1l. \# Kapitell aus 'Aqrqūf

" Kuppel der Sittah Zubaidah

" Tür des Heiligtums Bint 'Amrān

" inneres Tor des Bāb al-Wastāni

" babylonische Statue auf einem Privathause

„CXXXIIIA.

" Khān Ortmah, Inschrift 5

Mosul, Manārah al-maksūrah

Khān Kharnīnah, Miḥrāb

" CXXXIV. Mosul, Kenotaph des 'Aun al-dīn

"CXXXV. " "Aun al-dīn, Eckmiḥrāb

" Djāmi al-'Omariyyah, Mị̣rāb

" CXXXVI. , Q Qara Sarai

Altynköprü, Alte Brücke

" CXXXVII. 'Änah, Minaret

Irbil, Minaret, Sockelgeschoß

" " Gesamtansicht

" CXXXVIIl. Nisibis, Mār Yåqūb, Abklatsch der Gründungsinschrift

" " Innenansicht

" CXXXIX. " " Seitenportal

" Mār Yåqüb, Seitenportal

„ CXL. Raqqah, Zwölf Säulenkapitelle

" CXLI. Fragmente eines hellenistischen Stuckfrieses, Șālihiyyah Korinthische bemalte Tongefäße, Baghdad

Henkelvase mit rotem Firnis hellenistischer Zeit, Aleppo

" CXLII. Bruchstück eines frühislamischen, blauglasierten Tongefäßes, Raqqah Blauglasierter Henkelkrug parthischer Zeit, Hillah

Bruchstücke unglasierter Tongefäße spätantiker Zeit, Ṭābūs

Bruchstück eines bemalten Tongefäßes spätantiker Zeit, Halabiyyah

Ausguß elner Tonform parthischer Zeit

Blauglasierte Vase parthischer Zeit, Hillah 


\section{- VII -}

Tafel CXLIII. Großer grünglasierter Krug mit Reliefdekoration, Samarra

Großer unglasierter Wasserkrug mit Dekoration in Barbotine-Technik, Baghdad

" CXIV. Ausguß einer Tonform für einen unglasierten Wasserkrug, Baghdad

Hals eines unglasierten Wasserkruges, Baghdad

" CXLV. Babylonische weißglasierte Gefäße aus Hillah

Blauglasierter Henkelkrug im Museum für Völkerkunde

Blauglasierte Amphora parthisch-sassanidischer Zeit

Chinesisches Gefäß aus braunglasiertem Steingut in der Eumorfopoulos-Sammlung in London

" CXLVI. Stempelkeramik aus Takrīt und vom Shat! al-Nīl

„ CXLVII. Frühislamischer Gefäßscherben mit mehrfarbiger Malerei unter Glasur vom Schaț al-Nīl Napf derselben Gattung und Zeit

Malerei im Innern desselben Gefäßes

Chinesisches Steingutgefäß mit Malerei unter der Glasur in der Eumorfopoulos-Sammlung in London 



\section{KAPITEL XI \\ DIE KERAMIK IM EUPHRAT- UND TIGRIS-GEBIET}

von Friedrich SARre

Hierzu Taf. CXIII $\sim$ CXX, CXLI $\sim$ CXLVII; Abb. 378 - 399

Eine zusammenfassende Geschichte der Keramik Vorderasiens ist noch nicht geschricben worden. Dies wird erst dann möglich sein, wenn durch die Veröffentlichung einer größeren Anzahl von Ausgrabungen als bisher feste Anhaltspunkte für bestimmte Zeitabschnitte und Örtlichkeiten vorliegen werden.

Wenn wir es hier unternehmen, eine Auswahl der auf Ruinenstätten des Euphrat- und Tigris-Gebietes gesammelten Scherben und einige dort erworbene keramische Objekte zu veröffentlichen, so sind wir uns wohl bewußt, daß durch dieses Material keine erschöpfende Kenntnis der in Frage kommenden Keramik gewonnen werden kann. Immerhin sind diese Funde, wenn man sie in Rücksicht auf den Fundort und im Vergleich mit den Ergebnissen von Ausgrabungen betrachtet, von nicht unwesentlicher Bedeutung für unsere Kenntnis der mesopotamischen Töpferkunst. Von einer so genauen Beschreibung der in den Abbildungen und Tafeln wiedergegebenen Scherben, wie sie für die Veröffentlichungen von Grabungsergebnissen üblich ist, glaubten wir Abstand nehmen zu dürfen.

Die altorientalische und die hellenistische Keramik werden wir in Rücksicht auf die nicht allzu zahlreichen Funde nur kurz behandeln; die der parthisch-sassanidischen und der islamischen Epoche, vor allem die Keramik von Raqqah, kann jedoch auf Grund des reichhaltigeren Materials erschöpfender untersucht werden.

Einige der hier besprochenen keramischen Gruppen islamischer Zeit sind schon vor längerer Zeit, vor 15 Jahren, von uns behandelt worden. Seitdem hat die auf neue Entdeckungen sich stützende Forschung unsere Kenntnis wesentlich erweitert, so daß manche früher gewonnene Resultate auf ihre Richtigkeit von neuem geprüft werden mußten. Daß dies ohne Voreingenommenheit geschah, ist wohl selbstverständlich; von einem "mesopotamischen Schlagbaum, der mir für die islamische Forschung zwischen Persien und Zentralasien nötig schiene", ist mir nichts bekannt ${ }^{1}$ ). Wie frühere werden auch die folgenden Untersuchungen zeigen, daß das Vorhandensein ostasiatischer Einflüsse neben der auf altorientalisch-hellenistischer Tradition beruhenden Entwicklung mehrfach von mir erkannt und nachgewiesen worden ist.

Abgesehen von einigen wenigen zum Vergleich herangezogenen Gegenständen veranschaulichen die von Prof. Herzfeld und Maler Bollacher gezeichneten Textabbildungen und die Lichtdrucktafeln die bemerkenswertesten der auf unserer Reise gewonnenen keramischen Funde; letztere befinden sich in der Islamischen Abteilung des Kaiser Friedrich-Museums. Einige der Textabbildungen sind schon im I. Bande veröffentlicht worden.

\section{KERAMIK ALTORIENTALISCHER UND HELLENISTISCHER ZEIT}

Der al tass y ris ch en Zeit gehören Bruchstücke von dickwandigen, gut gebrannten Gefäßen mit scharfen Profilen an den Rändern an²), die wir auf dem Ruinenfelde von Tulūl 'Aqr am Tigris,

1) JOSEF STRZYGowski : Altai-Iran und Völker-

2) I. Band. S. 212.

wanderung. Leipzig 1917. S. $260 \mathrm{ff}$.

1 SARRE-HERZFELD, Archäologische Reise. Band IV. 


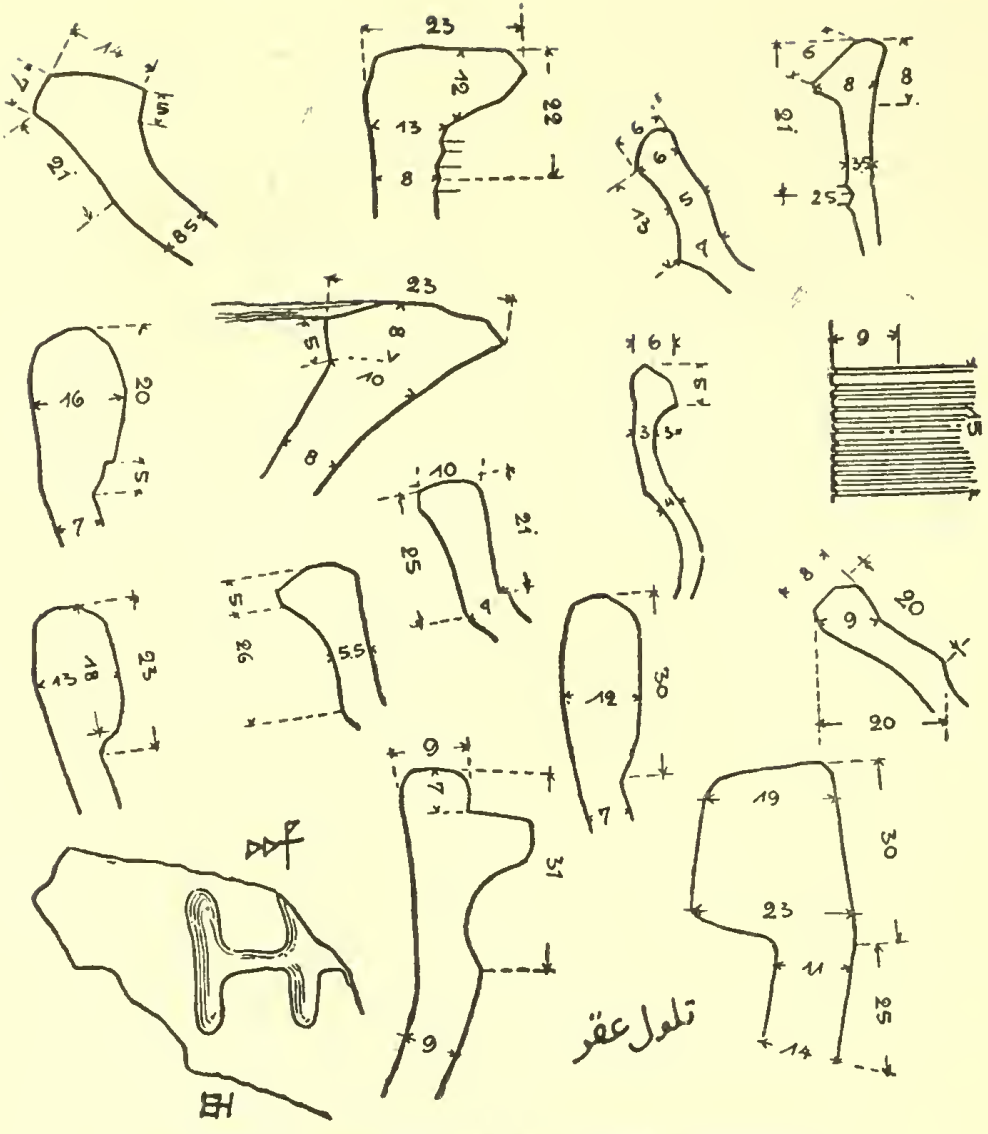

Abb. 378. Altassyrische Keramik aus Tulūl 'Aqr.
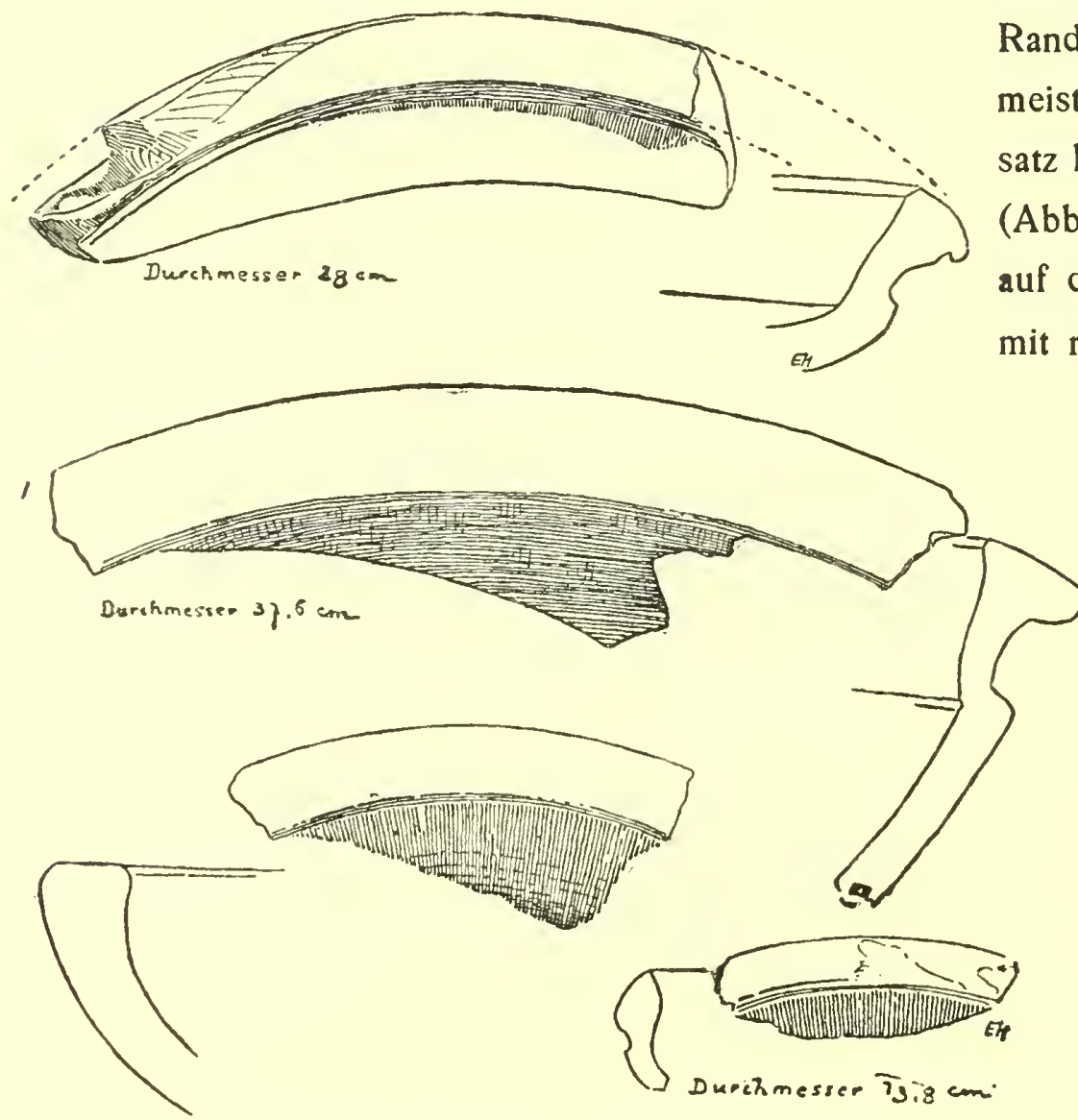

Abb. 379. Assyrische Keramik aus Nimrud. gegenübervon Assur, fanden, und die durch die beschränkte Zeitdauer der Besiedlung, um 1300 v. Chr., bestimmt sind (Abb. 378). Feiner im Ton und noch schärfer in den Profilen sind in Nimrud gefundene Fragmente von Schüsseln (Abb. 379), denen auf dem nahen Tell Kushāf und auf dem Tell al-Thadayain (Thapsakos) aufgelesene Scherben sehr nahe stehen und auf die Besiedlung des letzteren Ortes schon zu altassyrischer Zeit hinweisen. Gemeinsam ist diesen Gefäßen, meist großen dickwandigen flachen Schalen, neben denen seltener auch kleinere dünnwandige vorkommen, die Eigentümlichkeit, daß sich die innere Wandung des Randes in einem scharfen Winkel von dem Gefäßboden absetzt, und daß der äußere Rand über einer Hohlkehle oben meist flach gestaltet ist. Im Gegensatz hierzu zeigen andere, in Nimrud (Abb. 379 r. unten), in Ninive und auf dem Tell Radjamān gefundene, mit rotem Mennig bemalte Scherben aus sehr fein geschlemmtem rötlichem Ton einfachere Formen mit maßvoller gebildeter Profilierung. Beispiele jungassyrischer bemalter Keramik, bei der in rötlich brauner Farbe einfache geometrische Muster oder Kreisformen auf den gelblichen Scherben angebracht sind, fanden wir gleichfalls in Nimrud, Ninive und bei Assur. Sie sind schon von Herzfeld im I. Bande S.209zusammen miteineman-

geblich aus Hatra stammenden, mit Schriftzeichen bemalten Bruchstück erwähnt worden (Abb. 380).

In den babylonischen Kulturkreis gehört eine keramische Gattung, die aus einer als „Fritte" zu bezeichnenden Masse besteht. Sie ist hellweiß, körnig und sehr brüchig. Die in der 
Verwitterung silbrig erscheinende weiße Glasur löst sich leicht vom Körper ab. Von dieser sehr reizvollen Keramik seien vier Beispiele abgebildet (Taf. CXLV Nr. 1 -4), die in Hillah erworben wurden. Diese kleinen zierlichen Aufbewahrungsgefäße für Flüssigkeiten haben die Form von schlanken Henkelflaschen, von gedrungenen, eiförmigen oder abgeflachten Gefäßen oder von zylindrischen Bechern. Charakteristisch ist die durch einfache Abplattung hergestellte Fußfläche und die kleine Öffnung im Mündungsstück, das gleichfalls oben horizontalflächig geschlossen ist. Bruchstücke derartiger Gefäße wurden in der Nähe von Samarra, östlich in Albu Shhammah am Hamrĩn und südlich in Mandjūr bei Iștabulāt, wo man fälschlich das alte Opis vermutet, gefun-

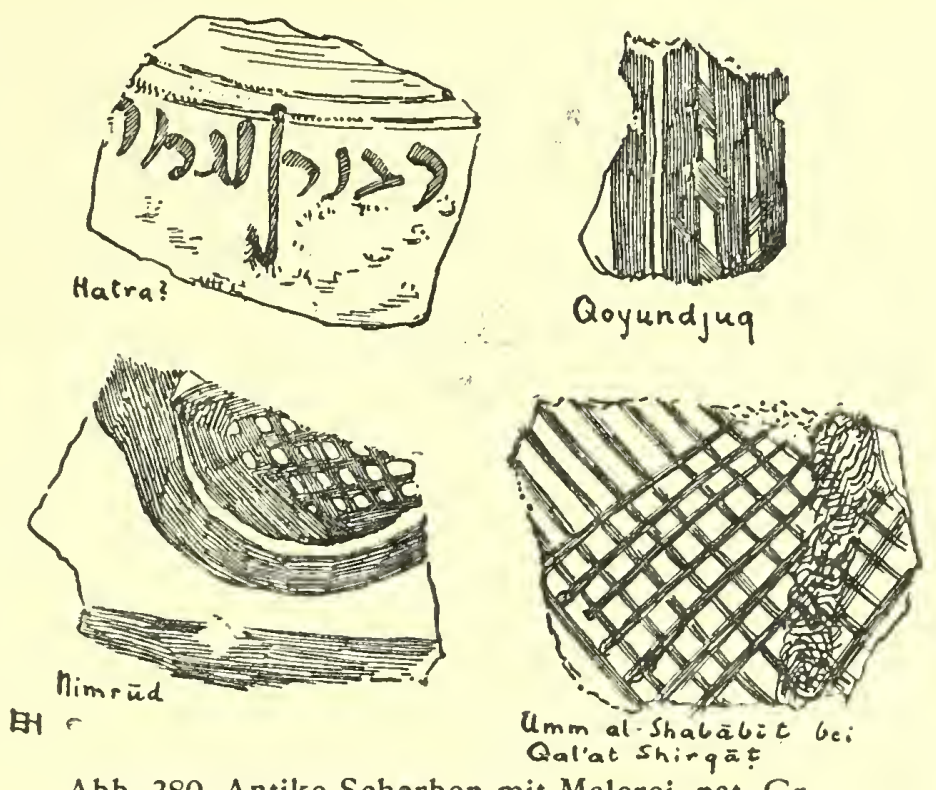

Abb. 380. Antike Scherben mit Malerei, nat. Gr. den. Diese babylonischen Gefäßformen sind, wie wir sehen werden, für die spätere, parthischsassanidische Keramik vorbildlich geworden.

Beispiele antike r Keramik d.h. unter griechischem Einflußstehender Gefäßbildnerei fanden sich in allen in die hellenistische Epoche zurückgehenden Ruinenstätten des Euphrattales und am Khäbür. Die gleichzeitige Keramik im Tigristal läßt mehr wie dort in Material und Formgebung die Weiterbildung altorientalischer Gefäße erkennen. In der reichen Ebene zwischen Aleppo und dem Euphrat fanden sich in den verschiedenen von uns besuchten Ruinenstätten, z. B. in Quwairis, Humaimah, Dēr Häfir, Tell Abu Muṭla' Beispiele verschiedenartiger antiker Tonware. Neben feinwandigen Gefäßen, deren Schmuck aus geritzten Wellenlinien und Schraffierungen besteht, kommen auch dunkelrot oder schwarz bemalte oder rot gefirnißte Gefäße vor, die mehr oder weniger fein poliert sind. Letztere sahen wir häufig auf den Ruinenstätten am Euphrat und Khäbür, in Eski Meskene (Bālis), Tell al-Thadayain (Thapsakus), Sūriyyah, al-Sinn, Shaddãdah, 'Arbān, Tell Tunainīr; sie begegneten uns nur ganz vereinzelt in den auch in hellenistischer und bis in die islamische Zeit noch besiedelten Gebieten von Nimrud und Ninive.

Unter der roten Firnisware hebt sich eine über ganz Vorderasien verbreitete Gruppe von Getäßen ab, die einen so einheitlichen Charakter zeigt, daß ihre Herstellung auf eine bestimmte Fabrik zurückgeführt werden darf, die wegen der Häufigkeit des dortigen Vorkommens wohl im nördlichen Syrien gesucht werden darf. Die auf Taf. CXLI Nr. 5 abgebildete, aus Aleppo stammende Henkelvase (h. $14 \mathrm{~cm}$ ) ist in ihrer straffen, an die Glasbildnerei erinnernden Form ein charakteristisches Beispiel; auch sie zeigt, daß der rote Firnis nur in dünner Schicht aufgetragen ist und bei der Abnutzung den dünnen hellgelben, fast weißlichen Scherben zum Vorschein kommen läßt ${ }^{1}$ ). Gröbere Scherben derart, die hier und da auftreten, lassen auf örtliche Nachbildung dieser keramischen Erzeugnisse schließen.

Als Beispiele direkten griechischen Imports nach Babylonien seien zwei kleine bemalte Tongefäße korinthischer Herkunft erwähnt und abgebildet, die aus dem Baghdader Kunsthandel

1) Eine größere Anzahl derartiger Gefäße befindet sich im Antiquarium im Alten Museum in Berlin. 
stammend in der Nähe zum Vorschein gekommen sein sollen (Taf. CXLI Nr. 4 u. 6; h. 7,1 cm und $5,7 \mathrm{~cm}$ ). Trotz starker Lädierung lassen Formgebung und Reste der braunroten Bemalung mit Rosetten auf dem Körper des größeren Stückes keinen $Z$ weifel über die westliche Herkunft. Daß nach den Welt- und Residenzstädten Babylon, Seleukeia und Ktesiphon in seleukidischer und parthischer Zeit ein Import westlicher Töpferware stattgefunden hat, ist nicht verwunderlich. Wie stark der hellenistische Einfluß in Babylon war, zeigen die Terrakottafiguren der griechischen und parthischen Zeit, die in Babylon ${ }^{1}$ ) zum Vorschein gekommen sind, und die Sima-Profile aus Șāliḥiyya (vgl. II. S. 392; Taf. CXLI Nr.1 - 3). Wie in Babylon würden Ausgrabungen in Seleukeia und Ktesiphon reiches Beweismaterial für die griechische Kunstübung erbringen. Auf letzterem Ruinengebiete kam im Jahre 1915 in den von den Türken ausgehobenen Schützengräben südlich vom Palast, dem Ṭāq i Kisrā, eine Terrakottafigur, die eine Quellnymphe darstellt, zum Vorschein.

\section{KERAMIK PARTHISCH-SASSANIDISCHER ZEIT}

In spätantiker Zeit - das lehren die Fundorte - beginnt eine Keramik, die wir uns gewöhnt haben als „parthisch“ zu bezeichnen. Es handelt sich um starkwandige Gefäße, die mit einer grünblauen, dicken Glasurschicht überzogen sind, die in unebenem, blasigem Auftrag meist stark verwittert und dann den Haarrissen folgend leicht vom Scherben abspringt. Eine ähnliche Glasur finden wir auf den mit figürlichen Darstellungen bedeckten parthischen Pantoffelsärgen $^{2}$ ), wie sie in Warka in Babylonien zum Vorschein gekommen sind, und von denen sich erhaltene Exemplare im Museum in Konstantinopel, Bruchstücke in der Islamischen Abteilung des Kaiser Friedrich-Museums (Inv. Nr. 1623ff.) befinden. Auf die Masse, die bei den Sarkophagen äußerst roh, brüchig und porös, sei hier nicht weiter eingegangen; sie ist sehr verschieden. Als typische Beispiele bilden wir den aus Hillah stammenden kleinen Henkelkrug und ein gleichfalls dort erworbenes Gefäß mit eiförmigem Körper ab (Taf. CXLII Nr. 1b und 3; h. 12,2 cm und $24,5 \mathrm{~cm}$ ). Die langgezogene Form des letzteren, dessen Körper an die Puppe eines Insekts erinnert und dessen $\mathrm{Hals}$ einem aufrechtstehenden Becher gleicht, geht auf altorientalische Vorbilder ${ }^{3}$ ) zurück. Derartige unten spitz zulaufende Gefäße wurden an die Wand gelehnt oder in dazu gehörenden Standringen aufgestellt. Auch die Bildung des Halses mit dem ausladenden profilierten Rande und das Fehlen eines besonderen Fußes sind Eigentümlichkeiten, die wir schon bei der altorientalischen, frittenähnlichen Glasurware aus Mesopotamien erwähnten (Taf. CXLV Nr. 1 - 4). Griechischen Vorbildern schließt sich die Formgebung von zweihenkligen Amphoren an, von denen ein im Kaiser Friedrich-Museum aufbewahrtes schönes Exemplar wiedergegeben sei (Taf. CXLV Nr. 5); hier wird in der Bildung der tauartig gedrehten Henkel und in dem Reliefmuster am Halse und auf der Schulter die vollständige Schmucklosigkeit der älteren Gefäße dieser Art schon verlassen ${ }^{4}$ ). Auf einer anderen derartigen Vase des Kaiser Friedrich-Museums

1) R. KOLDEWEY: Das wiedererstehende Babylon. Leipzig 1914. S. $275 \mathrm{ff}$.

2) Die aus den älteren Werken von LAYARD, RAWLINSON, LOFTUS entnommenen Abbildungen zusammengestellt bei Dieulafoy, l'Art antique de la Perse V. S. $35 / 36$.

3) Koldewey a. a. O. Abb. 165.

4) Aus Nimrud stammende Beispiele in farbigen Abbildungen bei LAYARD, Monuments pl. 85. -
Ferner aus Susa in Délégation en Perse. Mémoires I. Recherches Archéol. Paris 1900. Fig. 10-21, 133, 134, 180, 182, 290. - Aus Assur in W. AndRAE, Festungswerkevon Assur. Leipzig 1913. Abb.37,79.Aus Babylon in R. Koldewey, Tempel von Babylon und Borsippa. Leipzig 1911. Abb. 64. - Über das Vorkommen von Resten bläulich-grüner Gefäße in Ost-Turkestan und über „grüne, an parthische Glasuren erinnernde Fragmente" vgl. A. v. Le CoQ: 
(Inv. Nr. 885) weisen die dem Körper aufgelegten Masken-Medaillons glcichfalls auf hellenistische Beeinflussung hin ${ }^{1}$ ). Gemeinsam ist allen diesen Gefäßen die charakteristische dicke, brüchige, blau-grüne Glasur, die vielfach in silbrige Irisation übergegangen ist. Sie findet sich auch bei jenen, oft in sehr bedeutenden Abmessungen gehaltenen Gefäßen, deren Schmuck aus aufgelegten, meist gekerbten Bändern besteht, die in gradlinigen Borten oder in Wellenlinien, in deren Bogen Rosetten oder Knoten gestellt sind, die Körperwandung, meist nur im oberen Teil, bedecken. Ein charakteristisches Belspiel dieser jüngeren, wohl schon der sassanidischen Zeit angehörenden Gattung der mesopotamischen Gefäßbildnerei ist eine achthenklige Vase im Museum für Völkerkunde zu München (Taf. CXLV Nr. 6) ${ }^{2}$ ). Neben jener eiförmigen Formgebung des Körpers mit kurzem Hals, wie sie hier auftritt, findet sich bei diesen Gefäßen auch ein mehr gedrungener, bauchiger Körper, dem ein hoher gerader Hals aufgesetzt ist.

Es ist nun von nicht geringem Interesse, daß wir die gleiche Dekorationsart, die aufgelegten gekerbten und in Wellenlinien mit zwischengestellten Ornamenten geführten Bänder, auch in der älteren ostasiatischen Keramik finden. Als Beispiel diene ein in der Eumorfopoulos-Sammlung befindliches, mit dicker brauner Glasur überzogenes Gefäß aus hartem rotem Steingut (Taf. CXLV Nr. 7), das von Mr. Hosson in die zwischen der Han- und der T'ang-Dynastie liegende Epoche, also in die Zeit $z$ wischen dem 3. und dem beginnenden 7.Jahrhundert gesetzt wird ${ }^{3}$ ). Nach dem Urteil des besten Kenners früher ostasiatischer Keramik fällt also dieses Gefäß in dieselbe Zeit, der wir die gleich dekorierte mesopotamische Keramik zuschreiben, in die Sassaniden-Epoche, das 3. bis 7.Jahrhundert. Es fragt sich nun, ob hier der Osten der gebende oder der empfangende Teil gewesen ist. Wir möchten es nicht eher entscheiden, als bis mehr keramisches Vergleichsmaterial aus dem Osten vorliegt, das als vorbildlich für diese mesopotamische Gefäßbildnerei sicher angesprochen werden kann. Es liegt freilich nahe, hier ostwestliche Beeinflussung anzunehmen, in Rücksicht auf die vorbildliche Rolle, die die T'ang-Keramik später, im 9. Jahrhundert, in der mesopotamischen Töpferkunst gespielt hat, wie die Ausgrabungen von Samarra gelehrt haben ${ }^{4}$ ).

Scherben dieser parthisch-sassanidischen Keramik fanden sich in allen, zu jener Epoche besiedelten Ruinenstätten, sowohl im Euphrat- als auch im Tigris-Gebiet, u. a. in Eski-Meskene, Raḥba, Ḥalabiyyah, Tābūs, Tell-Fudain, Șuwwar und in Ninive, Nimrud, Ktesiphon. Ein in Tābūs (Abb. 381) gefundenes, außen und innen mit der charakteristischen blau-grünen, blasigen Glasur überzogenes Fragment ist das Halsstück eines ähnlichen, aber straffer geformten Gefäßes, als das auf Taf. CXLI Nr. 5 wiedergegebene.

Die vierte deutsche Turfan-Expedition in "Türän", 1918. S. 7 ff. Taf. V. - Über die der parthischen ähnliche Keramik, die in Abessinien gefunden wurde, vgl. Ältere Denkmäler Nordabessiniens. Berlin 1913. Kleinfunde von RoBert ZaHn. S. 213.

1) Medaillonartige Löwen - und Gorgonenköpfe, in Formen hergestellt und den zu verzierenden Gefäßen aufgesetzt, finden sich häufig in TöpfereiResten von Ost-Turkestan, z. B. in der Oase von Chotän (A. von LE CoQ. Túrán 1918. S. 339). Hierher gehören auch die mit aufgesetzten Köpfen, Brustbildern und Figürchen versehenen Terrakottavasen, die M. A. STE1N in Chinesisch-Turkestan gefunden hat (Preliminary Report. 1901. Taf. 1), und die gleichfalls aus Zentralasien stammenden Fragmente in der Eremitage in St. Petersburg, die Strzygowsk1 veröffentlicht (Altai-Iran und Völkerwanderung. Abb. 212-215).

2) Bericht des Museums, herausg.von L.SCHERMAN. Münchner Jahrbuch der Bildenden Kunst. 1916/17. S. 287. Abb. 16. - Ein sehr großes Gefäß dieser Art im Kaiser Friedrich-Museum.- SARREMaRTin: Meisterwerke mukammedanischer Kunst. München 1912. Taf. 89 (Kat. 1099).

3) Burlington Magazine. June 1919. p. 231. The Eumorfopoulos Collection IV. by R. L. HoBson. Pottery from Han to T'ang. Pl. I. A.

4) F. SARRE: Kleinfunde von Samarra im Islam. V. Heft 2/3. S. 180 ff. 
$\mathrm{Zu}$ islamischer Zeit erhält sich diese Keramik; aber die Glasur wird dünnflüssiger und klarer, der Schmuck mit Gravierungen und aufgelegten Bändern wird reicher und nimmt oft den größten Teil des Körpers ein. Erhalten bleibt die Gestalt der Gefäße; so die der großen eiförmigen

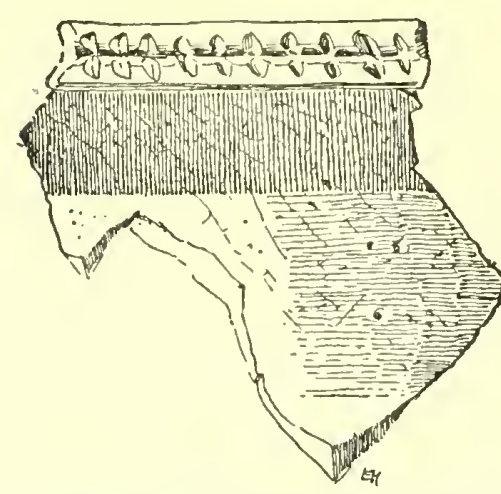

A bb.381. Halsstück eines glasierten Kruges ausTābūs.

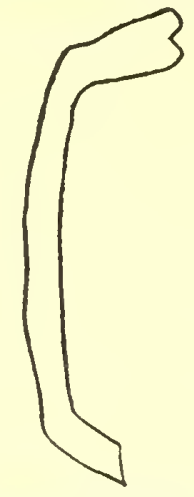

$3 / 4$ nat. Gr.

Krüge, deren kleine, am Halse sitzende Henkel dazu dienen, um den Deckel festzuschnüren. In der Berliner Islamischen Sammlung sind zwei derartige große Krüge, von denen der auf Taf. CXLIII links abgebildete aus dem Baghdader Kunsthandel stammt, aber in Samarra gefunden sein soll. Die einfachen, strengen Wellenlinien der früheren Zeit haben sich hier in mit Blättern besetzte Spiralranken aufgelöst, die die Füllung von halbovalen Feldern bilden.

Zur parthischen Keramik gehört auch eine Tonform, die von uns im Kunsthandel in Aleppo erworben wurde. Der Ausguß (Taf. CXLII Nr. $4 ; 13 \times 13 \mathrm{~cm}$ ) zeigt rechts eine männliche, links eine weibliche Figur unter bezw. vor einer Ädikula. Letztere Figur, in ein faltiges um die Hüfte gegürtetes Gewand gekleidet, faßt mit der Linken in den Saum eines Mantels, der von der linken Schulter zum rechten Knie fallend den Unterkörper bedeckt. Der rechte Arm ist mit nach außen geöffneter Hand erhoben. Eine Mauerkrone bedeckt das lockige Haupt. Auf der Brust ist ein Schmuckstück angebracht. Die männliche Figur zeigt einen Mann mit Schnurrbart und umfangreicher, perrückenartiger Haartracht. Die linke Hand faßt den Griff des kurzen, gerade abstehenden Schwertes, während die rechte mit ausgestrecktem Zeigefinger auf die weibliche Gestalt zu weisen scheint. Ein bis zu den Knien reichender, am Halse durch einen Ringkragen geschlossener, faltiger Ärmelrock bedeckt den Oberkörper, während die Beine in oben breiten, unten engen Faltenhosen stecken. Über der linken Schulter befindet sich eine sechsstrahlige Rosette.

Es ist also ein Krieger oder Großer vor dem unter einer Ädikula stehenden Kultbilde einer Göttin dargestellt. Der parthisch-sassanidische Kunstkreis ist unverkennbar. Während die Göttin in der Haltung, mit Stand und Spielbein, und in der Gewandung rein klassisch wirkt, ist die männliche Figur orientalisch gestaltet. Die gleiche Haartracht begegnet uns bei figürlichen Darstellungen auf parthischen Sarkophagen ${ }^{1}$ ), ähnlich kommt sie auf sassanidischen Felsreliefs vor, z. B. auf dem Denkmal von Salmas ${ }^{2}$ ) und dem leider bisher nur ungenügend bekannten Relief von Teng iSaulek ${ }^{3}$ ). Die Tracht, der schoßkittelartige Überrock und die an den Knöcheln zusammengebundenen Beinkleider finden wir auf den sassanidischen Felsreliefs ${ }^{4}$ ) und auch auf Silberschalen ${ }^{5}$ ), wo wir auch Beispielen für die altorientalische Darstellung begegnen, daß über den Schultern eines Herrschers die Symbole von Sonne und Mond angebracht sind (Smirnow a. a. O. Nr. 43).

Das hellenistische Kultbild ist wohl unzweifelhaft eine Statue der Göttin Anahit, der Artaxerxes II. zuerst in den Tempeln aller Hauptstädte des Perserreiches Statuen errichtet haben

1) W. K. LofTus, Travels and Resarches. p. 205.

2) C. F. Lehmann-Haupt, Armenien einst und jetzt. Berlin 1910. S. 317. - A. V. W. JACKSON, Persia part and present. New York 1906. p. 80.

3) Baron C. A. DE Bode, Travels in Luristan and Arabistan. London 1845. p. 352. - Flandin et Coste, Voyage en Perse. pl. 224. 225.
4) Relief auf einem Felsblock bei Bisutun: Priester (?) neben einem Feueraltar. OSKAR MANN, Archäologisches aus Persien. Globus vom 4. Juni 1903. Abb. 2.

5) J. Smirnow, Argenterie orientale. St. Petersburg 1909. pl. XXXVII. Nr. 66. 
soll, und deren Bild wir auf sassanidischen Felsreliefs und Gemmen begegnen ${ }^{1}$ ). Auch hier trägt sie eine Mauerkrone, langes Ärmelgewand und reichen Schmuck. Die Geste des Segnens mit erhobener Hand ist nicht überraschend, und die Haltung der linken, den Gewandsaum fassenden Hand finden wir bei Frauendarstellungen auf sassanidischen Gemmen und Silberschalen häufig wieder. Dargestellt ist also ein parthischer Großer vor der Statue der Anahit; denn der parthischen und nicht erst der sassanidischen Zeit müssen wir das Relief zuschreiben. Die rein hellenistische Auffassung der Göttin und die Tracht des Mannes weisen in erstere Periode.

Auch für die auf den ersten Blick überraschende, ungew ðhnliche und unsymmetrische Komposition von zwei nebeneinander gestellten Figuren, die der Künstler sich bemüht hat durch die gleiche Größe der beiden Hälften, der Ädikula mit dem Götterbilde und der anbetenden Figur, auszugleichen, gibt es in dem parthisch-sassanidischen Kunstkreis Analoga. Wir erinnern an das noch nicht genügend bekannte Relief von Fynyk ${ }^{2}$ ), deren zwei mit faltigen Beinkleidern und Gewändern bekleidete Figuren auf die parthische Periode hinweisen, und an die beiden sassanidischen Reliefs von Barm-i-Dilak bei Schiraz (SARRe-Herzfeld

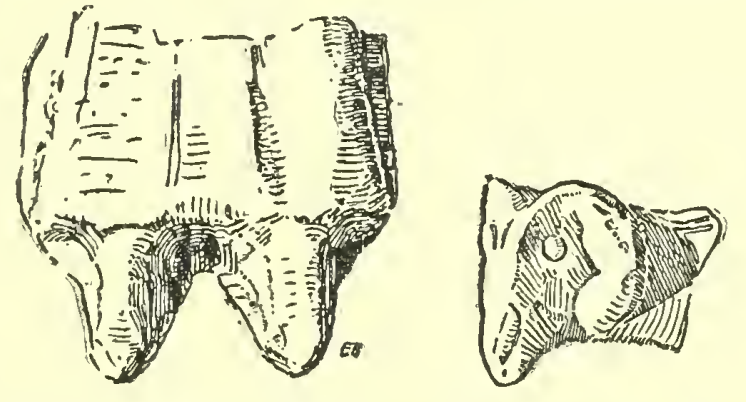

Abb. 382. Bruchstück einer Terrakottafigur aus Quraiyah und Widderköpfchen aus Bagdad; $3 / 4$ nat. Gr. a. a. O. Taf. XXXII).

Welchem Zweck die Form gedient hat, ist nicht sicher. Ob der Ausguß für ein Votivrelief bestimmt war, oder ob er, was wahrscheinlicher, als Plakette für ein großes Tongefäß dienen sollte, wissen wir nicht. Eine aus einer Form gepreßte Tonplakette frühsassanidischer Zeit mit einer Gewandfigur, die einen Spiegel vor die Brust hält, hat Hubert Schmidt in Giaur Kale (Alt Merw) in Turkestan ausgegraben ${ }^{3}$ ). Die Formgebung dieser Plakette - es ist ein sich nach oben verjüngendes Viereck, wie die für eine Barbotine-Vase bestimmte Form islamischer Zeit auf Taf. CXLIV r. - legt die Vermutung nahe, daß es sich bei letzterem Stück wenigstens um eine Plakette handelt, wie sie auf den hellenistischen Plakettenvasen vorkommen ${ }^{4}$ ).

Hierher gehören auch die beiden aus Afrasijab bei Samarkand stammenden figürlichen Plaketten der Eremitage in St. Petersburg, die StrzYgowSki veröffentlicht ${ }^{5}$ ). Auch hier handelt es sich wohl um Ausgüsse von Formen, wie sie bei der Dekoration von großen unglasierten Tongefäßen verwandt wurden. Beide Figuren, thronende Gestalten mit dem Schwert zwischen den Beinen ${ }^{6}$ ), sind in Kostüm und Auffassung typisch parthisch-sassanidisch. Mit der „Barbotin“- oder Gießbüchsen-Technik haben solche aus Formen gepreßte Plaketten direkt nichts zu tun, wenn auch beide Dekorationsarten gelegentlich zu islamischer Zeit nebeneinander verwandt wurden, wie wir sehen werden.

1) SARRE-HERzFELD, Iranische Felsreliefs. Taf. VII. Abb. 38. 41-43. S. $84 \mathrm{ff}$.

2) LAYARD, Discoveries. p. 54. - G. L. BeLl, Amurath to Amurath. fig. 190.

3) H. Schmidr, Archeological Excavations in Anau and Old Merv. Carnegie-Instit. of Washington. Public. Nr. 73. Pl. 55. Nr. 4.

4) Das Antiquarium im Berliner Museum besitzt einige große Exemplare aus ptolemäischen
Nekropolen stammender Plakettenvasen des frühen 3. Jahrhunderts.

5) Altai-Iran und Völkerwanderung. Abb. 207. 208.

6) Auch die Figur Abb. 208 dürfte so und nicht als "Musikant" aufgefaßt werden. Die Haltung des Mannes und die Form des Schwertes sind durch sassanidische Denkmäler belegt. Vgl. z. B. SARREHerzfeld, Iranische Felsreliefs. Taf. XLII. 
Der Unterteil einer wohl gleichfalls parthisch-sassanidischen kleinen, aus der Form gepreßten Terrakottafigur wurde von uns in Quraiyah gefunden. Das aus Bagdad stammende, lebendig aufgefaßte Widderköpfchen dürfte zeitlich schwerer zu bestimmen sein (Abb. 382).

\section{SPÄTANTIK-BYZANTINISCHE UNGLASIERTE KERAMIK MIT MALEREI}

Eine eigenartige Keramik fand sich auf den Ruinenstätten spätantiker (palmyrenischer) und byzantinischer Ansiedlungen am Euphrat (in Halabiyyah-Zenobia, Zalūbiyyah, Sūriyyah, al-Sinn)
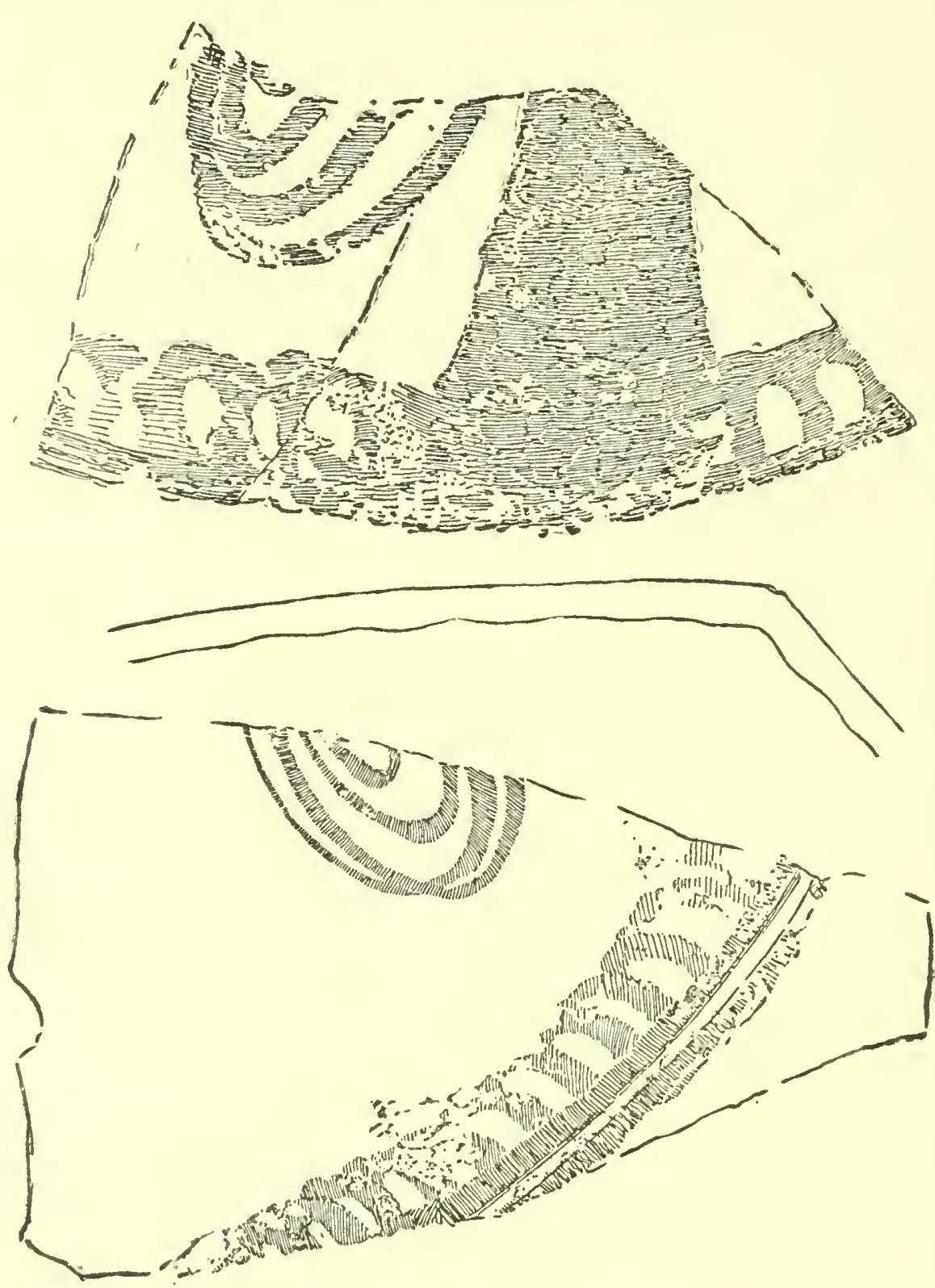

Abb. 383. Bruchstücke bemalter unglasierter Gefäße aus Sūriyyah; $3 / 4$ nat. Gr. und vereinzelt auch am Tigris (Tell Kushäf). Es sind große dickwandige Gefäße aus rötlichem Ton, derenimWinkelgebrochene Wandung die Vermutung nahe legt, daß es sich um Gefäße handelt, deren Formgebung, noch den antiken Charakter wahrend, in vergrößertemMaßstabeetwa der Firnisware entspricht, von der ein Beispiel auf Taf. CXLI Nr. 5 abgebildet ist. Die in dünnem Auftrag in rotbrauner Farbe ausgeführte Bemalung zeigt, den Profilen folgend, flüchtig gezeichnete Borten und Spiralrosetten. Taf. CXLII $2 c$ und $A b b .383$ geben ein paar in Halabiyyah (Zenobia) und Sūriyyah aufgelesene Fragmente wieder. Bisher ist kein intaktes Gefäß oder auch nur ein so umfangreiches Fragment zum Vorschein gekommen, $\mathrm{da} B$ man sich ein genaues Bild von der Formgebung und der Bemalung dieser wahrscheinlich in einer bestimmten Fabrik des Euphrattales hergestellten Ware machen kann. Es mag sich um große Wassergefäße handeln. Als Zeit dürfte das 4. bis 6. Jahrhundert in Frage kommen. Zum Vergleich mögen die großen, gleichfalls der byzantinischen Epoche zugeschriebenen Amphoren herangezogen werden, die in Jericho gefunden sind und auf Schulter und Bauch in rotgelber Farbe eine ähnliche Malerei aufweisen ${ }^{1}$ ).

1) E. Sellin und C. Watzinger, Jericho. Leipzig 1913. B1.43. S. $160 \mathrm{ff}$, und Mitt.der Deutschen
Orient-Gesellschaft Nr. 39. Abb. 15. 


\section{$9-$ \\ UNGLASIERTE KERAMIK \\ MIT GRAVIERUNG UND AUFGELEGTEN VERZIERUNGEN}

In dem heißen Klima von Mesopotamien spielen die unglasierten Tongefäße, in denen sich das Wasser infolge der Durchlässigkeit des Materials und der Verdunstung des Wassers kühl erhält, eine besondere Rolle. In jedem Hause im Irak sieht man auch heute noch im Hausflur oder unter der schattigen Hofarkade ein großes unglasiertes Tongefäß ( $h a b b)$, dessen eiförmiger Körper in einem Holzgestell ruht, und das den täglichen Bedarf an Wasser aufnimmt, während kleinere unglasierte Krüge weitere Verwendung in der Haushaltung finden. Auch diese Gebrauchsgeräte ent-
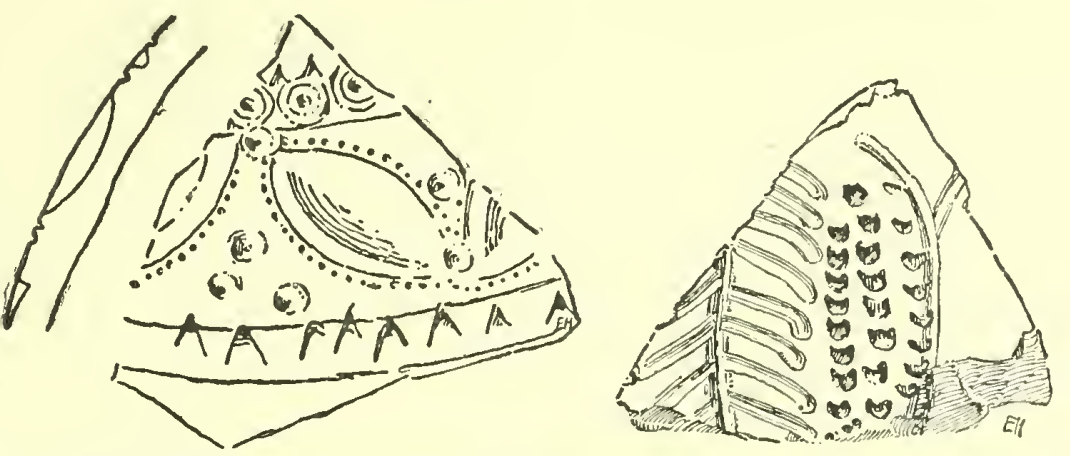

Abb. 384. Scherben unglasierter Keramik aus Sudēre und Kushāf; $3 / 4$ nat. Gr. behren in den Zeiten, von denen wir sprechen, nicht eines gewissen Schmuckes, der es gestattet, sie ungefähr zeitlich zu bestimmen; natürlich kann es sich hier meist nur um größere Zeitabschnitte handeln, die für die Herstellung der verschiedenen Gattungen in Anspruch zu nehmen sind.

Bei den unglasierten bauchigen Henkelkrügen, deren Öffnung direkt dem Körper in wulstartiger Profilierung aufsitzt, begegnen uns dieselben Verzierungen wieder, die wir an den gleich gestalteten glasierten Gefäßen beobachten konnten: Aufgelegte Bänder, die durch Einkerbungen weiteren Schmuck erfahren haben (Taf. CXLIINr. 2b; Durchm. $10 \mathrm{~cm})$. Dieser Kerbschnitt findet sich nicirt nur an den aufgelegten Borten, am Rande und an den Henkeln; er bildet, meist aus dreieckigen oder runden Vertiefungen bestehend, Borten und Muster, von denen Abb. 384 ein hübsches Fragment aus Sudēre und eine interessante Scherbe aus Kushāf am Tigris wiedergibt, bei der sich der Töpfer bemüht
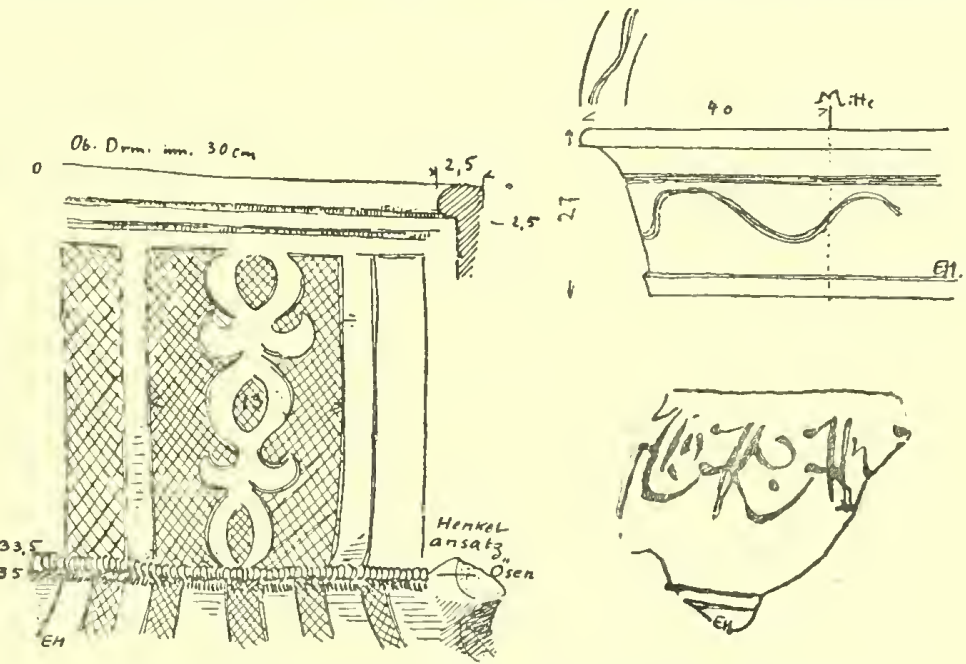

Abb. 385. Unglasierte Keramik mit Gravierung aus Raqqah und Baghdad.

hat, Palmenblätter und Datteldolden wiederzugeben. Neben dieser seltenen freien Zeichnung sind mit dem Kamm hergestellte geradlinige Riefelungen, Borten und Wellenranken in überwiegender Häufigkeit vorhanden $\left.{ }^{1}\right)$.

Diese im gesamten Euphrat- und Tigrisgebiet zu parthisch-sassanidischer Zeit vorkommende Technik der Gravierung erhält sich weit in die islamischo Zeit hinein, wie das aus Baghdad stammende Fragment mit der eingeritzten ornamental behandelten Buchstabenborte (Abb. 385

1) Gravierte und kerbschnittartig dekorierte unglasierte Tonwaren früh-byzantinischer Zeit aus Jericho bei Sellin und WATZINGeR a. a.O.--Große dickwandige unglasiertc Vorratsgefäße mit einfachen 2 SARRE-HERZFELD, Archäologische Reise. Band IV. geometrischen Mustern, unter denen das Wellenband voransteht, kamen bei den Turfan-Ausgrabungen zum Vorschein. A. von LE COQ, Chotscho Taf. 65-66. Keramische Funde von M. EBers. 
r. unten) und zwei große Tongefäße beweisen, die wir in Raqqah, wo sie vor kurzem zum Vorschein gekommen waren, zu sehen Gelegenheit hatten. Die Schüssel (Abb. 385 r. oben) zeigt als einzigen Schmuck der geraden Wandung eine eingeritzte Wellenlinie, während sich auf dem Hals des Wasserkruges in rechteckigen Feldern ein ausgespartes Muster auf schraffiertem Grunde wiederholt (Abb. 3851.). Wir werden auf diese Technik in Verbindung mit anderen, in der vorgeschrittenen islamischen Zeit geübten Techniken später zurückzukommen haben.

\section{STEMPELKERAMIK}

In engster Verbindung mit der eben behandelten freihändigen Gravierung steht die mit einer Form oder einem Stempel vor dem Brande hergestellte Verzierung unglasierter Tongefäße.

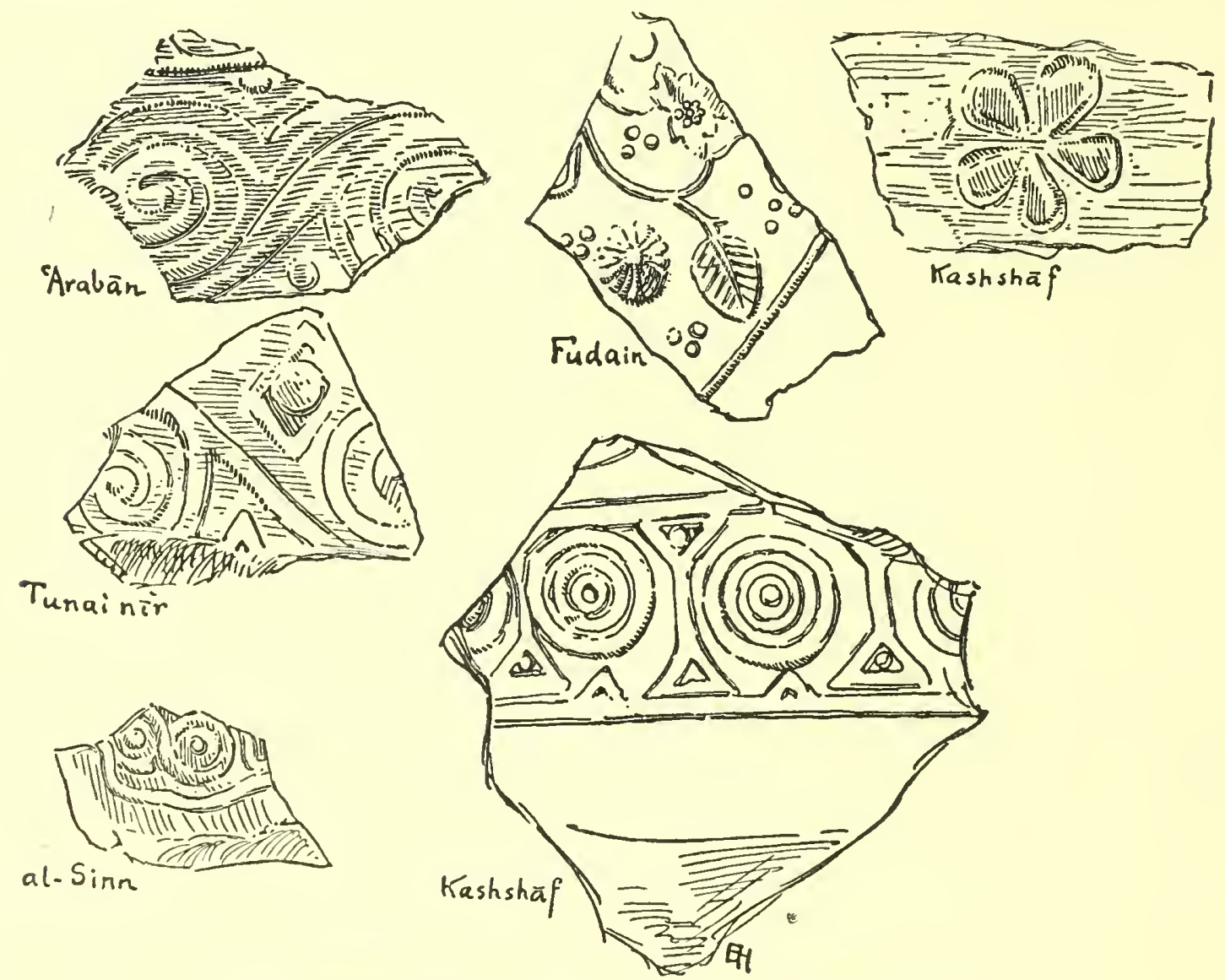

Abb. 386. Stempelkeramik verschiedener Herkunft; nat. Gr.

An die Stelle der eingeritzten Wellenlinien treten hier in den noch feuchten Ton eingedrückte und sich nun in Relief über die Gefäßwandung erhebende, mehr oder weniger reiche Borten und Verzierungen, von denen Abb. 386 charakteristische Beispiele spätantiker oder früh-islamischer

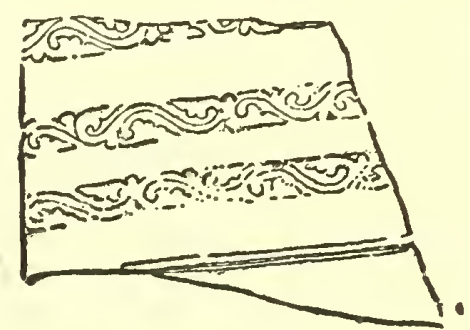

Abb. 387. Stempelkeramik aus Takrīt; $3 / 4$ nat. Gr.

Zeit aus 'Arabān, Tunainīr, al-Sinn und Kushāf wiedergibt. Von besonderer Feinheit ist ein aus Takrīt stammendes Fragment (Abb.387), bei dem sich das gleiche Muster in drei übereinander laufenden Palmettenborten wiederholt, die zweifellos auf frühislamische Zeit hinweisen.

Gleich häufig ist die Stempelung mit Rosetten oder runden und eckigen Medaillons, die zu Borten geordnet oder vereinzelt über den Gefäßkörper verteilt werden. Wir fanden diese Stempelkeramik vor allem am Tigris und hier wiederum besonders häufig in Takrīt und an dem Nīl genannten Kanal, der schon zu frühislamischer, umayyadischer Zeit südlich von Baghdad die beiden Flüsse 
verband. Die Ausgrabungen von Samarra haben ergeben, daß die Stempelkeramik im 3. islamischen Jahrhundert nicht mehr so gebräuchlich war wie in früherer Zeit; denn im Stadtgebiete selbst kamen derartige Scherben nur in geringer Menge zum Vorschein. In Takrīt scheinen, wie Herzfeld vermutet, vor allem die aramäischen Christen als Verfertiger dieser Keramik in Frage zu kommen; dann bestand jedenfalls eine Fabrik in Nīliyyah und eine andere aut dem jetzigen Ruinen-
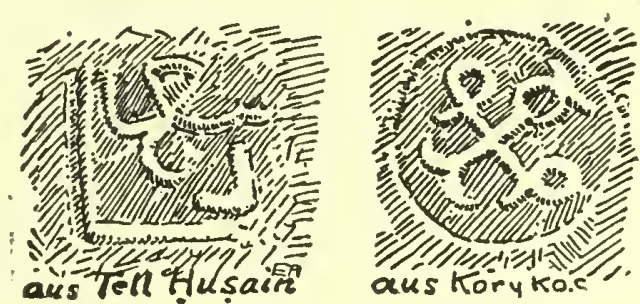

Abb. 38ช. Keramische Stempel; nat. Gr.

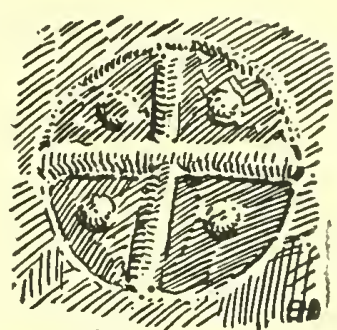

aus Tăbis'

gebiet von Ghanā'ūr, östlich von Samarra. Auch in Ninive, Nimrud, Kushāf, Baghdad und Ktesiphon fanden wir Beispiele dieser Technik.

Runde, einfach gemusterte Stempel kommen schon auf spätantiken Gefäßen vor, und so
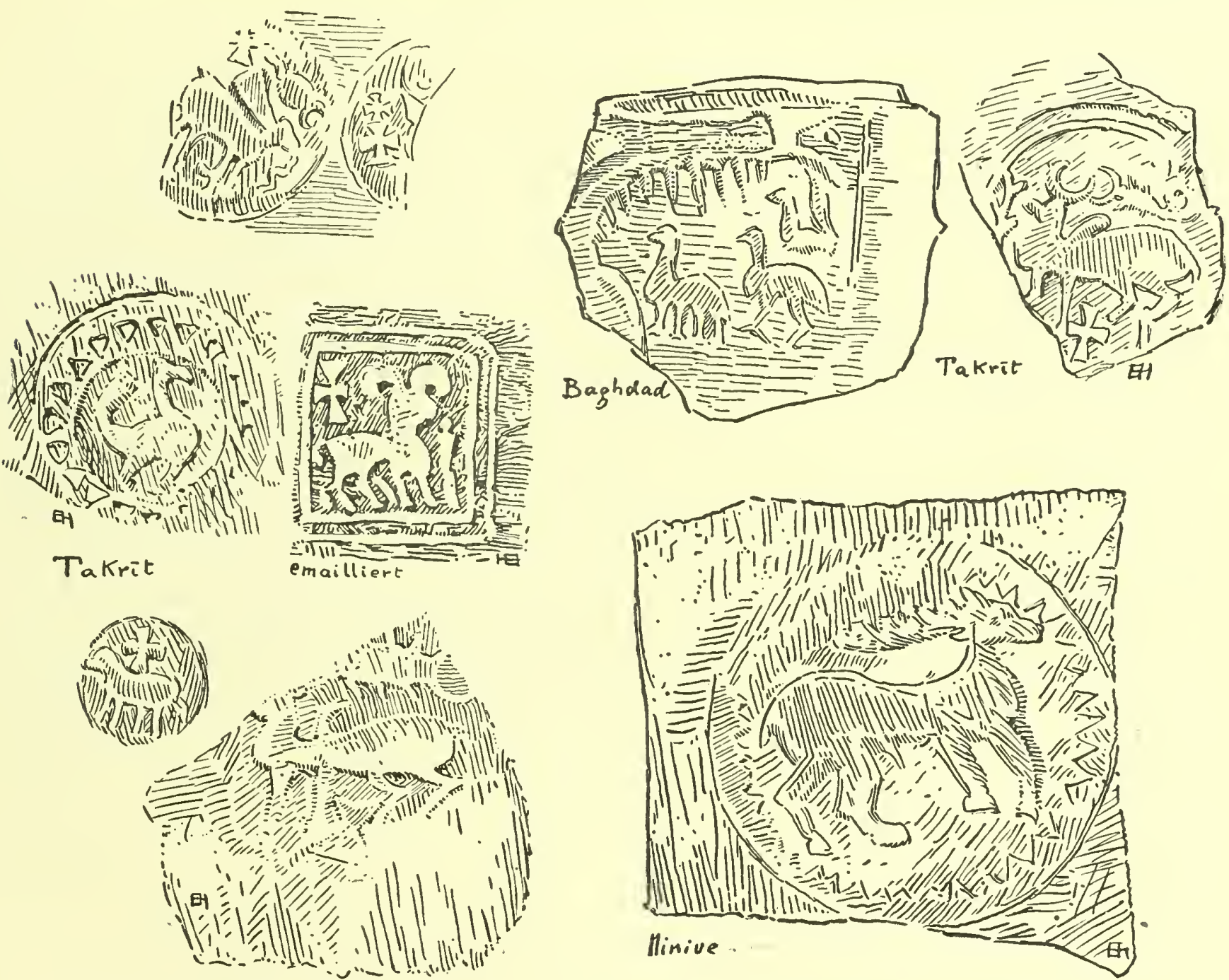

$\mathrm{Abb}$. 389. Figürliche Stempelkeramik aus Takrīt; nat. Gr.

Abb. 390. Figürliche Stempelkeramik verschiedener Herkunft; nat. Gr.

scheint der primitive Stempel auf einem aus Ṭābūs stammenden Scherben (Taf. CXLII Nr. 2a) nichts mit dem christlichen Kreuz zu tun zu haben. Diese sparsame Verwendung der Stempelung erinnert an die Amphorenstempel griechischer, in Babylon gefundener Topfware'1), die meistens auf den Henkeln angebracht waren; einen schon islamischer Zeit angehörenden Henkelstempel

1) Koldewey a. a. O. Abb. 167. 
fanden wir in Tell Hụsain am Khābūr, der Herzfeld an ähnliche, in Korykos in Kilikien gefundene Stempel erinnerte (Abb. 388).

In jüngerer Zeit ist die Verwendung der Stempel auf den Gefäßen eine reichere. Die Tafel CXLVI zeigte Beispiele ornamental gemusterter Stempel aus Takrīt und vom Shaț al-Nīl, unter denen das besonders in Takrīt häufig vorkommende christliche Kreuz, meist in der Form des Eisernen Kreuzes gebildet, hervorzuheben ist. Die beiden Scherben auf der linken Seite der Tafel veranschaulichen die bortenartige Anordnung der Stempel in einer oder mehreren Reihen.

Von größerem Interesse sind die figürlichen Stempel, von denen Abb. 389 u. 390 charakteristische Beispiele wiedergeben. Teils in ein Rund, teils in ein Viereck gestellt, begegnen wir

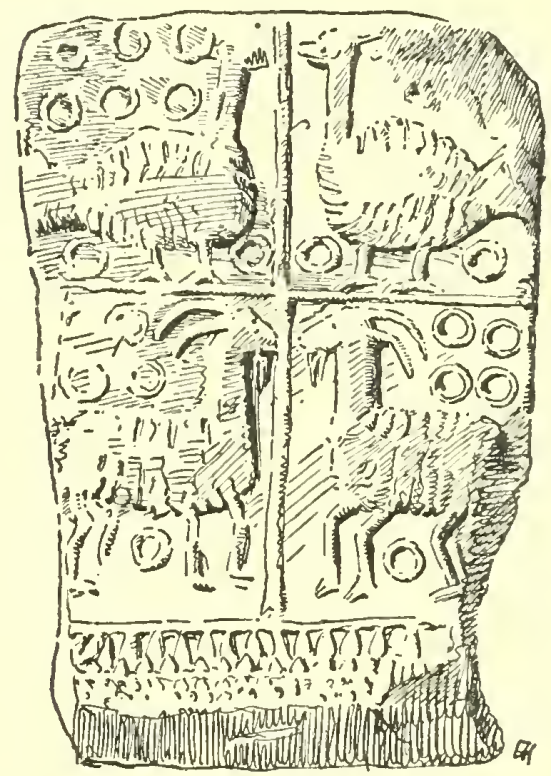

Abb. 391. hier den verschiedensten Tieren, die, wenn auch oft unbeholfen, so doch meist naturalistisch und nicht stilisiert wiedergegeben sind. Wir finden Widder, Steinbock, Hirsch, Büffelochsen, Lamm, Trappe und gelegentlich auch den sassanidischen Greifen mit dem Pfauenschweif. Manchmal wird das Kreuz neben den Tieren angebracht, die Vögel halten Zweige im Schnabel, am Hals und an den Beinen der Vierfüßler flattern die charakteristischen sassanidischen Bänder. Die Tierfiguren gehören zum alten Bestand der Darstellung im Tigrisgebiet und finden sich schon auf der frühen Keramik von Susa und dem präislamischen Samarra (Islam. V. S. 190 ff.). Sie bilden häufig vorkommende Motive in den bildlichen Darstellungen auf altorientalischen und sassanidischen Siegelzylindern. Daß in den Tierfiguren der Takrīt-Keramik sassanidisch-zoroastrische und christliche Motive und eine Tonmodell für die Dekoration eines Symbolik steckt, wie sie auch in den gleichzeitigen Stoffmustern, unglasierten Gefäßes; ${ }^{3 / 4}$ nat. Gr.

in den bekannten Gipsstuckmedaillons des Kaiser Friedrich-

Museums und in Glasstempeln zum Ausdruck kommt, ist schon von Herzfeld erwähnt worden (Bd. I, S. 225 ff.).

Eine gut erhaltene große Vase mit figürlichen Stempeln befindet sich $1 \mathrm{~m}$ Babylonian Room des British Museums (Nr. 92394 ; wall case 36). Nach gütiger Mitteilung von Prof. Watzinger trägt das aus hellbraunem Ton bestehende und mit weißlichem Überzug versehene Gefäß um die Mitte des bauchigen Körpers einen von Mäanderborten eingefaßten Fries, der aus zwei Medaillonreihen mit äsenden Hirschen besteht. Hergestellt wurde dieser Fries, indem man den gleichen Stempel in fortlaufender Wiederholung verwandte. Das Tonmodell zu einem solchen Stempel wurde von mir während des Krieges in Bagdad erworben (Abb. 391). Es ist für einen Fries bestimmt, der den unteren Teil des Halses eines großen Wassergefäßes umgibt, und zeigt in rechteckigen Feldern je zwei naturalistisch gezeichnete Ziegenböcke und je zwei Vögel, die die größte Ähnlichkeit mit Perlhühnern haben. Den Hintergrund bilden raumfüllende Kreispunkte. Der untere Teil des Modells bildet in einer vorkragenden kerbschnittartig gemusterten Borte einen Teil der Gefäßschulter und den Übergang zu dem bauchigen Vasenkörper.

Ein in Ost-Turkestan zum Vorschein gekommener unglasierter Krug, der sich im Museum für Völkerkunde in Berlin befindet, ist auf dem Oberteile des bauchigen Körpers reich mit der Antike entlehnten, aus Formen und Stempeln gepreßten Ornamenten verziert. Eine Borte zeigt eine Reihe von runden Medaillons mit figürlichen, an griechisch-skythische Vorbilder erinnernden 
Darstellungen. Der Krug ist als Beispiel für das Vorkommen der Stempelkeramik in Zentralasien von besonderem Interesse ${ }^{1}$ ). Auf die in der zentralasiatischen unglasierten Keramik übliche Verwendung von aufgelegten Köpfen und Figürchen haben wir schon oben (S.5 Anm. 1) hingewiesen.

\section{DIE BARBOTIN-KERAMIK}

Schon im alten Orient und dann in erhöhtem Maße in parthisch-sassanidischer, bzw. frühchristlicher Zeit spielt im Zweistromlande, wie wir zeigten, die unglasierte Keramik in künstlerischer Hinsicht eine hervorragende Rolle; diese Bedeutung nimmt in der islamischen Epoche zu, wo neben der Gravierung und Stempelung eine Technik auftritt, die man nach dem Instrument, der Gießbüchse (Barbotine), die bei ihr verwendet wurde, Barbotin-Technik genannt hat ${ }^{2}$ ). Im Grunde genommen handelt es sich nur um eine Weiterbildung jener Verzierungsweise, die schon früher geübt wurde, und die in der Anbringung von Reliefbändern und Medaillons bzw. Rosetten bestand (Taf. CXLII Nr. 2b; CXLV Nr. 6).

Von einem großen, aus harten, weißgelblichen Ton bestehenden Wassergefäß (habb) konnte ein großes Fragment des Halses von uns in Takrīt erworben werden (Taf. CXIV r. unten; Durchm. $40 \mathrm{~cm}$ ); es ist deshalb interessant, weil hier in der Dekoration verschiedene Techniken vereinigt sind. Neben der Gravierung und dem Kerbschnitt tritt hier die plastische Verzierung in der Form roher, nur andeutungsweise ausgeführter menschlicher Figuren auf, die in der Barbotintechnik hergestellt sind. Die primitiven Formen geben keinen sicheren Hinweis auf das Alter des Gefäßes, das vielleicht der frühislamischen Zeit angehört.

Die beiden auf Taf. CXIV r. oben abgebildeten Fragmente, gleichfalls aus Takrīt stammend, gchören zu einem Wassergefäß, von dem sich ein intakt erhaltenes gleich dekoriertes, aber weniger scharf modelliertes Exemplar im British Museum befindet (Nr. 91950. c. 34). Der die obere Hälfte des bauchigen Körpers umgebende Fries zeigt in rechteckigen Feldern abwechselnd je zwel Vögel (Gänse?), die einen bandartigen Zweig im Schnabel halten, und je vier nebeneinander gestellte weibliche Figuren, die durch Bänder, die den Oberkörper einrahmen, miteinander verbunden sind. Mit seitlich vorgestreckten Ellbogen haben die Frauen die Hände vor der Brust gefaltet. Bei diesen Figuren ist die Herkunft klar; sie sind in Nachahmung altorientalischer Göttergestalten, der Ninmach oder Ishtar, entstanden, die in gleicher Armhaltung dargestellt werden (vgl. KoldEweY a.a.O. S. 271); und zwar ist hier wohl eine Darstellung aus jüngerer, parthischer Zeit vorbildlich gewesen, wo die früher nackte Göttin mit einem Ärmelgewand bekleidet wird (KoLDEwEY a. a. O. Abb. 214 u. 217). So dürfte dieses Gefäß mit den Frauengestalten verhältnismäßig frühe Zeit, etwa den ersten Jahrhunderten der Hedschra angehören; derselben Zeit auch ein kleiner Henkelkrug des Kaiser Friedrich-Museums (I. Nr. 2646), der, in Bagdad erworben, mit ähnlich gezeichneten Vögeln, einem Greifen und einer roh gezeichneten menschlichen Figur dekoriert ist. Auch hier wiederum das teilweise aus der Technik hervorgegangene Bestreben, durch einzelne

1) Ein spätantiker Krug aus Chotän, von A.v. LE CoQ, Túrán. 1918. S. $338 \mathrm{ff}$.

$\left.{ }^{2}\right)$ Die Technik tritt vereinzelt auch schon in altorientalischer Zeit auf. So zeigen merkwürdige kleine "Terrakottahäuschen“, die im archaischen Ishtar-Tempel in Assur gefunden wurden, in Barbotin-Technik hergestellte Reihen von Vögeln, Schlangen und Löwen. Mitteilungen der Deutschen
Orient-Gesellschaft Nr.54. Abb. 7. - Bei den Ausgrabungen auf Toprakkaläh bei Van kamen große Pithoi mit keilinschriftlicher Maßbezeichnung und Randverzierung durch Tierskulpturen zum Vorschein. Vgl. C. F. LeHMANn-HAupt: Materialien zur älteren Geschichte Armeniens und Mesopotamiens. Berlin 1907. S. $111 \mathrm{ff}$. 
Linien oder Bänder den Körper in seinen charakteristischen Teilen wiederzugeben. Dies Bestreben ist künstlerisch oft glänzend gelöst. In dicse Gruppc gehört auch ein großes, von uns in Takrīt gesehenes Gefäß (Abb. 392).

Über diese Barbotin-Keramik habe ich schon vor vierzehn Jahren gehandelt und ihre Herkunft aus Mesopotamien nachgewiesen ${ }^{1}$ ). Die damals bekannten Stücke konnte ich einer ver-

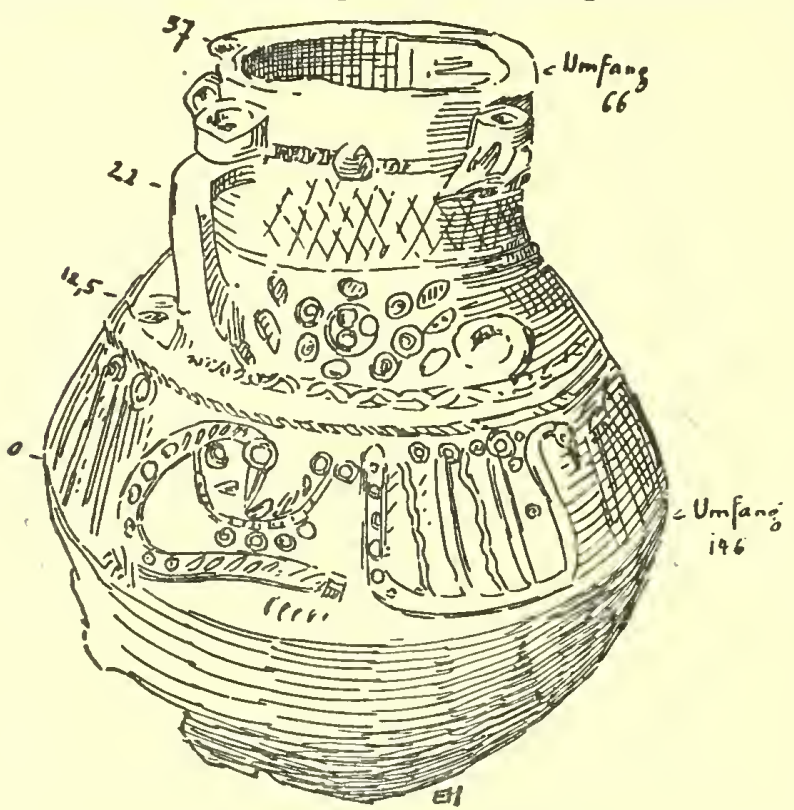

Abb. 392. Großer Wasserkrug aus Takrīt. hältnismäßig jüngeren Zeit, dem XII. - XIII. Jahrhundert, zuschreiben; ungefähr aus derselben Epoche, vielleicht aus noch etwas älterer Zeit, dem XI. - XII. Jahrhundert, stammt der auf Taf. CXLIII r. abgebildete große Wasserkrug (h. 70 $\mathrm{cm})^{2}$ ). Er zeigt wiederum die drei Techniken: Gravierung, Kerbschnitt und Barbotinrelief. Das Zinnenmotiv in der oberen Abschlußborte des Frieses und das Wellenband mit den eingestreuten Rosetten in der unteren Abschlußborte sind uns aus der parthisch-sassanidischen Keramik bekannt. Auch die phantastischen, lebhaft bewegten Tierfiguren (Pferde? Panther?), die mit ihrem reichen Schmuck von Bändern und Zierraten und in stets neuer Auffassung die vier Medaillons in der Mitte füllen, gehen in Zeichnung und im Beiwerk auf altorientalische und sassanidische Vorbilder zurück. Die einen der üblichen Segenswünsche auf den Besitzer enthaltende Inschrift gibt einen Anhalt für die Datierung.

Noch enger mit den früher behandelten Barbotingefäßen hängt das große schöne, gleichfalls aus Takrīt stammende Fragment zusammen, das wir auf Taf. CXIV l. veröffentlichen. Es steht dem großen Fragment des Viktoria and Albert-Museums sehr nahe, das ich in meinem Aufsatze im Jahrbuch abbildete (a. a. O. Abb.3), und ich verzichte hier auf eine eingehendere Beschreibung. Es handelt sich auch hier um den oberen Teil eines eiförmigen großen Wassergefäßes, bei dem die Zwischenräume zwischen den Henkeln durch durchbrochene Zierfelder geschlossen sind. Diese wurden, wie auch die Frauenköpfe an den Henkeln, nicht frei modelliert, sondern aus einer Form gepreßt und dann überarbeitet. Diese feinere Modellierung, das Anbringen von kleinen Schmuckornamenten, wie der überall vorkommenden Rosetten, das Punktieren und Gravieren des Hintergrundes und das Auflegen der Barbotin-Ornamente vollendete dann ein solches Gefäß, ehe es gebrannt wurde.

Taf. CXLIV Nr. 1. zeigt den Ausguß aus einer Tonform $(26 \times 17 \mathrm{~cm})$, die, in Baghdad erworben, bei der Herstellung von dem Berliner und Londoner Exemplare sehr ähnlichen Gefäßen benutzt worden ist. Die sitzende Figur mit dem Becher in der Rechten und dem Tuch in der Linken ist fast die gleiche, ebenso die beiden Löwen, zwischen denen aber hier ein dort nicht vorkommendes Schrifteld mit dem Segenswunsch : „Ehre dem Besitzer" angebracht ist.

Ein gleichfalls aus dem Baghdader Kunsthandel stammendes Halsstück eines kleinen Henkelkruges (Taf. CXLIV r.; h. 20,5 cm) ist entsprechend seinen Abmessungen wesentlich einfacher

1) Jahrb. der Kgl. Preuß. Kunstsammlungen. 1905. S. 69. Islamische Tongefäße aus Mesopotamien.
2) Schon einmal, aber von der anderen Seite, veröffentlicht in SARRE-MarTin: Meisterwerke mohammedanischer Kunst. Taf. 90. 
gestaltet. Der Zwischenraum zwischen zweien der vier Henkel wird hier mit einem Relief gefüllt, das einen Harfenspieler (oder eine Harfenspielerin) darstellt, und bei dem deutlich zum Ausdruck kommt, daß der Hintergrund erst nachträglich ausgestochen worden ist. In Anlehnung an jene reicheren Gefäße hat auch hier der Töpfer an den einrahmenden Henkeln Köpfe angebracht und die Henkel mit einem eingeritzten rohen Rautenmuster versehen. Der künstlerische Unterschied zwischen dem aus einer Abformung gewonnenen figürlichen Relief und dem sonstigen, auf den Töpfer selbst zurückgehenden rohen Schmuck des Gefäßes ist in die Augen fallend.

Eine Reihe von Fragmenten dieser Gruppe der mittelalterlichen Gefäßkeramik Mesopotamiens wurde von uns im Tigristal, in Mosul, Takrīt und Samarra teils gefunden, teils von den Einwohnern erworben, so daß das Kaiser Friedrich-Museum, auch abgesehen von dem intakten $\mathrm{Ge}$ fäße und den größeren Fragmenten, ein sehr reiches Material von Barbotin-Keramik besitzt. Auch bei den Ausgrabungen in Assur kamen in den jüngeren Schichten Fragmente dieser Art zum Vorschein. Den Engländern LAYARD, Jones und Smith sind Funde dieser Art aufgefallen, die ersterer jedoch für

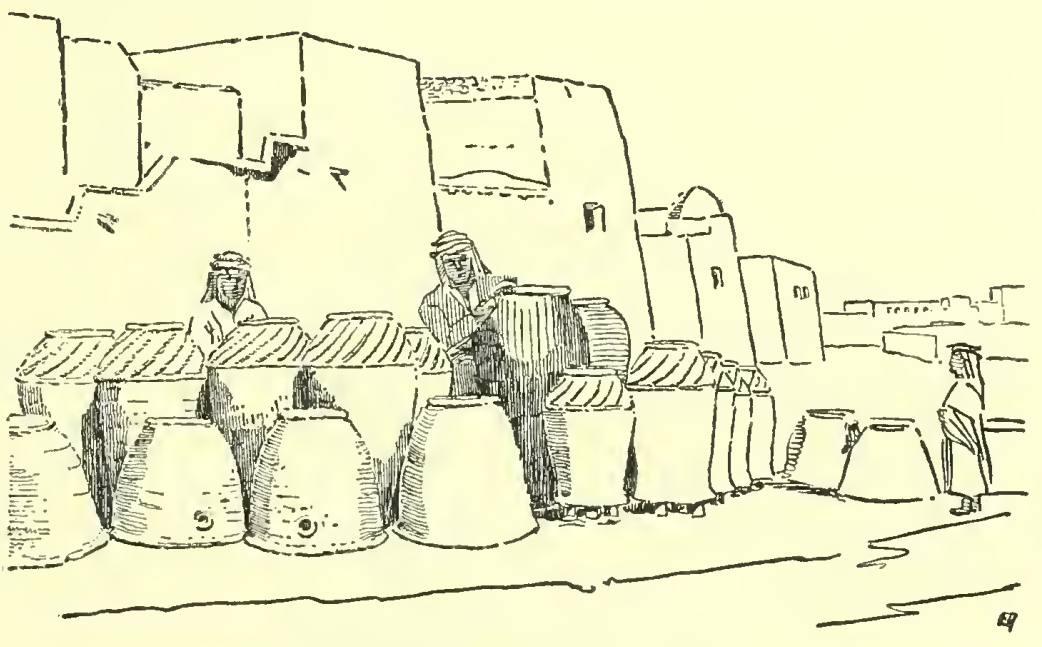

Abb. 393. Topfmarkt in Mosul. vorislamisch hielt. Dies wohl der Grund, weswegen sie Im British Museum bei den altorientalischen Altertümern Aufstellung fanden'). Die zahlreichen Scherben dieser Art, die den Boden des mittelalterlichen Mosul bedecken, und der Umstand, daß noch heute in Mosul eine blühende Fabrikation von Tongefäßen aller Art, auch von großen Wasserkrügen, besteht, die auf dem Flusse bis nach Baghdad und südlicher versandt werden, macht es sehr wahrscheinlich, daß wir in Mosul den Herstellungsort der hauptsächlichsten mittelalterlichen, aus gelblichem, äußerst hartem Ton bestehenden Gefäßkeramik des Tfgris-Tales und auch der Barbotin-Keramik zu suchen haben (Abb. 393). Ob die ältere und primitivere Gattung letzterer aus Takrīt und nicht aus Mosul stammt, wie Herzfeld annimmt (I. S. 225), sei dahingestellt. Die Modelle und Formen für den Schmuck der Barbotin-Keramik brauchen natürlich nicht von den Töpfern selbst herzustammen; zu der Annahme jedoch, daß diese von auswärts, aus dem Osten, importiert worden sind, liegt kein Grund vor. Die künstlerische Verwandtschaft dieser Formen mit dem sonstigen Stil der Zeit in Mesopotamien schließt diese Annahme aus. Ich weise auf das hin, was ich oben gelegentlich der Ornamentik des Qara Sarai gesagt habe (II. S. 243 ff.).

In engstem Zusammenhange mit der oben behandelten Gruppe stehen kleinere unglasierte Gefäße, deren Reliefschmuck durch Formen aufgepreßt wird. Wir haben sie oben (S. 10) schon erwähnt, soweit es sich bei ihnen um einen teilweisen, durch Stempel hergestellten Schmuck handelt. Hier seien die kleinen Gefäße, meist bauchige oder auch schlanke Henkelkrüge angeführt, deren Körper sich aus zwei aus Formen gepreßten Teilen zusammensetzt. Die Verbreitung dieser künstlerisch oft sehr reizvollen Keramik erstreckt sich von Kleinasien und Syrien bis nach

1) LAYARD: Discoveries. p. $278 \mathrm{ff}$. G. Sm1TH:

Herzfeld in Bd. I. S. 224. Assyrian Discoveries. London 1875. p. 141. Vgl. 
Persien ${ }^{1}$ ) und südlich den Euphrat und Tigris hinab. Neben einfacheren geometrischen Mustern, unter denen die Aneinanderreihung von tropfenartigen Verzierungen sehr häufig ist ${ }^{2}$ ), verdienen die figürlichen Bortenmuster auf kleineren Krügen und Vasen besondere Beachtung. Taf. CXV zeigt als charakteristische Beispiele zwei derartige, aus Mosul stammende Gefäße. Der Stil der ganz persisch empfundenen Tierfriese und der Segenswünsche enthaltenden Inschriften weist die Stücke in das XII. - XIV. Jahrhundert; ihre Dekoration erinnert stark an die Fragmente figürlicher Stuckreliefs, die aus Diarbekr und Konia stammend in das Museum auf der Sarailspitze in Konstantinopel und in das Kaiser Friedrich-Museum gekommen sind ${ }^{3}$ ). Eins dieser hübschen kleinen Gefäße, das sich im Museum für Völkerkunde zu München befindet ${ }^{4}$ ), trägt den Namen „al 'Amīd“. Es ist das ein Beweis mehr für die Richtigkeit der Vermutung, daß einer der Fabrikationsorte dieser interessanten Keramik im oberen Tigristal, spez. in Diarbekr zu suchen ist. Eine halb-

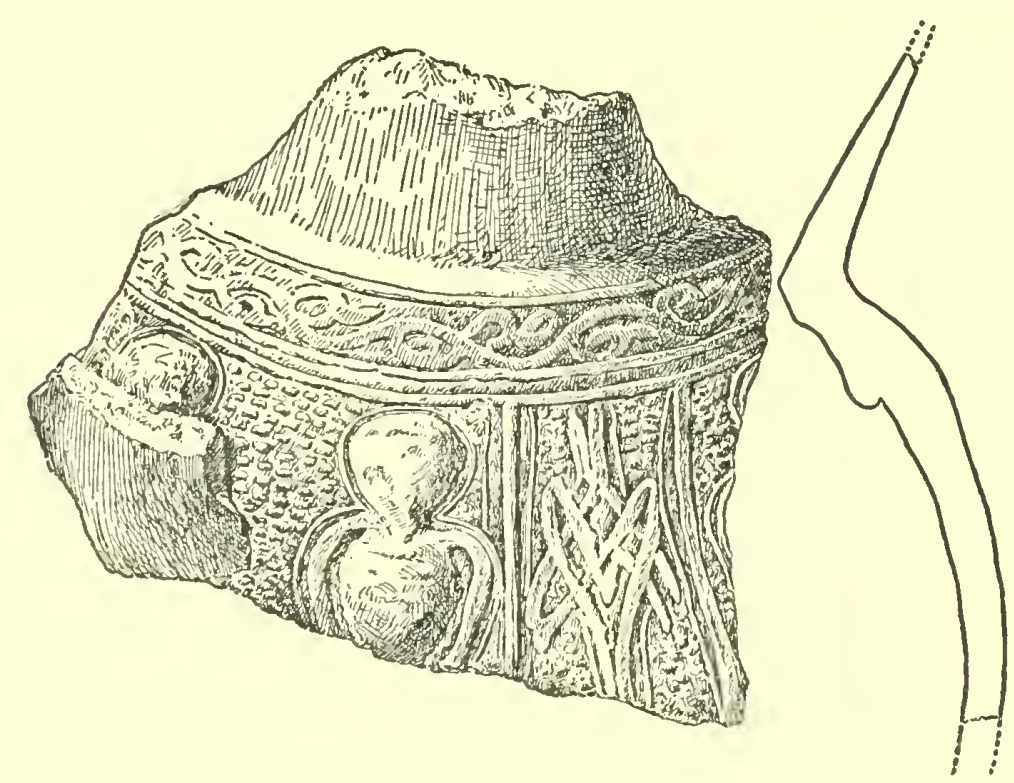

Abb. 394. Bruchstück eines unglasierten Tongefäßes aus Tell Husain; 3/4 nat. Gr. kugelartige Tonform, für den Oberkörper eines derartigen Gefäßes bestimmt, kam aus dem Kunsthandel in das Kaiser Friedrich-Museum (Inv. Nr. 2308). Scherben derart fanden sich

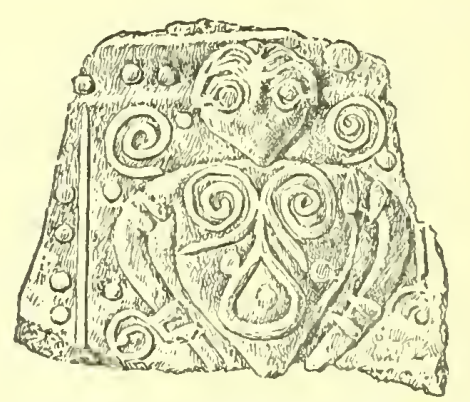

Abb. 395. Bruchstück eines unglasierten Tongefäßes aus Takrīt; $1 / 2$ nat. Gr.

vor allem in nordmesopotamischen Ruinenstätten, auch bei den Ausgrabungen in Assur, während in Südmesopotamien das Vorkommen dieser Ware verhältnismäßig selten ist. Der enge Zusammenhang, der zwischen der Barbotin-Ware und den in Rede stehenden gepreßten Gefäßen besteht, zeigt die Nebeneinanderstellung von zwei Scherben (Abb. 394 u. 395), von denen das eine in Takrīt, das andere in Tell Husain aufgelesen wurde. Die merkwürdige Darstellung, die auf der gepreßten Wandung des letzteren Fragments vorkommt, und die einem Käfer ähnelt, wird erst verständlich im Hinblick auf den Barbotinscherben aus Takrīt. Hier ist eine jener phantastischen menschlichen Figuren dargestellt, die für diese keramische Gattung charakteristisch sind und sich in ihrem Stilcharakter teilweise durch die Technik erklären lassen. Der vermeintliche Käfer ist nichts anderes, als eine Nachbildung eines solchen Barbotin-Männchens.

1) Aus Persien stammende Fragmente im Kunsthistor. Institut der Universität Wien (Lehrkanzel STRZYGOWSK1). Altai-Iran und Völkerwanderung. Abb. 221-223. Andere persische Gefäße derart im Berliner Museum.

2) So eine schöne Vase im Museum zu Konia (SARRE: Seldschukische Kleinkunst. Abb. 36). Fragmente derart fanden wir u. a. in Eski Meskene, 'Ara- bān, und Takrīt. - Eine große, in Assur gefundene Tonvase zeigt gleichfalls diese Dekoration. Mitt. der DOG. Nr. 26. Abb. 3.

3) Seldschukische Kleinkunst. Taf. IV, V. Abb. 23.

4) Im angegebenen Bericht 1916/17. S. 288. Abb. 17 . 
Einc besondere Gruppe bilden die Gefäße, auf dcren Wandung selbstständige runde oder ovale Medaillons eingelassen sind. Taf. CXV Nr. 2-5 zeigt drei derartige, teilweise figürliche Schmuckplättchen neben einer Form für dieselben; ein Krug des K. F.-Museums in Berlin (Inv. Nr. 2194), das eine reichhaltige Sammlung auch dieser keramischen Gruppc besitzt ${ }^{1}$ ), läßt die Verwendung der Medailons erkennen. Die in vorher angebrachte Vertiefungen des Gefäßkörpers eingedrückten Tonmedaillons kann man mit den Glasstempeln vergleichen, die in frühislamischer Zeit auf der Wandung von Gläsern angebracht wurden²).

Sehr reich und mannigfaltig, auch figürlich ornamentierte, aus Formen gepreßte Tongefäße, vor allem in der flachen Form der sogen. Pilgerflaschen, sind bei den Ausgrabungen der arabischen Burg von Baalbek zum Vorschein gekommen. Eine besondere Stelle nimmt ferner die gleichfalls aus Formen gepreßte, stark glimmerhaltige, rote Tonware ein, dic bei den Ausgrabungen von Milet gefunden wurde. Daß hier eine Fabrik dieser ziemlich rohe, rein ornamentale Muster aufweisenden Ware vorhanden war, beweist der Fund der dazugehörenden Tonformen.

\section{FRÜHISLAMISCHE KERAMIK MIT FARBIGER MALEREI UNTER DER GLASUR}

Bei den keramischen Funden von Samarra, die sämtlich dem 9. Jahrhundert angehören, haben wir nachweisen können, daß hier importierte chinesische Keramik teilweise vorbildlich gewesen ist (Der Islam V. S. 182). Diese Vorbilder kamen in zahlreichen und mannigfachen Fragmenten von Steingut und echtem Porzellan zum Vorschein, aber in größerer Menge nur an einer bestimmten Stelle des Kalifen-Palastes. Dies beweist, daß die ostasiatische Ware nicht als Massenware ausgeführt wurde und als etwas Kostbares galt. Auch auf den von uns besuchten Ruinenstätten Mesopotamiens fanden wir nur ganz vereinzelt Bruchstücke ostasiatischer Keramik, hie und da Fragmente von seladongrünem, seltener von weißem Steingut, von dem wir das Bruchstück einer großen weißen Schale in Ktesiphon auflasen ${ }^{3}$ ).

Am ehemaligen Nīl-Kanal (Shaț al-Nîl) in Babylonien, vor allem auf dem Ruinenfelde von Nìliyyah, der unter dem Kalifen 'Abd al-malik (685 - 705) gegründeten bemerkenswertesten Stadt an seinem Ufer (I.S.239), weisen Schlackenhaufen und Reste von Gefäßuntersetzen, die beim Brennen der Töpferware verwandt wurden, auf eine umfangreiche keramische Industrie hin. Dem Nîl-Gebiete eigentümlich ist eine dickwandige Ware aus gelblichem, feingeschlemmtem Ton, die, mit oder ohne Malgrund (Engobe), unter der Glasur in brauner, blauer und grüner Farbe bemalt ist. Die auf gleichmäßigen Brand zurückzuführende glatte Glasur, jetzt vielfach gesprungen, ist durchscheinend und läßt, wenn die Engobe fehlt, den gelblichen Scherben in grün-grauer Tönung als Hintergrund für das in flotten Pinselstrichen aufgetragene Muster erkennen. Das Muster der Teller und Schüsseln, von denen wir leider nur Fragmente fanden (Abb. 396 u. Taf. CXLVII Nr. 1), zeigt im Innern braun-grüne konzentrische Krcise, denen sich auf den Rande ein Kranz

1) Amtl. Berichte der Kgl. Preußischen Museen. XXXIII. Abb. 11 und XXXIX. Abb. 94.

2) Ein wahrscheinlich aus Syrien stammender, frühislamischer Glasbecher mit aufgelegtenStempeln im Kaiser Friedrich-Museum. Abgeb. bei RoBerT Schмidt: Das Glas. Berlin 1912. Abb. 20.

3) Über das Vorkommen von Scherben chinesischer Steingut- (auch Seladon-) und Porzellangefäße in der Turfan-Oase vgl. A. v. LE CoQ in 3 SARRE-HERZFELD, Archäologische Reise. Band IV.
Túrán. 1918. S. 338. - Die Islamische Sammlung des Kaiser Friedrich-Museums besitzt eine größere Menge von Fragmenten chinesischen Steinguts und Porzellans, die in Kleinasien (Milet, Pergamon, Konia), Syrien (Baalbek), Ägypten (Fostat, Fayyūm) und in Persien zum Vorschein gekommen sind. Meist handelt es sich um Seladon-Steingut, doch kommen auch andere Arten von Steingut und von Porzellan vor. 
von pfauenaugenartigen Spitzovalen') auf einem Hintergrunde von verschlungenen Bändern in blauen und grünen Farbtönen anschließt. Eine im Kunsthandel erworbene tiefe Schale des Kaiser Friedrich-Museums, in der Art der Glasur und der farbigen Bemalung mit diesen Scherben vom Nìl übereinstimmend, zeigt auf der äußeren Wandung das gleiche Pfauenaugenmotiv und im

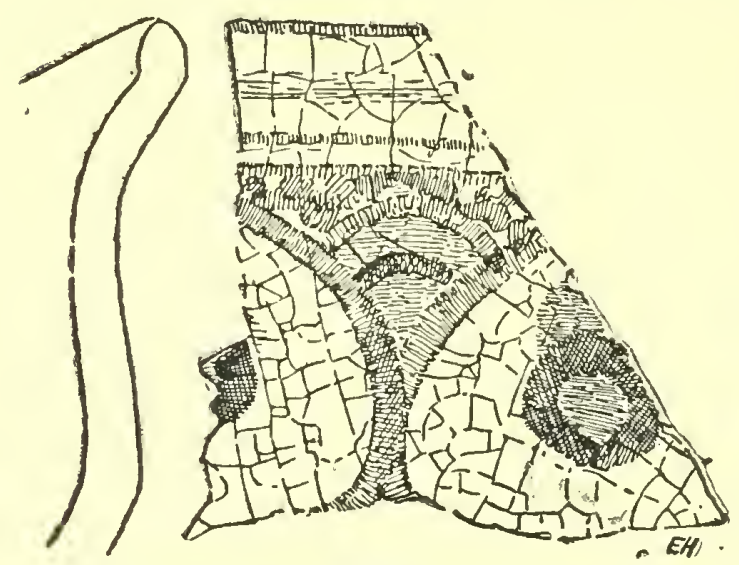

Abb. 396. Bruchstück einer glasierten Schüssel aus Nīliyyah; 3/4 nat. Gr. Innern ein Medaillon mit einer grün-blauen Blume inmitten von schwarz-braunem Blattwerk (Taf. CXLVII Nr. 2 u. 3). Dieser Blumenstrauß mit seinen mageren Zweigen, an denen eingerollte Blätter sitzen, ist so charakteristisch ostasiatisch in der Zeichnung, daß man eine direkte Nachahmung voraussetzen darf. Zum Beweis für diese Übereinstimmung sei in Abb. 4 derselben Tafel nach $\mathrm{HoBsoN}^{2}$ ) eine in der Sammlung Eumorfopoulos befindliches grün glasiertes chinesisches T'ang-Gefäß abgebildet, dessen Bemalung die gleichen

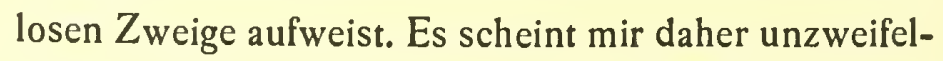
haft zu sein, daß diese schöne frühislamische Keramik, deren Fabrikation wir am Nīl nachweisen können, auf importierte chinesische Ware der T'ang-Zeit zurückzuführen ist und in ihr sowohl zeichnerisch als koloristisch ihre Vorbilder hat.

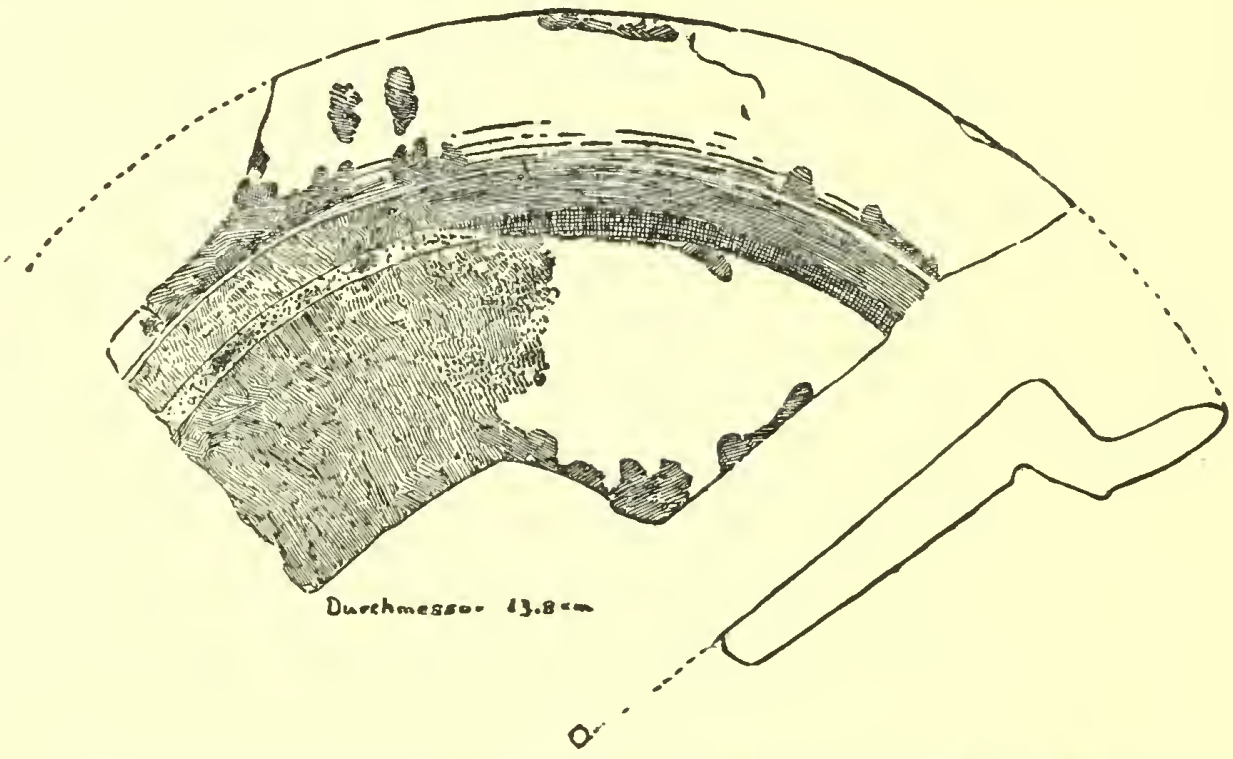

Abb. 397. Bruchstück eines glasierten Tellers aus Baghdad; 3/4 nat. Gr.

Das Gleiche gilt von jener Fayence-Ware, die in zahlreichen Beispielen in Samarra vorkommt, und die nichts anderes als eine Nachahmung des meist auf weiß-gelblichem Grunde mehrfarbig, gelb, grün, braunrot gefleckten ostasiatischen Steinguts der T'ang-Periode ist. Die Farbflecken, die teilweise auseinandergelaufen sind, wirken ohne eine ausgesprochene Zeichnung rein dekorativ. Wir fanden diese in direkter Nachahmung jener importierten chinesischen Ware gefertigte Fayence, die wir am Nìl nicht sahen, die also vielleicht erst im 9. Jahrhundert aufkommt,

1) G. STrocch1: La „Pavona" christiana e la „Pavona" di Galeotto Manfredi (Faenza. Bull. del Maseo della Ceramiche I. p. 105). Strocchı führt das „Pfauenauge" der altorientalischen und der jüngeren Keramik auf die Sonnendarstellungen zurück, wie wir sie in typischer Form, die allerdings dem „Pfauenauge“ ähnlich sieht, auf der alten Keramik von Susa finden (Mémoires de la Délég. en Perse. Tome VIII. p. 139).

2) R. L. Hobson: Chinese Pottery and Porcelain. 1915. I. Pl. 12, Nr. 3. 
allenthalben in den frühislamischen Ruinenstätten des Euphrat- und Tigrisgebietes. Das aus dem alten Baghdad stammende Bruchstück eines Tellers (Abb. 397), dessen strenge Profilierung des Randes auf engen Anschluß an das ostasiatische Vorbild hinweist, zeigt grüne auslaufende Farbflecke auf gelblich-weißem Grunde. Weitere Beispiele auf Taf. CXIII Nr.1.2.4 in Scherben, die wir im Gebiete von Samarra, im Qaṣr al- Āshiq und in Abū Isa fanden. Sie gehören zu einer bestimmten, bisher nur in Samarra beobachteten und wohl auch dort gefertigten Ware, deren feiner, gelb-weißlicher Scherben mit einer starken elfenbeinfarbenen Glasur bedeckt ist, auf der dann in dunkelblauer Farbe Blattrosetten oder auch Schriftborten mit kufischen Lettern, daneben auch unregelmäßige Farbflecke in grüner Farbe angebracht sind. Wir haben diese Gattung der Samarra-Keramik mit einer chinesischen Töpferware der Sung-Periode in Verbindung gebracht, deren Dekoration auf rahmfarbigem Grunde Blattmotive in dunkelbrauner Malerei aufweist (Der Islam V. S. 180. Fig. 3).

\section{KERAMIK MIT FARBIGER MALEREI UND GERITZTER ZEICHNUNG UNTER DER GLASUR}

Auch die Graffito-Technik, bei der die Zeichnung in den weichen Scherben oder in eine auf dem Scherben liegende weiße Stuckschicht eingeritzt ist und durch die helle Glasur in der Farbe des Scherbens sichtbar wird, finden wir zur T'ang-Zeit schon in Ostasien. Sie scheint also keine Erfindung Vorderasiens zu sein, wie man bisher annahm ${ }^{1}$ ), sondern wurde hier nach ostasiatischen Vorbildern, wie wir sie in Samarra fanden (Der Islam. V. S. 180. Fig. 4), nachgeahmt. In Persien kommt auch schon in frühislamischer Zeit eine sehr merkwürdige, in sassanidischen Formen gehaltene Graffito-Keramik vor ${ }^{2}$ ). In mesopotamischen Ruinenstätten fanden wir Beispiele der primitiveren Gattung, bei der ohne Bemalung und meist auch ohne Deckschicht ein eingekratztes einfaches geometrisches Muster oder Borten aus korrumpierten Buchstaben von einer hellfarbigen Glasur bedeckt ist, verhältnismäßig selten; einige wenige Beispiele liegen aus Busairah (Circesium), Mosul und Baghdad vor.

Umsomehr ist die Graffito-Technik bei den Nachahmungen der ostasiatischen Keramik mit farbigen Überlaufglasuren in Vorderasien verbreitet; wir fanden sie nicht in Samarra (9. Jahrh.), dann aber umso häufiger in den folgenden Jahrhunderten, wo man ihr vor allem in den Ruinenstätten am Euphrat begegnet. Ein schönes Beispiel ist die auf Taf. CXIII Nr. 6 abgebildete tiefe Schale aus Dēr ez-Zōr $(\mathrm{h} .11 \mathrm{~cm}$, Durchm. $21 \mathrm{~cm})$, deren rötlicher, starkwandiger Scherben auf der von der Glasur teilweis freigebliebenen Außenseite sichtbar wird. Das in die weiße Engobe eingeritzte Muster des Innern zeigt einen schwimmenden Fisch zwischen ostasiatisch gezeichneten primitiven Blattranken. Die Farbflecke sind grün, gelbbraun und manganviolett und beschränken sich auseinanderlaufend nicht auf die Stellen des Musters, für die sie bestimmt sind. Ein aus Abū Hurairah am Euphrat stammendes Fragment (Taf. CXIII. Nr. 5) ist vor allem wegen der glänzenden, frischen Glasur bemerkenswert.

Die bei allen im Euphratgebiet gefundenen Fragmenten übereinstimmend gleiche Masse, ein roter, feingeschlemmter, starkwandiger Scherben, und die Übereinstimmung in der Zeichnung legen die Vermutung nahe, daß diese keramische Gattung aus einer bestimmten Fabrik stammt. Wir möchten annehmen, daß dieser Herstellungsort am Euphrat oder in Syrien gelegen hat. Die

1) O. WULFF: Altchristliche und mittelalterliche Bildwerke. II. Berlin 1911. S. 106.

2) Frühislamische in Graffito-Technik deko- rierte Keramik persischer Herkunft. Amtl. Berichte der Kgl. Preuß. Museen. XXXV. S. 46. $3^{*}$ 
ursprünglich, wie wir sahen, von Ostasien abhängige Graffito-Keramik hat sich dann auch im weiteren Vorderasien verbreitet und ist in Ägypten (Fostat), Kleinasien (Milet, Pergamon), Byzanz und in Südrußland zum Vorschein gekommen. Für diese Gebiete sind ohne $Z_{\text {weifel eigene }}$ Fabrikationsorte anzunehmen, so für das mamelukische und jüngere Ägypten, für die kleinasiatische Küste und für Byzanz. Nach letzterem Orte hat man diese gesamte keramische Gattung „byzantinisch“ genannt. Die für die christlichen Gebiete hergestellte Graffito-Ware zeigt vielfach im Muster christliche Symbole; aber auch hier ist, wie WULFF hervorgehoben hat, die frühislamische Tradition unverkennbar (a. a. O. S. 106).

Was die in Mesopotamien zu Tage kommende farbige Graffitoware betrifft, so lehnt sie sich direkt an ostasiatische Vorbilder der T'ang-Periode an, was bei dem sonstigen Vorkommen dieser keramischen Gattung nicht der Fall ist. Die gleichen oder ähnliche Ranken mit primitiven Blattmotiven, wie sie auf ostasiatischer Ware in Samarra vorkommen, zeigt die Schale aus Dēr ezZōr; und den hier in der Mitte wiedergegebenen Fisch, den gegen den Strom schwimmenden Karpfen, ein Symbol der Kraft, sehen wir in gleicher Zeichnung auf einem in Samarra gefundenen Seladonschälchen ostasiatischer Herkunft (Der Islam. Band V. Taf. 1. Fig. 2).

\section{DIE KERAMIK VON RAQQAH}

Bei der Beschreibung der Ruinen von Raqqah am Euphrat hat Herzfeld (Bd. I S. 156 ff. u. II. S. 349 ff.) ausgeführt, daß die auf der Stelle des antiken Nikophorion entstandene islamische Stadt $1 \frac{1}{1} 2 \mathrm{~km}$ östlich von der durch die Kalifen Mansür und Hārūn begründeten und seitdem bis zur Gegenwart besiedelten Ortschaft gelegen ist. Die sogen. Raqqah-Keramik ${ }^{1}$ ) kommt von der jüngeren Anlage her, wo ein großer Teil, die östliche, jetzt brach liegende Hälfte des Stadtgebietes nach Funden durchwühlt ist und den Eindruck einer Ausgrabungsstätte macht (Taf. LXIV). Leider sind hier nie systematische Grabungen vorgenommen worden; auch die von Seiten des K. Osmanischen Museums im Jahre 1909 unter Makridi Bey vorgenommenen Schürfungen haben sich auf die Suche und Bergung keramischer Fragmente beschränkt, ohne im Anschluß an die noch vorhandenen Architekturreste, die immerhin gewisse Anhaltspunkte hätten geben können, oder auf die Tiefe der Fundschicht Rücksicht zu nehmen. Die nicht unbeträchtlichen Ergebnisse dieser türkischen Grabung sind im Tschinili-Kiosk des K. Osmanischen Museums auf der Sarailspitze ausgestellt und noch nicht bearbeitet. Diese und die von Seiten der tscherkessischen Bevölkerung des Ortes auf Anstiften und unter Mitwirkung von Antiquitätenhändlern vorgenommenen Raubgrabungen haben hauptsächlich die oberen Schichten des lange besiedelten Ortes betroffen; kam hier doch unter jüngeren Erzeugnissen die geschätzte, aus dem 12. - 14. Jahrhundert stammende lüstrierte Ware zum Vorschein. Die älteren, dem 9. - 11. Jahrhundert angehörenden primitiven Erzeugnisse fanden, da sie der Kunsthandel nicht kannte und nicht suchte,

1) Uber die Keramik von Raqqah vgl. G. Migeon: Manael de l'Art Musulman. Paris 1907. S. 284 ff. Ch. Hercules Read: Burlington Club. Exhibition of the Faience of Persia and the nearer East. London 1908. XVIIff. - SARRE und MARTIN: Meisterwerke muhammedanischer Kunst. II. München 1912. Taf. 94. 104. - Katalog der Ausstellung München 1910. Nr. 1075-1098. - G. Chatfield P1eR: Pottery of the hither Orient. Burlington Magazine.
XIV. p. 120. - F. SARRE: ebendort p. 388. H. NOldeKe: Zur Kenntnis der Keramik von Raqqa, Raghes und Sultanabad. Orientalisches Archiv. 1910. S. 16 ff. - The Kelekian Collection of Persian and analogous Potteries. Paris 1910. P1. 12.14. 21. 35. 36. - Henri Riviere et Gaston Migeon: La Céramique dans l'Art Musulman. Paris 1913. PI. 1-12. 
keine Beachtung. Das geschäftliche Interesse, das die Bevölkerung an diesen Raubgrabungen nimmt, hat uns von dem Gedanken abgebracht, die Ausgrabungskonzession für Raqqah zu erwerben. Eine solche Unternehmung wäre an dem Widerstande der Bevölkerung gescheitert. Der längere Aufenthalt, den wir zur Untersuchung der Ruinen im Orte nahmen, ermöglichte es jedoch, von der bei den Grabungen vorkommenden Keramik charakteristische Beispiele und Kleinfunde anderer Art zu erwerben. Sie dienen dazu, einen Überblick über die Raqqah-Keramik zu gewinnen, was bisher noch nicht versucht worden ist (Taf. CXVI - CXX).

Die gesammelten Scherben dürften sämtlich nach dem Jahre 1000 entstanden sein; die meisten erst dem 12.-13. Jahrhundert angehören. Einige hier nicht abgebildete Fragmente stammen aus einer älteren Zeit; es sind Bruchstücke jener buntfleckigen Graffito-Keramik, die wir als Nachahmung ostasiatischen Steinguts erkannt haben.

Daß die in Raqqah zutage kommende Keramik durchschnittlich nicht von auswärts importiert, sondern an Ort und Stelle hergestellt ist, beweisen die vielen vom Töpfer verworfenen, im Brande mißlungenen Gefäße, die an der Stelle von Töpferwerkstätten zum Vorschein gekommen sind, wo man auch gelegentlich große unglasierte Töpfe fand, die mit kleineren, gut erhaltenen Glasurgefäßen gefüllt waren. Die reiche Sammlung von schöner Raqqah-Keramik bei Mr. Charles F. Freer in Detroit U.S. A. geht zu einem großen Teil auf einen solchen, durch einen Aleppiner Antiquar auf den Kunstmarkt gebrachten Fund zurïck.

Durchschnittlich ist der mäßig fein geschlemmte Ton nach dem Brande leicht brüchig und von weißlicher, manchmal bräunlich-grauer Färbung; die kieselhaltige Glasur ist durchscheinend und von leicht grüner Färbung, wenn sie nicht in der Masse türkis- oder kobaltblau oder auch intensiv dunkelgrün gefärbt ist.

Beispiele unglasierter Gefäße, die in der üblichen Weise in Gravierung gemustert sind, kommen natürlich gleichfalls in Raqqah vor. Eine derartig verzierte Schüssel und ein großer Wasserkrug sind schon oben von uns erwähnt und abgebildet worden (Abb. 385).

Im folgenden seien an der Hand der Abbildungen die verschiedenen Arten, die die glasierte Raqqah-Keramik aufweist, besprochen. Im Gegensatz zu der gleichzeitigen persischen Keramik fällt das Zurücktreten des Figürlichen dem Ornamentalen gegenüber auf, was in Übereinstimmung mit der gesamten künstlerischen Entwicklung mit der freieren religiösen Stellung dem Bilderverbot gegenüber im schiitischen Persien zusammenhängt. Für die seltenen Gefäße, bei denen man ganz auf Farbe und Malerei verzichtet hat, und deren künstlerischer Reiz allein in der Form besteht, ist der auf Taf. CXVI abgebildete Kelch ein Beispiel (Durchm. $16 \mathrm{~cm}$ ). Von gleicher, durch die silbrige Irisation nachträglich erhöhter Schönheit ist die ebendort wiedergegebene Fliese (h. $31,5 \mathrm{~cm}$ ) mit ihren kräftigen Relief buchstaben und den Blattranken dazwischen. Nur der Grund ist unter der Glasur kobaltblau gemalt. Die Inschrift besagt, daß es sich um das Ende einer Meistersignatur handelt: „Gemacht hat es der demütige Knecht . ...“ (II. S. 363); die Fliese ist demnach wahrscheinlich die vorletzte eines längeren Schrifffrieses, von dem andere Beispiele in der Sammlung Eugène Mutiaux in Paris (Rivière-Migeon a. a. O. pl. 4) und bei Herrn Marcopoli in Aleppo vorhanden sind. Herzfeld setzt den Fries in die Zeit des Nūr aldīn (1146 - 1173); es ist demnach nicht ausgeschlossen, daß der Fries mit der großen Moschee dieses Herrschers in Raqqah in Zusammenhang steht. Weitere hervorragende Beispiele derselben Gattung sind zwei große bauchige Vasen aus dem Besitze der Cesse de Béarn und von M. Doucet in Paris (Rivière-Migeon a. a. O. pl.6. 8); auch hier wird die künstlerische Wirkung durch die 
Irisation gesteigert, die in dem Boden von Raqqah in ihrem matten Silberton eine seltene Schönheit erreicht, der Patina antiker Bronzen vergleichbar, die auch an bestimmten Örtlichkeiten, z. B. in Dodona, einen ganz besonders wirkungsvollen Charakter erhalten hat.

Die Technik, nicht eine farblose Glasur über einfarbiger Malerei, sondern eine in sich farbige, aber trotzdem durchscheinende Glasur zu verwenden, kommt schon in frühislamischer Zeit vor. In dieser Art dekorierte Keramik, starkwandige Gefäße, bei denen das auf dem Scherben ohne Malgrund auf getragene Muster - flüchtig gezeichnetes, auf ostasiatische Vorbilder beruhendes Blatt- und Rankenwerk - durch die grün-blaue Glasur hindurchscheint, fanden wir häufig am Nīl und auf anderen frühislamischen Ruinenstätten Babyloniens. In Raqqah ist diese Dekorationsart vervollkommnet, und Gefäße mit schwarzer Malerei unter türkis-blauer Glasur sind in der Zeichnung und in der dekorativen Wirkung oft von großem Reiz (Taf. CXVII. 2. 4).

Ein Teller mit zwei Pfauen aus der Sammlung von M. Kouchakjı in Paris (Rivière-Migeon a. a. O. pl. 12), auch eine Fliese mit einem stilisierten Pferde auf Rankenhintergrund im Berliner Museum gehören zu den schönsten Erzeugnissen der orientalischen Keramik. Diese einfarbige, in verschiedenen Tönen gehaltene blaue Glasur findet nun auch bei reliefierter Ware Verwendung, bei jenen großen, mit Schriftcharakteren bedeckten bauchigen Vasen und vor allem bei kleinen Taburetts (Kursi), die in Raqqah besonders häufig zum Vorschein kommen (Taf. CXVIII. Nr. 6. 7). Eine neben den üblichen Tellern, Schüsseln, Vasen, Henkelkannen, Albarallos usw. seltene Gefäßform ist eine als Hohlplastik modellierte Flasche in der Gestalt einer sitzenden Figur, die ein Kind an der Brust hält. Abgesehen von dem auf Taf. Nr. CXLII 1 a abgebildeten Fragment ist nur noch ein 1910 in München ausgestelltes intaktes Exemplar bekannt (Katalog Nr. 1153. Münchner Ausstellungswerk Taf. 104). Ein ähnliches Gefäß, eine persische Lüsterkeramik des 13. Jahrh., besitzt die Berliner Sammlung ${ }^{1}$ ). Man kann wohl bei diesen Figuren kaum annehmen, daß es sich um eine für Christen hergestellte Darstellung der Madonna handelt; näher liegt die Vermutung, daß hier ein altorientalisches Motiv lebendig geblieben ist, die Göttin Ishtar, die in ähnlicher Auffassung in Terrakotten jungbabylonischer Zeit vorkommt (Koldewey a. a. O. Abb. 207).

Häufig begegnen uns in Raqqah kleine, ziemlich roh geformte, blauglasierte Tierfiguren (Taf. CXIX. Nr. 7.9. 10), die wahrscheinlich als Kinderspielzeug gedient haben; ein Widderfigürchen derart befindet sich im Münchener ethnographischen Museum²). Neben sechsseitigen, einfach grün glasierten Fliesenplatten (Durchm. 12,5 cm) gibt es viereckige Sternfliesen, deren reliefierte Vorderseite blau glasiert, während der Körper keilförmig zugeschnitten ist (Taf. CXX Nr. 6). Wie diese Fliesen an der Wand Verwendung gefunden haben, ob in Verbindung mit anderen Fliesen oder als belebender Schmuck von Stuckornamenten, wissen wir nicht. Auch hier liegen vielleicht altorientalische Reminiszenzen vor. Man wird an Wanddekorationen aus Emailziegeln in Assur erinnert, wo innerhalb eines Musters hervorstehende Knäufe angebracht $\operatorname{sind}^{3}$ ).

Als Beispiel der in schwarz-blauer Farbe unter farbloser Glasur ausgeführten, oft sehr reizvollen Malerei ist ein Scherbenboden mit einem schreitenden Affen abgebildet (Taf. CXVIII Nr. 3). Hier zeigt sich beim Vergleich mit den oben erwähnten plastischen Tierfiguren, wie viel besser dem islamischen Künstler die figürliche Darstellung in der Malerei als in der Plastik ge-

1) KÖHNEL: Ein Madonnenmotiv in der islamischen Kunst? Amtl. Berichte der Kgl.Preuß.Museen. XXXVI. S. 55.
2) Bericht von L. Scherman 1916/17. Abb. 18.

3) W. ANDRAE in den Mitteilungen der DOG. Nr. 26. Abb. 5. 
lingt. Der Affe ist mit sicherem Blick für die charakteristische Bewegung und das komische, den Menschen nachahmende Gebaren des Tieres wiedergegeben.

Hier mag auch ein sehr merkwürdiges Fragment (Abb. 398) Erwähnung finden: Ein großer leicht gewölbter Teller, auf dem in blauer Malerei unter der Glasur in flotter Zeichnung eine sitzende Figur dargestellt ist, die zwei Becher in den Händen hält. Die Figur soll absichtlich rein dekorativ wirken und gleicht im Umriß einem ornamentalen oder pflanzlichen Gebilde. Der Kopf ähnelt den auf einer syrischen Lüsterschale in der Sammlung Mutiaux in Paris ${ }^{1}$ ) vorkommenden Büsten, die auch sonst mit der Figur auf unserm Fragment Berührungspunkte haben.

$\mathrm{Zu}$ den im Kunsthandel am meisten geschätzten keramischen Funden von Raqqah gehören die Gefäße mit Lüstermalerei. Man hat früher hier das älteste Vorkommen dieser Technik zu erkennen geglaubt, die übrigens eine Erfindung des islamischen Kunsthandwerks ist; wollte man sich doch für das durch den Koran verpönte Edelmetallgerät einen wenigstens äußerlich ähnlichen, wie Edelmetall schimmernden Ersatz schaffen²). Die Ausgrabungen von Samarra haben den Beweis erbracht, daß die Lüstermalerei dort schon im 3. islamischen Jahrhundert eine später nicht mehr vorkommende technische und künstlerische Vollendung erreicht hat (Der Islam. V. S. $187 \mathrm{ff}$. Abb. 1. Taf. 4. Fig. 8). Man darf wohl annehmen, daß die Technik der Lüstrierung in Mesopotamien entstanden und von hier aus nach Westen,

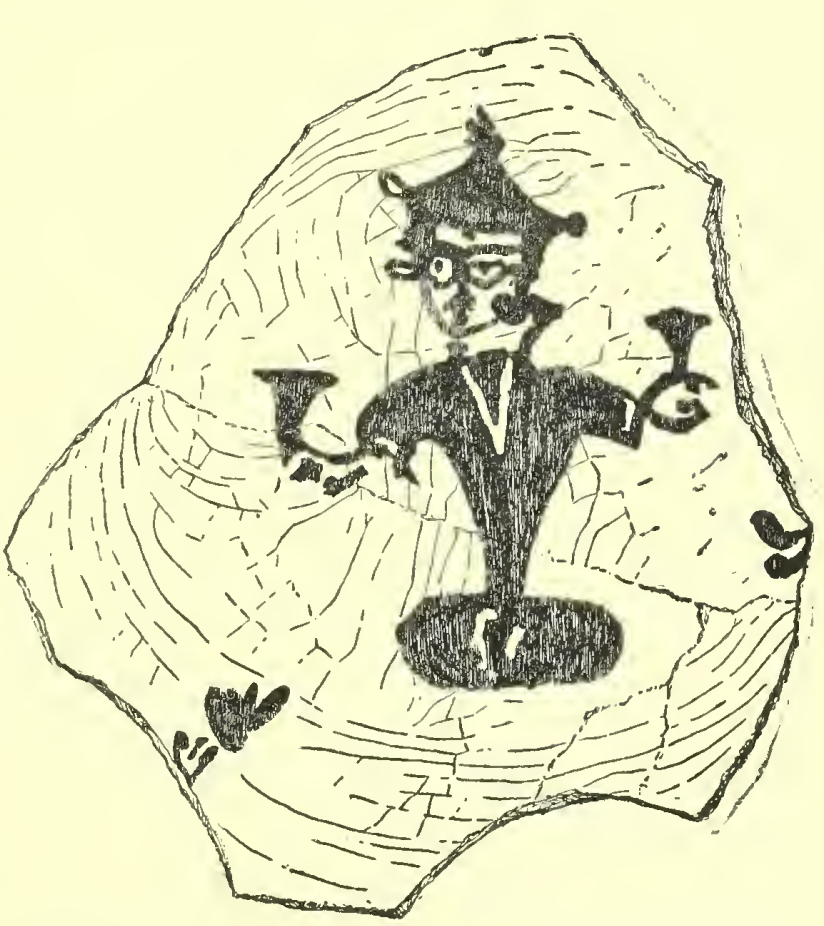

Abb. 398. Bruchstück eines glasierten Tellers aus Raqqah; $1 / 2$ nat. Gr. nach Syrien, Ägypten und Spanien, dann auch nach Italien, und nach Osten, nach Persien, gekommen ist. Im Gegensatz zu Samarra, wo verschiedene Töne des Lüsters vorkommen, gibt es in Raqqah nur einen, mehr oder weniger tief gefärbten braunen Lüster, der mit dünnem Pinselstrich auf dem gebrannten Scherben aufgetragen und in einem zweiten leichten Brande fixiert wurde. Dieses Verfahren hat es mit sich gebracht, daß sich bei Gebrauchsgeräten der Lüster vielfach abgenutzt und abgerieben hat. Von dunkelbrauner Färbung ist der Lüster auf dem Bruchstück einer jener großen, mit Reliefbuchstaben und Blattmotiven auf punktiertem Hintergrunde dekorierten Vasen (Taf. CXVII Nr. 5), von denen ein besonders schönes Exemplar bei RivièreMigeon auf Pl. 11 wiedergegeben ist.

Die anderen auf Taf. CXVIII abgebildeten Fragmente zeigen charakteristische Beispiele für die Dekorationsmotive der Gefäße: bei dem Schalenfragment Nr. 1 die aus dem Rollwerk des Hintergrundes ausgesparten lappigen Blätter und Schriftcharaktere ${ }^{3}$ ), bei Nr. 2 und 5 andere häufig vorkommende Borten- und Spiegelmotive und endlich bei Nr. 4 wiederum eine der seltenen figürlichen Darstellungen, eine Harpyie, die in der Wiedergabe und Anordnung der Flügel und Federn in letzter Linie auf sassanidische Vorbilder zurückgeht.

1) Migeon, Manuel fig. 231.

2) Jahrb. der Kgl.Preuß. Kunstsammlgn. 1903.
3) Amtl. Berichte der Kgl. Preuß. Museen. XXXI. Abb. 72. S. 103. 
Neben der Lüstrierung kommen häufig unter der Glasur angebrachte Tupfen oder Umrahmungen und Tcilungen bildende Striche in blauer Malerei vor, die zur Belcbung außerordentlich beitragen. Dies ist z. B. bei den beiden plastischen Henkelstücken (Taf. CXIX Nr. 4.6) der Fall, die in Nachahmung von Metallhenkeln mit Ringen gebildet sind.

In Lüster bemaltc Fliesen aus Raqqah sind äußerst selten. Das Berliner Museum besitzt zwei quadratische Fliesen mit den stilisierten Darstellungen eines Löwen und eines Pfauen, die wir den Werkstätten von Raqqah und zwar schon dem 10. - 11. Jahrh. zuweisen zu müssen glaubten ${ }^{1}$ ). In cnger Verwandtschaft zu diesen Stücken steht das Fragment einer rechteckigen,

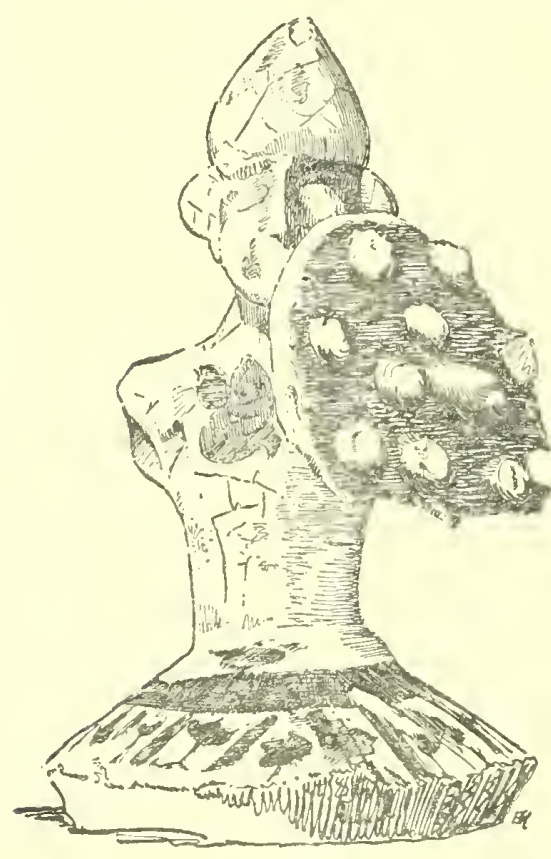

Abb. 399. Figürchen aus glasiertem Ton aus Raqqah; ${ }^{4 / 5}$ nat. Gr. bortenartigen Fliese mit einem Fisch (Taf. CXX Nr. 5). Im Gegensatz zu den persischen kreuz- und sternförmigen Fliesen sind alle diese frühen Fliesen, auch die von Samarra ${ }^{2}$ ) und die in Bagdad für die Moschee Sidi Oqba in Kairuan ${ }^{3}$ ) hergestellten Fliesen von quadratischer Form.

Der stark lädierte Knauf eines Gefäßdeckels (?), der Oberkörper eines schildhaltenden Mannes (Abb. 399) wurde von mir nicht in Raqqah selbst, sondern erst im Jahre 1918 in Aleppo im Kunsthandel erworben; aber die braune Lüsterbemalung weist ohne Zweifel auf Raqqah als Herstellungsort hin. Als seltene, plastisch-figürliche Darstellung ist das Stück von einem gewissen Interesse; auch der Buckelschild und die mützenartige Kopfbedeckung verdienen Beachtung.

Die verschiedcnen Gattungen der Keramik von Raqqah, die wir kurz erwähnt haben und in der Hauptsache dem 12. 13. Jahrh. zuweisen müssen, sind nicht auf Raqqah als Fundort beschränkt. Wir sahen Raqqah-Scherben auf dem Boden der meisten der von uns besuchten, in jener Zeit besiedelten Ruincnstätten des Euphrat- und Tigris-Gebietes, in Dair Hafīr, Balis, Halabiyyah, Busairah, auf den Tells am Khābūr, in Nimrud, Qal'at Djåbar, Babylon und am Nīl. Wenn auch anzunehmen ist, daß hic und da Töpferwerkstätten ähnliche Ware hergestellt haben, so darf man doch nicht daran zweifeln, daß aus den Werkstätten von Raqqah ein umfangreicher Export von Töpferwaren weithin stattgefunden hat. Wie weit sich in der Blütezeit des Kalifats von Baghdad, im 9. - 10. Jahrh., der Export von mesopotamischer Keramik erstreckt hat, beweist der Umstand, daß die schöne Lüsterkeramik von Samarra in Ägypten (Bahnasa ${ }^{4}$ ) und Fostat ${ }^{5}$ )), in Persien (Rhages), in Algier (Qal'a der Ben̄̄ Hammād ${ }^{6}$ )) und in Spanien (Medinat Azzahra bei Cordova ${ }^{7}$ )) zum Vorschein gekommen ist.

1) Ebendort XXXIV. S. 68. Abb. 40.

2) Der Islam. V. Taf. 4 . Fig. 7.

3) Henri Saladin: La Mosquée de Sidi Oqba à Kairouan. Paris 1899. PI. XXII. p. 7. Die durch die Tradition beglaubigte Herkunft dieser Fliesen aus Mesopotamien habe ich im Gegensatz zu ButLer (Burlington Magazine 1907. S. $48 \mathrm{ff}$.) schon vor den Ausgrabungen von Samarra, die sie beweisen, angenommen (Denkmäler persischer Baukunst. 1910. Text. S. 65). Auch G. MarçAIS teilt diese Ansicht
(Les Poteries et Faiences de la Qal'a des Benî Hammâd. Constantine 1913. p. 27).

4) Rivière-Migeon a. a. O. Fig. 5.

5) Eine größere Sammlung von ägyptischen Samarra-Scherben besitzt die Islamische Sammlung des Kaiser Friedrich-Museums.

6) Général L. DE Beylié: La Kalaa etc. Paris 1909. p. 87. - G. MARÇAIS a. a. O.

7) R. Velazquez Bosco: Medina Azzahra $y$ Alamiriya. Madrid 1912. pl. L-LIII. 


\section{ANDERE KLEINFUNDE AUS RAQQAH}

Über die im 9. Jahrhundert in Mesopotamien üblichen Techniken und Formen des Glases haben die Ausgrabungen von Samarra Auskunft gegeben. Neben der Gravierung war das Schleifen und Schneiden des Glases bekannt; auch die Verzierungsart mit gepreßtem Dekor, die Fadenauflage, die Vergoldung und die Bemalung mit Lackfarbe kamen vor (Der Islam V. S. 192ff.). Diese Techniken wiederholen sich in Raqqah; ebenso die Gefäßtypen, aus farblosem oder einfarbig blau, grün oder weinrot gefärbtem Glase bestehende Pokale, Kannen und Becher'1). Auch das Kännchen, dessen oberen Teil wir auf Taf. CXIX Nr. 5 wiedergeben, ist uns seiner Form nach schon von Samarra bekannt, wo wir auf die Übereinstimmung mit gleichen Glasfläschchen im Shosoin zu Nara in Japan hinwiesen.

Von Wichtigkeit ist es, daß in Raqqah die in Samarra noch nicht bekannte Technik der Emaillierung des Glases auftritt ${ }^{2}$ ). Auf Taf. CXIX Nr. 1-3 sind Bruchstücke von Glasbechern abgebildet, wie solche in der gleichen Form, mit gerader, sich nach oben erweiternder Wandung und mit angesetztem Ringfuß, aus Funden in Vorderasien, Syrien, Ägypten und Südrußland bekannt, in Museen und Sammlungen gelangt sind oder sich in altem Besitz in Europa erhalten haben ${ }^{3}$ ).

Soweit es die starke Irisierung des Raqqah-Glases zu erkennen gestattet, ist die Glasmasse im Gegensatz zu den aus Südrußland stammenden Bechern klar, wenig mit Blasen durchsetzt und, was besonders hervorzuheben ist, teilweise von außerordentlicher Feinheit. Die in Vergoldung und Emaillierung ausgeführte Zeichnung ist auch hier rot umrandet und von großem Reichtum; sie bedeckt manchmal die gesamte Oberfläche der Becher, die sonst meist nur mit Borten verziert sind. Auf dem Fragmente Nr. 2 sehen wir einen in Gold gemalten Fries mit schreitenden Löwen, auf Nr. 3 ein rundes Medaillon mit geometrischem Muster in weißem Email auf Perlgrund, während der Hintergrund aus goldenen Ranken gebildet wird. Das ganz besonders dünne Fragment Nr. 1 zeigt unter einer Schriftborte eine figürliche Darstellung mit dem vollen runden Gesichtstypus, wie er für das 12. - 14. Jahrhundert üblich ist.

Unter den sonstigen Kleinfunden, die wir in Raqqah erwerben konnten, sei ein getriebener und gravierter Bronzeteller (Taf. CXX Nr. 4, Durchm. $25 \mathrm{~cm}$ ) hervorgehoben; das geometrische Muster der Mitte erinnert an das Medaillon auf dem eben erwähnten Glasbecherfragment. Trotz der Flüchtigkeit der Zeichnung lassen sich doch in der Gravierung des Hintergrundes ungefähr die gleichen Formen erkennen, wie sie an den Kapitellen der Großen Moschee von Raqqah (II. Abb. 334. 335) vorkommen.

1) Das Kaiser Friedrich-Museum besitzt einen Henkelkelch aus blauem gepreßtem Glase (Inv. Nr. 2856) und eine Kanne mit Fadenaufschlag (Inv. Nr. 2328), die beide in Aleppo erworben wurden und aus Raqqah stammen sollen. Für letzteres Glas vgl. Könel in den Amtl. Berichten der Kgl. Preuß. Museen XXXV. S. 11. Abb. 9.

2) HaMdy Bey, der verstorbene Direktor des

K. Osmanischen Museums in Konstantinopel, macht in einem Briefe vom 31.3.07 an Dr.ZAmbaco PASCHA in Kairo auf derartige Funde in Raqqah aufmerksam. Bull. de l'Institut Egyptien. 1907. p. 90.

3) Robert Schmidt a. a. O. S. 48 ff. Abb. 26. 27. - Amtl. Berichte der Kgl. Prenß. Museen. XXIX. S. 29. Abb. 50. 


\section{ANHANG}

\section{HERBARAUFNAHMEN}

Schon 1908 hatte ich Gelegenheit, ein Herbarium zu veröffentlichen, das in der Zeit vom September 1903 bis Dezember 1905 entstanden war ${ }^{1}$ ). Weitaus der größte Teil der Pflanzen stammte von dem Ruinenhügel, der Steppe oder den Tigriswiesen von Qal'at Shirqāat (Assur), nur wenige von der Gegend südlich des Djabal Sindjār und einige mehr vom mittleren Tigris und aus den Gebirgen des Lūristān und Fārs. G. Schweinfurth hatte mich damals bei der Sichtung der Sammlung unterstützt und hatte J. Bornmüller veranlaßt, sich der Mühe der Bestimmung zu unterziehen. $\mathrm{Zu}$ diesem Herbarium haben mir P. Ascherson und A. Houtum-Schindler eine Anzahl wertvoller Anmerkungen brieflich mitgeteilt. Und als ich $1907 \mathrm{zu}$ der SARRE'schen Expedition aufbrach, machte mich G. SchweInfurth auf die Beobachtung der Salsolaceen-Flora aufmerksam, die ich in den ersten Monaten der Reise noch in Blüte antreffen mußte. Er gab mir zum Sammeln dieser Pflanzen nicht nur die notwendigen Materialien mit, sondern stellte mir auch ein kleines Taschen-Herbarium zusammen, das mir als Leitfaden dienen sollte, und das die Widmung trägt:

Durum iter - serpens, sitis, ardor, arenae

Dulcia virtuti: gaudet patientia duris.

Tantus amor florum!

Die neu mitgebrachten Pflanzen hat Schweinfurth selbst bestimmt. Im folgenden habe ich sie in die frühere Sammlung eingeordnet und auch die brieflichen Mitteilungen Aschersons und Houtum-SCHINDLERS aufgenommen²).

Mein Ziel bei der Sammlung war, ein Material zu liefern, das für die Pflanzengeographie und für die Erkenntnis der assyrischen Pflanzenlisten verwertet werden könnte. Daher habe ich mich bemüht, die arabischen Namen möglichst zuverlässig festzustellen. Niemals habe ich Städter nach den Namen gefragt, denen diese so unbekannt sind wie unseren Großstädtern, sondern immer Hirten oder Ackerbauer ${ }^{3}$ ). Die literarische Namenform war nur in wenigen Fällen zweifellos zu ermitteln, und so habe ich eine Transkription gewählt, die in der Wiedergabe der Konsonanten sich an die sonst in diesem Buche gebrauchte Art hält, in den Vokalen aber die Vulgäraussprache zum Ausdruck bringt. Die Frage der Transkription ist ungeheuer verwickelt, und man darf nicht erwarten, daß ich sie in allen Fällen folgerichtig behandelt hätte. Wenn aber Differenzen zwischen der transkribierten Form und dem daneben gesetzten arabischen Namen bestehen, so liegt das daran, daß ich den Namen anders hörte, als ich ihn mir von Arabern notieren ließ.

Ascherson und Houtum-Schindere erreicht mein Dank nicht mehr. So möge dies Herbarium SchweInfurth gewidmet sein!

1) Vgl. Herbaraufnahmen aus Kal'at-ŠerkātAssur im Beiheft II zur Oriental. Literat. Ztg. 1908.

2) Die von Ascherson sind durch nachgesetztes ASCH., die von Houtum-Schindler durch H.-ScH. bezeichnet. ScHw. bedeutet Illustration de la Flore
d'Égypte par P. Ascherson et G. SCHWEINFURTH, Le Caire 1887.

3) Die Methode habe ich in den oben zitierten Herbaraufnahmen beschrieben, unterwegs stellte ich die Namen in ähnlicher Weise fest. 
1. Achillea Santolina $L$.

Qal'at Shirqāt Wüste Anf. März 1905. ss, 0 قيصوم g قِ قيصوم usus illius plantae in medicina a Firuzabadio describitur. Djeuh. cf. Yāqūt III s. v. und II 955, wo in einer dunklen Stelle die Gegend östlich Rușāfah als „Land mit qaișūm und shīh" "charakterisiert wird.

2. Adonis dentatus Dell.

Qal'at Shirqāt Wüste u. auf Wiesen Ende März 05.

3. Aegilops crassa Boiss. $\beta$ macrathera Borss. (= A. platyathera J. \& Sp.).

Qal'at Shirqāt grasige Plätze am Tigris April-Mai 05. bui ḥn $\bar{e}^{i}$ !̣, demin. v. abiح triticillum.

4. Aeluropus litoralis (W.) Parl. $\beta$ repens Coss. Qal'at Shirqāt am Tigris Frühjahr 1904.

جذله dji dhele, äg. moulleyh, 'akrîch, neguîl beledy Schw. 1219, conf. جذلة ramus luxurians.

5. Agropyrum sqarrosum Roth.

Qal'at Shirqāat grasige Plätze am Tigris Mai 05.

شوير.به shuēiribe, dem. v. شارب mustax.

6. Alcea spec. ex aff. A. Hohenackeri Boiss. et Huet.

Baghdād Garten 15. Sept. 05. wächst auch wild und gilt als eine Art Wunderblume. S o-

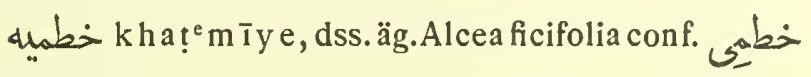
nomen herbae cuius in medicina usus in Kamuso describitur, nempe Althaea Gol. ex BeIth.

7. Alhagi Maurorum DC.

Tell Dhahab östl. Tigrisufer gegenüber Djebel Mukēịiil 2. Sept. 05 und am Khātūniyyah See 15.Dez.07. عاقول tshōq, daneben der allgem. arab. Name 'āgül, conf. SCHw. 387. حوق ist wohl nichts andres

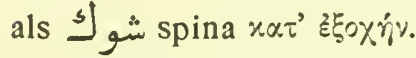

8. Allium stamineum Boiss.

Qal'at Shirqāt Steppe und Schutt 7. Mai 05.

بصيلة båșẹeile, dem.v. بصل cepa, bulbus.

9. Alopecurus agrestis $L$.

Qal'at Shirqāt grasige Plätze April Mai 05.

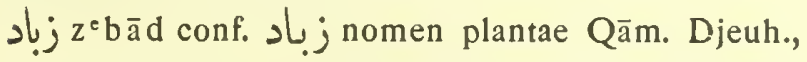
psyllium esse alii tradunt; Dozy: زبادة Schnittlauch. conf. No. 134-136 Plantago.

10. Althaea hirsuta $L$.

Qal'at Shirqāt grasige Plätze Febr. Mai 05.

11. Alyssum linifolium Steph.

Qal'at Shirqāt Wüste 10. Apr. 05.

12. Ammi majus $L$.

Qal'at Shirqāt grasige Plätze am Tigris Frühjahr غريره ghurēire, äg. kerafs, khelleh ScHw. 469. 每 conf. غُ غرئر planta boni odoris quaedam, Qām. -
Dozy : Fenchel, Petersilie.

äg. bedeutet غريره Artemisia herba alba Asso, ScHw. 577; vgl. No. 24.

13. Anagallis arvensis $L$. $\mathrm{f}$. caerulea.

Qal'at Shirqāt Wüste April-Mai 05, äg. saboûn gheyt, qounfoundeh ScHw. 674.

14. Amygdalus scoparia Spach. Dugumbadhān im Fārs, Anfg. Nov. 05. Mandel arab. زو $1 \overline{0}^{\mathrm{u} z}$, pers.

15. Anchusa strigosa Lab.

Qal'at Shirqāt auf Ruinen u. in d. Wüste. Jan. bis April 05.

lisān eth-thōr, i. e. lingua bovis, äg. bedeutet es Borrago officinalis ScHw. 723. - ct. Dozy s. v. Jul und 165

16. Andrachne telephioidis $L$. Qal'at Shirqāat Steppe, unentwickelte Pflanze.

4. لإ lāmme, i. e. claudit, colligit vulnera, conf. No. 51 .

17. Androsace maxima $L$.

Qal'at Shirqāt Ruinenhügel Jan. 05, 10. April 05.

18. Anethum graveolens $L$.

Qal'at Shirqāt Garten Mai 05. Dill.

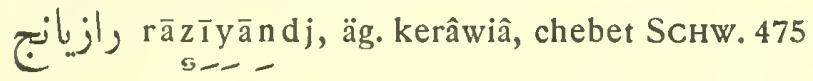
conf. pers. chebet ScHw. ist das pers. shibit, vulg. shiwīt, Dill, Anethum graveolens; pers. rāzīanedj, rāzīanah = Fenchel, A. Foeniculum, H.-ScH.

19. Anisosciadum Orientale DC.

Qal'at Shirqāt Wüste 30. April 05.

20. Anthemis pseudocotula Boiss.

Qal'at Shirqāat auf grasigen Plätzen Anfg. März 05.

نو nūwār, vgl. Chamaemelum No. 48.

21. Anthemis scariosa $D C$.

Qal'at Shirqāt auf grasigen Plätzen 23. April 05.

بابونج bābūndj, a pers. بابو Chamaemelum herba.

22. Arnebia decumbens (Vent.) Coss. et Kral. = A. cornuta (Led.) F. et $M$.

Qal'at Shirqāt Ruinenhügel 1904 im April 05.

Q tsh a hal, blauroter Saft in der Wurzel. - von

mit palatalisiertem k; Dozy $=$ Anchusa tinctoria; conf. äg. A. linearifolia DC: kahaly ScHw. 738.

23. Artemisia campestris $L$.

Zwischen Șuwwar und Marqadah in der Steppe 10. Dez. 07.

un silmās.

24. Artemisia herba alba $B$.

Djazlah am Euphrat, Steppe 30. Nov. 07. 
حُ shī ịh, vgl. Yāqūt s. v. und II 955, oben No. 1; Avicenna 256 Artemisia iudaica, Sprenger, Hist. rei herb. T. I.

25. Asiragulus bombycinus Boiss. f. Or. II 240. Qal'at Shirqāt Ruineniüügel 30. April 05.

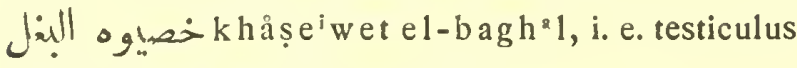
muli, conf. äg. qerny ScHw. 370.

26. Astragalus crucialus Lnck.

Qal'at Shirqāt Ruinenhügel.

ک $\int_{\text {g }}^{\infty}$ urēine. vgl. Nr. 52. aeg. Malcolmia aegyptica $=$ qoreyn ScHw.pg. 790, 18. - Qoreyn ist sicher nach der hornähnlichen Frucht (qurn) benannt. An Astragalus dagegen ist nichts hornähnliches, АsсH.

27. Astragalus dactylocarpus Boiss. Qal'at Shirqāt Steppe u. Ruinen.

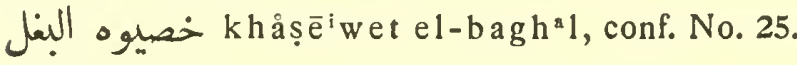

28. Astragalus Mossulensis Pge.

Qal'at Shirqāt in der Wüste am Hamrīn Ende Apr.05.

29. Astragalus Russelii Boiss.

Qal'at Shirqāt Steppe u.Ruinenhügel Febr.05. harzig.

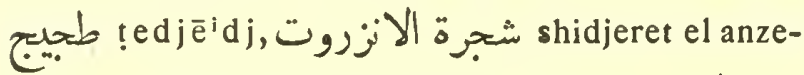
rūt, i. e. Schnupfpulverpflanze; besser طقوة طقو zu schreiben, nom. onomatopoët. vom Geräusch der knallenden Kelche, conf. verb. طق - Lexica haben anzerūt $=$ Sarcocolla oder Trifolium odoratum; pers. Lexica: „ein bitteres Gummi, hauptsächlich in Salben und Pflastern verwendet; arab. عنزروت, H.-SCH.

30. Bellevalia ciliata (Cyr.) Nees. Qal'at Shirqāt Steppe März 05.

31. Bellevalia densiflora Boiss.

Qal'at Shirqāt Steppe März-April 05.

نle 'âneṣlān.

32. Bellevalia flexuosa Boiss.

Qal'at Shirqāt März 05.

jلإع 'åneṣlān, aeg. 'onsol, 'aïsalān SCHw. 1064.

o - os sos

conf. عنصل et exa in agris nascens Qām.

Djeuh., et Avic. Can. LII. p. r. ; Dozy: Meerzwiebel.

33. Biarum Carduchorum Schott.

am Sindjār, zw. Quṣaibah und Wardiyyah 20. Okt. 03. und bei Qașr i Shīrīn u. Sarpul Anf. Okt. 05. uc lāiciye, conf. Dozx: lāiyah Wolfsmilch und जि-

لاعية nomen arboris in pede montis crescentis, lactariae, fulvo flore, cuius lactis si quid in piscinam iniicitur, efficit ut pisces in superficie appareant. Qām. Djeuh. - Diese im Qāmūs erwähnte لإع لإِ kann nur eine Euphorbia sein. Bei Lôw, Aramäische Pflanzennamen 193, 428 auch in dieser Bedeutung; dort 323 Heliotropium, 84 Melisse (?); Euphorbia als Fiscingift in der Literatur mehrfach erwähnt, Аsch. - vgl. No. 85.

34. Biarum platyspathum Bornmüller, species nova.

Nach meinem Exemplar veröffentlicht von BORNMÓlLER in FEDDE, Repertorium V, 1908 pp. 57, 58. Bāsht und Fahliūn im Fārs 12. Nov. 05.

35. Brassica spec.

Qal'at Shirqāt grasige Plätze im April schon verwelkt.

خردل khardel, wild, aeg. = B. nigra Koch, ScHw. 82. conf. خردل semen sinapi; DozY: B. eruca.

36. Bromus macrostachys Desf. Qal'at Shirqāt in Bergen und auf Wiesen 30. Apr. 05.

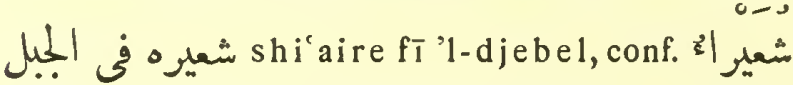
arbor vel planta quaedam Qām. Djeuh. - Sollte شعار شerste gehören? Asch.

37. Bromus tectorum L. f. spiculis glabris.

Qal'at Shirqāt grasige Plätze am Tigris 2. April 05. März-Juni.

سنيسله $s^{i} \bar{e}^{i}$ sele, conf. aeg. sileyseleh = Paracaryum micranthum (D. C.) Boiss. ScHw. 747.

38. Bupleurum protractum Link. $\beta$ heterophyllum Boiss.

Qal'at Shirqāt Ruinenhügel Jan. 05.

39. Caccinia Russelii Boiss.

Qal'at Shirqāat in der Wüste Febr. bis Ende März 05.

40. Calamagrostis pseudophragmites Baumg. $=$ C. litorea Schrad.

Qal'at Shirqāt grasige Plätze März-Juni.

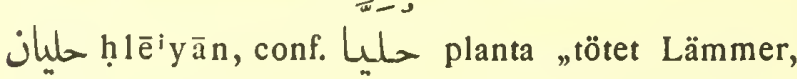
bevor die Blüte kommt". Zu diesem Aberglauben bemerkt Dr. BornMốller: Die vorl. Pflanze ist in den Alpen sehr gemein, überhaupt verbreitet, aber als giftig nicht bekannt. Die Angabe beruht gewiß auf einer Verwechslung mit irgendeiner anderen Grasart, stipa?

41. Calendula officinalis $L$.

Masdjid i bardī bei Shīrāz, verwildeter Garten, Ende November 05. aeg. qehawân ScHw. 589.

42. Calendula Persica C. A.M. $\beta$ gracilis (D. C.) Boiss.

Qal'at Shirqāt Ruinenhügel April-Mai 05.

43. Capparis spinosa L. $\beta$ canescens Css.

Qal'at Shirqāt Juni-Juli, Kapper, betäubend duftend, sehr tief wurzelnd, blüht vor Sonnenaufgang und welkt nach 2 Stunden Sonne.

kubbar, conf. كَّ vox versica, Capparis, pro 


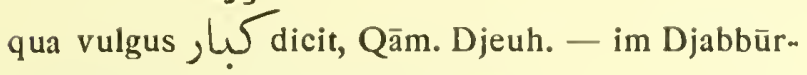
dialekt wird kubbar gesprochen.

44. Capsella bursa pastoris (L.) Moench. Qal'at Shirqāt Ruinenhügel März 05.

'așā'et er-rä̃ì, i. e. baculus pastoris. - Auffällig daß auch dort nach den Hirten benannt, bei uns Hirtentäschel, AscH.

45. Centaurea hyalolepsis Boiss.

Qal'at Shirqāt Ruinenhügel 7. Mai 05.

Șåffīir, conf. aeg. safî̀ry = Diplotaxis acris, SCHw. 81 ; et صفير Cassia sopheraForSK. Flor.Aeg.

Ar. LXV. - صفيرى Hesperis acris FORSK. LXIX, 118. - Ná neupers. calamus tritici. - DozY s.v. صفير und اصفر .

46. Centaurea patula D.C. fol. integris.

Qal'at Shirqāt in der Wüste 30. April 05.

47. Ceratocephalus falcatus pers.

Qal'at Shirqāat Steppe März-April 05.

على الغزال 'iltsh el-ghazāl, i. e. quod gazellae manducant.

48. Chamaemelum praecox (M. B.) Vis.

Qal'at Shirqāt Steppe und Ruinen Anfg. März 05.

نو nūwār, nur als nom. propr. dieser Pflanze ge$s \div$

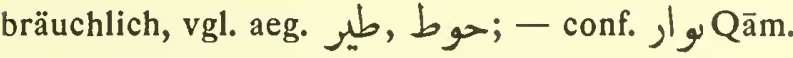
Djeuh. Dozr: Anemone, Echium - conf. No. 20.

49. Chenopodium murale $L$.

Qal'at Shirqāt Ruinenhügel März-Mai 04.

غं) rugh"l, aeg. mitteyn Schw. 870.

conf. غ ر) planta quaedam Qām. Djeuh., aeg. = Atriplex leucocladum Boiss. SCHw. 880.

50. Citrullus Colocynthis L. al-Fathah am Tigrisufer 3. Sept. 05.

لظ ha anzal, i. e. colocynthis, allgem. arab.

51. Cleome glauca $D C$.

Hamrīn April 05.

الامه lāmme, zلم المجرح zieht Wunden zusammen. conf. 16.

52. Convolvulus pilosellifolius Desr.

Qal'at Shirqāt 3. Nov. 04. Anfg. Mai 05.

ارشا ارشه zu schreiben, conf. فر نوه أَ أَ appellatur.

53. Convolvulus waltherioidis Boiss.et Hausskn. rariss.

bei Shīrāz, Steppe, Nov. 05. weichfilzig.
54. Cornulaca setifera Mg. T.

zwischen Busairah und Fudain am Khābūr 9. Dez.07.

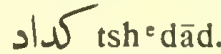

55. Crambe orientalis $L$.

Qal'at Shirqāt grasige Plätze am Tigris.

56. Cressa cretica $L$.

am Khātūniyyah-See 15. Dez. 07.

شُويل shuwwēl, vgl. ' شويلا planta Qām.

57. Crocos cancellatus Herb. $\beta$. Damascenus G. Maw.

Qal'at Shirqāt Steppe April 05.

فرو zu schreiben, von فريوا أريون oder فروه vestimentum pelliceum, wegen der Beschaffenheit der $\mathrm{Z}$ wiebel.

58. Cucumis melo $L$.

Qal'at Shirqāat Garten 14. Mai 05.

2 خ khiyār måi, i. e. cucumis aquae.

59. Delphinium oliganthum Boiss.

Qal'at Shirqāt A pril-Mai 05.

60. Delphinium Olivierianum D. C. [Mai 05. Qal'at Shirqāt grasige Plätze und Ruinenhügel April61. Diplotaxis Harra (Forsk.) Boiss.

Qal'at Shirqāt feuchte Stellen auf dem Ruinenhügel März 05. und am Djabal Mukaihil Mai; - aus den Blüten wird rote Farbe gewonnen.

سمره simre; in Aeg. ist diese Pflanze حاره xat' Éçoxív, daher der botan. Name; vgl. No. 162.

62. Ducrosia anethifolia (DC.) Boiss.

Qal'at Shirqāt an den Bergen 7. Mai 05. unangenehm stark tannenartig riechend, als Medizin gebraucht.

63. Echinops spec.

Qal'at Shirqāt Steppe Jan.-Mai 05.

الإبو ka"üb el bacr, i. e. K. Cameli, conf. aeg. chôk-el-guemel = E. spinosus, SCHw. 592.

64. Erodium cicutarium $L$.

Qal'at Shirqāt auf den Ruinen April 05. \& - -

بخترى båkhatrī, mit Metathese, conf. بخَترى pulcher incessu et corpore; conf. aeg. E. laciniatum = bakhtery ScHw. 231 u. pg. 793.

65. Erodium glaucophyllum Ait.

Qal'at Shirqāt Wüste Febr. 05. aeg. oummeyr, kabchiyeh (Forsk.) Schw. 237.

66. Eruca Cappadocia Reut.

Qal'at Shirqāt in Wadi's 10. April 05.

67. Erucaria microcarpa Boiss.

Qal'at Shirqāt in Wadi's April.

68. Euphorbia helioscopia L.

Qal'at Shirqāat auf grasigen Plätzen und Schutt März 05.

الع الع الى الى um el-'awāfī, i. e. mater incolumitatis, eine Magenmedizin. 
69. Falcaria Rivini Host. (prob. var. Persica Stapf et Wettst. pro spec.)

Qal'at Shirqāt grasige Plätze am Tigris Anfg. Apr.05.

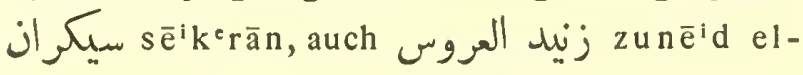

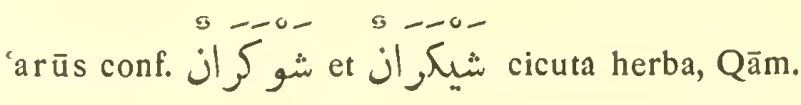

- sponsa, عروس عihi ignotum est.

70. Ficus Carica L.

Bustān Farḥān Pasha bei Qal'at Shirqāt, verwild. Garten 7. Mai 05.

ثين tîn allgem. arab.

71. Ficus Carica L. var. Johannis Boiss. Shīrwān im Pusht i kūh Anfg. Sept. 05.

72. Ficus Carica L. var. rupestris Hsskn. zw. Shaddādah und Quṣaibah in d. Djazīrah, Wüste, 19. Okt. 03.

تين tin berrī, i. e. ficus agrestis.

73. Fumaria Schleicheri Soy.-Will. $\beta$. microcarpa.

Qal'at Shirqāt Wiesen und Wadi's Anfg. April 05. aeg. chahtreg ScHw. 31 ss.

74. Gagea reticulata (Pall.) Sch.

Qal'at Shirqāt Ruinenhügel u. Steppe 2. April 05.

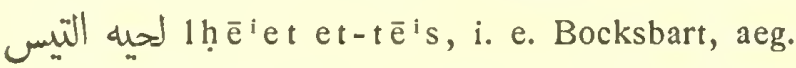
za'eytemân SCHw. 1037. — plantae cognomen Qām., hypicistis ReIsK. ad Gol.

75. Glaucium grandiflorum Boiss. var. malacocarpum (Hsskn.) FedDE.

Qal'at Shirqā̄ am Djabal Mukaihịil 5. Mai 05.

lülo māmīthā, conf. Avic. pg. ri. .

76. Glaucium leiocarpum $B$. am Khātūniyyah-See 15. Dez. 07. lüno māmīthā, vgl. 75 .

77. Glossostemon Bruguicri Dsf. Sterculiaceae. am Hamrīn u. Ostufer des Tigris Mai-Juni. Massenhaft zwischen Shahrabān und Qyzylribāt.

عرب قوزى 'arab. gōzì sehr harzig, stark rot färbend. - Vielleicht eine stengellose Variante. Borssier's Beschreibung liegt eine Pflanze mit deutlichem Stengel zu Grunde (caulis dichotomus), wie mir die Pflanze auch nach dem Herbar in der Erinnerung steht. Diese acaule Form ist also etwas Besonderes. Nach Borssier sind die Blüten doch so groß wie die der Kartoffel. Eine klebrige Behaarung gibt $B$. auch nicht an, sondern eine rauhe (scabra), die ja wohl auch am Finger anhaften mag. Auch über die färbenden Eigenschaften schweigt die bisherige Literatur. FIGARI, Studi scient. sopra l'Egitto II 389 erwähnt eine Wurzel „mugāth“, die aus Persien (?) über Damaskus komme und eine wunderbar stärkende Wirkung haben soll. Diese
Wurzel, aber wohl „muqāt" zu schreiben, fand ich 1880 in Kairo im Drogenbazar (sūq al-'atțārīn); es waren fingerlange Stücke einer Kinderarm starken Wurzel. Haussknecht erkannte sie als Glossostemon. Diese Pflanze, die Boissier nur bei Baghdad angibt, wurde neuerdings auch in Südarabien (Hadramaut) gesammelt und von SchweINFURTH erkannt, Asch. - Vgl. Loftus, Travels \& Researches pag. 306: in Susiana: Dendrorhū, türk. 'Arab khozī oder Arab nut, durch Mr. BennetT vom Brit. Mus. als Glossostemum Bruguieri bestimmt, cf. DesfonTAINes, Mém. du mus. hist. nat. t. III p. 238 pl. 11, scheint seit BRUGUIER's Zeit, 1797, nicht wieder angetroffen zu sein.

78. Gündelia Tournefortii $L$. Qal'at Shirqāt März-April 05., eßbar.

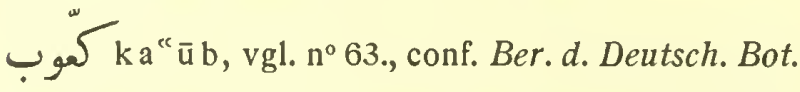
Ges. 1908 pg. 319, n. 1: Goeby, Ascherson.—Goeyb gehört wohl ebenso, wie $\mathrm{Ka}$ "ūub dem Dialekt der Beduinen an, während die Fellachen sie 'akkūb nennen. Dieses Wort wird in Lôw 293 wenigstens aus einer Stelle der arabischen Literatur Bt II 203 zitiert, was doch wohl Ibn Baitār heißen soll, wofür er allerdings in der Übersicht der Abkürzungen "J. Bait." hat. Es kommt aber in der Mischna als

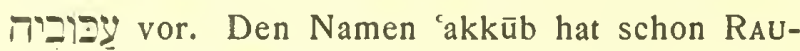
wOLF, dann WeTZSTEin, der es fälschlich mit schreibt. BOISSIER und SCHWEINFURTH haben es mit Gündelia identifiziert, während noch Lōw a. a. O. es als Cynara abhandelt, erst pag. 429 gibt er die richtige Bestimmung, $\mathrm{AsCH}$.

79. Gymnarrhena micrantha Desf.

Qal'at Shirqāt Ruinenhügel Mai 05.

80. Gypsophila melampoda Bienert.

Djabal Hamrīn Gipsfelsen 7. Mai 05.

81. Haloxylon articulatum Bge.

Djazlah am Euphrat, Steppe, 30. Nov. 07.

Jï n èt ùl.

82. Haplophyllum Candolleanum Spach. Qal'at Shirqāt Steppe Mai 05.

نوينو nuw ể nuwe, conf. H.tuberculatum aeg. mouguennineh (FORSK.) ScHw. 264.

83. Helianthemum Aegyptiacum $\mathrm{l}$. Qal'at Shirqāt in der Wüste April 05. э -

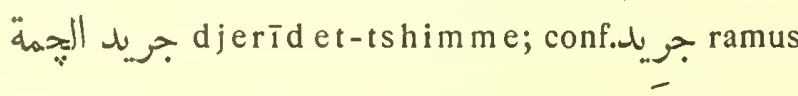
palmae foliis nudatus, Qām. Djeuh. und جردأجردid, planta quae indicat locum tuberum, FreYtag. जक्ष०

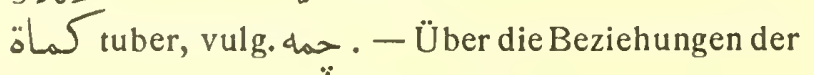
Helianthe،num-Arten zu den Trüffeln vgl. WeTzstein bei Ascherson, Sitz.Ber.d.Bot.Ver.Brandenburg XXII 1880 pag. 127, wo "djerīd“ als Name des 
Helianthemum salicifolium erwähnt wird, das aber von den Beduinen als „khāl“, Onkel der Trüffel bezeichnet wird. Das Wort جريد für Blattrhachis der Palme ist in Egypten sehr gebräuchlich, AscH. 84. Helichrysum Aucheri Boiss.

Qal'at Shirqāt Ostufer Mai 05.

زفرةzafre (nec صفره unverwelkliche gelbeStrohblume.

85. Helicophyllum Rauwolfii (Blum.) Schott.

Qal'at Shirqāt Ostufer des Tigris im April schon verwelkt.

.

لا $1 \bar{a}^{\mathrm{a}}$ i ye conf. No. 33.

86. Heliotropium Europaeum L. var. tenuiflorum (Guss.) Boiss.

Qal'at Shirqāt grasige Plätze Mai-Juli 05.

زريجه zurēidje, die Körner werden mit Wasser gestampft, so entsteht eine Milch, die wie Schafsmilch zu Butter bereitet wird. conf. aeg. sekrân (Forsk. Del.) 'afeyn (Aschers.) Schw. 717.

87. Heliotropium villosum $W$.

Rușāfah, Steppe, 23. Nov. 07.

文l u dhe $\bar{e}^{\mathrm{i}} \mathrm{ne}$ Öhrchen.

88. Herniaria cinera $D C$.

Qal'at Shirqāat Steppe u. auf grasigen Plätzen Mitte April 05.

89. Hippocrepis biflora $S p$.

Qal'at Shirqāt.

90. Hordeum spontaneum C. Koch. (H. Ithaburense Boiss.).

Qal'at Shirqāt Frühjahr, wild.

شع sha'ir, die wilde Urform der zweizeiligen

Gerste H. distichum.

91. Hyoscyamus reticulatus $L$.

Qal'at Shirqāt Ostufer d. Tigris April 05.

ب bendj conf. H. albus aeg. beng. ScHw. 767. ex

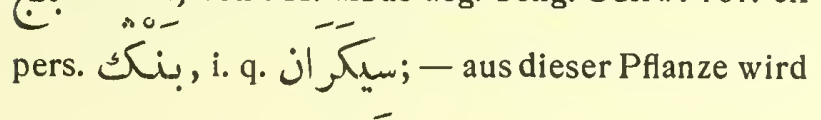

Rauchopium (ḥashīsh) gewonnen.

92. Hypecoum pendulum $L$.

Qal'at Shirqāat März 05.

93. Imperata cylindrica (L.) P. de B.

Qal'at Shirqāt grasige Plätze Anfg. April 05.

ذيل السبع dhêil es-sebc, i. e. cauda leonis aeg. sill (AsChers.) Schw. 1138.

94. Iris Palaestina Baker. var. caerulea (?) Post. bei Shumailah, östl. Tigrisufer 2. April 05.

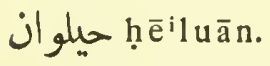

95. Iris Sisyrinchium $L$.

Qal'at Shirqāt in Wadi's 2. April 05.

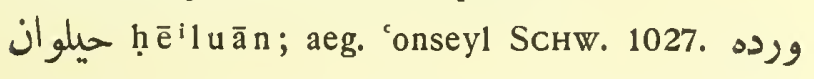

i. e. seine Blüte färbt Kleider.
96. Isaiis Aleppica Scop.

Qal'at Shirqāt Steppe u. grasige Plätze April-Juni.

97. Ixiolirion Pallasii Fisch. et Mey.

Qal'at Shirqāat Steppe 1904.

98. Koelpinia linearis Pall.

Qal'at Shirqāt Wüste u. Ruinenhügel Jan.-Juni 05. 99. Lathyrus hirsutus $L$.

Qal'at Shirqāt Garten-Zierpflanze 10. Mai 05.

'ot ${ }^{u} r$, conf. aeg. 'etr. Pelargonium radula Ait. ScHw. pg. 55 conf. عطر aroma. - Der Name für diese geruchlose Pflanze ist auffällig, $\mathrm{AsCH}$.

100. Leontice Leontopetalum $L$.

Qal'at Shirqāt Steppe u. auf grasigen Plätzen April aeg. raqaf.

101. Lepidium Draba L.

Qal'at Shirqāat grasige Plätze am Tigris Mitte April.

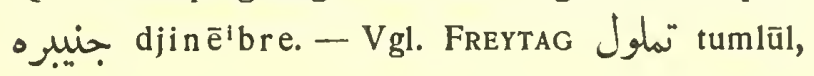

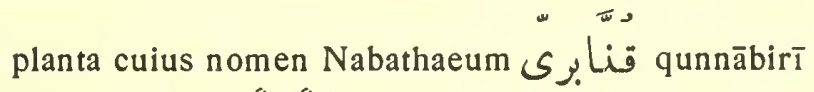
et Persicum برغست. barghast est, Qām.

102. Lepidium perfoliatum $L$.

Qal'at Shirqāt grasige Plätze u. Ruinenhügel März 05. 103. Lepidium sativum $L$.

Qal'at Shirqāt Gartenunkraut 14. Mai 05.

aeg. rechâd ScHw. 63. 104. Leptaleum filiferum DC.

Ruṣāah, Steppe, 22. Nov. 07.

ذزيع البس dhurē' al - biss Katzenpfötchen. 105. Leptaleum filifolium $D C$.

Qal'at Shirqāt grasige Plätze am Tigris 2. April 05. aeg. qeseysah ScHw. 53. 106. Malcolmia africana (L.) $R . B r$.

Qal'at Shirqāt grasige Plätze Febr. 05. 107. Malva Aegyptia L.

Qal'at Shirqāt auf Ruinen u. grasigen Plätzen Febr. bis Mai 05.

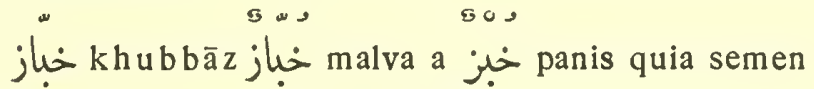
forma est panis. - Diese Malwe ist die deutsche „Käse-Blume, Käse-Pappel“; pers. gul i panīrak „Kleine Käseblume“, H.-ScH. 108. Malva parviflora $L$.

Qal'at Shirqāat Ruinenhügel, dominierendesUnkraut, Febr.-Juni.

ز خ khubbāz, aeg. chobbeyzeh ScHw. 202.

109. Matthiola oxyceras $D C$. $\beta$ lunata Boiss.

Qal'at Shirqāt Steppe April-Mai 04, 05.

110. Medicago denticulata Willd.

Qal'at Shirqā̄t Steppe 1904. s _-

نق nefel, allg. arab. conf. نفnomen herbae campestris odoratae, flore flavo, species medicae, qua pinguescunt equi Qām. Djeuh. - Der نقل des Qā- 
mūs kann, weil nichtriechend, kein Medicago, sondern nur eine Trigonella oder Melilotus sein, welche Gattungen freilich von den Eingeborenen nicht recht von Medicago unterschieden werden, АsсH.

111. Melilotus parviflora Desf.

Qal'at Shirqāt Steppe, 7. Juni 05, sehr wohlriechend. ن nefel.

112. Mesembrianthemum nodiflorum $L$.

Qal'at Shirqāt auf Schutt April 04 u. 05.

Blätter und Blüten sind, frisch, stark wasserhaltig, aeg. ghassoul, ScHw. 446.

113. Micropus longifolius Boiss. et Reut. Qal'at Shirqāt in der Wüste März 05.

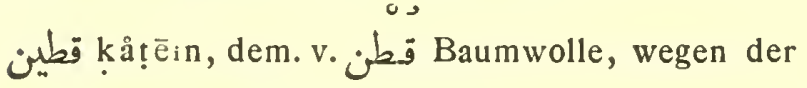
wolligen Behaarung der Pflanze.

114. Moltkea angustifolia DC.

Qal'at Shirqāt am Hamrīn 7. Mai 05.

115. Muscari pulchellum Heldr.

Qal'at Shirqāt Steppe u. in Wadi's 10. April 05.

116. Myrtus communis $L$.

Pul i mūrd im Fārs 14. November 05.

pers. مورد mūrd, arab. مرسين mersīn.

117. Nerium Oleander $L$.

Ambār i Șaimarah im Pusht i kūh 14. Okt. 05. arab. دفله difle, kurd. ك. u. u. bid und pälk,

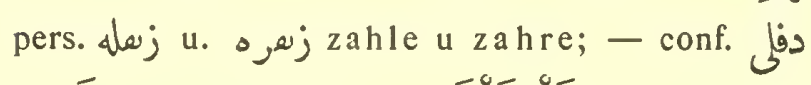

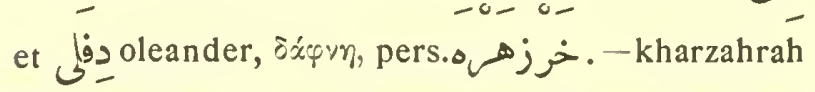
Eselsgift oder -galle, also zahrah wohl = Gift. General Houtum-SchindLer, Zeitschr. d. Ges. für Erdkunde XIV hat auch die Variante kharzaleh.

118. Nerium odorum Sol. var. Kotschyi Boiss. Pul i mūrd, Bāsht im Fārs, blühte noch Ende November.

119. Noaea spinosissima $D$.

aus Halabiyyah am Euphrat, bei Qarqīsiyyah, Fudain am Khābūr und aus Qal' at Djabbāram Tigris, 3. Dez., 9. Dez. 07, 11. Jan. 08, auf Gipsboden.

سر sirr oder surairah, demin.v. sirr, vielleicht صر cf. Qām.: in terra dura crescentes arbores ad genus Slle gummi pertinentes.

120. Notobasis Syriaca $L$.

Qal'at Shirqāt Steppe v. April an. كشّوب, keshū b, aeg. bawâl, ScHw. 599.

121. Oldenlandia Schimperi (Presl) Boiss. Qal'at Shirqāt Steppe März-Juni 05.

'arag el-ḥṣān, i. e. sudor equi.

122. Onobrychis lanata Boiss.

Qal'at Shirqāat grasige Plätze am Tigris Ende April 05.
123. Onopordon heteracanthum Cam. u. anisacanthum Boiss.

Qal'at Shirqāt Ruinenhügel 14. Mai 05.

ك kākhūrt (kurdisch?)

124. Onosma dasystrichum Boiss.

Shīrāz Steppe November, borstige Behaarung.

125. Ornithogalum montanum Cyr.

Qal'at Shirqāt Steppe.

ورد الززال wår ${ }^{e} d$ egh-ghazāl, i. e. Gazellenblume. - Das 1 des Artikels wird dialektisch manchmal an gh assimiliert.

126. Ornithogalum tenuifolium Guss.

Qal'at Shirqāt Wüste 10. April 05.

ورد الغزال wåred egh - ghazāl.

127. Panicum sanguinale $L$.

Qal'at Shirqāat grasige Plätze Mai 05.

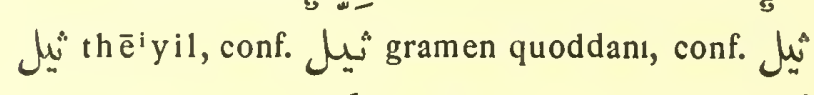
describ. Avicenna T. II pag. 266.

128. Papaver polytrichum Boiss.

Qal'at Shirqāt Steppe März-Mai.

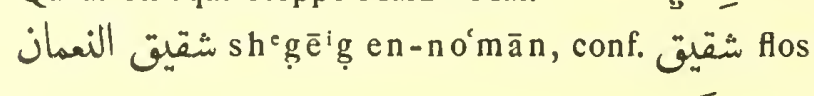
anemone appellatus, jhai sanguis sive nom. propr. conf. No. 144.

129. Peganum Harmala $L$.

Qal'at Shirqāt Steppe an feuchten Stellen Frühjahr 1904.

حر harmal, Name durchgehend vom Tigris bis s- -

zum Atlantischen Ozean, conf. حرمل peganum Harmala Sprengel, Hist. rei hern. T. I pg. 253. Avicenn. 174.

130. Phalaris brachystachys Link. Qal'at Shirqāt grasige Plätze am Tigris März-Juni 05.

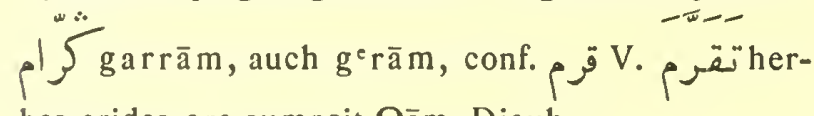
bas aridas ore sumpsit Qām. Djeuh.

131. Phoenix dactylifera $L$.

Qal'at Shirqāt Ruinenhügel, Sämling aus weggeworfenem Kerne.

jخ̈ nakhas, allgm. arab.

132. Pistacia Khinjuk Stocks.

Qohra im Fārs, bei Telespīd Anfang November 05. arab. فستق fustuk, a pers. ستّه pistacia.

133. Pistacia mutica F. et M.

Qohra im Fārs bei Telespīd Anfg. Nov. 05.

134. Plantago decumbens Forsk.

Qal'at Shirqāt auf grasigen Plätzen Mitte April 05. j zebād, aeg. djeneymeh Scнw. 852, conf. No. 9. 
135. Plantago Lagopus L.

Qal'at Shirqāt grasige Plätze Frühjahr. aeg. widneh (Aschers.) ScHw. 854.

136. Plantago Loeflingi $L$.

Qal'at Shirqāt grasige Plätze April 04.

ز zebād.

137. Plantago notata Lag.

Qal'at Shirqāt grasige Plätze April 05.

138. Poa Persica Trin.

Qal'at Shirqāt grasige Plätze am Tigris Mitte A pril 05.

da ia ni'aime, dem. v. نaris sive Achyranthus Forsk. Flor. Aeg. Arab.

139. Polypogon maritimus Willd.

Qal'at Shirqāt grasige Plätze am Tigris Mai 05.

140. Prangos peucedanifolia Fenzl.

Qaĺat Shirqāt östl. Tigrisufer Anfg. April 05.

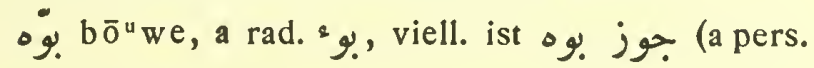

ى. nux myristica zu vergleichen.

141. Pteranthus dichotomus Forsk. $=$ P. echinatus Dsf.

Qal'at Shirqāt Steppe 30. April 05.

142. Pteropyrum ericoides Boiss.

bei Baghdād, Wüste Ende September 05, diese Art bisher nur aus Balūtshistān und Persien nachgewiesen.

143. Quercus Persica Jaub. et Spach.

Pusht i kūh. Kawur Kūh, Lūristān Oktober 05.

bوّ ballūt, allg. arab.

144. Ranunculus asiaticus $L$.

Qal'at Shirqāat Niederung März bis Ende April 04. شقيق النعمان المخنث sheg ēig en-no'mān elmukhnith, sive el-mukhannith, i. e. debilis, agrestis; conf. No. 128.

145. Ranunculus lomatocarpus $F$. et $M$.

Qal'at Shirqāt auf grasigen Plätzen April-Mai 05.

146. Raphanus sativus $L$.

Qal'at Shirqāt Garten April-Mai 05.

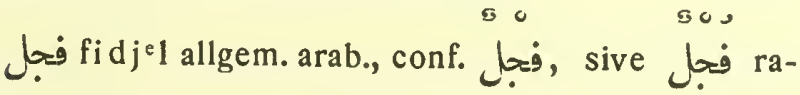
phanus.

147. Reseda alba $L$.

Qal'at Shirqāt Ruinenhügel April 05.

148. Reseda Aucheri Boiss.

Qal'at Shirqāat Ruinenhügel.

149. Roemeria hybrida (L.) DC.

Qal'at Shirqāat Steppe 1904.

150. Rumex obtusifolius $L$.

Qal'at Shirqāt auf Grasplätzen Anfg. März 05.

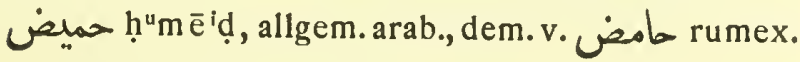

151. Salsola auricula Mg. T.

bei Ṭābūs am Euphrat, im Zōr des Flusses, 4. Dez. 07.

5 SARRE-HERZFELD, Archäologische Reise, Band IV.
152. Salsola spissa M. B.

von Rușāfah u. Djazlah am Euphrat, Steppe, 21. und 30. Nov. 07.

Unter verschiedenen Namen genannt, die teilweise falsch sein dürften: abū șuwei $i^{i}$ zweimal harbak, khudrāf und rimmeth, das letztere رمن , wird im Qām. als Kamelfutter, ad genus حَّ pertinens erklärt und ist jedenfalls der richtige Name.

153. Salsola vermiculata $L$.

Qal'at Djabbār, auf Gipsfels, 11. Jan. 08.

¿̈و الر ar-rōthah.

154. Salvia (spec. unbestimmbar).

Qal'at Shirqāt Ruinenhügel und Wüste Febr. 05.

اذين الكر udhêin el-kurr, i. e. auricula aselli.

155. Salvia compressa Vahl.

Qal'at Shirqāt Steppe 7. Mai 05. s o

سملسمه sume $\bar{e}^{i}$ s eme, dem.v. vمسم sesamum, semen coriandri Qām.

156. Salvia? Verbascum? (Blätter zur Bestimmung unzureichend).

Qal'at Shirqāt Ruinenhügel Januar 05.

ازن إلك udhn el-kurr, i. e. auris aselli.

157. Saponaria Vaccaria L. $\beta$. grandiflora Fisch. (= Vaccaria grandiflora Jaub. et Spach).

Qal'at Shirqāt grasige Plätze April.

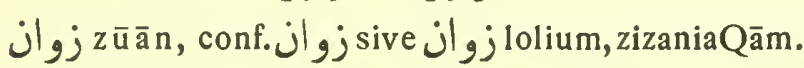

158. Satureia Boissieri Hsskn. (?).

Qal'at Shirqāt Wüste Febr. 05.

159. Scabiosa Palaestina $L$. var. calocephala Boiss.

Qal'at Shirqāt in Wadi's Mitte A pril 05.

160. Scorzonera papposa DC. f. nana.

Qal'at Shirqāt in der Wüste Anfg. April 04 und 05.

乙ب̣ ḍa bāh, aeg. Sc. mollis dabâh ScHw. 642.

conf. ضinis Qām. Djeuh.

161. Scrophularia deserti Del.

Qal'at Shirqāat Ruinenhügel Jan. 05. Sämling, (unkenntlich), aeg. zeyteh ScHw. 785.

162. Silene coniflora Otth.

Qal'at Shirqāa Wüste 30. April 05.

163. Silene Oliveriana Otth.

Qal'at Shirqāat Wüste April 05.

164. Silybum Marianum L., Sämlingspflanze (? Notobasis Syriaca L.).

Qal'at Shirqāt Ruinenhügel Januar 05.

حرف ب urfēish. - aeg. Reseda decursiva=khircheyf. - Es ist auch kharshūf, die Artischoke, zu vergleichen, mit Verstellung von 4 und $\boldsymbol{~}$ ارضى شوكى , italien. u. span. carciofo, Alcachofa, Carxofer, franz. artichot, ein Kreuzzugswort; AsCH. 
165. Sisymbrium altissimum $L$. v. rigidulum Boiss.

Qal'at Shirqāt, überall, März-A pril 04 u. 05.

حاُّ hạarre, conf. No. 61.

166. Sisymbrium runcinatum Lag. (ein Exemplar mit Pilz: Albugo candida).

Qal'at Shirqāat grasige Plätze März-April 05.

167. Spergularia diandra (Guss.) Heldr. et Sart. Qal'at Shirqāt grasige Plätze Ende April 05. aeg. qeleyqelah. ScHw. 157.

168. Spinacia tetranda Stev. pl. masc.

Qal'at Shirqāt Ruinenhügel, feuchte Stellen, MärzApril 05.

غلئ ghalīs, viell. غليس

169. Statice spicata Willd.

Qal'at Shirqāt Steppe.

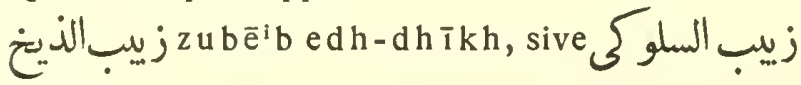
$z u b \bar{e}^{-1} b$ es $s^{e} l \bar{u} g \bar{i} i$. e. penis lupi sive penis vertagi.

170. Sternbergia stipitata Boiss. et Hsskn.

Teng i Djāw̄ī, Pylae Persicae, im Fārs, Anf. Nov. 05. 171. Tagetes.

Masd jid i bardī bei Shirāz, verw.Garten, EndeNov.05.

172. Teucrium Polium L.

Qal'at Shirqāt Wüste Mai 05 und zwischen Busairah und Fudain am Khābūr 9. Dez. 07.

جلده djecád e, Name vieler Labiaten, conf. T. sinaicum, aeg. ğa'adeh, ScHw. 837, conf. جعدة planta odorifera in litore fluvium vere proveniens quae cito crescit; polium, Avicenna L. II pg. 153 sq. - eine Sämlingspflanze aus d. Jan. 05, fälschlich als 'alende bezeichnet, - das Exemplar vom Khābūr als n'ádje.

173. Tribulus terrestris $L . \beta$. robustus Boiss. Qal'at Shirqāt auf Schutt Anfg. Juli 05.

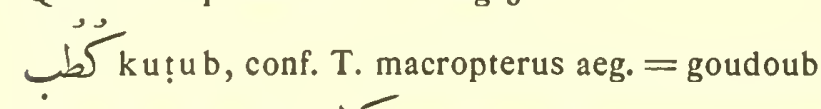
SCHw. 244. radix. ك ك deest, credo scribendum esse

قطب plantae nomen Qām.

174. Trifolium resupinatum $L$.

Qal'at Shirqāt Wiesen 30. April 04.

b $\int_{\text {gure }}^{*}$, conf. No. 177.

175. Trifolium tomentosum $L$.

Qal'`at Shirqāt Steppe Mai-Juni.

176. Trigonella aurantiaca Boiss. Qal'at Shirqāt Wiesen April 04, Mai 05.

نق nefel allg. arab.

177. Trigonella monantha C. A. M. Qal'at Shirqāt Mai-Juni 05.

b ${ }^{*}$ gur ${ }^{e} t$, aeg. 'ort $=$ Trifolium resupinatum oder
Melilotus indicus. - vgl. No. 174. - conf. species foeni Burgundiaci praestantissimiQām.Djeuh.

178. Trigonella Noëana Boiss.

Qal'at Shirqāt Steppe und grasige Plätze April und Mai 05. Spielart mit lebhaft karminroten Rippen auf den Blättern.

179. Trigonella radiata $L$.

Qal'at Shirqāt grasige Plätze Frühjahr 1904.

180. Triticum durum Desf. var. obscurum Körn. Qal'at Shirqāt grasige Plätze am Tigris.

biح hånṭa allg. arab. - Der Weizen wird in Aeg.

قمح genannt, Asch.

181. Turgenia latifolia $L$.

Qal'at Shirqāt Steppe und grasige Plätze Frühjahr. 182. Valerianella vesicaria (Willd.) Moench.

Qal'at Shirqāa 30. April 05.

183. Verbascum Euphraticum Bth.

Qal'at Shirqāat Berge und Wüste 7. Mai 05, conf. V. sinaiticum aeg. khermâ ScHW. 772, u.V.Tourneuxii ScHW. 784.

184. Veronica didyma Ten.

Qal'at Shirqāt Ruinenhügel 7. Mai 05.

185. Vicia calcarata Dsf. $\beta$. cinerea (M. B.) Boiss. Qal' at Shirqāt Steppe und grasige Plätze 17. April 05. aeg. kharîg ScHw. 392.

186. Vicia Faba L.

Qal'at Shirqāat Garten Mai 05.

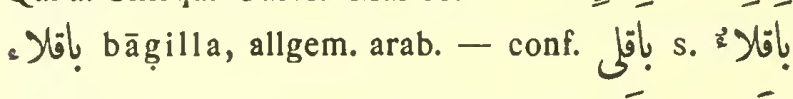
s. بَّ faba. - Vicia faba in Egypt. nur fūl, was ja auch im Hebr. als לiפ vorkommt. Asch.

187. Vicia Narbonensis $L$.

Qal'at Shirqāat wild, 23. Apr. 05, in Symbiose mit Faba. كُّون keshūn, Blähungen عضرن veranlassend,aeg. baker ScHw. 391.

188. Vitex Agnus castus L.

al-Fatḥah am Tigrisufer beim Djabal Hamrīn 3.Spt.05. سزبان sizbān, aeg. kef meryam, - conf. سيس arboris nomen, ex cuius ligno sagittae conficiuntur,

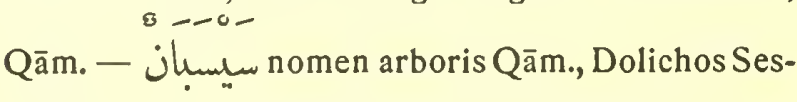
ban Forsk., fl. aeg. arab. p. LXX., Sesbania.

189. Vitis vinifera $L$.

Shīrāz November 05 .

ic 'aneb, allg. arab.

190. Ziziphora tenuior $L$.

Qal'at Shirqāt Wüste Ende April 04 und 05, wegen starken Pfeffermünzgeruches von Eingeborenen als Parfum beliebt.

191. Zollikoferia mucronata (Forsk.) Boiss. Qal'at Shirqāt Steppe. 


\section{REGISTER DER ARABISCHEN NAMEN}

\begin{tabular}{|c|c|c|c|c|c|c|c|c|c|}
\hline 63 & كموب الاباعر & 77 & عرب قوزى & 86 & زريجه & 165 & طاره & 152 & 'بو صوى \\
\hline 83 & كاd & 121 & عرق الحصان & 84 & زفره & 152 & حربك & 156 & اذن الكرّ \\
\hline \multirow{3}{*}{130} & & 144 & عصاه الراعى & 59 & زنيد العروس & 164 & حرفيش & 154 & اذين الكرّ \\
\hline & & 99 & & 117 & زهره (زهله) & 129 & & 87 & \\
\hline & & 47 & علك الغزال & 157 & زوان & 40 & حليان & 52 & ارشه (ارشاء) \\
\hline 174,177 & كرط & 172 & علنده & & & 150,152 & حميض & 68 & ام العواف \\
\hline \multirow{3}{*}{26} & كن & & عنب & 119 & سر & 3,180 & حنطه & & \\
\hline & & 29 & عنزروت & 119 & سريرة & 50 & حنذ | جن & 21 & \\
\hline & & 32 & عنصلان & 188 & سزبانن & 3 & & 186 & \\
\hline 33,85 & لاعيه & & & 23 & سلماس & 94, 95 & حيلوان & 64 & \\
\hline \multirow{2}{*}{$\begin{array}{r}16,51 \\
74\end{array}$} & لامه & & & 61 & سمره & & & 14 & \\
\hline & للحيه التيس & 168 & & 155 & سميسمه & 107 & خبّاز & 101 & 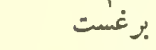 \\
\hline 15 & لسان الثور & 108 & يسيس & 37 & سنتسله & 152 & خدراف & 8 & \\
\hline \multirow[t]{2}{*}{14} & لوز & & & 59,91 & سيكران & 35 & خردل & 143 & \\
\hline & & 146 & فجل & & & 117 & خرزهرة & 91 & بتئ. \\
\hline 75,76 & ماميثا & 57 & فريون (فريو) & 36,90 & شعير & 25 & خصيوه البغل & 140 & \\
\hline 116 & مرسين & 132 & فستق & 36 & شعيره & 6 & & 117 & ب \\
\hline \multirow[t]{2}{*}{116} & مورد & & & 128,144 & شقيق النعمان & 58 & خيار ماء & & \\
\hline & & 173 & قطب & المخنث 144 & شقيق النعهان | & & & 117 & باك \\
\hline 131 & نخل & 113 & قطين & $\begin{array}{l}5 \\
7\end{array}$ & شويريه & 117 & دفاه & & \\
\hline 172 & نمجة & 101 & قنابرى & $\begin{array}{r}7 \\
56\end{array}$ & شوك & & & 70 & تين \\
\hline 138 & نعيها & 1 & قيصوم & $\begin{array}{l}56 \\
24\end{array}$ & شويل & $\begin{array}{r}104 \\
93\end{array}$ & ذريع البس & 72 & "ين برى \\
\hline $110,111,176$ & تقل & & & & $E$ & & & 127 & ثيّّل \\
\hline 20,48 & لوار & 123 & كاخورت & 119 & صرّ & 18 & رازيانج & & \\
\hline 82 & نوينوه & 43 & & 45 & صفير & 49 & رغل & 4 & جذله \\
\hline \multirow[t]{2}{*}{81} & نيتول & 22 & $\infty$ & & & 152 & رمت & 83 & جريد الجهه \\
\hline & & 54 & كماد & 160 & ضباح & 153 & روثة & 172 & جمده \\
\hline \multirow{4}{*}{125,126} & و.د الغ: ال & 120 & كثوب & & & & & 101 & جنيبره \\
\hline & פבע וلعزיט & 187 & كمثون & 29 & طجيج & $9,134,136$ & زباد & & \\
\hline & & 173 & كطب & & & 169 & زبي الذيخ & 22 & \\
\hline & & 78 & كمّوب & 7 & عاقول & 169 & زيب السلوقى & 7 & ميوق \\
\hline
\end{tabular}




\title{
ADDENDA ET CORRIGENDA
}

\author{
Band I pg 60 Zeile 2 Tell Mandjür ist $\mathrm{n}$ i c h t gleich Opis \\ 62 . 4 sasanidisch statt sasin \\ 74 "23 Die Bogenform ist der reine Halbkreisbogen, bis auf die etwas engere Bogenreihe \\ der Nordhalle \\ 93 Abb. 35 Mihrāà statt Mitteltür \\ 115 Zeile 8 v.u. Stele statt Stelle \\ 121 " 25 Hdjára statt Hadjarrah \\ 145 Anm. 4, Zeile 3 v. u. pg 116 statt 118 \\ 157 Zeile 16 tsherd statt djird \\ 186 „ 14 v. u. 'Axp $\alpha \beta$ st statt 'Ax. \\ 212 zu Kushāf: kommt bei Abū'l-fidā's v. كمثاف und bei Barhebraeus pg 581 vor, auch bei \\ Thévenot, Reisen \\ 2217 v. u. Kanīsah statt =at \\ 2332 v. u. tāäbiyah statt Tābiyyah \\ 2336 v. u. Der Rahmen ist eine tabula ansata \\ 23412 v. u. Tell al-banāt ist ein Bau der Samarra-Zeit \\ 2357 Haṭab statt Huṭab \\ 2398 v. u. wasm statt wusm \\ 240 Anm. 1 Bellino statt-ins \\ 244 Anm. 2 nördl, von 'Ānah statt unterhalb Dair; dazu: seither Herzfeld Mashhad 'Alī im Islam \\ V 1914 pg 358-69
}

Band II pg 78 Anm. 2 r. Zeile 4 Diyālah statt -lāh

82 paenult. Ortmah statt Warthmann

85 Anm. 6 Zeile 5 al-Imārah statt 'Am.

86 Anm. 8 paenult. Oopvas statt Top.

87 Zeile 10 Die Gleichung Ganzaka = Takht i Sulaimān ist ganz fraglich, cf. HerzFeld „Der Thron des Khosrö" in Jahrb. d. Staatl. Museen 1920,1

87 » 14 'Imādiyyah statt 'Am.

89 Zeile 11 Shahrazūr statt Shahriz

111 v 4 v. u. Isḥāq statt Ișh

112 Anm. 5 Zeile 3 v. u. غرب غرّب statt

133 Anm. 1 setze am Ende Anführungsstriche!

134 Anm. 3 und 4 tauschen

135 Z. 6, 136, Z. 10, 14, 16, 137, Z. 13 und Abb. 184: șaḥn statt șakhn

138 Anm. 4 und 5 tauschen

149 Zeile 19 Nāṣir statt Nașir

158 Anm. 2 Z. 3 v. u. carré statt -ée

159 Zeile 5 v. u.: „Die genaue Schreibweise ist طارمة bei DozY, auch bei Mudjīr al-dīn für Jerusalem, طيرمة in Süd-Arabien nach LANDBERG, Dialectes de l'Arabie méridionale; dann aus țārima naturgemäß tarma (wie aus Fāțima - Faṭma), durch Verkürzung des langen ā, als Folge des Abfalls des kurzen i." M. v. BercheM

160 Zeile 2 v. u. Nizām al-mulk statt al-dīn

162, Inschr. 47 Zeile 5: „Das erste Mal gewiß مسمورة, das zweite aber wohl مغورة, von ghamara, decken, einhüllen, überschwemmen, also: „mögen seine Untertanen .... überschwemmt sein!", vgl. pg. 163 Anm. 3 über Parallelismus zweier ähnlichen Worte und C.I. A. I (Eg.) Inschr. no. 138, Zeile 3: ,der aus dem Meer s. Freigebigkeit schöpfende, der für seine Gnade dankbare usw." M. v. B. 
Band II pg 179 Zeile 18 carré statt -ée

180,7 v. u. Grab statt Crab

188, Inschr. 50, Zeile 3: المض statt المخصوص

189. Anm. 3: „Odoric, éd. Cordier pg. 374 ..... „par tout tel empire a li roys hotelx (worauf die Variante: domus Yam vocatur, als Zusatz in einem Ms. aus der Bibl. Nationale; bei Yule: called Yam), où ils treuvent (nämlich die Reisenden) ce qu'il leur fault“. Dazu eine Anmerkung von Cordier (pg. $417 \mathrm{ss)} \mathrm{mit} \mathrm{Zitaten} \mathrm{aus} \mathrm{Marco} \mathrm{Polo,} \mathrm{(éd.}$ Pauthier 335s.), Quatremere, Notices et Extraits XIV, 395 s. und D'OHSson, Mongols I 406f." M. v. B.

198 \ 4 Salīm II. statt I.

198 ”-10: Die Bemerkung „mit vielfacher Verwendung der Involuti o“ gehört zur vorhergehenden Inschrift 52

215,18 qu'ils sont statt ont

252 ๓ 15 Rị̣ā statt Rizeā

267 » 9 u. 14 v. u. malakì statt malikī

275 » 6 v. u. rāzūnah statt ras

296 - 10 Einzelelemente statt Ziegelelemente

297 » 20 des statt der, Z. 21 Kultus statt -tur, Anm. 3 Z. 3 v. u. maqsūrah statt maqș

300 Anm. 1 ult. Edessa statt Wessa

307 Zeile 3 Uwēnāt statt -āh

308 „ 19 carré statt -ée

312 » 13 v. u. Khudēdā statt Khūd

317 Anm. 1 gehört zu pg 316, Z. 5 v. u. „ergreift". Anm. 2 wird 1, Anm. 3 wird 2

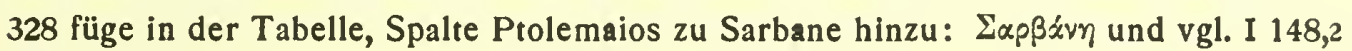

354 Minaret Z. 1: Anm. zu Manārah al-munaitir: „munaitit, dem. von manțarah, denom. von $n \bar{a} t \bar{u} r$, also „Wachttürmchen ${ }^{\alpha}$

363 Zeile 12 v. u. Zengi statt Nūr al-dīn 


\section{ALLGEMEINER INDEX}

Die Disposition unseres Werkes ist die eines Reisewerkes. Die Kapitel behandeln die einzelnen Etappen unserer Reise. Die Herstellung des Werkes erstreckte sich über zehn Jahre, in deren Laufe neue Funde und Erkenntnisse die früheren berichtigten. So wurden ausführliche Indices ein Erfordernis. Sie sollen nicht nur die Benutzbarkeit erleichtern, sondern sie sollen bis zu einem gewissen Grade die systematische Gliederung der in dem Buche behandelten Stoffe ersetzen.

Der Index ist in drei Teile geteilt: den geographischen, den historischen und den technischen.

Der erste Index enthält alle Namen von Orten und Bauten. Die Namen sind im allgemeinen in ihrer modernen, d. h. meist arabischen Gestalt gegeben, außer einigen europäisierten Namen. Da im Texte dem Stoff entsprechend häufig die antiken Namen benutzt werden, wie Circesium für Qarq̨īsiyyah, Ktesiphon für Salmān Pāk, Seleukeia für al-Madā’in, so sind diese Namen in den ersten Index zwischen die arabischen Namen aufgenommen. Herausgezogen sind hingegen alle in griechischer, in lateinischer oder in altorientalischen Sprachen überlieferten Ortsnamen, deren Identifizierung oder Etymologie im Texte behandelt werden.

Der zweite Index enthält alle Namen von Personen und einige von Geschlechtern und Völkern. Namen von Autoren sind nur aufgenommen soweit besondere Untersuchungen über sie vorliegen, z. B. Muḥammad al-Khwārizmī, Ptolemaios, Xenophon. Die arabischen Namen erscheinen vielfach in ausführlicherer Gestalt, als im Texte.

Der dritte Index enthält technische Ausdrücke der Archäologie und Architektur. Daran sind angeschlossen diejenigen arabischen oder sonst orientalischen technischen Ausdrücke und Vokabeln, die in diesem Werke gebraucht oder erklärt sind.

Die kleinen Zahlen hinter dem Komma bedeuten die Nummer der Anmerkung, in der das Stichwort vorkommt; s bedeutet die nächste, ss die beiden folgenden Seiten.

Von einer Zusammenstellung der benutzten Literatur glaubten wir absehen zu dürfen, da diese bei den einzelnen Kapiteln schon teilweis im Zusammenhang angeführt und sonst ausführlich genug zitiert ist, um auffindbar zu sein.

\section{GEOGRAPHISCHER INDEX}

Āb i Shīrwān cf. Djurwān und Di-
yālah II $83 ; 328 \mathrm{~s}$
Ābdānān I 239,3

Ābruwān in Dasht i Bārīn II $332 \mathrm{~s}$ Abū Habbā = Sippar II 100

Abü Hanāyah = Eragiza I $122 \mathrm{~s}$

Abū Hatab I 235,7; $244 \mathrm{~s}$; IV 35

Abū Hurairah I 132-135; II 229,1;

317,$1 ; 354 \mathrm{~s} ; 361 ;$ IV 19

Abū Qubaí I 150; 155 s; 163 s

Abū'l-Riḍā, Aleppo II 282,1

Abū Shahrain I 121;

Abū Sudair(ah) I 246;249; II 158,4; 176,1; 229,1; IV 9

Abū Șukhair I 235

[II 192

'Aḍaim I 57,6; 59s; 63; 106; 204;

Ādharbaidjān II $87 ; 181 ; 211 ; 252,4$; 313

'Adhrā'-Kirche cf. Ḥāḥ, Mayāāāi qīn, Mosul

Adhramah, al-Adhramī II 278

Afrāsiāb IV 7

Aḥmadābād in Indien II 226,1 Ahwāz I 121; II 139,2
'Ain 'Alī bei Mayādīn II 320,3; 333

'Ain al-baidā' I 208

'Ain al-ghazāl I 183; 205

'Ain al-ḥayyāl = Tell al-hayyāl

I 195,$6 ; 200 ; 201,1 ;$ II 307

"Ain al-rummān I 199

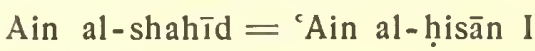
205: 305-07

'Ain al-wardī I 183; $201 \mathrm{~s}$;

'Aințāb II 356

'Akkār II 213,3

Ala Kiliseh in Kilikien II 8,$1 ; 70$

Alahan Monastyr in Kilikien II 10,$1 ; 11 ; 40 ; 345$

Albū Kamāl II 367; 382; 386

Albū Shamānī II 306

Albū Shhammah IV 3

Aleppo = Berrhoia I 85,2; 98,2; $114 ; 117 ; 119,6 ; 145 ;$ II 43 ; $125,3 / 4 ; 150,3 ; 154,2 ; 156 ; 165$; 172,$4 ; 198 ; 212 ; 217 ; 220 ; 239,1$; 251,$2 ; 272 ; 273,1 ; 274$; 282,1; 287,1 ; 300; 303; $312 \mathrm{~s} ; 317 \mathrm{~s}$; $348 ; 355 ; 387$
Alexandreia II 347

Alexandrette I $114 ; 143 ; 145$

Alqōsh II 303,2; 238

al-'Alth I $60 ; 64$

Altynköprü II $305 ; 318 ; 322-29$

Ālūsah II 388

'Amārah I 248; II 215

Amida $=$ Diyārbakr I 5,5;6,2; 81,5; 203; II 2,$2 ; 21,7 ; 22,5 ; 121,6$; $125 ; 144 ; 150,3 ; 165,3 ; 167 ; 203$; $211 ; 213,3$; 215; 239; 270,2; 273,$1 ; 274 ; 282,1 ; 301 ; 325 ; 327$; $343 ; 345 ; 348$; IV 16

Amida, jakobitische Marienkirche II $28 ; 32,1 ; 35 ; 44 ; 345 ; 347$

Amida, Ulu Djāmí II 21,$7 ; 45$; $343 ; 360 ; 362 \mathrm{~s}$

Amīnābād II 201,2

al-'A mq, ass. Unqi I 116; 119,2; 144

all-Amshātiyyīn II 190

'Ānah I 171; II 239; 317,1; 319$21 ; 333 ; 364 ; 383$

Anbār = Pērōz-Shāpūr II 112,3; $114 ; 321 ; 388$ 
Andarīn $=$ Androna I 124; II 7,7; 8,$1 ; 9,3 ; 33 ; 43 \mathrm{~s}$

St. Anna, Jerusalem II 267,$1 ; 311,1$

Antiocheia = Antākiyah I 92: 128; 145; II 2,$2 ; 36: 43 ; 48 ; 70 ; 144$; $345,3: 347 \mathrm{~s}$

Aosta II 17,4

'Aqabah, Golf von II 307

al-'Aqanqal Il 395,2

'Aqdah (Edjde) I 60,2

'Aqrqūf $=$ Dūr Kurigalzu I 109; II 87,$2 ; 96-102 ; 104,9 ; 144 ; 188$; $190 ; 320,1$

'Arabān I 6-8; $115 ; 165 ; 184-87$; $191 ; 195$ s; II $238 ; 307 ; 325$; IV $3 ; 10 ; 16,2$;

al-'Arba 'īn in Takrīt I 222ss; 233; II $245 ; 320 ; 333$

Arbela oder Irbil I 144,3; 146 ss; $150 \mathrm{~s}$; II $83 \mathrm{~s} ; 87 ; 157,5 ; 159,1$; $205 ; 229 ; 252,4 ; 303,2 ; 305 ; 312-$ 16 ; 318s; 326-29

Ardabīl II 234; 276,1

Armenische Thore I 146

Arnās II 298,2; 302

Arradjān $=$ Behbehān I 152

Arshīn, Kirche II 7,6

Arzan II 350

Asfānabr II 58,2; 63,2; 73

Ashnās, Shinās=Karkh Fairūz I 52; 55,$3 ; 65,4 ; 69,1 ; 109 ; 229$; II 77,1

'Ashshār I 241

'Askar al-Mu'tașim I 69,1; $86 \mathrm{~s}$

Assuān II 273,1; 283

Assur $=$ Qal'at Shirqāt I 210;212s; 216 ; 228 ss; II 103 ; $105 ; 125,3$; 233,3 ; 303; 306 s; 330; 355 s; 372,2; IV $2 ; 4 ; 13,2 ; 15 ; 22$

Āstān Shādh Qubādh II 83,1

al-'Attābiyyīn II 114 ss

'Aun al-dīn cf. Imām 'Aun al-dīn

Awānā I 60; 227

A'zāz, 'Azāz=ass. Khazāzu I 115s; 119,$2 ; 144$

al-'Azzibah I 239; 246; II 178,3

Azīziyyah I 235; II 58

Baalbek IV 17

Bāb I 114 s; 119s; 144

Bāb Anțākiyah, Aleppo II 273,1

Bāb al-baiḍ, Yumurta Qapu, Mosul II 214

Bāb al-djadīd, al-'Irāq,Mosul II 214; $283 ; 292$

Bāb al-djisr, Mosul II 214
Bäb al-futūḥ, Kairo II 275,2

Bāb al-gharabah, Baghdad II 188; $190 \mathrm{~s}$

Bāb al-Halbah und Halbah, Baghdad I 149;189; 191

Bāb al-'Imādiyyah, Mosul II 210; 212

Bāb Lakish, Likish, Liqsh, Mosul II $214 ; 163 ; 286$

Bāb al-Múazzam, Baghdad II 149 s

Bāb al-nașr oder al-djisr, Baghdad II $149 \mathrm{~s}$

Bāb al-nașr, Kairo II 273,1; 275,2

Bāb al-Sarai und Bāb al-țōb, Mosul II $214 ; 236 ; 286 ; 288$

Bāb Shāghūr, Damaskus II 275; 282,1

Bāb al-sharqī, Baghdad II $149 \mathrm{~s}$

Bāb Sindjār, Mosul II 212-14; 270; $279 ; 287 ; 288$

Bāb āl-wasțānī, Baghdad I 35; II $148 ; 150 ; 151-56 ; 174 ; 176$; $179 ; 325,10$

Bāb Zuwailah, Kairo II 275,2

Bābā Gūrgūr II 327 ss

Bābillā I 115; 120,2

Bābisqā Ostkirche II 6,2

Babylon I $121 ; 145 \mathrm{ss} ; 150 \mathrm{~s} ; 246 \mathrm{~s}$; II $46 \mathrm{~s} ; 49 ; 66,1 ; 77 ; 96 ; 98,1$; $104 ; 113,3 ; 125 ; 147 ; 154 ; 205$; 327 ; 388; 394; IV $4 \mathrm{~s} ; 11 ; 24$

Babylonische Tore II 386

Bādjabbārah = Manșūriyyat al-djabal II 84,$1 ; 86$

Bādjarmā II 331

Bādjisrā = Abū Djisrah I 59,2; II $83 ; 85 ; 86,1$ und 4

Badrān $=$ Baradān II 148

al-Badriyyah II 137: 190

Bādūriyā II 105

Baghdad I 24,1; 29; 34-51; 58; $63 ; 65 ;$ II $49 ; 77 ; 80 ; 82 ; 94-$ 202; 215; 224; 239; 309; 316; 326; 348; 354 ss; 362; 383; 388; IV $10 \mathrm{~s} ; 13 \mathrm{~s} ; 19 ; 24$

Bāghūz II 386

Bāḥamshā = Abū Hamshah $=$ Bēth Hōmesh II 86,1

Bahnasa in Aegypten IV 24

Bahrain I 239,3; II 399

Balad, Balat nördl. Mosul I 195; II 208,1

Balad, südl. Samarra II 113

Baladrū $z=$ Barāzrū $z$ II 80,$5 ; 83$ ss

Balātunus = 'Ain al-ṭ̂̄n II 213,3
Balāwāt, Balābādh, Bīlād/t II 132,6; 312

Balikh I 116; 136; 145; 156ss; 161; 175

Bālis = Eski Meskene I $2 \mathrm{~s} ; 33 \mathrm{~s}$; 113,$1 ; 119 ; 123-29 ; 144 ; 159,1$; II 229,$1 ; 303 ; 317,1 ; 369 ;$ IV 3 ; $5 ; 16,2 ; 24$

Balkuwārā I 58; 69,1; 103s; II 130,$1 ; 132 ; 136$

Bānah II 319

Band i 'Aḍaim I 57; 62s; II 192; 326

Band i Amīr II 325

Bānqūsā, Kirche II 7,5

Băqūbā I $55 ; 58 s ;$ II $77 ; 78,2$; $82 \mathrm{~s} ; 85 ; 86,2 ; 189 ; 191$

Baradan Tepeh II $83 ; 85$

al-Bārah, Kirche II 20,1; 21,2 und 4 Bardha'ah, Moschee II 138,1

Bārimmā = Bēth Remmān, Rimmōn I 213s; II 105,3; 307

Barm i Dilak IV 7

Barțūbah II 383,2

Bāṣalwā, Bāb Șalwā, Șālwā I 59,1; 61,2; II 209,5

Bash Ṭābiyāh, Mosul I 30; II 209; 212; 236; 239; 249; 290s; 309

Baṣrah I $97 ; 101,1 ; 121 ; 147$; II 49 ; $114 ; 139,2 ; 158,4 ; 176 ; 178 ; 208,1$; $209 ; 239 ; 299 ; 362 ; 382$

Bațman Șu II 325

Bawāzìdj = Bēth Wāzìq = Mbā'ūsiyyah? I 217,5 ; II 318

Bērūt II 150,3; 330

Bethlehem, Geburtskirche II 21, 1 und 2

Bihqubādh II 83,1

Binbirkiliseh II 346

Binkudrah I 69,1; 229

Biredjik $=$ ass. Til Barsip I 116,3; 121

Birs $($ Nimrūd) $=$ Borsippa I 121; 247

Bistāam II 158,3; 159,1; 165; 176; 229,2

Bizāâ I $114 \mathrm{~s} ; 120,2 ; 144$

Boghazköi $=$ Khatti I 116 ; II 327

Bostra $=$ Boșrah II $31 ; 38 ; 282,1$; 345,2 und 3

Būdh Ardashīr = Mosul II 208

Būghailah I 58; 234s;

Būharīz, Buhriz I 58; II 189; 191 Bukhārā, Manār i Kalyān II 159,1 229,2 
Būmāriyah I 207,5

Busairah, cf. Circesium I 172-74; II 307; IV 19; 24

Bustān i Kisrā II 59 s

Circesium = Qarqīsiyyah, Qarqīsiyā I $117 ; 128 ; 159 ; 165 ; 172$ $74 ; 174,2 ; 193 ; 195 ; 197 ; 382$; 388; 394

Constantinopel, Goldenes Tor: II 125,3 ; Stadt: II 345

Cordova I 81,$2 ; 99,5 ; 100$; IV 24

Sta. Costanza II 279

Dair al-álā (Mār Gabriel?) Mosul II $209 ; 212$

Dair al-'Aqūl, (al-Dair) I 240,2

Dair al-'Āṣi im Sindjār I 204

Dair al-banāt (od. Dār) bei Takrīt I 230,11

Dair Basīr I 171; 172,1

Dair BāZmā (Tīrmah?) II 79,$2 ; 80$

Dair Hāfir I 114; 117 s; 120; IV 3; 24

Dair Hanzalah II 383,2

Dair Núm II 383,2

Dair Sētā II 345,3

Dair al-Süryānī II 221,1

Dair al-Tell im Sindjār I 204

Dair al-Za'faran II 22,$4 ; 23 ; 31$

Dair al-Zaur (Dēr ez-Zōr) I 112,1; $113 ; 114,2 ; 168 ; 170$ s; $367 ; 382$; 388; 394; IV 19

Dāliyah II 383,1

Daltāwah = Daulatābādh I 61,2 II $191 ; 318$

Damaskus I $66 ; 99,1 ; 128 ; 136 \mathrm{~s}$; 140 ; II $38 ; 125,3$ und $4 ; 128$; 150,$3 ; 156 ; 161,1 ; 198 ; 220 ; 239,1$; 273,$1 ; 274 \mathrm{~s} ; 282,1 ; 301 ; 318 ; 348$; $350 ; 363 ; 383$

Dāmghān II 159,1; 176;229,2; 273,1

Dānā II 346

Dār al-khilāfah, Khalifatspaläste od. Harīm, Baghdad II 143; 148; $189 \mathrm{~s} ; 249 ; 302$

Dār al-khuld, Baghdad II 111; 115

Dāral-qazz, Baghdad II 114,2; 115s

Dār al-raihāniyyīn Baghdad II 148

Dār al-shifă' am Bāb al-gharabah II $188 ; 191$

Dara $=$ Anastasiupolis I $138 \mathrm{~s} ; 149$ II $12 ; 23 ; 37 ; 44 ; 351,2$

Dārāb, Dārābgerd in Fārs I 162; II 132,4

Dasht i bārīn in Fārs II 332 s
Dasht i Kazīmbān II 287,3

Dastagerd I 59,2; 216; 229; II 66,2; 67,$1 ; 76-93 ; 116 ; 121 ; 325 ; 333,2$ Daula iyyah I 208

Dehlī II 226,1

Deli 'Abbās II 318

Demir Qapu II 307

al-Dhībain II $83 \mathrm{ss}$

Dhū'l-Kifl (Hezekiel) I 239,3; II 178,$3 ; 179,1$

Didjlah al-'aurâ', der „einäugige, falsche Tigris" I 60,4; 248

Diwrigi II 165,3

Diyālā I $55 ; 57 \mathrm{~s} ; 60,3 ; 62$ s; II 77; 78,$2 ; 83 \mathrm{~s} ; 88 ; 95 \mathrm{~s} ; 150 ; 326$

Diyār Bakr cf. Amida

Diyār Muḍar I 131 s; II 203; 355

Diyār Rabīah I 204; II 203; 211

Djabal 'Abd al-'Azīz I 184,5; 188; $192 ; 200$

Djabal al-Aḥaș I I14,3; 117; 126

, Barakāt I 244

- Bishr I 1 16;121;164; $165 \mathrm{~s}$; 168

„ Djūdī I 144; 199

" Djuraibah I 193; 197; 199

» Ghurābah I 184,5; 188,2; 189

” Hamrīn I 53 s; 57;213;219; II $77 ; 80,5 ; 84 ; 191 \mathrm{~s} ; 326$

" Haurān II 196,2; 298,4

„ Kibrītiyyah I 207

» Mahlabiyyah bei Tell A'far I 189,1; 206; II 307

" Makḥūl I 53; 165,3; 212$14 ; 229$

» $\quad$ Maqlūb $=$ Elpep II 144 ; $160 ; 204 ; 334$

» Minkhar od. Manākhir I 164

” Muḍabba' I 121; 141; 155

- Sanām I 249

Sēs II 123,2; 124 Abb.; Shaqūq I $214 \quad\lceil 130,3$ Shbisah (Shibsah) I 184

" Shubaith (Shbêt) I 114,3; $117 ; 123 ; 126$; II 11

» Sindjār I 182; 188; 192; 196-204; 213

- al-Șughur II 386

Taktak I 175

Djabbūl-See, al-Șabkhah I 114; 119,3

Dja/uddālah = Gedhālā, cf. alKhān, Djudāl I 13; 201,6 und 8; II 208,$7 ; 307,3$
Djalūlā al-waqīah = Glāl II 79,6;

$80 ; 82 \mathrm{~s} ; 84 \mathrm{~s} ; 86 ; 88,7 ; 188 ; 191$

Djalultā II 80,$5 ; 83 ; 85$

Djāmi' al-aghawāt Mosul II 288

„Ahmad b. Tulun Kairo I 81,$3 ; 100-03$; II $138 ; 151,4$; $218 ; 352 ; 360$ ss

n al-aḥmar Ḥarrān I 94,l; 98; $100 \mathrm{~s}$

- al-ahmar Mosul = Khiḍr Iliyās oder Mudjāhid al-dīn II 235

„Altynbogha Aleppo II 216,

» Amru Kairo I 98,3; 99s; 101; II 354; 362

, Aqmar Kairo II 282,1

„ al -'Áqūlī Baghdad II 197; $262 ; 270$

al-Aẓhar Kairo II 219; 273,1; 282,1

* al-Bāshā Mosul II 288

- al-dabbāghah al-'atīqahAleppo II 355

" abū Dilif in Mutawakkiliyyah I $52 ; 69-77 ; 100$ ss; 109 ; II 226; 325,11; 362

» al-Guyūshī Kairo II 273,1

» al-ḥadjjjārīn Aleppo II 282,1

》 Hāakim Kairo I 100; II 151,4; 219,$4 ; 272 ; 273,1 ; 275$

” HammōQaddō Mosul II 288 al-ḥayyāt Aleppo II 303

" Husain Pasha Baghdad II $196 \mathrm{~s}$

n al-kabīroder al-Nūrī Mosul I 16-18; 98,2; II 215-31 u. ö. bis $301 ; 360$

" al-Khāṣakī Baghdad I 81,2; 92; 102; II 139-45; 171 ; 221 s; 297,2; 352

„ al Khazām Mosul II 286s

" al-Khulafă' oder al-qașr Baghdad I 44s; II 147; 156 bis $60 ; 192$ al-Manșūr Baghdad I 91,1; $99 \mathrm{ss} ;$ II $111 \mathrm{ss} ; 113,1 ; 135$ bis $39 ; 362$

" Mudjāhid al-dīn Mosul II $215 ; 234-36$

øl-Murādiyyah Baghdad II 197

» al-Mutawakkil Samarra I 52; 87-97; 100 ss; II 138; 217; $297 ; 362$ 
Djāmí al-Nưmānī II 197

» Nūrī Ḥamāh I 93,1; II 225,2; 254,1

" Nūrī Raqqah I 3-6; 100s; 223; II 218; 229,1; 279; 31 7,1; $355 ; 359-62$

"al-'Omariyyah Mosul II 217,$1 ; 283-86 ; 296 ; 297,2$

»al-Qamriyyah Baghdad II 146

" al-Șāliḥ Kairo II 275; 282,

» al-Shaikh ('Abdulqādir Gīlānī) Baghdad II 197

” Sultān Hasan Kairo II 270,2

n Sultān Uwais Mosul II 288

” Sūq al-sīf Baghdad II 146

” al-Ṭalấ̃ Kairo I 100

” 'Uțrush Aleppo II 215,1

» al-Zaitūnah, Tunis I 99,4; 101

Djara'at al-bārūdah II 50-53

Djarri-za'dah (Tcherizade) I 121; 249,3

Djauharatain Baghdad II 189; 191

Djausaq al-khāqānī = Bait al-khaInfah Samarra I 69,1; 82; 86s; II $132 ; 135 ; 178 ; 325,11 ; 359$

Djazīrah, Land I 175; II 203; 300

Djazīrat ibn 'Omar = Bezabde, Sapphe I 148ss; II 213,3; 215; 239 ; 266 ; 267,2; 269; 293; 295,1; $299 ; 303 ; 325 ; 328 ; 330$

Djazlah Burg I 163s; 168

Djibbārah bei Samarra I 56; 58; $60 \mathrm{~s} ; 104,2$

Djibrīn I 117; 120,2

Djiddah Moschee II 138

Djisr Harbah cf. Harbah

Djisr Nahrawān II 70; 79s; 8 $86 ; 112$

Djubairiyyah 1109

Djūkhā, syr. Gōkhai I 62 Anm.

Djund al-'awāṣim I 128; 140

Djund Qinnașrīn I 128; 140

Djurdjān II 273,1

Djurwān $=$ Shirwān $=$ Diyālā II 78,$2 ; 84$

Dudjail-District I $54 ; 60 ; 64 ; 227$;

II $84 ; 87,4 ; 102 ; 299$

Dughairāt I 188

Dukkān i Dāūd II 313

Dūlāb, Dawālīb in Dastagerd II 76; 90

Dulaidjmiyyah $=$ Tell Ledjmiyāt I $182 ; 188$

6 SARRE-HERZFELD, Archäologische Reise. Band IV.
Dulūk = Doliche I 128

Dumēr II 298,4;

Dūr 'Arabāyā I 66,4; 69,1; 229; 234; II 106

Dūr al-khārib = Imām Dūr I 30$34 ; 30,3 ; 54 \mathrm{~s} ; 69,1 ; 223 ; 231-$ 34 ; 239 ; II $147 ; 176 ; 178 ; 210$; 233,$2 ; 239 ; 245 ; 273,1 ; 274 \mathrm{~s}$; $320 ; 327 ; 336 ; 364$

Dūrā II 189; 191

Edjmiatsin II 296,2

$\mathrm{Eg} / \mathrm{kbatana}=$ Hamadān I $146 \mathrm{~s}$; 150; II 77; 259; 327

Ephesos II 347

Esneh II 273,1; 274

Eski Baghdad in Samarra I 68

$» \quad>\quad$ bei Dastagerd II 76; $80 ; 82 ; 85 ; 89 \mathrm{~s}$

Euphrat I 116; 118; 120-74; II $325 ; 367 ; 376 ; 382 ; 387 \mathrm{~s} ; 394$

Ezra $=$ Zor'ah, St. Georg II 31; 180,$1 ; 345,3$

Fakhrīqah II 313

Fallūdjah I 121; II 112,3; $114 ; 320,1 ;$ 387

Fasā in Fārs II $137 \mathrm{~s} ; 383,3$

al-Fathah I $53 ; 213 ; 219$

Fīrūzābād = Ardashīr-Khurrah I 76,$1 ;$ II $10 ; 74$ ss; $332 \mathrm{~s}$

Fīrūzābād in Khurāsān II 229,2

Fudain I 176 ss; II 307; IV 5

Fuhaimah II 388

Furāt al-Bașrah od.-Maisān, Perāth Maishān I 251;299

Fusțât = Alt-Kairo II 104,2; 218; 301 und $3 ; 354$; IV 20; 24

Fynyk IV 7

Ganzaka = Gandjak, Djaznah II $87 ; 89$; IV 36

Gaugamela = Tell Gōmel I 144,1; $145 \mathrm{ss} ; 150 \mathrm{~s} ; 327 \mathrm{~s}$;

Ghaibat al-Mahdī Samarra II 165,1; $171 ; 224$

Ghanāūr IV 11

Gharrah I 200,3

Ghaznī II 229,2; 273,1

Giaur Kale, Alt-Marw IV 7

Gindares, Gindere $=$ hett. Kinalua? I 116; 119,3

Gird a Māmik II 328

Gireh II 332 s

Gizeh II 283
Grab des Abū'l-fidā,Hamāh II 217,1

„ „Ạ̣mad b.HanbalBaghdad II 115

, $\quad$ ibn al-Athīr Mosul II 287

" "Bahlūl Dānā Baghdad II $180 \mathrm{~s}$

• "Bilāl, Maq̣barat Bāb alShāghūr Damaskus II 275

” "Djunaid Baghdad II 114; 179

" „Mánu bei Serrīn II 367

” "Ma'rūf al-Karkh̄̄ Baghdad II $114 ; 158,5$

„ $\quad$ Sampsigeramos bei Hims II 367,4

- "Shihāb āl-dīn 'Omar alSuhrawardī Baghdad II 179

Gumbadh i Qā'ūs Djurdjān II 273,1

Ḥabl Ibrāhīm I 244

nal-sakhr I 240

, al-sūq II 57

Hadīthah am Euphrat I 192,2; II $178 ; 239 ; 320-22$; $333 ; 364 ; 383 ; 388$

„ "Tigris Tell al-Sha ${ }^{\top} \mathrm{r}$ I 217,4 ; II 326

Hadjrah (Hdjara) I 121; IV 35

Hagia Sophia Constantinopel II 33; 365

Hāh 'Adhrā'-Kirche II 10; 31; 298,4; 345s

" Mār Sovo II 277,2; 298,2

al-Hair Samarra I 86

Halabiyyah $=$ Zenobia I 121; 124 ; 165-170; 210; 218; II 7ss; 12 ; $37 ; 44 ; 75,1 ; 125,3 ; 321$; $365-73 ; 392 ; 394$; IV 5; 8; 24

Hamāh = Epiphanias I 98,2; 136s; 192; II 154,$2 ; 217,1 ; 220 ; 239,1$; $313 ; 363$

Hammah I 165,$3 ; 168 ; 180 ; 182$; 191 ; II $367 ; 374$

Hammām 'Alī I 206; 208; II 306

Haram von Jerusalem II 352

Harārāt I 205

$[164,4$

Harbah I 36,$2 ; 14,2$; II 161 und 6 ; Harbiyyah Baghdad II 114; 116

Harīm Baghdad cf. Dār al-khilāfah

Harīm i Kisrā od. al-Ḍbá̄i Ktesiphon II $60 \mathrm{~s}$

Ḥarrān I 94,1; 98; 128; 137; II 45; 132,$3 ; 239 ; 303 ; 311 ; 317 ; 348$; $353 ; 355 ; 361 \mathrm{~s}$ 
Hụarrān al-'awāmīd I 117

Hārūniyyah Samarra II 80,$5 ; 82$; $84 ; 86$

Hashtarak. Țūr 'Abdīn II 277,2

Haș̣ Diogenes-Grab II 346

Hatra = al-Haḍr I 136; 162; 202; $205 \mathrm{~s} ; 228 \mathrm{~s} ;$ II 1 ; 25,$1 ; 77,1$; 105,$3 ; 132 \mathrm{~s} ; 142$; 154 ; 208,1; 233,2; 252,2; 306s; 367; 372; 378; 391

al-Hayāt, Haus des Fl. Seos Olbanu II 130,3

Hazār Pushtah II 191

Herakleia am Taurus $=$ Eregli I 162

Hillah I 247 ; II $112 ; 114 ; 321$; IV 4 al-Hillū II 375

Himṣ = Emesa I 98,2; 117; 128; 136s; II 43s; 125,3; 213,3; 220; 239,$1 ; 273,1 ; 311,2 ; 313$; 317,1 ; $348 ; 356 ; 363 ; 367 ; 383$;

Hị̂rah I $121 ; 228,1 ; 235 ; 247$; II 104,$2 ; 130,1$

Hiraqlah I 161-63; II 93; 116; $121 ; 132 \mathrm{~s} ; 134 \mathrm{~s} ; 359$

Hisisn al-Akrād II 213,3

„Kaif I 8,7 ; II 215; 239; 302; 325

Hīt I $171 ;$ II 239; 382; 386; 394

al-Hōl I $197 \mathrm{~s}$

Hōr al-Saqlawiyyah oder Nahr II $50 ; 103 ; 111 ; 114$

Ḥṣakah = Ḥsaätchä, Haṣkah ; 175; $189 ; 196$

al-Hubais (Tell Hiabash?) I 157,2

Hudjaif Ayyāsh oder al-Shăm I 170

Hulailiyyah, Minaret bei 'Ānah II 320,1

Hulwān = Sarpul I 69,1; 229,4; II $77-80 ; 82 \mathrm{~s} ; 93 ; 191 ; 201 ; 328 \mathrm{~s}$

Huumaidāt I 207

Humaimah I 118; IV 3

Humrīn cf. Djabal Hamrīn I 214 Hưwaișilāt Samarra I 107

Idjāz Apostelkirche II 7,1 Jericho IV 8

Jerusalem I 80,$1 ; 81,3 ; 85 ; 93 \mathrm{~s}$; 99 ss; II $31 ; 252,2 ; 267,1 ; 273,1$; $274 ; 311,1 ; 348 ; 351,3 ; 352$

'Imādiyyah II 87; IV 36

Imām 'Abd al-rahmāan Mosul II 236,$1 ; 282 s$

- 'Aun al-dīn Mosul I 20-22;
$-42-$

II $234 ; 238 ; 245 ; 247 ; 249$; 261 ; 263-70; 287,1; 292; $301 ; 311$

Imām Bāhir Mosul II 288

" Dūr cf. Dūr al-khārib

"Yahyyā b. al-Qāsim Mosul

I 22-24; II 234; 238; 249-63;

264,$1 ; 267 \mathrm{~s} ; 276$; 287,1; $291 \mathrm{~s}$;

$301 ; 311 ; 316 \mathrm{~s}$

Imāmzādeh 'Abdallāh bei Shūshtar I 239,3

'Irzī II 75,1; 321; 367; 386; 392

Ișfahān I 14; II 160; 325

İshān und Nahr Ghāfah I 240

„ Khālid I 235

Iștabulāt bei Samarra I 59

Ișțakhr Moschee II 138s; 139,1

Itshqal'ah Mosul II 209; 215; 231

İwān $\mathrm{i}$ Karkh = Karkhā de Lādhan II 195

„der Qal'ah Baghdad II 170$72 ; 174 ; 177 ; 221 ; 240 ; 249 ; 261$

Ka'bah II 207,1; 252; $261 ; 265$ al-Kabsh wa'l-AsadBaghdad II 110 Kafr Tabīl I 132

Kafr Zeh = Mār Azizael, Țūr 'Abdin II 277,2; 298,2

Kairo II 125 und $_{3} ; 259 ; 272 ; 273,1$; $274 ; 282,1 ; 301,3 ; 360 ; 362$

Kalwādhā = Qarārah = Kurigalzu? II 100,$4 ; 105$

al-Kanīsah al-khaḍrā' Takrīt I 221 ; 230

Karāt II 229,2

Karamlīs = Kermesh II 312

Karbālā I $85 ; 121 ; 235$; II 58; 130; $160 ; 201 ; 252$

Karkh Baghdad II 105; 110; 112; $114 s ; 147 ; 172,4 ; 173$

» Maisān = Muhammerah $=$ Spasinucharax I 251,2; 252;

Karkhemish $=$ Djarābīs I $115 \mathrm{~s}$; $143 ; 174$

Karkhīnē = Karkūk II 326,4; 327 Karkūk = Karkhā de Bēth Slōkh I 104,1; II 77, $; 88,,_{1} ; 179,1,198,4$; 205; $297 \mathrm{ss;} 305 ; 318$; $326 \mathrm{~s}$; $329-36$

Karrātīn, Kathedrale II 7,8; 8,2; $9 ; 11 ; 33 ; 44$

Kārūn I 252

Kārwānsarai Mādar i Shāh, Iṣfahān II 201,2

Kāshān II 252,4
Kaskar $=$ Kashkar II 299

Kaspische Thore I 146s; 150

Kāth-Shahristān am Djaiḥūn II 138,6

Kawur Kūh I 248

Kāẓim, Baghdad II 102ss; 110; $116 ; 145$ ss; $160 ; 173 ; 215$

Kesik Köprü II 307

Khābūr I 1 16; $118 ; 121 ; 165 ; 171-$ 96; 386; IV 3; 24

al-Khān = Djudāl, cf. Djaddālah I $13-15 ; 201 ; 205 ; 208,7$; II 238; $305 ; 307,3$

Khān abū Djisrah cf. Bādjisrā I 59,2 " banī Sád II 83

» Djighāl (Djaghān), Baghdad II 198

》 Ḍulū'iyyah I 56,2; 57; II 58,1

» Kharnīnah I 219; II 201,2

» Mahmū diyyah I 57; 200s

" al-Mashāhidah II 199s

, Mirdjān, Baghdad II 187

- Mizraqdji 157,$1 ; 59,1 ;$ II 201

- Nahrawān I 56,1;59,2;61;63

》Ortmah II $82 ; 102 ; 182 \mathrm{~s}$; 187-96; 198; IV 36

» Tarmiyyah I 60

„ al-zurūr, Baghdad II 197s

Khānīdjār = Ṭuz Khurmatū II 318; 319,$2 ; 326,3 ; 327$

Khānīqīn II $76 ; 79 ; 82-85 ; 191 \mathrm{~s}$; 287,$3 ; 328$ s

Khānūqah am Euphrat I 164-66; 167,$3 ; 180$; II 365 ; $374 ; 386$

" $\quad$ Tigris I 214

Khargird in Khorāsān II 274

Kharput II 282,1

Khātūniyyah-See I 191; 193; 198; 198; II 307

Khiḍr Iliyãs in Baghdad II 103; $146 ; 179$

» $\quad$ in Mosul II 235,2; 237,3

- $\quad$ beiSamarra I 56;60s; 104,2

Khirr-Kanal Baghdad II 103; 111 ; $113 \mathrm{ss}$

Khōṣar II 205; 215

Khosrōgird II 229 und 2

Khotan IV 5,1; 13,1 [191

Khurāsān-Strasse II 77—85; 112;

Khurhah bei Kāshān-Kum II 351 Khurramābād = Kharnābāt II 188; 191 
Khursābād $=$ Dūr Šarrukēn II Madrasah al-Niẓāmiyyah, Baghdad II $125,{ }_{3}$; II 268,4

Khusāf I 114

Khuwarnaq I 121; 235; 247

$\mathrm{Ki} / \mathrm{ufri}=$ Salāhiyyah II $83 ; 329$

Kiliz $=$ hett. Kinza I 116; 119,1

Kirmān II 230

Kirmānshāhān II 201; 325,10

Kiu-yung Kwan, Tor der chinesischen Mauer II 153

Kōkanāyā, Kirche II 7

Konia II $146 ; 217,1 ; 260 ; 287,1 ; 317$; IV 16

Korykos in Kilikien I 127; 180; IV 12

Ktesiphon I 228s; II 46-76; 88 ; 89,$1 ; 105,3 ; 106 ; 116 ; 121 ; 210$; $262,{ }_{1} ; 306,{ }_{3} ; 321 ; 325 ; 386,2 ; 388$; IV $4 \mathrm{~s} ; 11 ; 17$

Kūfah I 97,$2 ; 101,1 ; 235 ; 247 ; 250$; II $49 ; 84 ; 104,2 ; 112 ; 114 ; 128$; $138 ; 139,2 ; 178 ; 208,1 ; 210 ; 321$

Kum II 176, $; 226 ; 252$

Kurtak- und Qarabulī-Pass II 318 Kūt al-Imārah I 247s; II 207; IV 36

al-Ladj südl. Ktesiphon II 57,1

Laodikeia $=$ Lādhiqiyyah I 92; II $69,,_{3} ; 144$

al-Laqlaq I $54,,_{1} ; 219$

Lehen der Umm Djáfar, Baghdad II $110 \mathrm{~s}$

Lu'lu'at al-djausaq, Samarra I 82

Ma'adhanat al-Munaitir I 156s; II $354 \mathrm{~s}$

Ma'arrat al-Nu'mān I 117; II 239, 355

al-Madā'in $=$ Medhīnāthā $=$ Seleukeia-Ktesiphon I 66; 87; 206; II 48,$4 ; 321$

Màdān, Qyshlah I 164

al-Madīnah al-'atīqah, Ktesiphon II $58 ; 63,2 ; 76$

Madinah al-zahrah IV 24

Madrasah al-Halāwiyyah, Aleppo II $20,{ }_{3} ; 22 ; 31 ; 282$,

Madrasah al-Mirdjāniyyah, Baghdad I 45-50; II 85,6; 102; 105 ; $147 ; 165,4 ; 181-87 ; 260 ; 264,2$; 276

Madrasah al-Mustanșiriyyah,Baghdad I 42-44; II 105; 147; 158,2; $161-70 ; 171 \mathrm{~s} ; 189 ; 191 ; 253$; 319
II $160 \mathrm{~s}$

Madrasah al-Tutushiyyah ” II 161

Mahall al-Ṣafșāf II 367

Mahdiyyah II 132,$5 ; 133$

Māh i dasht II 201

Mahlabiyyah am Khābūr, cf. Djabal al-M. I 188; 194

Mahrūd Kanal II 80; 83 ss

al-Māhūzah I 66,4; 69,1

Makhrabiyyah II 188; 191

Mākisīn = Marqadah I 182,1; 195 ; $198 ; 200 ; 383,2$

Makkabäerkapelle in Mār Tahmazgerd, Karkūk II 297; 331 ss

Malatia I 115

Malta II 282,

Malwiyyah, Manārah al-, I 96-97; 109

Måmūniyyah I 58; 59,

Ma'mūrah bei Hīt, Minaret II 320,

Manārah al-maksūrah, Mosul II 229 ; 232 s

» al-maqțū'ah, Baghdad II 161

» al-munaitir II 354s; IV37

Munaitir I 153 I 115,$1 ; 119,6 ; 128 ; 131$

Mandalī $=$ Bandanīdjīn II 83; 85,6; 189 ss; 287,3

Manșūrah in Sind II 138,

Manșūriyyah bei Qairawān II 132,$5 ; 133$

Maqām Aulād Sayyid Aḥmad alRifāī II 321

" Bint 'Imrān b. 'Alī II 147; 213, thah II 178,3; $321 \mathrm{~s} ; 334$

Mār Abāi II 302

, Aḥ̄ dēmmeh 238,2; 291 ;294s ; 311

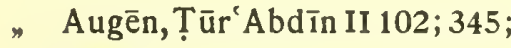
351,3

„ Azizael, Kafr Zeh II 298

» Behnām bei Khị̣̂r Iliyās II 146,$5 ; 247$; Abb. $247 ; 265 \mathrm{~s}$; 267,$2 ; 268 ; 277 ; 285,1 ; 289$; 295 ss; 302; 311 s; $335 ; 344$

* Daniel, Karkūk II 330

» Gabriel, Qartmīn II 45; 298, 3 und $4 ; 335,5$;

" Gabriel cf. Dair al-a'lā, Mosul
Manbidj $=$ Mabbogh $=$ Bambyke

" Nadjm al-dīn bei Hadi-
Mār Gorgīs od. Gwargīs, Djirdjīs II 238,2; $291 \mathrm{ss}$

" Ibrāhīm, Midyād II 298,4

„ İshá yā, Mosul II 208; 291

- Kyriakos, Qiryāqūs, Mosul II 208; 291

- Kyriakos, in Arnās II 298,2

„ Mattā, Djabal Maqlūb II 334 s

» Philoxenos Midyād II 298,2; 335,5

» Pythion, Fāthiyūn, Mosul II 238,$2 ; 291 ; 293$

^ Shem'ūn al-Șafā od. Petros, Mosul II 238,2; 252; 290; 292s; 294

n Tahmazgerd, Karkūk II 301,3; $330-36$

» Theodoros, Mosul II 292

» Tūmā, Mosul II 261; 266; 267,$2 ; 289 ; 291$; 311

» $\quad$ der Jakobiten, Mosul II 291

^ Ūbil, Midyād II 298,4

„Ya'qūb, Mosul II 277; 291; 295-97; 334

» $\quad$ Nașībīn II 20,1; 23; 294,$2 ; 336-46$

» al-Habīs, Șalaḥ II 298,4

- Yūḥannā, Mosul II 291

\% Tūr 'Abdīn II 298,3

Marāghah II 259; 318

Mar'ash = ass. Marqasi, Marrhasion

I $115 \mathrm{~s} ; 119,5$

San Marco, Venedig II 218,1

Mārdīn I 149; 189; II 213,3; 239;

Marfiyyah I 184,5 [302

Marqadah I $165 ; 179-82 ; 191 ; 195$ Marsala II 282,1

Marw, Dār al-imārah des Abū

Muslim II 134,5; 318

Marw al-rūdh, Moschee II 138,6

Masdjid al-aqsā, Jerusalem I 93, 99ss; II 351,3

» Bait al-Takrītī, Mosul II 292

^ Ibrāhīm al-khalīl, Aleppo II 254,1

- al-Shu'aibiyyah, Alleppo II 241,$1 ; 282,1$

al-Mashhad bei Aleppo II 287,1 Mashhad (Maqām) 'Al̄̄ bei 'Ânah I 244,2 ; IV 36

n al-munțaqah II 111,2 ; $113 ; 115$ 
al-Maskin I 69,1; 227; II 87,$2 ; 105$

Maskintā, Mosul II 291

Matīrah I 58; 69,1; 103 s

Mausoleum von Halikarnass II 346; 367

Mayādīn II 320

Mayāfāriqīn = Fārqīn = Martyropolis I 138 ; 230 ; II 21,$6 ; 22 \mathrm{~s}$; 34 ; 36 ; 38 ; $43 \mathrm{~s} ; 102 ; 165,3$; 239; 273,$1 ; 274 ; 298,3 ; 299 ; 325 ; 351,3$

Mazār Dausat 'Alī, Mosul II 278 » al-Hanafiyyah, Mosul II 288 Medina, Masdjid al-Nabī I 98,3; 101

Medische Mauer $=$ Sidd Nimrūd $=$ Semiramis-Mauer I 104,2; 107,$4 ; 146$; II 46,3

Meriamlik in Kilikien I 124; 127; II $7 ; 25 ; 33 ; 330 ; 345,3$

Meskene I 121; II 387

Mhayy II 298,4

Minaret des Abū'l-Fawāris Bekdjūr, Himṣ II 273,1; 275; 356

Minaret des Gökbüri, Irbil II 314 bis 19

\# Malikshāh, Aleppo II 2,$2 ; 82 ; 159 \mathrm{ss} ; 164 \mathrm{~s}$; $217 ; 272$ s; 355

„ Qal'ah, Mosul II 229; $231 \mathrm{~s}$

» Quṭb al-dīn, Sindjār I $9 \mathrm{~s}$; II $308 ; 316$; 317,$2 ; 318$ s;

» „Shaikh 'Alī, Karkūk II 330

Misma'i I 63,i

al-Mitrās I 196; II 307

Mosul I 16-30; 195 ; 207s; II 144 ;

150,$3 ; 154,2 ; 159$ s; 165 ; 176;

$203-304 ; 307$; 312; 318; 326;

$336 ; 352 ; 355,5 ; 356 ; 358 ; 382$;

IV $15 ; 19$

Mshattā I 81,$3 ;$ II $3 ; 25 ; 36 ; 45$; 67,$3 ; 121 ; 132 ; 135 ; 160,1 ; 280,2$; $325 ; 358$

Mu'aẓzam = Ruṣāfat Baghdad II $111 ; 113 \mathrm{~s} ; 136 ; 147 \mathrm{~s} ; 150 ; 320,3$ Mudjdah, Minaret bei Ukhaidir II 320,1

Mudjlayyah II 345,3

Muḥaidjir I 54,2

Muhammadiyyah I 66,5

Muhammerah $=$ Spasinucharax $\mathrm{cf}$.

Karkh Maisān

Muḥawwal II 112,4; 114
al-Mukhattat I 235

al-Munkharaq I 198

Musayyib I 121

Musmiyyah, Praetorium II 42,5; 345,3

Mutawakkiliyyah I $62 ; 65-77$ 61,1 ; II 151,4

Muwaqqar I 162; II 102; 352

Mylasa, Grabmal II 367

Nabga $=$ nabqah $=$ Nabagath $\mathrm{I}$ 105,2

Nabī Daniel, Mosul II 288; 303

» $\quad$ Susa I 239,3; II 178,3; 179,1

„ Djirdjīs, Mosul II 207; 211 ; $236-38 ; 238,2 ; 252 ; 291 \mathrm{~s}$; 301

”Shīth, Mosul II 207; 303

„Yūnis,Mosul II 205-07;211; $237 ; 252 ; 292 ; 301 ; 303$

„Yūshá, Baghdad II 179-80

Nadjaf I $85 ; 121$; II $58 ; 160 ; 201$; 252

al-Nadjmī I 235; 237-240; 244

246; II 178,$3 ; 179$

Nahr Barazā II $84 ; 86$

* Batt I 57;62s

„ Bīn I 63; II 80; 149,1

„ Būq II 80

„ al-dhahab od. Buṭnān I 114s; $119 ; 144$

" " Kanal vom Tigris I 240

» Djaghdjagh I 170,2;175; 183; 189s; 192ss; 196; 204s; II 307

, abū'l-djāmūs I 235

” Dudjail I 78

» Ghīrān I 200

Hadīdah I 55,2; 63

" "frīn, ass. Apre I 119,1; 144

„ '̂̂sā I 161; II 102; 111; 112,4; $113 \mathrm{~s} ; 191 \mathrm{~s}$

„ Ishâạî I 78; 83

"Karkhāyā II $111 ; 114$

” Khāliṣ I 63; II 84s; $191 \mathrm{~s}$

„al-malik, Königskanal II 57; 192

» Mirdjānah II 85; 191

» Mưallā II 149

”al-Mustanșir I 64

„ Nẳifah I $53 \mathrm{ss} ; 58 ; 62 \mathrm{~s} ; 66,4$; 219

al-Qā'im I 56s; 59s

"Quwaiq I 114; 144
Nahr Rādhān, Rādamān I 57; 62; II $188 ; 192$

” al-Raṣāṣ I 52ss; 54,$5 ; \quad 55$ ss; $60 ; 66$

„ Razin in Baghdad II 111

” Sābus I 237; 243

" Sādjūr $=$ ass. Sagurri, gr. Saokoras I 116; 119,1

× Sa/irāt I 243-46; II 110s; 112,$4 ; 188 ; 192$

„Shirwin II $84 \mathrm{~s}$

„Silsil II 83; 85

„TTābith II 84ss

" Tāmarrā, syr. Tōrmarrā, cf. Diyāalā I 57,$3 ; 58 ; 61,2$ und 4 ; II 78,$2 ; 84 ; 86,2 ; 87,4$

- Tarțar = Taltal = al-dhahab I $115 ; 119 \mathrm{~s} ; 144$

» Tharthār I 107; 175; 193s; 196; 202; 204 s; II 307,2

„ Zuraidjī $=$ Tshīwā-shār II 312

" Zurraq od. Surraq I $204 \mathrm{~s}$

Nahrawān I 55s; 56,1; $57 \mathrm{~s} ; 60 ; 61,4$; $63 ; 219$; II $56 \mathrm{~s} ; 77$; $83-86$; 104,$9 ; 326$

Nairab (Tell) I 114ss; 119

Nakhtshawān II $176 ; 220 ; 229,2$; 252,$4 ; 282,1 ; 317 \mathrm{~s}$

Napoli II 273,$1 ; 282,1$

Naqsh i Radjab II 285

Naqsh i Rustam II 367

Nașībīn $=$ Nisibis I 138,2; 148s; 228 s; II 23 ; 31 ; $36 ; 212 ; 278$; 302 s; 305ss; 328s; 336-46; 351 Nașriyyah II 114,$2 ; 115 \mathrm{~s}$

Nà'ūsah II 388

Nayy I 63

Nēshāpūr II 161

Nīliyyah I $235 ; 239-43 ;$ IV $11 ; 17$ Nímatābād II $191 \mathrm{~s}$

Nimrūd = Kalhi I 209s; II 103; 144; 207; 246; 286,1; IV 2ss; 5 ; $11 ; 24$

Ninive $=$ Ninos, cf. Qoyundjuq II $83 ; 84-87 ; 105 ; 125,3 ; 203$; 205-07; 239; 246,3; 300; 303; 327; IV 2s; 5 ; 11

$\mathrm{Ni} /$ ashābah II 75,$1 ; 321 ; 367$

Nizib II 43,4

Nuhiyyah II 388

Nukhailah, Burg I 163s; 168

'il-'Odjah II 287,2

Omān, Moschee II 138,6 
Opis $=$ ass. $\bar{U}_{\mathrm{p}} \overline{\mathrm{I}}=\mathrm{K}$ ēsh I 60 (fälschlich $=$ Mandjūr); 146; II 46,$3 ; 77 ; 327$; IV 36

Orkhon II $286 ; 348$

Paikuli I 105,1; II 89

Palermo II 267,1; 282,1; 311,1

Palmyra $=$ Tudmur I 136s; 140; 143 ; 159 ; II $39 ; 47 ; 69,3 ; 75$; $321 ; 365 ; 367 ; 394 \mathrm{~s}$

Pamir II 325,10 ;

Pandjah 'Alī, Mosul I 24-27; 24,1;

II $251 ; 270-78 ; 287,1 ; 296 \mathrm{~s} ; 311$

Pandjah 'Alī, Baghdad I 24,1; II 197

Pasargadae II 367

Passangān II 201,2

Perge, Stadtmauer II 26,2

Persepolis I $147 ; 152$; II $75 ; 139$; 233,$1 ; 285 ; 325$

Petra II $345 ; 367$

Philippeion,Shahbā Haurān II 298,4

Pīr Zekker, Sindjār I 203,3; II 311,5

Porta Nigra, Trier II 17

Pusht i Kūh I 55; II $178 ; 287,3$

Qabr Mạ̣mūd Shaikh al-Djabbür II 112,4

Qabr al-nudhür, Baghdad II 148,5

Qadīib al-bān, Mosul II 287

Qādisiyyah Samarra I 52; 57; 59;

$62 ; 104-07 ; 109 ;$ II $93 ; 116$; $121 ; 132 \mathrm{~s}$

al-Q $\bar{a}^{\prime} \mathrm{im}$, Samarra I $52 ; 56 ; 58 ; 62$; 104 und 2; 109

al-Qā'imiyyah II 188; 192

Qairawān, Sidi 'Oqba I 6,3; 95,3; 96,$1 ; 99 ; 101$; II 104,$2 ; 218,1$; 226; 273,$1 ; 274$ s; IV 24

Qalaiqalā, Armenien II 392,2

Qal'ah māl albū 'Îsā, Samarra I 68; IV 19

Qal'at banī Hammād IV 24

al-bint I 214-17; II 355

„ al-Dibsī I 129s

» Dja'bar = Dausar I 113,1; $120 ; 131 ; 135 ; 163$; II 303; 355,4 ; IV 24

, Djabbār I $217 \mathrm{~s}$

" Marwān I 207

- al-Maḍiq = Apameia I 119,6

$\quad$ al-Nadjm $=$ Djisr Manbidj I 131 ; II 367

" Simª̄n II 7,$12 ; 8 ; 12 ; 18$; $20 ; 22$ s; $31 ; 39 ; 44 ; 335$; $343 ; 345,3$
Qalb Lauzah II 9; 18; 20; 23; 39; 44

Qambaluq = Cambaluc II 189

al-Qanātị, Samarra I 57; 59,1

Qanbar 'Alī, Sindjār I 203; II 311; 334

Qan Qale, Qanqalesi II 395

al-Qanțarah = Altynköprü II 326

Qanțarat al-Rașāṣ Samarra I 55; $67 ; 92$

Qara Sarai, Mosul I 18 ss; II 165 ; $209 ; 214 ; 220,1 ; 239-49 ; 266$; 310

Qara Tepe II 318

Qaraghan Dere II 191

Qarāḥ al-djāmūs, Baghdad II 192 Qaraqōsh II 302; 312

Qarārah = Kalwādhā II 105; 147; 215

Qarq̄isiyyah cf. Circesium

Qaryat al-Turk II 188; 192

Qașr al-abyad, d. weiße Schloß, Ktesiphon II 63,2; 76

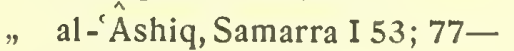
$81 ; 109 ; 131,1$; II 131,$1 ; 245$; 325,11; 358; IV 19

„ Bāb al-dhahab cf. Qubbah alkhaḍrā', Baghdad I 91,1; II 134-36

» bint al-qāḍ $\overline{1}$, Seleukeia II $52 \mathrm{~s}$

» Fircaun, Petra II 298,4; 345

* al-Hārūnī, Samarra I 65; 86; II 127,$2 ; 138,2$

" al-Kharān̄̄ I 94,1; 124; II 123,$3 ; 130,3 ; 355$

" al-ma'shūq = al-'̂Ashiq, Samarra I $82 \mathrm{~s}$

” al-Mutawakkil, Samarra I 55; 62; 66

- Rabbā, Prov. Arabia II 298,4

„ al-salāmah I 160

„ al-șawāmic I 86,5

" i Shīrīn I 216; II 79s; $82 \mathrm{~s}$; II $132 ; 201 ; 329 ; 333,2$

» al-tādj, Baghdad I 92; II 63,2; 148

» al-thurayyā und al-Hasan $\overline{1}$, Baghdad II 104,5; 148

» Țūbah II $325 ; 358$

” ibn Wardān I 124; II 29; 31; $37 ; 92,1 ; 325,11 ; 333,2 ; 345,3$

\section{Qassaim I 121}

Qațrabbul I 64,1; II 105,4; 299

Qāțūl, Stadt I 107,2; II 116,5; 132

Qạțūl abū'l-djund I 59;61; 63
Qātụ̂l al-Kisrāwī I 56ss; 61 ss; II $77 ; 79 ; 183,2 ; 192 ; 326$

Qạțūl al-Ma'mūnī I 58; 59,1

» al-Yahūdī I 58; 59,1

Qazwīn II 136,2

Qinnașrīn $=$ Chalkis I 119, 3 und 6 ; $128 ; 144$

Qoyundjuq cf. Ninive I 118,2; 210; 226; II $205 \mathrm{~s}$

Qubāb al-nār 235

al-Qubbah al-khaḍrāe , Grüne Kuppel, Baghdad II $126 ; 127,2 ; 134 \mathrm{~s}$ al-Qubbah al-khaḍrā', Wāsiṭ II 127,$2 ; 135,3$

Qubbat al-mințaqah, Samarra II 127,2

n al-șakhrah, Jerusalem I 80,$1 ; 81,3 ; 85 ;$ II $31 ; 252,2$; 273,$1 ; 345,3$

, al-Ṣulaibiyyah, Samarra I 83-86; II 252,2

Qurayah am 'Aḍaim IV 8

Qurnah I 248; 252

Qușaibah I 183; 200

Qușair 'Amrah I 37

” al-Dibsī I 130s

al-Quwair (Leguwēr), Samarra I 108,1; II 104

$” \quad$ am Gr. Zāb II 312
wairis I 114,$1 ; 116 \mathrm{~s} ; 118 ; 120$

IV 3

Qyrmyzy Dere II 80,5

Qyzylribāt = Djalūlā II 82,1 und 5;

83 ss; 88,$8 ; 188 ; 191$ s; 201

al-Rabb II 388

Rabbān Hormuzd II 335

Rādkān im Nīkā-Tale II 273,

Rāfiqah I 159s; 222; II 132s; 356

Raḥbah od. Raḥbat Mālik b. Ṭuq II $239 ; 333 ; 365 ; 382-86$; IV 5;

Raqqah I 3-6; 107,2; 128, 131; $136 ; 140 ; 156-61 ; 165$; II 93; $116 ; 119,6 ; 122 ; 132 ; 212 ; 233,2$; 245 ; 303; 325; 349-64; 382; IV 1; $21-24$

Raqqah, Moschee extra muros I 99; 160 s; II 229,1;317, 353 ss; 362

Raqqah, Palast I 223; 245; II 320; $363 \mathrm{~s}$

Rās al- 'ain I 105, ; $115 ; 128 ; 131$; $149 ; 175 ; 191$

Rawāndu/iz II 87

Rayy $=$ Rhages II 136,2; 153; 252,4; IV 24 
Reims II 113,3

Ribāṭ in Dihistān Moschee II 138,6; Rūd i Djarshīk II 333

Rūmiyah $=$ Weh Andēw-Khosrō II 48,$3 ; 70$

Runde Stadt des Manșūr, Baghdad I 160 ; II 93; 104,2; 106-12; 191

Ruṣāfah, Ruṣāfat Hishām I 128s; $136-41 ; 143$; II $1-45 ; 343 ; 345$; $347 ; 368-73$

Rūshanqubādh $=$ Zengābād II 83 ; 84,$2 ; 85,2 ; 88$

Rūsiyyah I $235 ; 237 ; 240$

Ruwaị̣ā, Basilika II 5,1;8,1; $9 ; 40$ n Bizzos-Kirche II 9,2

Sab'ah Sukūr I 193s

Șabkhah, Qyshlah I 164

Sabzawār II 201,2

Saffāriyyah I 209; 219

Șaghāniyān Moschee II 138,6

Sahlah I 235

Sakhnah II 313

Sakīniyyah (Skēniyyah) I 195,8; 199

Saktshegözü I 115

Salāmiyyah I 209

Salamyah od. Salamiyyah $=$ Salamias I $117 ; 136 ; 138,2 ; 273,1274$

Ṣāliḥ̄in bei Aleppo II 273,$1 ; 282,1$ Șālihiyyah II 125,$3 ; 365 ; 368 \mathrm{~s}$; 386-95

Salmān Pāk Ktesiphon II 58; 262,1

Salmās IV 6

Samarqand II 117,$8 ; 149 ; 202$; IV 7

Samarra I $52-109$; II $73 ; 105$; $116 ; 142 ; 144 ; 148 ; 158,2 ; 160 ;$ $215 ; 217 ; 224 ; 252 ; 268 ; 271 \mathrm{~s}$; 285 ; $325 \mathrm{~s} ; 333,2$; 353; $358 \mathrm{ss;}$ 362 s; 388; IV $3 ; 6 ; 11 ; 15 ; 17$; $19 ; 23 \mathrm{~s}$

Samāwah I 121

Samosata $=$ Samsāt I 116; 146,3; $151 ; 155,3$

al-Ṣanam Samarra I 105s

Sangbast in Khurāsān II 229,2

Șaqalțutan II 83s; 191

Sarai i Kisrā Ktesiphon I 238

Sarakhs, Mausoleum des Luqmān II 163,2

Sarāmūn bei Mosul, Eliaskloster II $289 ; 302$

Sardasht II 318

Sārī in Māzandarān II 276,1

Sarmīn I 117; II 239,
Sarpul cf. Hulwān

Sarwistān II $10 ; 332 \mathrm{~s}$;

Sātīiamā I 214

Schutzanz in Armenien II 296,2

Seleukeia I 227 ; II $46-76 ; 77 \mathrm{~s}$; $93 ; 104$ ss; 115 s; $121 ; 333,2 ; 394$; IV 4

Seleukeia am Orontes II 48

Serrīn II 367

Sevilla II 273,1

Shaddādah cf. Sukair al-'Abbās I $157 ; 182 ; 192 ; 195 ; 200 ;$ IV 3

Shahr i Dāqianūs I 106,3

Shahrabān I 59,2; 213; 229; II 77;

80,$5 ; 82, \mathrm{~s} ; 84 ; 86 ; 89 ; 201$

Shahrazūr II $89 ; 317 \mathrm{~s}$; IV 36

Shahrqard/t, -qat, Shārgerd, cf.

Altynköprü II 77,1; 326 ss; 327,1; 328,$1 ; 329$

Shaikh Fathī, Mosul I $27 \mathrm{~s}$; II 279 bis $82 ; 284 ; 293 ; 297,2$

» Haḍid, Hadīthah II 321

„ Manșūr I 191；196-98; II 307

” Ma'rūf al-Karkhī, Baghdad I 246; II 172-74; 181,

" Muḥassin, Aleppo II 251,2; 282,1

„ 'Omar Shihāb al-dīn, Baghdad I 239; II 179

» al-Shațt, Mosul II 233s; 288

” Shiblī bei Mayādīn II 320,3 Shä'miyyah I 121

Shammāsiyyah cf. Múazzam I 65 ; II $148 \mathrm{ss}$

Shanāfiyyah I 121; 235

Shāpūr in Fārs I 105,1

Shārsūq al-Haitham, Baghdad II 116,1

Shathātah (Shifāthah) I 235; II 130 Shațt, Didjlah und Furāt I 60,4

” al-'A rab I $121 ; 213 ; 248$-52

al-Hayy I $247 \mathrm{~s}$

, al-Nīl I $234-47$; II 176; 178; 239 ; IV $10 ; 12 ; 17 ; 24$

Shillū I 200

Shīrāz II 139,3; 160

Shōrah II 306

Shu'aib Shār II $284 ; 297,2$

Shuraimiyyah I 219

Shuțaitah, Shuṭait I 56,1; 59; 60,4; II 87,$2 ; 113$

Sî, Tempel des Ba'alshamēn und des Dausara II 252,2

Siftīn I $135 ; 155 ; 157 ; 163 ;$ II 350
Sifwah I 58; 61,2; II 77

Sihl al-'Adjādjah,'Ain al-sihl I 184,5

Simnān II 159,1; 176; 229,2

Sinai II 298,$4 ; 345 \mathrm{~s}$

Sindiyyah, Sinnadiyyah II 320,

Sindjār I 7; 9-12; 34; 157; 193;

195 ; 202-04; II $159 ; 212 ; 229$;

261 ; 305-12; 316; 318s; 321;

$334 ; 355,5 ; 364$

al-Sinn am Euphrat I 171; 210; IV $3 ; 8 ; 10$

» am Tigris $=$ Shennā de Bēth Remmān I 217; II 326

n in Baghdad II 103

Sīrāf $=$ Shīlāw, Moschee II 138,5 Sittah Nafīsah, Kairo II 282,

» Ruqayyah, Kairo II 282,1

- Zainab, Sindjār II 165 und $_{3}$; 267,$1 ; 308-11$

》 Zubai Jah, Baghdad I 239; 246 ; II $114 ; 157 ; 158,4 ; 173$ bis $79 ; 181,1 ; 195 ; 255 ; 321 \mathrm{~s}$

Sīwās II 311,1

Slēm, Haurān II 298,4

Spalato II 17,2

S. Stefano Rotondo II $31 ; 345,4$

al-Șufayyah $=$ Thallaba I 189ss; 192 ss; 197

Sukair al-'Abbās = Shaddādah I $184,{ }_{3} ; 193$ s; 195s; 200

Sulaimāniyyah II 312

Sultanatspalast in Baghdad II 148; $171 ; 174 ; 249$

Sulțāniyyah II 158,3; 259

Sumaikah (Sumētshe) II 87,2

Sūq al-'Aț̣āriyyīn, al-'Atāțīr, Baghdad II 147

» al-ghazl, Minaret, Baghdad I 33 ; 44 s; 246 ; II 156-60; 164 ; $171 ; 173 ; 229 ; 253 ; 308 ; 315 \mathrm{~s}$

" al-Kharnābāt bei Baghdad II 101

, al-raihāniyyīn, Baghdad II $147 ; 192$

" al-șāghah, -șayyāghīn, Baghdad, Goldschmiedebazar II 147; 192

" al-Shuyūkh I 121; 252

„ al-thalāthā', Baghdad II 105s; 106,$2 ; 147 \mathrm{ss}$

Sūriyyah $=$ Sura I 113,$1 ; 145$ $153-55 ; 174$; II $352 ; 388$; IV 3; 8

Surp Hagop, Jakobskloster bei Qaișūm II 43,8 
Surp Hagop, Mār Yáqūb bei Urfah II 367,5

Susa I 146ss; $151 \mathrm{~s}$; II 178; 207; IV 4,$4 ; 12$

Suwaidā, Grab des Hamrath II 346 Suwwar I 157; 171; 177-79; 177,2; $183 \mathrm{~s} ; 195$; IV 5

\section{Tabarak II 153}

Țābiyat al-zāwiyah = Burdj al'adjamī Baghdad II 149,7

Tabrīz II 181; 184

Ṭābūs I $168-70 ; 180 ;$ II $321 ; 367$; IV $5 ; 11$

Tādif I $114 \mathrm{~s}$

Tahrah der Jakobiten in Mosul II

Tahrat Miryam al-'Adhrä, Mosul II $252 ; 290 \mathrm{~s} ; 293 \mathrm{~s} ; 331$

al-nadjdjārīn, Mosul II 291

Takht i Sulaimān cf. Ganzaka II 87; 89; IV 36

Takiyyah der Bektashī, Baghdad II $146 ; 319$

Takrīt I 30; 77; 204; 209; 219-31; II $105 ; 208,1 ; 239 ; 318 ; 364$; IV 10 ss; 14 ss

Talisman-Tor, Baghdad I 34-42; II $149 \mathrm{~s} ; 151-157 ; 165 ; 170 ; 174$; $177 ; 212 ; 220,1 ; 241 ; 260$

Tāmarrā cf. Nahr Tāmarrā

Tang i Saulak IV 6

Tāq i Bustān I 105,1; II 142

„ i Girrā,Zagros-Tor I 150; II 77

» i Kisrā, Ktesiphon I 81; 238; II $49 ; 59-76 ; 91 \mathrm{~s} ; 195,1$; 245 ; 324 s; 333,2; 367; IV 4

Tardjīnah $=$ Tärdjān II 312s

Tashkend II 181,1; 284

Táuq = Dāqūqã II 159,1; 210; $229 ; 318$ s; $321 ; 326 ; 328$

Tãza Khurmatū II 328

Tazaristān II 79,4;80; 88

Tell 'Adjādjah = 'Arabān I $184 \mathrm{~s}$

” A far I 182s; 188; 205-07

- al-'Alīdj, Samarra I 53s; 62; 109

»Arfād I 115s; 119,3; 137; 144

》Aswad Seleukeia II 97; 101

- abū Bakr I 192

» al-banāt bei Dūr I 54 s; 62; IV

, Bāshir ass. Til-Basheri, fränk. Turbessel I 116; 119,5

- Buṭnãn = Bathnae I 119,6

- al-dhahab in Assyrien I 210; 218
Tell al-dhahab im Dudjail I 59

» $\quad$ am Khābūr I 188

" $\quad$ in Ktesiphon 1238 ; II $57 ; 60$

„ $\quad$ in Seleukeia II 57

, Dibs = Dabausa I 131; 170,2; 189; II 307

» Djōkhā od. Yōkhā I 61,4

Duhaim II 188; 192

" Ermen II 239

- Fadgham I 182

- Gertshīn, ass. Yacudi I 115s;

" Halāf bei Rās al-'ain I 115, 116,3

» (Shaikh) Hamad I 180

- Ḥayyāl cf. 'Ain al-Ḥayyāl I 195,$5 ; 200 ; 201,1 ; 203$; II 307

Hidjnah I 176; II 386

n Husain I 179; IV 12; 16

» Ibrāhīm $=$ Kūthā I 244,3

" Ishārah = ass. Tirqa I 171; II 320,$3 ; 386 ; 391,1$

„ Kaukab I 175; 188-93

* abū Khamīrah I 206

" Khashmān I 192

- al-Khuwain I 53; 219

” Kushāf I 210ss; IV2; 8-11; 36

» Mandjūr (fälschlich $=$ Opis) I 59s; IV 3; 36

- Mannas $=$ Thelmenissos I $119 \mathrm{~s}$

„ Mästshīn, cf. al-Maskin, Bēth Mashkenē II 105,4

- Matariyyah I 188

" Midjdal=Magdalathon I 189; Turfan IV 4,4; 5,1;9,1; 17,3 II 307

, Mishnak(ah) I 188,

” Muhammad bei Baghdad II $95 \mathrm{~s}$

- Muḥașșil I 57,5; 60

" abū Muṭac I 118; IV 3

» Nu'mān = al-Nu'māniyyah I $235 \mathrm{~s} ; 243$

"Qayyārah I 206; 213

» Radjamān I 190; 192s; IV 2

„al-Riqlah I 190

Sakhariyyah I $236 ; 243$

- Shaikh Șulaib I 188

al-sha'îr = Hadīthah am Tigris I 217,4

» Shamsāniyyah I 182; 188; 195

- Suhaimiyyah I 188,7

- Tāābān I 188; 196s

, al-Thadayain $=$ Thapsakos I $136 ; 142 \mathrm{~s} ;$ IV $2 \mathrm{~s}$

„ al-nahr am Batt I 62
Tell al-Uhaimir $=$ Kish I 240,1; 246

\# Umailiḥ I 179,2

" 'Umair od. Djara'at 'Omar b. al-Khațāab, Seleukeia II 56,3

v Uwaināt II 307

Z Zädhan $=$ Zenodotion I 157; 184; II 350

- al-Zift, al-sabat I 206; II 306 und 2

Tellō II 233,3

Teppeh, Dorf am Sindjār I 204,5

Tî̉b II 207

Tibnī, Qyshlah I 164; 168

Tigris I 208-34; 247-52; II 4676 ; 103ss; 150 ; 210 ss 235; 303; 306 s; 327

Tilbis = Thelamuza II 319,3

Tirmidh II 229,2

Tōg I 199ss; II 308

Toprakkale bei Wan IV 13,2

Torcello II 279

Trapani II 273,1; 282,1

Tulūl 'Aqr $=$ Kār Tukulti-Ninib I 212s; 229; IV 1

» 'Attāif, al-'Attābiyyah, Baghdad II $114 \mathrm{~s}$

„al-mázah I 180

Tunainīr I 191; 194-96; IV 3; 10 Ṭūr 'Abdīn I 175; II 10; 21,5; 45; 277,$2 ; 296 ; 298,4 ; 299 ; 302 ; 336$; $345 ; \quad \check{\Sigma} 51,3$

Turaif I 170

Turmanīn II 7,4; 23

al-Tuwaibah, Ktesiphon II 58,1

Ṭuz Khurmatū $=$ Khānīdjār II $318 \mathrm{~s} ; 319,2 ; 326 \mathrm{ss}$

Tychaion von Șanamēn II 298,4

Ubullah, Obolla I 250s; II 394 Uiguristān II $243 \mathrm{~s}$

'Ukbarā = Buzurgshāpūr I 60; 64; II $84 ; 87,3$

Ukhaiḍir I 235; II 67,2; 93; 122,3; 123 ; 125 ; 130 ss; 135 ; 136,2; 233,$2 ; 333,2 ; 355 ; 358$

Ulu Djāmi', Karkūk II 298,3; 329s Umayyaden-Moschee, Damaskus I 92,$1 ; 98 ; 99,1 ; 100$ s; II 361

Umayyaden-Moschee, Mosul II $215 ; 232-34$

Umm al-aulād I 235; 245 s

'Uqāb (Aghab) I 60,1 
$'$ Urd $=$ gr. Oresa I 137; 140

Urfah = Edessa, al-Ruhä’ I 128;

138,$2 ;$ II $23 ; 36 ; 102 ; 208,1 ; 210$;

239; 300s; 307; 317, ; 335; 348;

355 ; 367 ; IV 37

'Uzair cf. Ezra I 64,3; 248

\section{Verona II 273,}

San Vitale, Ravenna II 233

Wādī Abdān = Abdeae I 206; II 307

” Djaddālah und al-Raqī' II 306

” al-Frātī I $196 \mathrm{~s}$

” 'Ibrah I 205 ss; II 307

" al-Mạ̣labiyyah cf. Djabal al-M. I 189,1; 206; II 307
Wădī Mu/eḥeiḥ = Umm al-shabābịt I 210,2

Warāmīn II 158,3; 176; 226

al-Wardī II 386

Warka I 162; II 132,$2 ; 233,3$; IV 4

Wāsit I $236 ; 248 ; 250$; II $49 ; 114$;

127,$2 ; 128 ; 135 ; 176 ; 207 ; 239$; 299

Wērānshahr II 32; 315,3; 347

al-Yāwan und al-Nadjmah II 306

Gr. Zāb I 210; II 87 s; 106; 312; $318 ; 326 ; 328$

KI. Zāb od. Kelwi I 217; II 88; Zubair bei Bașrah I 121; 249s; 318; 322ss

Zabad od. Qașr Zebed I 117,1; Zūnah I 235

138,$2 ;$ II 7,$10 ; 8,1 ; 9,1 ; 40$
$\mathrm{Za}^{\circ}$ farāniyyah I 66,1

Zākhō II 325; 328

Zalūbiyyah I $165 ; 166,1 ; 168$; II

125,$3 ; 365 ; 373-82 ;$ IV 8

$\mathrm{Za} /$ indān in Dastagerd I 59,$2 ; 76$; 80 s; $90-92$

$\quad$ in Samarra I 109

Zandaward II 128

Zarīn Djūi II 188; 192

Zendjirli $=$ ass. Shameal $\mathrm{I} 115 \mathrm{~s}$ 162; II 132

Zengūr, Samarra I 109

Zohāg, Rotes Kloster II 10,2; 31 ; 345

II 178,3

\section{GRIECHISCH ÜBERLIEFERTE ORTSNAMEN}

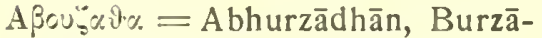
țyyah od. bùt abusātē II 86,6

Å̊rc, Anthis, Ati = Qușair Dibsī I $130 ; 155$;

Axp $\alpha \beta a t={ }^{\circ}$ A rabān I 186; IV 36

A $\lambda$ a $\alpha 9 \cdot \alpha=$ aram. Hilimtu I 151; $155 ; 159,9$

Alapeovdxpos - al-Mundhir II 41

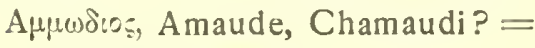
'Amūdah I 149,1

A

Avxî'w, Anatha = 'Ānah II 319; 395

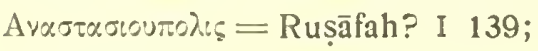

II $12 ; 36 \mathrm{~s}$

Avov\% $\alpha \varsigma=$ Khānūqah I 165; II 365; 374

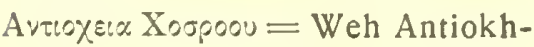
Khosrau $=$ Rūmiyah, Poylen II 48,3; 70

A $\pi \propto \mu \varepsilon เ \alpha$, A pamia $=$ Qal'at al-Mudīiq I 119,6 ; II 105,3

A $\pi \alpha \mu \varepsilon \%=$ Biredjik I 145,4

, in Sittakene II 77,1

Aro $\lambda .(\omega) \%$, Apolloniatis = Binkudrah I 69,$1 ; 150 ; 229 ;$ II $77 ; 83$

Arodo\%os = Ubullah I $250 \mathrm{~s} ; 394$

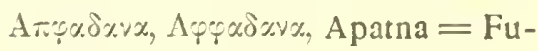
dain I 176; II 307

Ap aßic. -- ap. Arabāya II 208,

$A_{p} \alpha \xi_{\eta}, \varsigma=$ Khābūr I 174,2

Apc\% $\alpha=$ Arakh, Erech II 394

Ap $\delta \varepsilon \alpha=$ Ardakān I 152

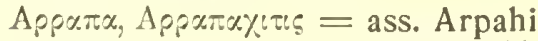
I 150

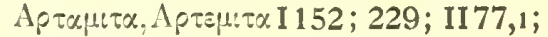
78,$2 ; 85$

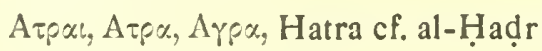
im Geogr. Index

Aur.os $\delta \varsigma$, Aladin I $149 \mathrm{~s}$

$\mathrm{B} \alpha \lambda \alpha \gamma \alpha \lambda \alpha, \quad \mathrm{B} \alpha \lambda \alpha \alpha_{\gamma} \alpha \leq \alpha, \quad " \Gamma \alpha \lambda \alpha \gamma \alpha \lambda \alpha$, ${ }^{*}$ A $\gamma \alpha \lambda \gamma \alpha \lambda \alpha=$ Qanqalesi II 395

$B \alpha \lambda \lambda \alpha \vartheta \alpha$, Banata I $149 \mathrm{~s}$

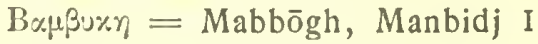
115,$1 ; 119,6 ; 128 ; 131$

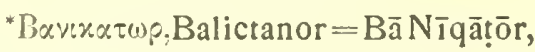
Qațrabbul I 64,1; II 77,1; 105,4; 299

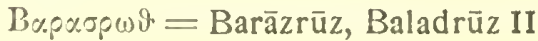
88

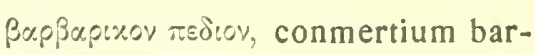
barorum II 2,2

Bupßuprosos, Barbalission, -lisso, -allissum $=$ Bālis I 119,6; 123; $128 ; 137 ; 144 ; 151 ; 155 ; 369$

Bapoxpq $\alpha_{5}$ II $86 \mathrm{~s} ; 87$,

Bapotr\% = ass. Borsippa, Birs I 151

Barvat - Bathnis, Bannis - Bathna,

Bata $=$ Tell Butnān I 119,6; 120

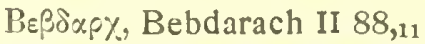

Beүخे $\alpha \lambda_{:}=$Glāl, Djalūlā II 88,6.7

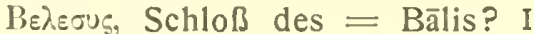
$127 ; 144$

Beppoıx - Berya, Beria - Bersera, Byrsa $=$ Aleppo I 119,6; 128

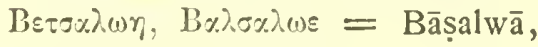
Șalwā I 59,2; 209,5

Brovay I 172

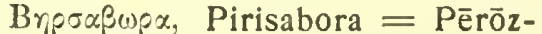
shāpūr, Anbār II 112,3

Bitoouy I 227

Bepqx, Virta = Takrīt, Citadelle I 69,$1 ; 220,1 ; 224,1 ; 227 ; 229 \mathrm{~s}$; II 105

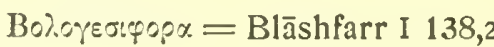

$\Gamma \alpha \delta \varepsilon\left[\rho \vartheta \alpha-{ }_{\text {LA }}^{\text {TA }}\right]$ dertha, Derta $=$ Dair al-Zaur? I $154 \mathrm{~s} ; 171,3 ; 388$

$\Gamma \alpha \lambda \alpha \beta \alpha \uparrow \gamma \alpha$, cf. Hanigalbat I 171,2

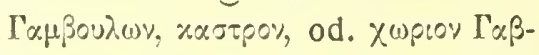
Boù $\omega v=$ Djabbūl I 119,3

$\Gamma$ w $\delta \alpha p \eta s=$ ass. Kinalua $?=$ Gindere I $116 ; 119,3$

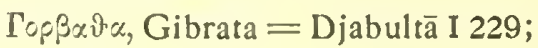
II 77,1

Topyos = Djurwān, Āb i Shirwān II 78,$2 ; 106$

Гouedsorip, Guheser $=$ Weh Ardashīr, Bahrasīr II 48,2; $52 ; 88,9$

Гuvờs = Diyālā I 61,4; II 78,2; 84,1

$\Delta \alpha \beta \times \cup \sigma \alpha=$ Tell Dibs I $131 ; 170,2$; 189; II 307

$\Delta \alpha p \delta \alpha \zeta, \Delta \alpha_{p}(\alpha) \delta \alpha \xi=$ Nahr Tarțar, Taltal I 120,1; $143 \mathrm{~s}$

$\Delta \alpha \tau \tau \alpha \gamma \varepsilon \rho \delta, \Delta \alpha \sigma \tau \alpha \gamma \varepsilon \rho \times \sigma \sigma \alpha \rho=$ Dastagerd i Khosrau II 78

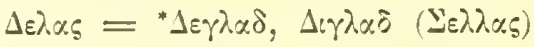

I 64,3 ; II 78,2

$\Delta \eta \mu \eta \tau p l \alpha \varsigma=$ Karkūk II $327 \mathrm{~s}$

$\Delta 0 \sigma \alpha$ II 327 


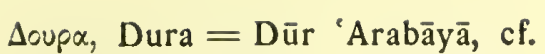

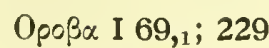

$\Delta \circ$ upov, cf. $\Theta_{\circ \rho \mathrm{p} \alpha}=$ Tāmarrā II 86,8

E $\delta \varepsilon \sigma \sigma \alpha=$ Urfah, al-Ruhā, cf. Index Geogr.

$\mathrm{E} t \vartheta \alpha$ in Batanaea $=$ al-Hìt im Haurān I 137,3

Exß $\alpha \tau \alpha v \alpha=$ Hamadān I 146s; 150

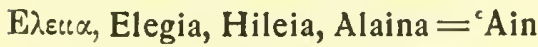
od. Tell al-Ḥayyāl I 200; 203; II 307

E $\mu \varepsilon \sigma \alpha=$ Himș, cf. Ind. Geogr.

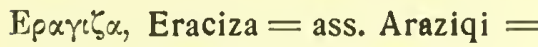
Abū Hanāyah? I $120 ; 122 \mathrm{~s}$; 123,$2 ; 128 ; 151$

Zeưนผ I $146 \mathrm{ss} ; 150 \mathrm{~s}$

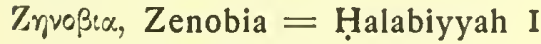
167; II $365 ; 392 ; 394$

Zñvoõotov $=$ Tell Zūdhan, Zïdān I 157,$3 ;$ II 350

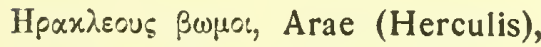
ad Herculem = Bēth Rimmōn, Bārimmā I 151; II 105,3; 307

$\Theta \alpha \lambda \alpha \vartheta \alpha \alpha=$ Sūq al-thalātha'? II 106,2.3

Exvoupts, Thannuris, Thaunaris $=$ Tunainīr I 194 s; 197

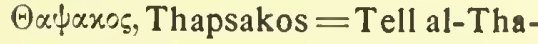
dayain I $131 \mathrm{~s} ; 142-53 ; 388$

$\Theta \varepsilon \lambda \alpha \mu \circ u \zeta \alpha, \Theta i \lambda \alpha \beta \odot u 5$, Thilutha? = Tilbis I 227,5; II 319,3

$\Theta \varepsilon \lambda \delta \eta=S \bar{q}$ al-thalāthā $=$ Baghdad II $105 \mathrm{~s}$

$\Theta \varepsilon \lambda \mu \varepsilon v \sigma_{\sigma} \circ \varsigma=$ Tell Mannas I 119,6 Oevreupte, Thegubris, Tigub(b)is I 149

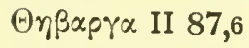

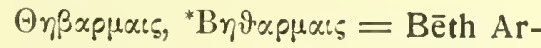
māyē II 87,6

$\Theta \circ \rho v \alpha=$ ass. Turnat $=$ Tornadotus, Tāmarrā I 57,3; II 86,8; IV 36

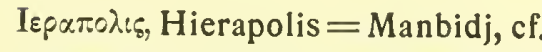
B $\alpha \mu \beta u x \eta$, I 119,$6 ; 120 ; 123 ; 128$

$\mathrm{K} \alpha \pi \rho \circ \varsigma=\mathrm{K} 1$. Zāb, Kelwi II 327,329 K $\alpha \rho \vartheta \alpha \rho \alpha=$ Brückenkopf bei Samarra, I 69,1; 227 s; II 105

$\mathrm{K} \alpha$ pev $\eta=$ Kirind I 150

Kappa, Carrhae, Charra = Harrān I $148 ; 149,2 ; 150$; II $307 ; 350$

7 SARRE-HERZFELD, Archäologische Reise. Band
Kauч̨ıx $\alpha=$ Dukūhak I 152

Kopxoup $\alpha=$ Bābā Gūrgūr II $327 \mathrm{~s}$

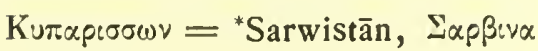
II 327

Kuppos, Kyrrhestike Qūrus I 120; 128

$\mathrm{K} \omega \times \eta, \mathrm{X} \omega \times \eta$, Cauchae $=\mathrm{Kōkhe}$, Seleukeia I 64,3 ; II 48,2

$\Lambda \alpha \beta \beta \alpha \nu \alpha, \Lambda \alpha \mu \beta \alpha \nu \alpha, \quad \Lambda: \beta \alpha \nu \alpha \iota, \quad \Lambda ; \beta \beta \alpha$, Sabbin $=$ Assur I 69,1; $227 \mathrm{ss;}$ II $77,{ }_{1} ; 105 ; 306,3$

$\Lambda \alpha p \iota \sigma \sigma \alpha=$ Nimrūd, Kalhi II 207

M $\alpha \gamma \delta \alpha \lambda \alpha \vartheta \omega \nu=$ Tell Midjdal I 189,2; II 307

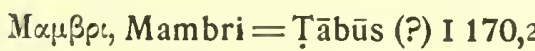

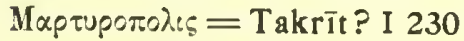

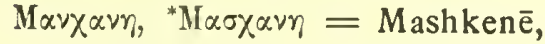
Tell Mästshīn I 69,1; 227,4; II 105

Irapparov =ass. Marqasi $=\mathrm{Mar}^{\circ}$ ash I $115 \mathrm{~s} ; 119,5$

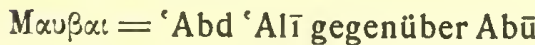
Qubai' I 150

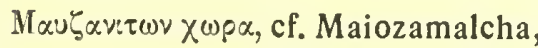
= al-Māḥūzā, Seleukeia II 48,2

Metvas $(M t v \alpha \varsigma) \Sigma \alpha \beta \alpha \vartheta \alpha(\Sigma \alpha \beta \alpha \tau \vartheta \gamma)=$ Șābāt al-Madā’in, Seleukeia II 48,2

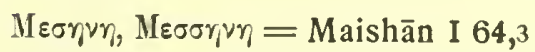

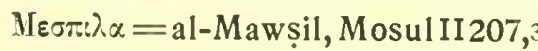

$N \alpha \beta \alpha \gamma \alpha \vartheta=$ al-Nabqah I 105,2; 172; 174,2

N $\alpha \rho \beta \alpha \xi, A_{\rho} \beta \alpha \xi$, Narbas $=$ Nahrawān II 89,2

Nrpaßos $=$ Nairab I 114 ss; 119

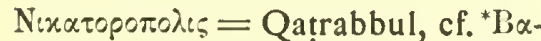

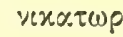

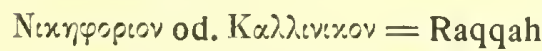
I $145 ; 147 \mathrm{ss} ; 158 \mathrm{~s}$; II 353

Nivos $=$ Ninive II $105 \mathrm{~s}$

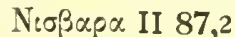

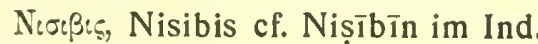
Geogr.

$\mathrm{N} \leftarrow \alpha \alpha \alpha \vee \alpha[\beta \eta,-\delta \alpha \lambda \beta \eta]=$ Mashkene I 228,1 ; II 87,2

Nocpō $\alpha=$ Djisr Nahrawān II 86

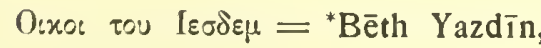
Karkūk II 88

Ope:xov opos $=$ syr.Ūrukh $=$ Djabal Hamrīn I 69,$1 ; 213,6 ; 229$

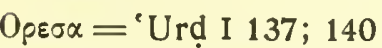

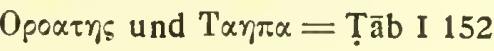

Opoßx, cf. $\Delta$ cup $\alpha=$ Dūr 'Arabāyā I 69,$1 ; 229,2$; II 106,327

$\Pi \alpha \lambda \lambda \alpha x \circ \tau \tau \alpha_{\varsigma}=$ ass. Pallukattum $=$ Fallūdjah II 387,2

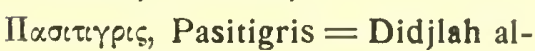
'aurā', Dudjail I 60,4; 64,3

$\Pi \alpha \propto \alpha \rho \alpha=$ Dair Hāfir ? I 120

Порбเx $\alpha,-\imath \pi \alpha=$ ass. Til Barsip I 116,$3 ; 121$

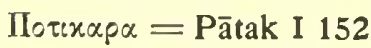

Peoctvo, Rhesaina, Ressaina, Rhisina $=$ Rās al-’ain I 148s; 197; II 307,3

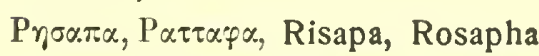
$=$ assyr. Rașap(p)a = Rușāfah I 136,3; 137-139; 139,2; II 2,2; 12

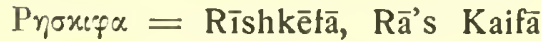
I 176,7

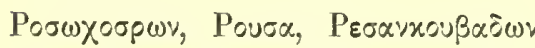
= Rūshanqubādh, Zengābād II 88,3

$\Sigma \alpha \delta \rho \alpha x \alpha \epsilon$ (cf. X $\alpha \tau p \alpha \chi \alpha \rho \tau \alpha)=$ Shahrkat $=$ Altynköprü II 327 ss

$\Sigma \alpha x \alpha \delta \alpha$ II 106

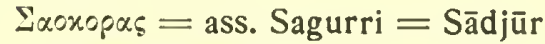
I $116 ; 119$,

$\Sigma \alpha \pi \bullet \eta \eta$, Sapphe, Sapha $=$ Bēzabdē, Djazīrat ibn 'Omar I 147ss; 230,3; II $299 ; 307,3 ; 327 \mathrm{~s}$

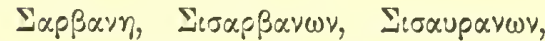
Sarbane I 148,2; II 328; IV 37

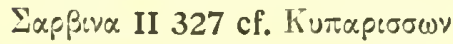

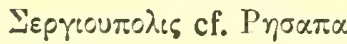

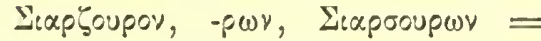
Shahrazūr II 89,3

$\Sigma_{\iota} \lambda \lambda \alpha=$ Nahr Silsil II 78,2; 85

Eıvra, Sihinnus, Sichinus $=$ syr. Shennā I 149; II 307,3

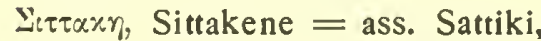
Dūr Kurigalzu? I 152; II 96; 98,2; $99 \mathrm{~s}$

$\Sigma_{x \eta \eta \alpha \iota}=$ Mashkenē od. $=$ Hīrah? I 228

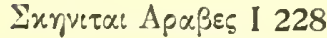

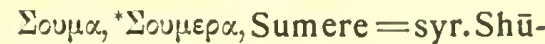
merā $=$ Samarra I 69, 1

इoup $\alpha$, Sure=SūriyyahI 137;146ss; $154 \mathrm{~s} ;$ II 2,$2 ; 388$

$\Sigma \pi \alpha \sigma$ vouX $\alpha \rho \alpha \xi=$ Karkh Maisān, Muhammerah I 251,1; II 394

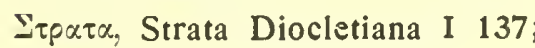
163; II 37 
Supßpav, Hucumbra = Ukbarā II $\Phi$ purı II 87,4 87,3

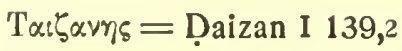

Tep $\delta \omega \nu=$ ass. Eridu I 121,$1 ; 146$; 151

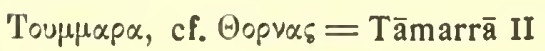
87,4

$\Phi \alpha \lambda เ \gamma \propto$ I 105,2

Фopaiou, Forat $=$ Furāt Maisān I 251,1
$\mathrm{X} \alpha \beta \omega \rho \alpha \varsigma=$ Khābūr I 174,2

$\mathrm{X} \alpha \lambda \alpha, \mathrm{Chala}=$ Hulwān cf. Albania

$\mathrm{X} \alpha \lambda \alpha \tau \alpha \rho$ II 89,3

[II 77

$\mathrm{X} \alpha \lambda x \varsigma_{\xi}$, Calcida, Chacida, Calhi, Cahi $=$ Qinnașrīn I 119,3.6; $128 ; 144$

$\mathrm{X} \alpha \mathrm{\lambda os}_{\mathrm{s}}=$ Nahr Quwaiq I 143

$\mathrm{X} \alpha \mu \alpha \eta \vartheta+\alpha, \mathrm{X} v \alpha v^{\vartheta} \alpha=$ Hnaithā, Hyparchie II 87,7
$\mathrm{X} \alpha \tau p \alpha \alpha_{\alpha \rho \tau \alpha,}{ }^{*} \Xi \alpha \tau p \alpha \gamma \alpha, \rho \tau \alpha=$ Shah $\mathrm{r}-$ gerd, cf. " $\alpha \delta \rho \alpha x \alpha:$ = Altynköprü II 327,$2 ; 328$, 1

$\mathrm{X} 0 \lambda . \lambda \eta=$ Sukhnah II 394

$\Omega \pi t \varsigma=$ ass. Upi-Kēsh I $60 ; 146$

II 46,$3 ; 77 ; 327$

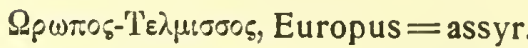
Karkhemish $=$ syr. Aghrīpōs, ar. Djarābīs, I 145,4; 151

\section{LATEINISCH ÜBERLIEFERTE ORTSNAMEN}

Abdeae $=W \bar{a} d \overline{1}$ abdān I 206; II $306 \mathrm{~s}$

Achaiachala, *Achalchala II 395

Albania = Hulwān I 69,1; II 77,1; 328

Apamea Mesenes I 64,3

Arzanene $=$ Arzōn II 299

Aturia Āthōr, Diözese II 207s; 299

Belnar, Bellum = Ar-bela II 328s

Biturs, Praetoris II 328

Carcha, Charcha, Charca, Charra $=$ Karkh Fairūz I 69,1; 229; II 77,1

Castra Maurorum $=\mathrm{Kafr}$ Tūth I 149,1

Castrum Circensium I 172-74; II 307

Charra = Harrān I 148-50; II 307

Concon, Congo $=$ Korkura $=$ Bābā Gūrgūr II 328,1

Ctesiphon, Cesiphun I 228s; II $46-76 ; 77,1$

Dagala $=$ Khān Djudāl, Dadjdjāl II 307,3

Danas II 328s;

Dezeridan $=$ Darzan̄̄dān II 88,2

Diabas und Adiabas $=$ die beiden Zāb II 78,2

Diacira, ${ }^{*}$ Idacira $=\mathrm{H}^{\top} \mathrm{t}$ II 395
Diothazi, -e, Adiazane I 155; II 388 Fons Scabore I 191; 198; II 307 Gabbula $=$ Djabbūl I 119,3

Garamaea = Bēth Garmai II 299 Izala mons $=$ Tūr 'Abdīn II 299

Lacus Beberaci = KhātūniyyahSee I 191; 198; II 307

Macepracta $=$ Mābhrakhtā - Māibahradj II 2,2

Maiozamalcha $=$ Māhōzēe de malkā II 48,2

Mesene $=$ Maisān I 64,3

Naharra I 155,2; II 388

Nisistu II $328 \mathrm{~s}$

Oroba $={ }^{'}$ Arabān I 186; 195; II 307

Paphenses equites $=$ Tell Fāfän $=$ Til I 148,2

Peloriarca I 229; II 77,1

Phaeniche $=$ Finik I 230,4

ad pontem II 306s

Praetavi Arabes I 203

Rhamma flumen, Rum = Rādhān? II 328 und 2

Roschirea, Vesceria I 149

Sahal $=$ Tell Sahal I 148s

Seleucia babylonia I 64,$3 ; 227$ s; II 327

Sepe, Sephe $=$ Siffīn I $155 ; 163$
Seriane $=$ Sūriyyah in Syrien $136 \mathrm{~s}$

Siher $=$ Shahrqat $=$ Altynköprü II $328 \mathrm{~s}$

Singara, kurd. Shingār, Sindjār I $197 ; 202-04 ; 206 ; 227$; II 105; 306

Sirgora = Singara II 307

Thallaba $=$ Brücke bei Șufayyah I 191 ; II 307

Tharrana, Tarana I 149

Thelser: Zelfir II 328.

Thiltauri, Phaltauri I 119,6

Thubida $=$ Shaikh Manșūr I 191 ; 197; II 307

Tigrim, ad flumen II $306 \mathrm{~s}$

Tilsafata I 206; II 306

Titana flumen, Thionas = Diyālah ? II 328 und 2

Tornadotus, cf. gr. Thornas u. ass. Turnat I 57,3; II 78,2; $84 ; 86,8$; 87,3

ad Ur $=$ Äthūr, Assur II 306,3

Vica II 328

Vicat II 307

Vologesias, Vologesocerta, Volocesia II 47,$10 ; 388 ; 394$

Zagurae I 206; II 306s

Zogorra II 307

\section{ALTORIENTALISCHE ORTSNAMEN}

'Aqalqalā, 'Aqanqalah II 395

Arpad $=$ Tell Arfād I 115 s; 119,3; $137 ; 144$

Bā-'alwāthā (= Bait al-așnām) = Batāwād II 312

baghōdāta, bagadāta, etc. II 104 u. 9 Bēth Armàjè I 61,4

" Germē $=$ Bādjarmā II 331

" h̆ōmesh = Bāḥamshā $=A b u ̄$ Hamshah II 86,1
Bēth khudēdā II 312; IV 37

» Lapaṭ = Gundēshāpūr II 299

* Mashken $\overline{\mathrm{e}}=$ al-Maskin II 105,$4 ; 299$

n Nīqātōr $={ }^{*}$ Nikatoropolis II 77,$1 ; 105,4 ; 299$

n Qatrājēe $=$ Qațar,Baḥrain II299

" $\operatorname{Re} / \mathrm{immā} / \bar{o} n=$ Bārimmā I 213s; II 105,2; 307

, Tittā II 330
Bēth Wāzīq = Bawāzīdj = Mbā'ūsiyyah I 217,5; II 315

Zabhdai $=$ Bezabde $=$ Djazīrah II 299

Dasqartā dě malkā = Daskarat almalik II 78,$4 ; 79$

Dūr Kurigalzu = 'Aqrqūf II 87,2; 97-102

E-girim II 97s; 101

E-temen-anki II 98,1 
Hana und Hanigalbat I 171,2; II Khalpa, Khalwan = Aleppo I 116; Shennā de Bēth Remmān = Sinn 386

118

Harmiš $=$ Nahr Hirmās I 190,3; $193 \mathrm{~s}$

Hesnā 'Ebhrāya $=$ Mosul II 208; 300

hinqu ša Purattē I 165,4; II 374

Kār Tukulti-Ninib (Tuklat-Nimurta) I $212 \mathrm{~s}$

Kermesh $=$ Karamlīs II 312
Khazazu $=A^{\circ} z \bar{a} z$ I 115s;119,2; 144

$\mathrm{Kinza}=\mathrm{Kil}(1) \mathrm{iz} \mathrm{I} 116 ; 119,1$ maškanātē ša mât Utưātē II 87,2 Patin I 116

Pithor $=$ Pitru I 116

nâr Râdânu I 57,3; II 192

Raqiqu und Rapiqu I 159,9

Sat-ti-ki $=$ Sittake II 98,2; $99 \mathrm{~s}$
I 217

Slīq ḥarūbhtā $=$ Seleukeia II 47,6

Teghrīth $=$ Bīrthā $=$ Takrīt I $227 \mathrm{~s}$

Til-Bašeri $=$ Tell Bāshir I 116; 119,5

Tirqa $=$ Tell Ishārah II 386

Unqi $=$ al-'Amq I 116;119,2; 144

Ya'udi $=$ Tell Gertshīn I 115s 


\section{HISTORISCHER INDEX} Haidjā

'Abdallāh b. Muhriz, Architekt II 117,9

'Abd al-'azīz, Umayyade II 301

'Abdul'azīz Khān, Sultan, Osmane II $162 \mathrm{~s}$

'Abd al-malik b. Marwān, Umayyade I 242s; II 143,2; 301

'Abdulqādir Gīlānī II 197

'Abdurrahmān Pasha, Baghdad II 172

abū Djåfar cf. al-Manșūr abū Dulaf cf. Dja far al-Barmakī abū l-Haidjā 'Abdallāh b. Hamdān II 210

abū Hanīfah, Imām II 117,9; 118

abū Hurairah I 132,2

abū Kalindjār cf. 'Imād al-dīn

abū Sa î̃d, Sultan, Îlkhān I 45; II $197 ; 210,3$

abū Sa T̃đ Sulaimān II. Pasha Baghdad II 157

abū 'Ubaidah I 128

Adad-nirari III. I 116; 224; II 103

'Aḍud al-daulah, Buyide II 191; 383,2

Afshīn Khaidar b. Kà̄ūs al-Ushrū$\operatorname{san} \overline{1}$ I 82

Ahmad Djalair, Sultan II 149s; 156 ; 196

A ḥmad Shāh al-Tabrīzī Zarīnqalam II 183,$1 ; 189$

Ahmad b. Tulun I 103,1; 128

'A'ishah, Gattin des Propheten II $284 \mathrm{~s}$

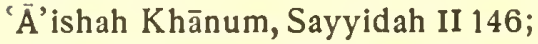
174

'Alā al-dīn Kāiqubādh, Seldjuke 260,$1 ; 287,1$

'Alā al-dīn Muḥammad, Khwārizmshāh I $36 ; 40 \mathrm{~s}$

Alexander d. Gr. I 144 ss; 159 ; II 327; 388

'Alī b. abī Ṭālib, Khalif I 159; 250; II $285 ; 311,2$

'Alī b. Mālik b. Sālim, 'Uqailide I 120

'Al̄̄ al-Riḍā, Imām I 32

Áliden-Genealogie I 231,7; II 193; 250 s; 264
Alp Arslan, Seldjuke II 160

Amīn b. Hārūn, Khalif II 111; 117,$2 ; 173$

Amīn al-dīn Mirdjān I 47 ss; II 181 bis 90

'Ammār b. Yāsir, Prophetengenosse I 157; II 350

Anahit II $327 \mathrm{~s}$

Anastasios, Kaiser I 139; II 12; 37

Antiochos I. II 47

Antiochos III. I 69,1; 213,6; 229; II 47

Antiochos VII. II 47

Āqā Muhammad Shāh Qadjar II 146

Aqsonqor, Vater des Zengi II 363 Aqsonqor al-Bursuqī II 206

Ardashīr I. Pāpakān I 251,1; II 52; 76; 208

A rghun, Sultan, İlkhān I 46; II 181; 275

Arik-dēn-ilu I 116

Arsakes VI. Mithradates II 47

Arslan al-Basāsīrī II 383,3

Asad al-dīn Shīrkūh II 383,5

Ashnās I 67; 69,

al-Așma î I 139,1; 140

Asurdān I 116

Asurirbi I 116

Asurnāșirpal III. I 1 16; 136,3; 154,2; $165 ; 208$; II $103 ; 313 ; 373 \mathrm{~s} ; 387$ Asur-rēsh-ishi I 116

Athanasius der Germaeer II 301

Augēn, Mār (Eugenios), Mönch aus Klysma II 345

Avidius Cassius II 47s; 52

Badr al-dīn Lu'lu' I $6 ; 10 ; 12 ; 15 \mathrm{~s}$; 18-21; 28; 30; 186s; 205; 211 ss; 220,$1 ; 226 s ; 234$; 238-70; 277; 282; 292ss; 295; 302; 305; 311

Bahā al-daulah b. 'Adud al-daulah, Buyide II 383,3

Bahlūl Dānā, Wahb b. 'Amr al-Kūfī II $180 \mathrm{~s}$

Bahrām II. II 285

Bahrām IV. Kirmānshāh II 93,1

Bahrām V. Gōr II 332

Baibars, Sultan, Mamluke II 211; 213,$3 ; 384$
Baidu Khān, Mongolenkaiser II 302

Barqūq, Sultan, Mamluke II 149; 156

Bayazīd, Sultan, Osmane II 149

Benjamin von Tudela I 128; 303

Bilgä i mulk Khātūn II 286

Būdh-Ardashīrānshāh II 208

Burnaburiaš II 98,2; 100

Caracalla I 228,8

Carus, Kaiser II 48

Constantin d. Gr. I 141; 184

Constantius, Kaiser I 200; 203

Crassus II 47; 350

Cyprianus, Metropolit von Nisibis II 343 und $_{3} ; 344$

Dabbāghzādah Dā'ūd Tchelebi II 209,8

Dābowai, Mār, Katholikos II 332

Dādīshōó, Mār, Katholikos II 332

Daniel = Beltsazar, Prophet II $288 ; 303 ; 330$

Dareios I 144; II 166,2; 327; 374

Dà'ūd Pasha, Baghdad II 146

Demetrios II. II 47

Diocletian I 137; 170,2; 174

Dja far abū Dulaf al-Barmakī I 52,1

Djafniden, Ghassaniden II $37 \mathrm{~s} ; 41 \mathrm{~s}$

Djalāl al-daulah, Buyide II 70,1; $173 ; 383,3$

Djalāl al-dīn Mangbarti, Khwārizmshāh II $318 \mathrm{~s}$

Djamīlah bint Nāṣir al-daulah Hamdān II 206

Djingiz Khān I 129; II 202

Djunaid, Șūfĩ II 114; 179; 320,3

Eratosthenes I 146ss; II 327; 388 Ezechiel, Chaldäischer Patriarch II 208

Ezra, 'Uzair, Prophet I 248

Ezra, 'Abednego od. Asarja II 330

Gallienus, Kaiser I 159

St. Georg, al-Khiḍr, Elias, Djirdjīs I 13,$1 ; 26,1 ;$ II $146 ; 211 ; 235$ s; $295 ; 296,1$

Ghiyāth al-dīn Maseūd, Seldjuke I 17 ; II 148

Gökbüri cf. Muzaffar al-dīn 
Gordianus, Kaiser I 203

Gregor abū'l-Faradj Barhebraeus

II $300 ; 303 ; 335$

Gümüshtekin II 282.1

Habr al-Umawī II 236s; 238,1

Ḥadjdjādj b. Arțāt, Architekt II 113; 117,$9 ; 135$

Hadjdjādj b. Yūsuf I 242,1; II 127,2; $128 ; 135 ; 311,2$

Hadrian I 228,8; II 48

al-Ḥākim bi amr Allāh, Fatimide II 274

Hallādj, Sūfī II 320,3

al-Hārith b. Djabalah, Ghassanide II $13 ; 37 \mathrm{~s}$

Harthamah b. 'Arfadjah II 209; 232

Hārūn al-Rashīd I 62s; 91,1; 107; $128 ; 160$ ss; II 63,$1 ; 93 ; 109 ; 132$; $136 \mathrm{~s} ; 148 ; 173 ; 180 ; 353 ; 356$; 359; 382

Hārūn al-Wāthiq I 65 ; II 117,6

Hasan III. Asssassinen-Großmeister I $40 \mathrm{~s}$

Ḥasan Dāmghānī, Sarbadaride II 158,3

Hasan Pasha, Baghdad II 174; 181,

Hĕnân-Î́shōe I., Chaldäischer Patriarch II 206; 292

Herakleios II 15,$3 ; 87,5 ; 88$ s; 90 s; 208

Hipparchos, Geograph I 146ss

Hishām b. 'Abd al-malik, Ummayade I 139; 160

Hiuen Tsiang II 117,8; 252,2

Hormuzd I., Hormizdas II 82; 93

Hudhaifah b. al-Yamān, Prophetengenosse II 59,1

Hulagu II $145 ; 149 ; 156 ; 181 ; 202$; $211 ; 302 ; 384$

Hunain, Hananja = Sadrach, Mann im feurigen Ofen II 330

Husain Pasha, Baghdad II 146; 196,1

Ḥusām al-daulah al-Muqallad, 'Uqailide II 210; 318

ibn al-Athīr, 'Izz al-dīn II 210,2; $224 ; 287$

ibn Hubairah II 84

ibn Khallikān b. Muḥammad b. Ibrāhīm II 318

ibn Shaddād, Bahā al-dīn II 210,2 Ibrāhīm Inal, Seldjuke II 383,3

Ibrāhīm b. Ishạq II 111
Ibrāhīm b. Muḥammad al-Fazārī II 117,9

Ilaldi, Inalide II 282

'Imād al-dīn abū Kalindjār II 383,2 'Imād al-dīn Zengi b. Aqsonqor II $210 ; 282,1 ; 363 ;$ IV 37

'Imrān b. 'Alī II 147

'Imrān b. al-Waddāh, Architekt II 117,9

Isidoros von Milet, Architekt I 128; 167 ; II $365 ; 373$

Ismāīl I. al-Ṣafawī, Shāh II 145 ; 192 s; 202

Īshō-yahbh II. von Gedhālā, Patriarch II 208; 300

İshō‘yahbh Bar-Qūsrā II 208; 291 Izz al-dīn Mas'ūd I. b. Maudūd, Zengide I 16 ; II $210 ; 236,1$; 282 s Iyāḍ b. Ghanm I 159; 203; II 300; 353

Jacobus Baradaeus II $37 ; 42$ Jacobus von Nisibis II 337; 343

Johannes von Byzanz, Architekt I 167; II 365; 373

Johannes der Täufer II 311,3; 312 Joscelin, Graf von Edessa I 116

Jovianus, Kaiser I 203; 206; II 338; 344

Julianus Apostata I 203; II 48; 86,$5 ; 133 ; 306 ; 338 ; 388$

Justinian I 124s; 138; 159; 165 ; $167 ; 174 ; 195 ;$ II $13 ; 22 ; 37 ; 70$; $365 ; 381$

Justinus, Kaiser II 37,1; 42

Kāiqubādh cf. 'Alā al-dīn

Kallinikos, Sophist I 159

Kawādh I 119,3; 155; 159; 230

Kāẓim al-Dudjailī II 262,1

Kāzim Pasha II 146s; 174

Khalīl Sulțān, Timuride II 149

Khosrau I. Anōsharwān I 61; 138; $167 ; 174 ; 203$; II $49 ; 70 ; 76 ; 93$; 365

Khosrau II. Parwēz I 128; $138 ; 155$; $159 ; 167 ; 203,8 ;$ II $34 ; 38 ; 78$; $82 ; 87 ; 90-93 ; 102 ; 208 ; 365$

Khosrō Pērōz, al-Malik al-raḥ̄im, Buyide II 383,2

Kisrā II 75s; $80 ; 86,3$

Kurigalzu II 97ss

Kyros II 84,1

Lakhmiden von Hīrah II $37 \mathrm{~s}$

Leo II. Thrax, Kaiser I 159
Ma'bad b. al-'Abbās al-Hāshimī II 363

Mahdī b. Manșūr, Khalif I 160; II 136,$2 ; 356 ; 361$

Mahmm̄̄d, Inalide I 81,1

Maḥmūd b. Sindjārshāh, Zengide II 270

Mahmūd II., Sultan, Osmane I 29s Makkīkhā, Katholikos II 156; 302 Mālik b. Tauq al-Taghlabī II 382

Malik al-'ādil Saif al-dīn abū Bakr, Ayyubide I $2 ; 10 ; 17 ; 126 ; 128$; II $210 ; 212 ; 224 ; 235 ; 303,1$

Malik al-mu'ayyad Shaikh, Mamluke II 213,3

Malik al-nāṣir Șalāḥ al-dunyā wa'1dīn cf. Saladin

Malik al-saeid Nadjm al-dīn Ghāzī I., Ortoqide II 302

Malik al-șālih Ismāê̄l, Zengide II 211

Malik al-șālih Nāșir al-dīn Mạ̣mūd, Ortoqide II 247,2; 248

Malik al-șālih Salāḥ al-dunyā wa'ldīn, Mamluke II 247,2

Malik al-žāhir Ghāzī I 2,2; II 172,4; 213,$3 ; 287,1 ; 355 ; 384,2$

Malikshāh II 2,2; $82 ; 159$ ss; 164 's; $217 ; 273,1 ; 274 ; 384$

al-Ma'mün, Khalif II 109; 285; 382 Mangbarti cf. Djalāl al-daulah

al-Mansūr, abū Dja'far, Khalif I 91,$1 ; 160$ s; II $49 ; 63 ; 76 ; 93 ; 104$; $106-24 ; 352 \mathrm{~s} ; 356 ; 360 \mathrm{~s}$

Marco Polo II 189; 194; 202s; 302

Marcus Aurelius und Lucius Verus I 159; II 47

Mārōn, Mār, Bischof von Karkh Slōkh II 332

Ma'rūf b. al-Fairūzān al-Karkhī, Shaikh II $105 ; 172,4$

Marwān II. b. Muḥammad, Umayyade II $209 ; 232 ; 234$

Māshallāh, Astronom II 118

Mas'ūd b. Maudūd cf. 'Izz al-dīn

Maudūd b. Zengi b. Aqsonqor I 4; II 235

Maurikios, Kaiser I 138; 159; 174 ; 203; II $34 ; 36 ; 38 ; 102$

Midhāt Pasha II 150

Mihrnarseh b. Burāzah, vazurk framatār II 332s

Mikhailghazizadeh Mẹmet Nuzhet Pasha II 330,2

Mirdjān cf. Amīn al-dīn 
Mithradates d. Gr. II $46 \mathrm{~s}$

Mu'ādh b. Djabl I 198

Mu'āwiyah. Umayyade II 285

Mudjāhid al-dīn Qāimāz II 211;

$215 ; 236 ; 249$

Mughīth al-dīn Maḥmūd, Seldjuke II 206

Muhammad 'Alī al-Nūrī al-Húusain̄̄, Sayyid II 224

Muhammad al-Badr b. Mūsā alKāẓim I 222

b. Mūsā al-Kāẓim, Shaikh Hadīd II 321 b. al-Khalf al-Waki $\overline{1}^{\mathrm{e}}$ II 117

Pasha al-Khāṣakī alSiliḥāre II $143 \mathrm{~s}$

" Khwandamīr? II 288

" al - Khwārizmī, abū 'Abdallāh, b. Mūsā II 107,1 und $4 ; 117$

b. Mūsā, abū A Abdallāh Imām Dūrī I $31 ; 231$; II 147

" Tāqī al-Djawād, Imām II 145

Mu'izz al-daulah, Buyide II 117,2; 173

al-Muktaf $\overline{1}$, Khalif I 44 ; II 63,$2 ; 76$; $156 ; 159$

al-Mundhir b. al-Hārith, Ghassanide II $38 ; 41 \mathrm{~s} ; 130,3$

Mūnis, Amīr al-djaish II 148

Munkir und Nakīr II 283,1; 285

al-Muntașir, Khalif I 65; 69

al-Muqallad cf. Husām al-daulah al-Muqtadir, Khalif I 64,$1 ; 81,1$;

II 213

al-Muqtadi, Khalif II 156

Murād III. Sultan II 198; 326

IV. „ I $29 \mathrm{~s} ; 38 \mathrm{~s}$; II $150 ; 212 ; 213$

Mūsā al-Kāẓim, Imām I 31; II 145 Mushēsh-Ninib, von 'Arabān I 186 Muslim b. Quraish cf. Sharaf aldaulah

al-Mustadī, Khalif II 149,3

al-Musta'īn, Khalif II 148; 150; II 382

al-Mustandjid billāh, Fatimide II al-Mustanșir billāh, 'Abbaside I $42 \mathrm{ss} ; 64 ; 157 ; 158,5 ; 161 \mathrm{ss} ; 172$; $175 ; 201,2 ; 227 ; 249 ; 318$

al-Mustanșir billāh, Fatimide II 219,4
al-Musta șim, Khalif II 59,2

al-Mustazhir, Khalif II 148s

al-Mu'tadid, Khalif I 91,1;92; 128; 139 ; II 63,$2 ; 76 ; 85,7 ; 104 ; 107$; $136 ; 143 ; 190$

al-Mu'tamid, Khalif I 82 s; II 107,1 al-Mu'tașim, Khalif I $65 ; 83 ; 87$; 107; II 93; 132

al-Mutawakkil, Khalif I $62 \mathrm{~s} ; 65 \mathrm{ss}$; 69ss; 87 ss; 139; II 143,2; 190; 301

al-Mu'tazz, Khalif I 69,1 ; II 148 ; 382

al-Muwaffaq I 83

Muzaffar al-dīn Gökbüri, Begtinide II 316,$1 ; 317 \mathrm{~s}$

Nabonid II 98,2

Nādir Shāh Afshār II 209; 211s; $271 ; 290 ; 293 ; 300$

Nadjm al-dīn Ghāzī I. cf. Malik al-sa'id

Nafīsah, Sittah, Umm al-arbaein I 224

» in Kairo II 282,1

Nahum ha-Alqōsh̄̄,Prophet II 303,2

Nāsir al-daulah abū Muhammad Hasan, Hamdan II 206; 210

Nāṣir li dīn Allāh, Khalif I 35 ss; 40 ss; II $146 ; 149 \mathrm{~s} ; 154,2 ; 156$; 158,$5 ; 171 \mathrm{~s} ; 174 \mathrm{~s} ; 177 ; 224,1 ; 227$

Nebukadnezar, Bukhtnasar I 224; 227; II 55s; 104; 113,3; 146; 311,3

Nikephoros, Kaiser I 162; II 359

Nizām al-mulk II 160s; 273,1; IV 36

Nūbakht, Astronom II 117,9

Nu'mān b. Hārith b. Aiham, Ghassanide I 138 ; II 38

Nūr al-dīn Maḥmūd b. Zengi I 4 ; $17 \mathrm{~s} ; 98,2 ; 133 ; 158 ; 233$; II 154,2 ; $156 ; 161 ; 164 \mathrm{~s} ; 210 ; 218 ; 220$; 223ss; 232; 234 ; 239; 241,1 251 ,2; $260 ; 263 ; 270 ; 272 ; 279$ s; 287 ; 303,$1 ; 359$ s; 363; 383; IV 21; 37 Nūr al-dīn Muhammad, Ortoqide II 247,2

Obadiah, Prophet II 303,

Odainathos von Palmyra II 48

Odoric di Pordenone IV 37

Ogotai Khān, Mongole II 189

Oltshaitu Khorbandah (Uldj.,Oldj., Oltsh.) I $46 \mathrm{ss}$; II 158,3 ; 163, und $4 ; 182,2 ; 188 \mathrm{~s} ; 198$
'Omar b. al-Khațāb, Khalif I 128; 250; II 59; 208; 283; 300

'Omar b. al-Djund al-Ghaffārī I 222

Önör, Amīr II 282,

'Othmān, Khalif I 128; 250; II 59

'Othmān, Sultan I 135

Paulus, Mafrian von Takrīt II 343,3

Pērōz II 332

Phokas, Kaiser I 167

Phraates II. II 47

Pīr Zekker, Imām, Zacharias I 203,3; II $311 \mathrm{~s} ; 311,3$

Ptolemaios I 69,1; 119,1 und 6;123; $128 ; 130 ; 137 ; 147-53 ; 155$; $171 ; 176 ; 186 ; 201$; 203; 227; 230; II 105s; 327s; 388; 394

Qaḥțabah II 84

al-Qā'im bi amr Allāh, Kalif II 192; 383,3

Qāimāz cf. Mudjāhid al-dīn

Qanbar 'Alī I 203; II 311

Qānșauh al-Ghūrī, Mamluke II 384,2

Qara Arslan, Ortoqide II 282,1

al-Qarabulī, Șalghar-Turkmene II 318

Qubilai Khān, Kaiser von China II 189

Qunghur oder Qunghuruz II 193 Quraish b. Badrān b. Muqallad, Uqailide II 383,3

Qutb al-dīn Muhammad I 9s; 202; II 308

Qylydj Arslan II, Seldjuke II 146

Rabāh, Architekt II 108s; 118; $121 \mathrm{~s} ; 127$

Rashīd al-dīn II 190 und 3

Ravennate, der Anonymus I 119,6; $123 ; 128 ; 130 ; 137 ; 155 ; 171$; II 307,$3 ; 328 \mathrm{~s} ; 388$

Rōzbih Buzurgmihr II 139,2

Sa'd b. abīl-Waqqās II 49 Sa'īd b. 'Abd al-malik, Umayyade II 209

Så̄id b. 'Āmir b. Djidhyam (Hudhaim) I 161; II 353

Saif al-daulah, Hamdanide I 128; 140

Saif al-dīn cf. Malik al-'Ādil

Šagaraktišuriaš II 98,2 
Saladin, Malik al-nâșir Șalāḥ aldunyā wål-dīn II 161; 210; 267,$1 ; 311,1 ; 317 ; 362 ; 383$

Șalāḥ al-dīn (Saladin) II., Ayyubide II 302

Salīm I., Sultan, Osmane II $197 \mathrm{~s}$

Salmān Pāk II 52; 58s

Salmanassar I. I 116; II 98,2

Salmanassar II. I 116

Salmanassar III. II 132,6

Šamši-Adad I 171

Sanherib I 116; 137; II 132,6

Sardanapal, Sardana, Asurbānipal II 332

Seleukos Nikator II $46 \mathrm{~s}$

Seleukos III. Keraunos II 47

Semiramis II $103 ; 374 ; 381$

Septimius Severus I $155 ; 159 ; 203$;

227,$5 ; 228$; II 47 s; 341,2

St. Sergios I $137 ; 138,2 ;$ II $1-45$

Shāhrokh, Timuride II 189

Shaikh 'Ā dĩ II 312

Shaikh Hadīd cf. Muhammad b. Mūsā

Shaikh Ḥasan Djalair, Buzurg I 45 ss; II 181

Shaikh Shiblī, abū Bakr Dulaf I 168 s; 198; II 320,3

Shaikh Uwais, Sultan, Aqqoyunlu I 16,$1 ; 45$ ss; II $181 ; 211 ; 288 ; 350$

Sharaf al-daulah Muslim b.Quraish, Uqailide II $147 ; 210 ; 273,1 ; 320$ s; 383,3

Shāpūr I. I 230s; II 76; 311,3337 Shāpūr II. dhū'l-aktāf I 200; 203;

II $76 ; 86,6 ; 105 ; 195 ; 311,3$

Shērōë II 89

Shihāb b. Kathīr, Architekt II 117,9

Shihāb al-dīn 'Omar al-Suhrawardī II 179

Shim ān al-Yahūdī I 235,1

Shīrīn II $80 ; 88$
Shīrkūh cf. Asad al-dīn

Shishrawān II 104,9

Sinān Pasha Cicala-oghlu II 198

N. Siouffi I 16

Slībhāzkhā, Bischof von Ṭīrhān II 343,3

Stratonike II 47

Sulaimān I., Sultan, Osmane II 145; 198; 202; 350

Sulaimān Pasha Buzurg II 174

Surkhāb b. Badr II 318s

Tabula Peutingeriana I 69,1; 119,6; $123 ; 127 \mathrm{~s} ; 130 ; 137 ; 155 ; 171$; 191 ; 197 ; 201 ; 206 ; 229 ; II 77,1 ; 306 s; 328s; 388

Tahmasp, Shāh, Safawide II 271

Tahmūraf II 97,2; 132,4

Takash, Khwārizmshāh II 153

TTalhah b. 'Uhaidallah I 250

Tancred von Antiochien I 128

Tiglathpileser I. I 116; II 98,2

$$
\text { III. I. } 116
$$

Timur Leng I 231 ; II 117,$8 ; 138$; 143,$2 ; 144 ; 149 ; 156 ; 202$; 206; $211 ; 238 ; 271 ; 326 ; 384$

Toghrulbeg I. Seldjuke II 84

$$
\text { ॥II. II } 153
$$

Toghtekin II 282,1

Trajan I 203; 206; 228; II 47s

Tshuban, Tshopan, Amīr I 46; II 181

Tuklat-Nimurta (Tukulti-Ninib) II. II 98,$2 ; 100 ; 387$

Tutush, Mālik Tādj al-daulah, b. Alp Arslan II 161; 272; 273,1

'Ubaidallāh al-Mahdī, Fatimide II 132,5

Ubayy b. Ka"b od. b. Qais I 157; II 350
Umēdh b. Ashwahisht, Mōbadh II 63,$1 ; 76,4$

'Utbah b. Farqad I 231; II 208; 300

Uwais b. 'Āmir al-Qarañ̄ I 16; 157; 198; 288,2; II 349s

Uwais, cf. Shaikh Uwais, Sultan

Uzun Hasan, Aqqoyunlu I 18,2 und ${ }_{3}$; II $211 ; 226 \mathrm{~s} ; 237$

Uzun Ibrāhīm Pasha II 144

Volagases III. II 48

Volagesos, Bischof von Nisibis II $337 \mathrm{~s} ; 342 \mathrm{~s}$

Wābiṣah b. Ma'bad al-Asadī I 157; II 363

Wartman II 187,1

al-Wāthiq cf. Hārūn

Xenophon I 120,1; 127; 143; 174,2; II $207 \mathrm{~s} ; 388$

Yahyyā b. al-Qāsim b. Ḥasan, Imām II $249 \mathrm{~s}$

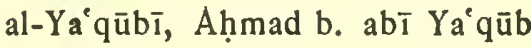
II 116

Yazdegerd I. und II. II 332

Yazdīn II 88

Yaziden I 199s; II 308,1; $311 \mathrm{~s}$; 3113

Yisun Timur, Kaiser von China II 181

Yûsuf al-Mallāh II 383

Zainab bint ${ }^{e} A l i ̄$ I $10 ; 203$

Zākir von Hamāt I 115

Zengi cf. 'Imād al-dīn

Zeno, Kaiser I 124 ; II $7 ; 33 ; 345,3$

Zenobia, Septimia, Bath-Zabbai,

Zabbā I 167; II 350; 365

Zubaidah II 110s; 173

Zubair b. 'Alwān I 250 


\section{TECHNISCHER INDEX}

Altarabische Kultstătten (nabataeische Tempel) II 252,2; 298,4;

Altäre II 268; 277; $292 \mathrm{ss;} \mathrm{296s;}$ 333; 339

Ambonen II 294; 299

Apotropaeische Bilder I 13,1; 38, 3-6; II $147 ; 153 ; 212 \mathrm{~s} ; 268$; $270 ; 294 \mathrm{~s}$

Arabesken und Ornamente II $141 \mathrm{~s}$; $153 \mathrm{~s} ; 158 ; 164 \mathrm{~s} ; 168 ; 170 \mathrm{ss}$; 175 s; $184 \mathrm{~s} ; 216-24 ; 226 \mathrm{~s} ; 230 \mathrm{~s}$; 237 ; 241；243-49; 260-263; 265; 267s; 270s; 275s; 280;285s; 292 s; $295 ; 309 ; 3350-53 ; 360 ; 372$

Aramaeische Nomenclatur (und altarabische) I $118 \mathrm{ss}$; II $207 \mathrm{~s}$; 207,$1 ; 395,5$

Arcosolien und ähnliche Gräber II $334 \mathrm{ss} ; 366$

Assyrische Inschriften I 186; 224; II $55 \mathrm{~s} ; 96 ; 312 \mathrm{~s}$

Baptisterien und Taufkapellen II $31 ; 293,5 ; 299 ; 301 ; 337-46$

Barbotine-Keramik II 244; 248; IV $7 ; 13-16$

Basaltskulptur und -Architektur I $117 \mathrm{~s} ; 126$; II 33

Basiliken u. Hallenkirchen I 166s; II $2-16 ; 22 ; 30 \mathrm{~s} ; 43 \mathrm{ss} ; 102$; 252,$2 ; 298$ s; 301; 303; 329; 345, ${ }_{3}$; 346 ss; $370-73$

Blendnischen-Dekorationen I 75s; 79ss; 222s; 232; 238; 246; 249; II $63 ; 69 ; 75 ; 241 ; 245$ s; 311 ; 319s; 321; 336; 358s; 364

Blendsäulen-Architekturen II $9 \mathrm{~s}$; $18 \mathrm{~s} ; 69 ; 75 ; 167 ; 265 ; 360 ; 362$ $366 \mathrm{~s}$

Bogenformen I $74 \mathrm{~s} ; 81 ; 85 ; 94$; II $53 ; 64-67 ; 68,1 ; 91 ; 92,1$; 151,$4 ; 167,2170 ; 194 ; 221 ; 252,3$; $267 ; 275,_{3} ; 280 ; 293 ; 324 ; 325,{ }_{11}$; 333 ; 354 s; $358 \mathrm{ss;} 366$; IV 36

Bogenkonstruktionen I $73 \mathrm{~s} ; 85$; 234; II 64-67; 91; 324 ss; 358s

Brücken: in Amida I 8,7; II 213,3; $215 ; 325$

„Altynköprü II 322-26

"Arabān I 6-8; 186s; II $238 ; 325$
Brücken von Baghdad II 105; 11 ; 113,$3 ; 114 ; 147$

des Baibars I 8,7; II 213,3 des Band i Amīr II 325,9 der banū Zuraiq I 92

über den Bațman Șu II $325,{ }_{3}$

über den Djaghdjagh

II 190 ; II 307

von Djazīrah I 8; II 215; 325

über den Djirdjib I 149 von Harbah I 36,2; 64,2; 161,6

von Ḥișn Kaif I 8,7 ; II $215 ; 325$

der Hūmāi bei Ē đhādj

I 63,1 ; II 325,10 von Isfahān II 325,9 von Khūzistān II 325,8 von Mosul II 209; $214 \mathrm{~s}$ von Nīliyyah I 241 al-Raṣāṣ I 52; 55 über den Tharthārbei Hatra II 307,2 von Zākhō II 325

Buddhistische Einflüsse in der Kunst I 19,$5 ; 42,1$; II $243-49$

Christliches in der Kunst I 62,3; $106 \mathrm{~s} ; 117 ; 139 ; 225 \mathrm{~s}$; II $1-45$; $142 ; 211 ; 239 ; 242 ; 251 \mathrm{~s} ; 261$ 266 ss; 269s; 277; 289-303; 329; 333; IV $11 \mathrm{~s}$

Chronogramme I 29,4; II 143

Ciborium II 292; 294; 297; 334

Citadelle-Maidān-Sarai II 148

Coufique carré II 158,$2 ; 179 ; 308$

Eiserne und bronzene Tore II 128; $135 ; 256,2 ; 268-70 ; 270,2$

Ellenmaße I $80 ; 84,1 ; 91,1$; II 70 bis $74 ; 92 ; 107-10 ; 118 ; 119,3$; $119 \mathrm{ss} ; 126$; 131,$2 ; 133 ; 134$; 151,$1 ; 194 ; 224 ; 306 ; 356 ; 358 \mathrm{~s}$

Embleme und Wappen: Becher II 247,2; Drache II 270; Kreuz I 117 ; 287,2; 292; 296s; 334,1; IV $11 \mathrm{~s}$; Vögel II $242 \mathrm{~s}$; 245; Wildtiere I $29 ; 30,2 ; 38,2$; II 212s; IV 12; 20; Mond des Lulu I 21 ; II 212
Entrelacs II 155; 168; 230; 255-59; 256,$2 ; 268$ s; $271 ; 315$ ss

Feuersteininstrumente I $118 ; 190$; 193

\section{Feuertempel II 333}

Figürliches in der islamischen Kunst I 36 ss; II 134,$4 ; 152-54$; $212 \mathrm{~s} ; 220,1 ; 239 ; 241-49 ; 260,1$; 265,2; 266

Flache Dächer und Holzdecken I $75 ; 92$; II $29 ; 137 ; 347 ; 361 ; 371$

Gemälde, Malereien II $48 ; 70$; 386,2; 392

Gewölbebau-Probleme I 76, $; 85$;

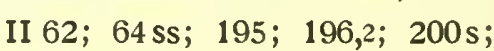
$225 \mathrm{~s} ; 233,4 ; 325,10 ; 332 ; 358$; 366; 369

Glasmosaiken I 140; 204; II 13 ; $33 ; 48 ; 70 ; 144,1$

Glasurziegel II 249; 252 und 4; 253; 283; 316s; 356

Goldlüster-Keramik I 91,$1 ; 95$; II $317 ; 356$; IV $20 ; 22-24$

Golgatha-Kreuz II 292; 295 s; 296, Grabsteine (shāhid) II 181,1; 267; 273,$1 ; 274 \mathrm{~s} ; 278 ; 282,1 ; 283-87$; 283,$1 ; 296 s ; 297,2 ; 311,1$

Grabtürme I 168-70; II 365-67; 386

Griechische Inschriften I 251, II $14 \mathrm{~s} ; 41 ; 337 \mathrm{~s} ; 342 ; 368,1 ; 392 \mathrm{ss}$

Heiligengräber, Ziyaret, Maqām I $10 \mathrm{ss} ; 20-24 ; 27 \mathrm{~s} ; 30-34 ; 56$; 126 ; $130 ; 132-35 ; 157$; 172 ; $196 \mathrm{ss} ; 200 ; 203$; $222 \mathrm{ss;} 231 \mathrm{ss}$; 238 s; 239,$3 ; 244$ ss; 248; 250; II 49; $58 \mathrm{~s} ; 114 ; 145 \mathrm{ss;} 172 \mathrm{~s} ; 178,_{3}$; $179 \mathrm{ss} ; 206 \mathrm{~s} ; 250-70 ; 277-83$; $287 \mathrm{~s} ; 308-12 ; 330-36 ; 349 \mathrm{~s}$; 363

\section{Hillani II 346}

Holzanker I $79 ; 81,{ }_{3} ; 250$; II 66ss; $324 \mathrm{~s} ; 354 ; 385,2 ; 386$

Holzsäulenbau I 90;91,1;99; 135, und $5 ; 137 ; 185 \mathrm{~s} ;$ II $313 ; 362$

Ikonostasis von Mār Ya'qūb II 295 bis $97 ; 311 ; 334$ 
Incipit- und excipit-Schnörkel II 185,$1 ; 276$

Inkrustation in Alabaster II 254, ; $264 ; 267 ; 280$

Islamische Eroberung, Verträge II 208; 211,2;300s; $347 \mathrm{~s}$

Jüdische Altertümer II 179s; 180, 237,$3 ; 303 \mathrm{~s} ; 330$

Justinianische Bauten I 124s; 128 ; $138 ; 165 ; 167 ; 174 ; 195 ; 230$; II $12 \mathrm{~s} ; 28 ; 30$

Karawanserais II 198-201

Kenotaphe und Sarkophage II 186,$1 ; 197 ; 207 ; 238 ; 250$ s; 261 s; $264 ; 270 ; 275 ; 279 ; 310 ; 312$; IV 4

Keramik I 118; 126s; 129; 130; $133 ; 142 ; 154 ; 158 ; 164 ; 166$; 169 s; 172 s; 176; 179; 181; 184; $186 ; 1938 ; 197 ; 203 ; 209$ s; 212 s; 215 s; $224-27$; 237 s ; 242 ; 250 ; II $52 \mathrm{~s} ; 59 ; 89 ; 114 ; 243 ; 349 ; 392$; IV $1-25$

Khalifengräber I 86,5

Kirchen I 166 s; $221, \mathrm{~s}$; 230; II I bis $45 ; 102 ; 143,2 ; 156 \mathrm{~s} ; 216$; $237 \mathrm{~s} ; 266 ; 277,2 ; 289-303 ; 329$ bis 36 ; $336-46$; $346 s s ; 370-73$

Kirchtürme II 294; 301; 354 s; 361

Klöster I 238, 8-10; II 38; 45; 146 ; 238; 277,2; 289-303; 298,4; 336; $345 ; 347$

Konche (Muschel) als Architekturform I 81,1 und $2 ; 133 \mathrm{~s} ; 223$; 233; II 6 ; 33; 68; 141 ; 178; 199,1; 222; 227; 233,2; 276; 309; 339; 358

„König im Fenster“, und „Frau im Fenster" II 246-48

Königstraße II 77; $327 \mathrm{~s} ; 386 \mathrm{ss}$

Kronen, coronae, in der Ornamentik II 260, Abb. 257

Kunststein I 81,$4 ; 83$ s; II 385,2

Kunstuhr II 167; 247,2, Abb. 248

Kuppelbau - Probleme und Konstruktionen II $10 ; 30 \mathrm{~s} ; 39 \mathrm{~s} ; 144$; 151,$4 ; 159 \mathrm{~s} ; 186 ; 196,2 ; 226 ; 341$; $345 ; 347$

Lapislazuli-Dekorationen I 91,1; II 138,2

Legenden von Bauten und Orten, I $82 ; 103,1 ; 167 ; 182 ; 230 ; 246$; II 58,$4 ; 85,3 ; 134,3 ; 146 \mathrm{~s} ; 172$; $180 ; 206 ; 237,1 ; 287 ; 321 ; 330$; 332; 336s; 338

8 SARRE-HERZFELD, Archäologische Reise. Band IV.
$136 ; 145 ; 237 ; 238,2 ; 249 ; 264$; 292 s; 308; 314; 359

Ornamentziegel I $246 \mathrm{~s} ; 249 \mathrm{ss}$; II $158 \mathrm{~s} ; 168 ; 171 ; 174-76 ; 230 \mathrm{~s}$; 253,$2 ; 260 ; 317$

Madonna im Rosenhaag II 295,2; 296; IV 22,

Maeander II 158,2; 168; 170; 179; 308s; 315 ss; 358

Magisches und Talismanisches in Epigraphik, Bildern und Architektur I 21,$5 ; 37 ; 39,3 ;$ II 63,2 ; 65,$1 ; 134,{ }_{3} ; 242$

Marmor-Architekturteile 192; 127 ; 158; II $6 ; 33 ; 48,4 ; 57 ; 69,3 ; 70,2$; 104,$2 ; 135,5 ; 139 \mathrm{~s} ; 144 ; 160$; 225,$1 ; 353 ; 356 ; 391$

Martyrien II 2; 28-39; 297; 299; $331 \mathrm{~s} ; 334 \mathrm{ss} ; 347$

Medresen von Baghdad II 16070; Irbil II 314-18; Halāwiyyah II $20 ; 22 ; 31$; Mirdjāniyyah I 45 bis 50 ; II $181-87$; Mustanșiriyyah I 42-44; II 161-70; Sindjār I 10; 202; II 308; 318 Meistersignaturen I $2 ; 11 ; 17 ; 21$; 31 ss; 49 ; II 2,$2 ; 163 ; 183 ; 223$; $267 ; 269 ; 309 ; 310,1 ; 363$

Mị̣rāb I 17s; 27 s; 81,1 und 2; 93; 95,$3 ; 133 \mathrm{~s} ; 223$; 244 ; II 130,1 ; $139-145 ; 218-24 ; 227 \mathrm{~s} ; 252$; 259 ; 265 ; $267 \mathrm{~s} ; 268,1 ; 271 \mathrm{~s}$; 275 ss; $280-82$; 283-87; 297,2; 309 s; 360; Entstehung des M. II 277; 296 s; 334

Minaret-Typen I 33; II 159; 228 bis $33 ; 232 ; 316 \mathrm{~s} ; 355$

Minbar-Memor II 179; 303

Miniaturen II 149,$10 ; 245,3 ; 247,2$

Moscheelampen-Motiv II 268; 276 ; $286 \mathrm{~s} ; 287,1 ; 309$

Moscheetypen I 5; 5,2;6;91,1; 97 bis $103 ; 161 ; 250$; II $138 \mathrm{~s} ; 215$ bis $38 ; 225 \mathrm{~s} ; 362 \mathrm{~s}$

Münzen I 83, ; $157 ; 178 ; 184 ; 203$; 224 ; 234; II 213 und 2 ; 220, ; $248 ; 319,3 ; 356$

Namen der 12 Imame I $23 \mathrm{ss;}$ II 251; 254,1

Narthex II $292 ; 296 ; 298,4 ; 299$; $346 ; 370$ s; 372

Opus sectile, Pflaster I 92; 95

Orientierung, Qiblah II 112,5; 113;
Orthodoxes Glaubensbekenntnis II $284 \mathrm{~s}$

Orthostaten II 160 und $1 ; 240 ; 253$; 254,$1 ; 264$

Palast-Typen II $116 ; 118,4 ; 130-35$ Pflanzen I 60; $141 ; 176 ; 179 ; 200$; 217,$1 ; 220 ; 237,1 ; 242 ; 248$ s; II 59,3; IV 25-34; 59

Planetendarstellungen I 8; II 212 Porzellan und Seladon IV 17s; 20 Praetoria oder Palatia I 124 s; 130 ; I73s; II 42,$5 ; 345,{ }_{3} ; 367,8 ; 369 \mathrm{~s}$

Predella II 292; 297

Probleme und Abarten des Naskhī und $K \bar{u} f \overline{1} I 33 s ; 234 ; 158,5 ; 164$; 165,$3 ; 220,1 ; 229,2 ; 265 ; 267,1$; 272 und $3 ; 273,1 ; 280 s ; 295$; 311,$1 ; 316,1$

Profile, Gesimse, Gebälke II 11 ; 22 ss; $33-36$; 44 s; 69 ; 154 ; 185; 265 s; 276s; 278; 311; 336 s; 392

Proportionen der Architektur I 79 s; II 9; 64; 68,1; 69-74; 119 ; $123 ; 125 \mathrm{~s} ; 129 ; 134 ; 194,1 ; 224$; $240 ; 242,1 ; 253 ; 298 ; 344 ; 345,_{3}$; 359

Protokolle u. Titel II 158,$3 ; 161$ ss; 164,$7 ; 182,1$ und $2 ; 190 ; 198,1$; 220,$1 ; 249 ; 251 ; 264,3 ; 282,3$

Querschiff in Moscheen I 6; II 361

Rhythmus in der Architektur I 712; 94,$1 ;$ II $18 ; 24 ; 168 ; 360 ; 362$

Römische Castren und Festungen, auch assyrische $1124 ; 130 ; 137$; $140 ; 153 \mathrm{~s} ; 163 \mathrm{~s} ; 171 \mathrm{ss} ; 176$; 191 ; $196 \mathrm{ss}$; II $132 ; 133,1 ; 305 s s ;$ 365-82

\section{Sabiertum II 207; 311}

Säulenkapitelle I $117 ; 154 ; 158$; II $11 \mathrm{~s} ; 15 ; 20 \mathrm{ss} ; 33 ; 40 \mathrm{~s} ; 101 \mathrm{~s}$; 141; 216ss; 280; 286; 293; 295;

Schießscharten-Fenster I 125; 133 ; 215; II 91; $354 \mathrm{~s} ; 361$

Schiitentum u. Schiit. Wallfahrtsstätten I $3 ; 25 ; 31$; II $145 ; 147$; $160 ; 242 ; 251,2 ; 284$ $329 ; 250-54 ; 360$ ss; 370 
Sgraffiti I $168 ; 223 ; 233 ; 239$; II Teppiche, II 89,$1 ; 207 ; 237 ; 245,4$; 296,$2 ; 368,1 ; 381$

Siegel Salomonis, Davidsschild II 169s; 178; 295

SI-YU-KI des Ch'ang Ch'un II 202; 302

Springbrunnen I 96,1; II 228

Statuen, Stelen und Reliefs I 105 und $1 ; 115 ; 118 ; 180 ; 186 ; 192$; 206; 209; II 56,3; 57; 102s; 246,3; 268; IV $6 \mathrm{~s}$

Stempelkeramik I 62,$3 ; 63,1 ; 107$; 180; 211; 225s; 237s; IV 10ss

Strickornamentik I 118 ; II $350 \mathrm{~s}$

Stuckreliefs I 62,3; 226; IV 12; 16

Sunnitische Reaktion II 220,1; 239; 242

Tabula ansata II 171,$1 ; 185,1 ; 284$; IV 37

Teakholz I 90, 2-3; 91,1; 93,2; II $67 \mathrm{~s} ; 127,2 ; 128 ; 138 ; 145 ; 173$

Tells, in Gruppen I 115; 175; 190; 205 s; II $312 \mathrm{~s} ; 386 \mathrm{~s}$ 287,

Terrakotten IV 4; 5,$1 ; 6$ ss; $12 ; 22$ Torweg in gebrochener Linie I $35,{ }_{3} ;$ II $123 ; 151 ; 212$

Trikonchos II 346

Turm zu Babel II 98,1

Vasen in der Ornamentik II $34 \mathrm{~s}$; $171 ; 216-19 ; 221 \mathrm{~s} ; 257$ und 3 ; $260-63 ; 268 ; 286 ; 296$

Veränderung von Flußläufen I 60s; $64 ; 122 ; 128 \mathrm{~s} ; 236 \mathrm{~s} ; 247 \mathrm{~s} ; 251 \mathrm{~s}$; II 115

Vergleiche, Arabische kunstgeschichtliche I 102,2

Verteidigungsanlagen an Kirchen II 294 und $2 ; 331 ; 340$

Vokalmetathese I $121 ; 164,3 ; 165$; $184 ; 189,6 ; 191 ;$ II $61 ; 374 ; 382$

Wegemaße II $77 \mathrm{ss} ; 79,1$ und 3 ; 306,1
Yam(b), mongolische Posthäuser II $189 ; 193 \mathrm{~s} ; 196 ; 198$; IV 36

Zellenkuppeln und -gewölbe, $m u$ qarnas I 233s; 238 s; 246 ; II 157; $159 ; 173 ; 177 \mathrm{~s} ; 179 ; 185 ; 196$; $240 ; 255 ; 265 ; 276 ; 308 ; 311$; $321 \mathrm{~s} ; 364$

Ziegelmaße I 79; $126 ; 133 \mathrm{~s} ; 154$; 215 ; $232 ; 239 ; 241$; II $53 ; 62$; $91 ; 151 ; 196 ; 249 ; 313 ; 354 ; 359$; 385,2

Ziegelmosaik I 3; 33s; 44; 125; 232; 234 ; $242 ; 246$; II $168 ; 174-76$; 229ss; 252; 265; 283; 308; 315; 319; 358

Ziegelstempel I 61,$4 ; 208 ; 212 s ;$ 224; II $55 \mathrm{ss} ; 56,2 ; 96 \mathrm{~s} ; 103 \mathrm{~s}$; 139,$4 ; 146 ; 312 \mathrm{~s}$

Zikkurrat-Minaret I 103,2; II 98; 101; 232

Zoroastrisches auf islamischen Grabsteinen II 285

\section{VERZEICHNIS ARABISCHER, SYRISCHER UND PERSISCHER TECHNISCHER AUSDRÜCKE}

ädjurr II $118 ; 119,2$ akhbār mulūk Ghassān I 138,5 $\bar{a} q \bar{a}, \bar{a} g h \bar{a}$ II 190,1 'aqab, mu'aqqab I $91,1 \mathrm{~b}$ azadj II 118; 119,2; 232,

bādiyah I 139 ; II 325, 11 bālā khānah II 200 bāshūrah I 35, bașrah I 250, bāzūband t.t. orn. II 154,$4 ; 155$; $171 ; 231 ; 258 ; 260$

bēma $\beta \tilde{r}, \mu \alpha$ II 299

bēth qadīshā II 293

be th șalotthā II 277,2; 296; 297,3 burdj, abradjah - זúpyos I 130;

II 121

da/ikkah II 279; 313; 330 dakumî (?) t.t.orn. II 156 al-darb al-sultān̄i I 114; 136 darg $\bar{e}=\Sigma \dot{\omega} \lambda \varepsilon \alpha$ II 298

daur 'adjamānah II 167;194; 252; 358

daur hilālī II 195

dausah II 278

al-da'wah al-hädiyah I 40,3 dihlīz II 123; 125

diraghliyyāt (?) t.t.orn. II 269

djamalūn I 5; II 360s

djāmah, -āt II 70,4

djaräah II 52

djașs II 118; 119,2; 225

dūlāb, dawālìb II 76,5; 90

al-fadan, fudain I 176

fahradj, $=$ pers. pahra II 2,2

faṣil I 158,3; II 109; 118,2; 122; $130 \mathrm{~s} ; 356$; 358s

fușaifișah ఛripís I 95; 140,5; II 70 und 3 u. 4

gagoltā II 294

habs $i$ kisrā $=$ Zandān II 80 hadjārat bānāt II 232,1

hadrah I 23, 2 und 3 ; II 251; 261 ; $265 ; 287$

halqah, hligă II 374

hammah, wa'ra I 165,3; 191

haqq II 285

hāshiyah, t.t. orn. II 158

hazārbāf II 158,1; 159; 171; 175; $185 ; 187 ; 196 ; 229-234 ; 253$; $308 ; 316 ; 319 ; 358 ; 383 ; 385,1$ hēkal, haiklā, èkallu II 292s; 295; 299; 329

ibn fulān ibn fulān I $9 \mathrm{~s}$ ishān I 237

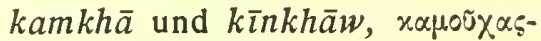
xouváxys II 89,

karkhā II 105

kārzuwān II 262

$k \bar{a} s$ II 173; 196; 308

$k \bar{a} s h \bar{\imath}, k a \bar{s} h \bar{n} n \bar{\imath}$ I 96; II 187

kashkül, t.t. orn. II 257,3; 315

khaizurānah II 256,2

khalkhāl, khalākhil II 228,1

khān̄ II 326,3

khātim t. t. orn. II 256,2

khwaruno I 62,3

kils $\bar{u}$ nūrah II 119,1; 225

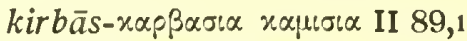

kiswah II 261; 265

kitāb fi mai rifat al-hiyal al-handasiyyah des Djazarī II 247,2 kitāb al-iftikhār (?) I 95,3; 96 kiwā' rūmiyyah II 129,3 kund, kunād, abu kundain t.t.orn. II $156 ; 176 ; 256 \mathrm{~s} ; 257$, 


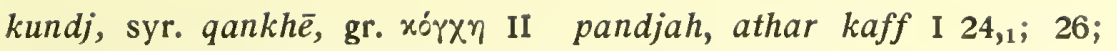
$174 ; 199,1 ; 200 ; 299 ; 343$

lakasha, lagasha II 214,2

lauzah, bādām t.t. orn. II 156; $185 ; 256 ; 257,1315$

madhbah, syr. madbahā II 292; 299

madīq, mudaiqah I 129,3; 166,2; II 374

madjālis wa murtafaqāt II 127,1 ; 134

māh $i$ tchār deh II 213,1

mahlab I 188s; 207

maidān, mayādīn II 148,$1 ; 382$

al-manqūl II 179

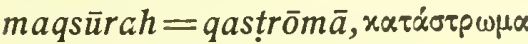

II $234 ; 297,3 ; 299$ und 3

ma' rifat Allāh II 163,2; 180,3

(bī)māristān II 235,1

mashra ah, sharīah 146,9

maștabah II 235,

mìl - manār II 179,2; 233,1

mìnā I 95

mīnāth? II 292

mințaqah II 127,2

misht t. t. orn. II 190; 259

miṣr, amșār II 209; 317

mudjaddid-muhaddid II 163,3

muhr II 170s

al-munadjdjid I 11,2; II 309

muqarnas-xopwvis II 157,$4 ; 178 \mathrm{~s}$;

$185 ; 196 ; 240 ; 265 ; 276 ; 308$;

$316 ; 320,3$

murabbaah - tchārsūk II 105; 209; 215

musāfir-khānah, 'oda II 313

al-mutarraz I 51,1

muzakhraf, mudhahhab II 127,2

nabq, Rhamnus, I 217; 242

nāhiyah al-Furāt II 382

$n \bar{a}$ 'ūrah I 192,2; II 80

nuyan I 47,2

$\bar{o} s t a \bar{n} n a h, \bar{a} s t a \bar{n} a h, d \bar{\imath} w \bar{a} n i^{`} \bar{a} m m$ II 74

pahlawān $i$ djahān I 14,5

pandj, pandj lang t.t.orn. II 170;

$185 ; 230 ; 257 \mathrm{~s} ; 315$
$197 ; 276 ; 276,1$

pasibīd, Populus Euphratica I 60,4 pradakshina II 252,2

qadī $b$ II 287,3

qaisariyyah II 235, ; 314; 317

qanāt, kahrīz I 201; 204; II 313

qandīl t.t.orn. II 219; $258 \mathrm{Abb}$;

271

qantara - xévepov I 59,1; II 278

qarāh II 149,1; 192

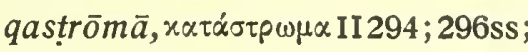

297,$3 ; 299,3 ; 302 ; 329$

qațā' $i^{\ell}$ I 87

$q \bar{\imath} r, g \bar{\imath} r, g \bar{a} r$ II 326,3

qubbah I 85,$1 ; 118,1$; II 118

rabad II 317

rahbah II $125 ; 128 ; 130 ; 356$ 382

raqqah, ruqaiqah (rgēidje) I 68; $77 ; 159,9$

rāzūnah, mishkātun II 197; 275

Rustam i Zāl al-waqt I 13,1; 15,

sādj II 67,4

șadr II $125 ; 134 ; 167,1$

șaḥn II 98,1; 135ss; 216; 226; IV 36

sandūq al-sāe àt II 167,

șārūdj, sārūk II 119,2

sarwistān II $48 ; 327$

shabakah t.t. orn. II 256,2

shāhid II 284

shahriyār al-Shä'm I 14,4

shak II 312

shamsah t.t.orn. II $156 ; 256 ; 258$; 270

shārsū $q$, tchārsūk II 116,1

shash und shash lang t.t.orn. II

$158 ; 170 \mathrm{~s} ; 176 ; 230$

al-shīkh wa'l-qaișūm I 139,1

shimāmah II 313

shlīhā II 299

230; 256 ; 257, ; 258ss; 269; 308;

315

sidr, sudair, Sisiphus lotus I 242; 246

sīf II 146,9

șiniyyah II 159s; 174; 180; 195 shōlah t.t. orn. II 168; 170; 185; șürah, t.t. orn. II 243

surmadān t.t. orn. II 258; 263

tābiyah I 221; IV 36

tabl t.t. orn. II $257 \mathrm{ss;} 269$

tacara, tacar II 79,4

tādj II 185,2

tafșill makhbūt t.t. orn. II 155; $170 ; 255 ; 257 ; 259$

„ mufrid t.t.orn. II 259

tailasān II 209; 382

takht II 200

takhtī, phalaka II 284,

tāktshah II 313

tamasa II 180,3

tannūr I 195,4

al-țāqāt II 128-131

tārimah II 159; 172; 185s; IV 36

tațawwa a bi imāratihi I 9; II 251, tawāf I 85; II 252

tazwī $q$ II 70

tchār 'Alī t. t. orn. und epigr. II

158,2; 179; 308

tchār qurūn od. lang, sih q. od. l.,

II $156 ; 219 ; 256$

tcherd, (kird) I 168,3; II 58; IV 36

tchini $\bar{\imath}$ I 96

tìm II 189,2

tīn II $118 ; 119,2$

tōob, tuwaibah II 58,

tōg (tauq) I 199,5

toqara'y II 234,1

tungah $t$.t. orn. II $221 ; 257$

turundj $t$.t. orn. II $168 ; 170 ; 230$;

256s; 257,1; 258

usțuwānah, asāțīn, esțewā II 299,2

walt̄ āl Muhammad I 21,6;25,1;

II $251 ; 270$,

wa'rah I 165,3; 191

ward t. t. orn. II 168

wasm II 368s; IV 36

yam, yām, yāmkhānah II $188, \mathrm{~s}$;

189, 2 und 6 ; IV 37

zahrah II $178 ; 185 ; 230$

zaur II 59

zill Allāh II 163, 1 und 2

ziyādah I 96 

Tafel CXXI

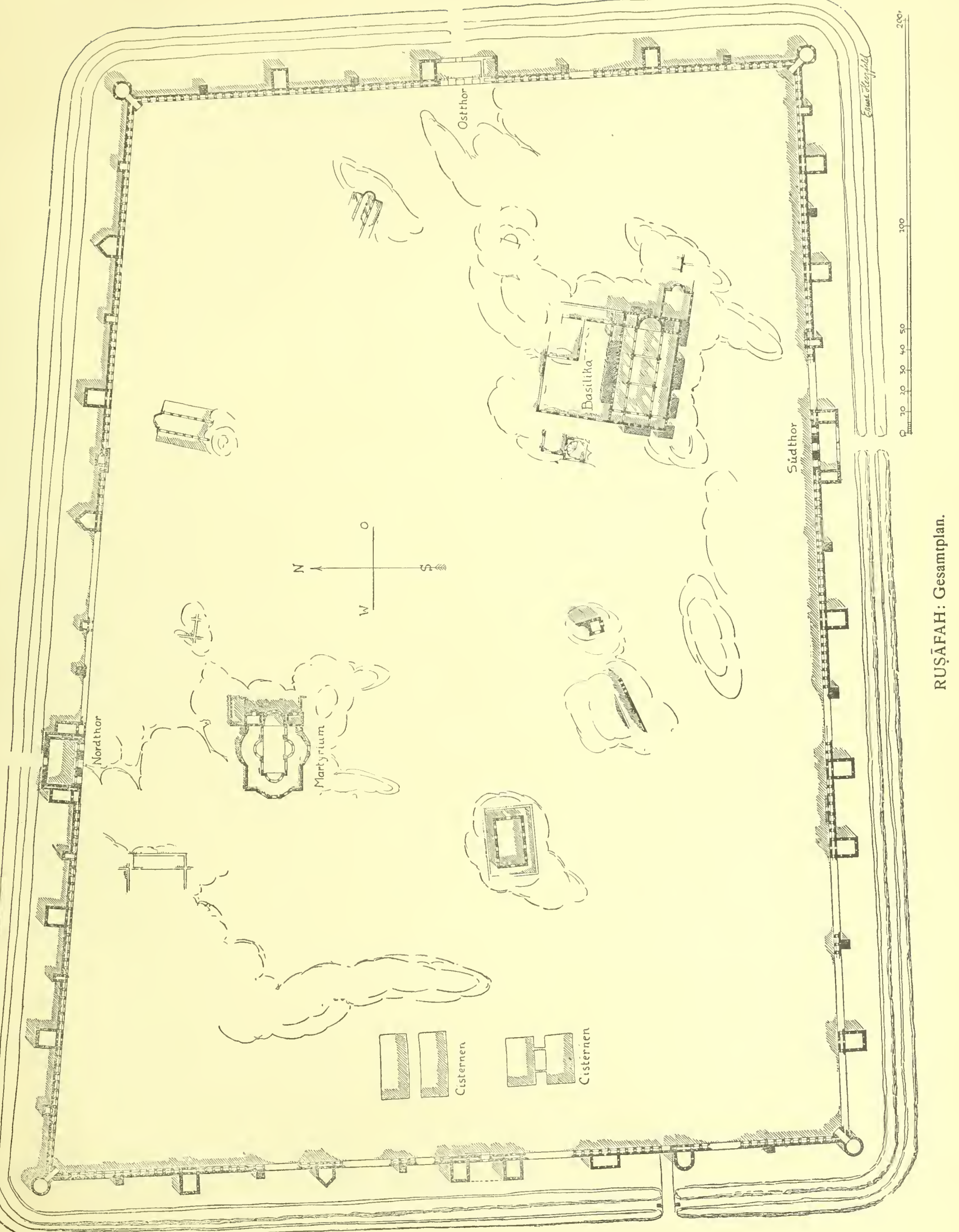




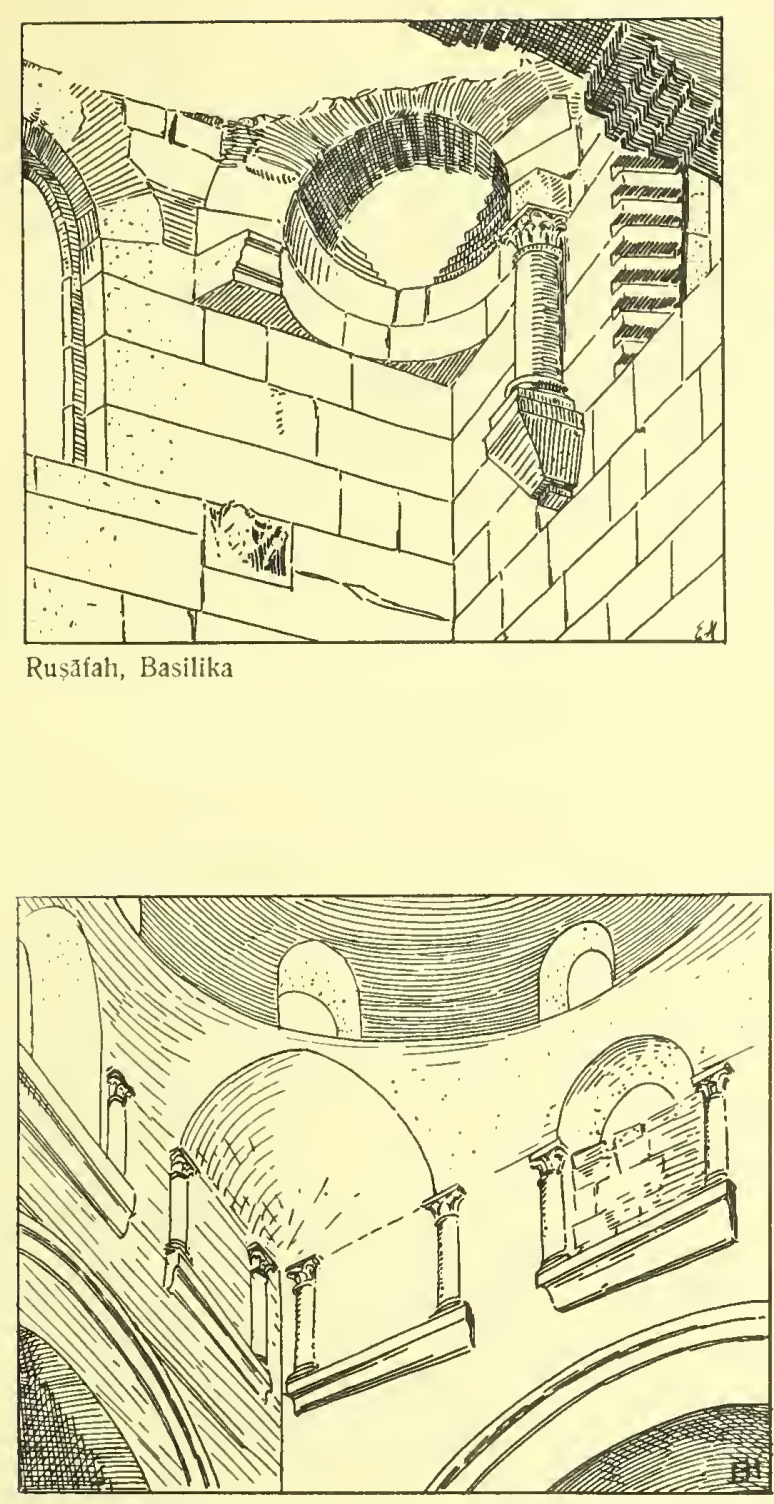

Zohag, Rotes Kloster

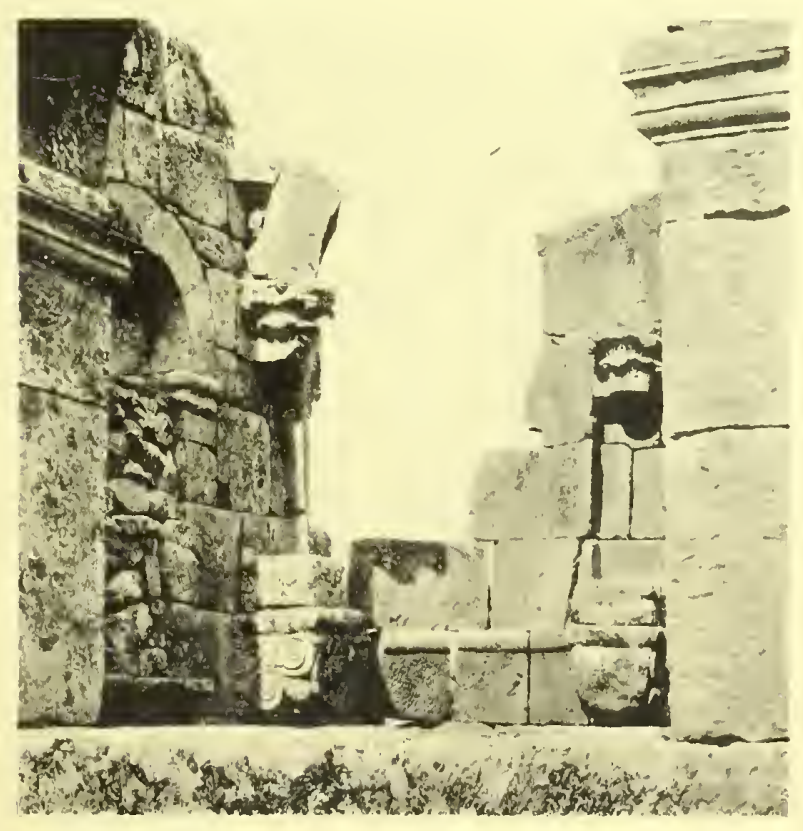

Alahan Monastyr

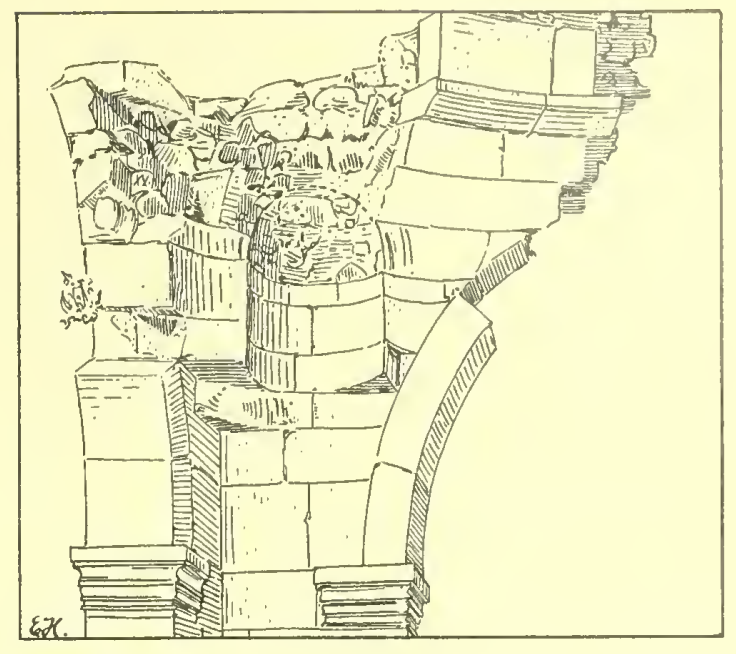

Korykos

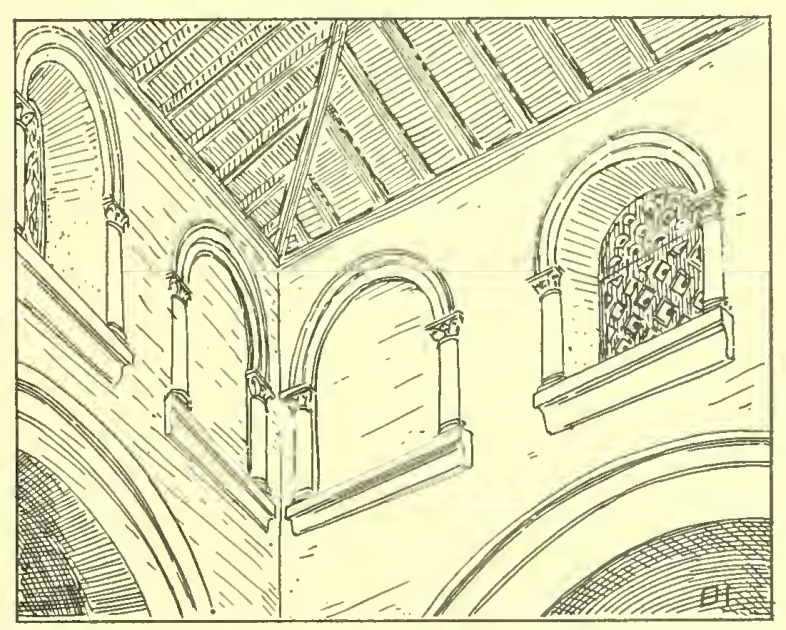

Zohag, Rotes Kloster, Restaurationsversuch

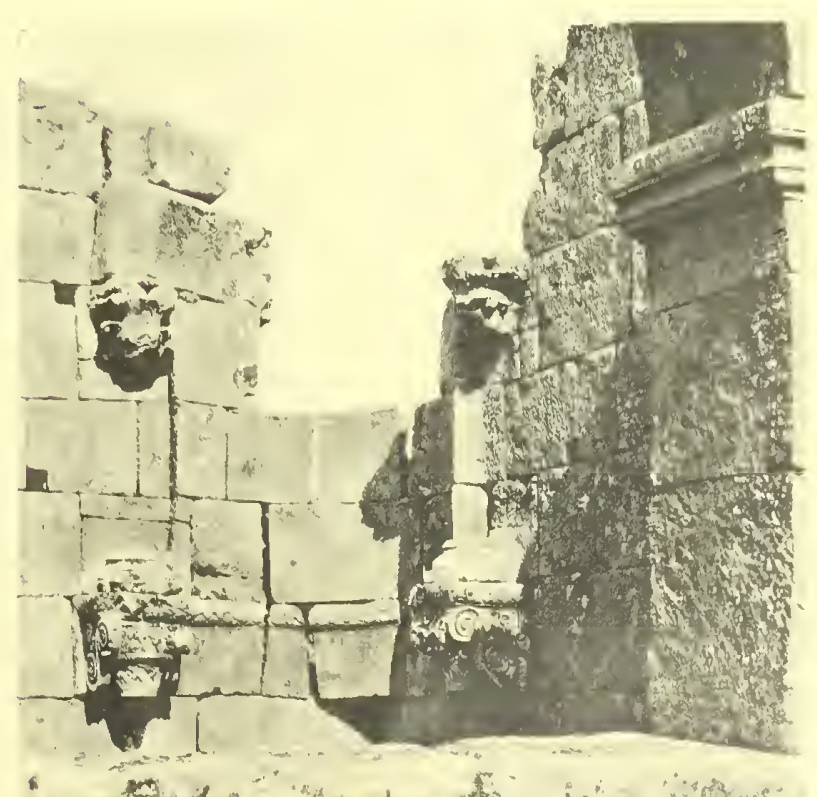

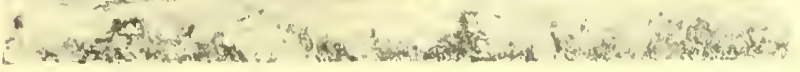
Alahan Monastyr 



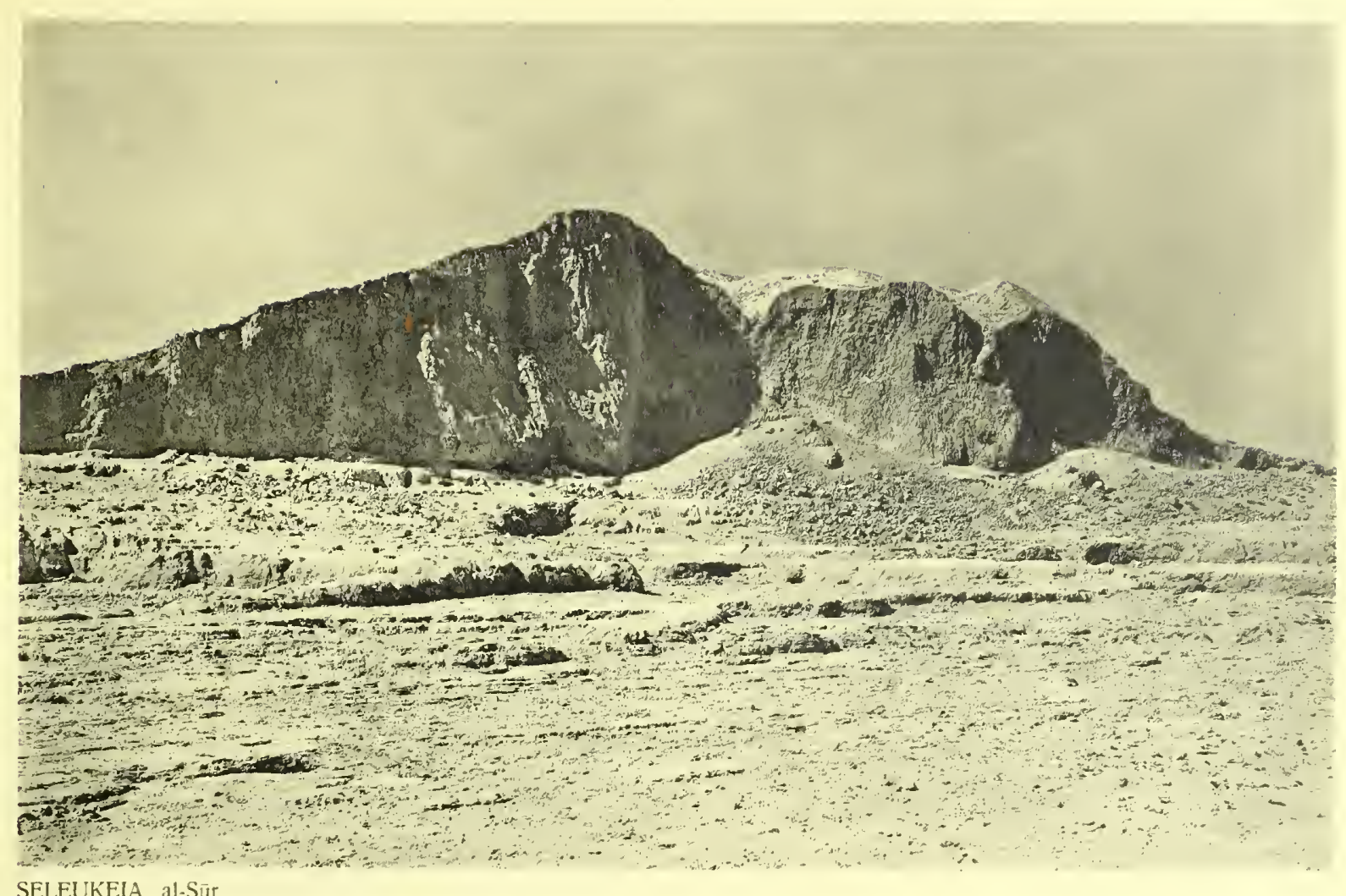

SELEUKEIA, al-Sür

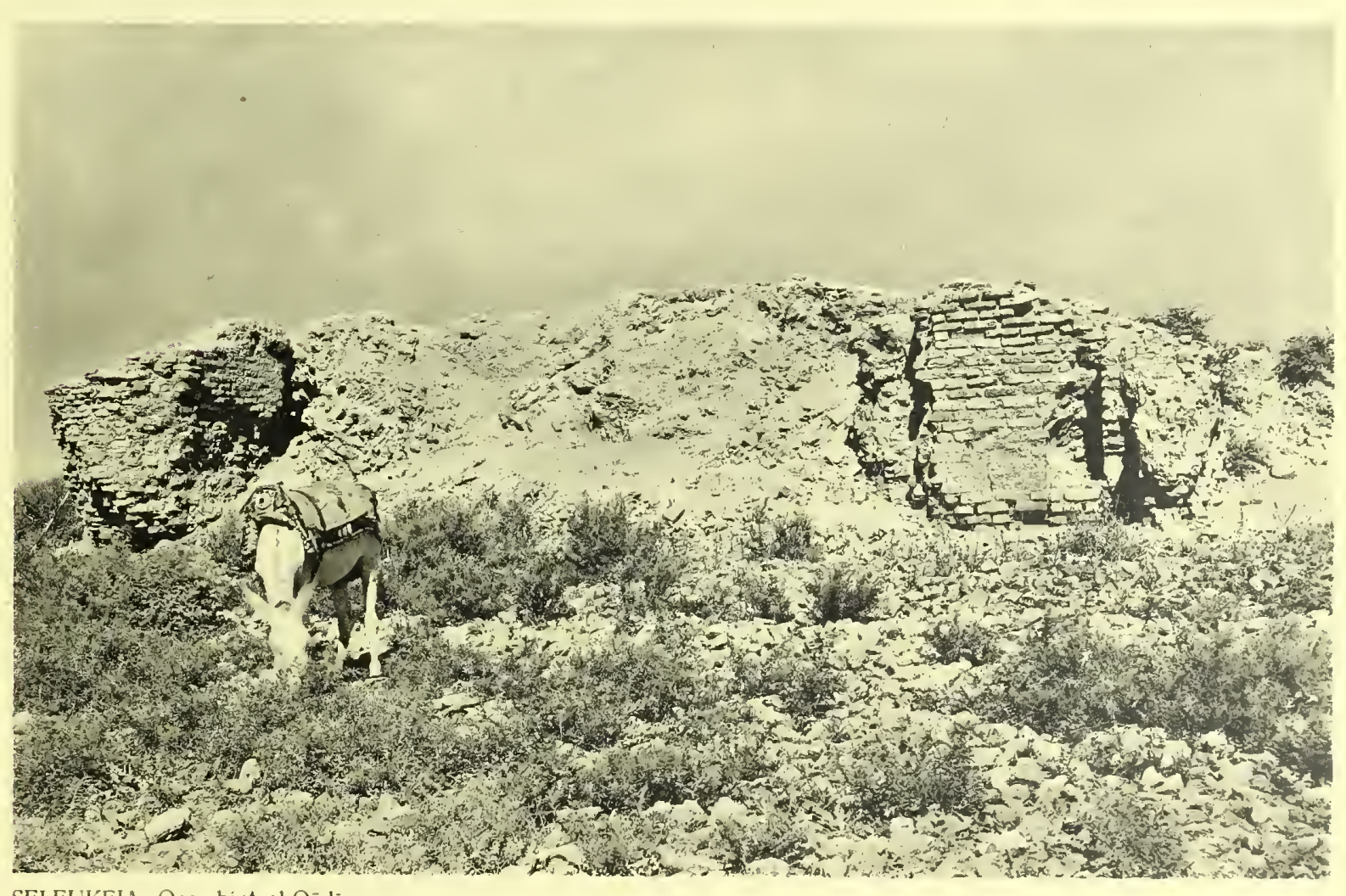

SELEUKEIA, Qașr bint al-Qādi 



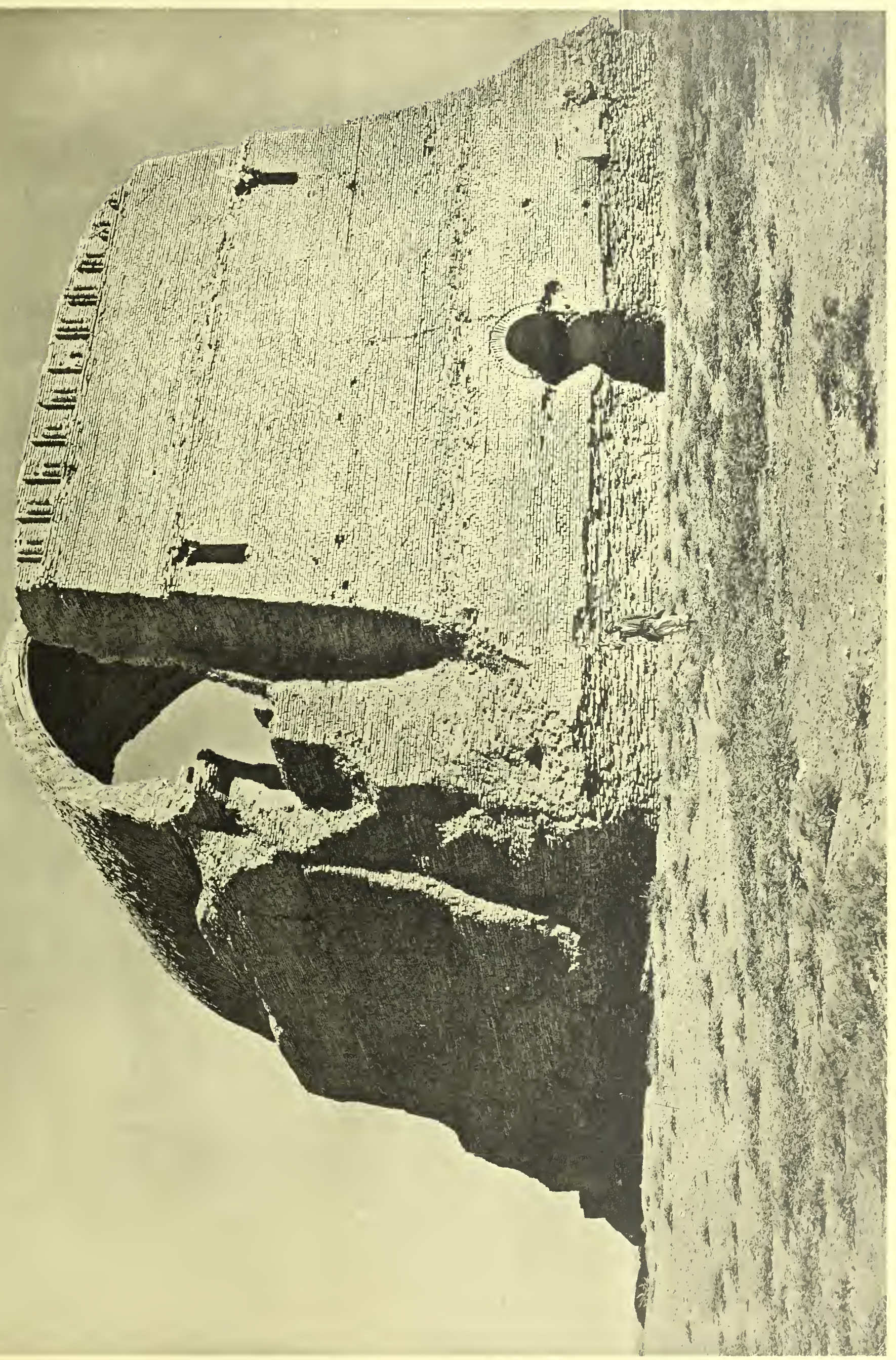




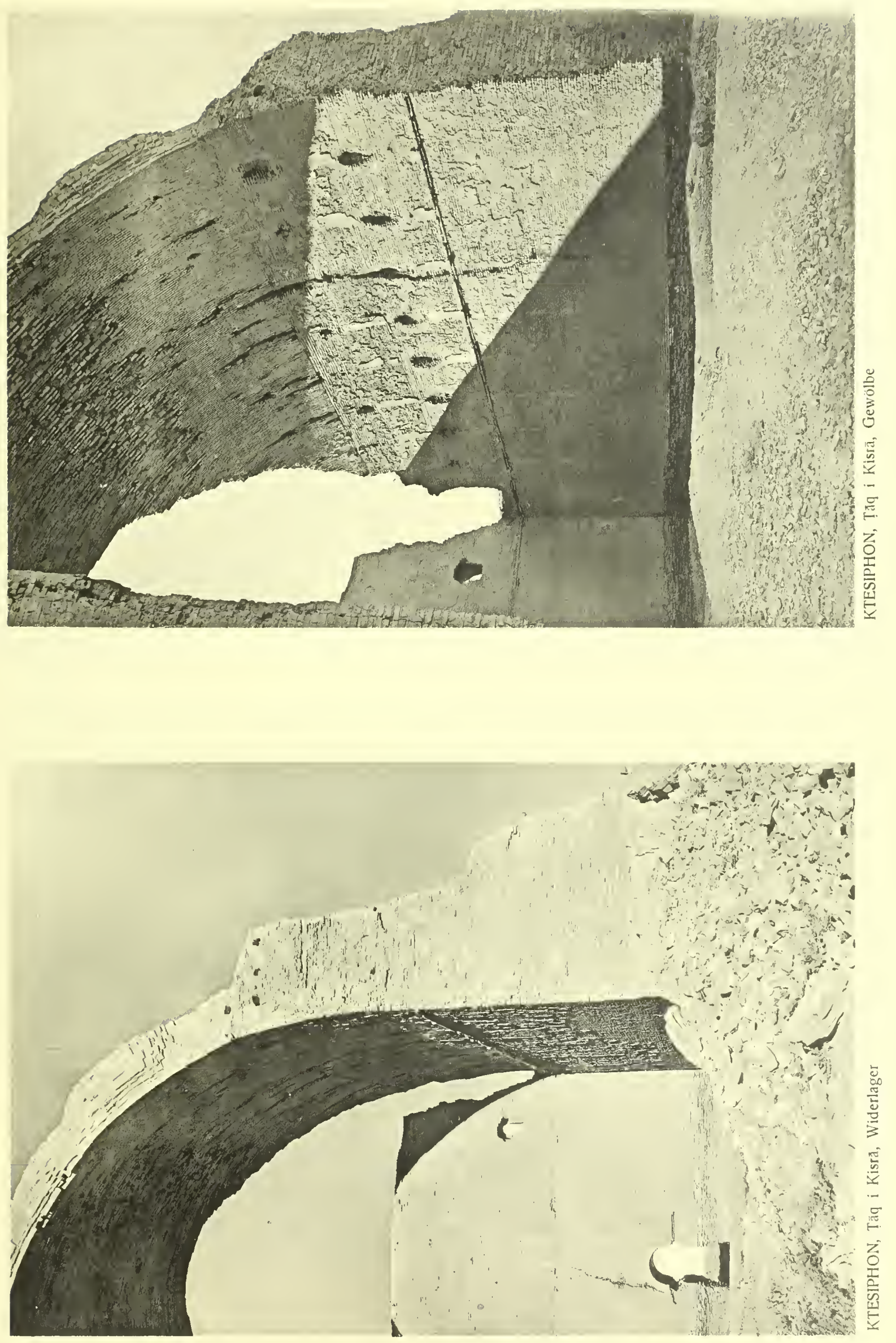



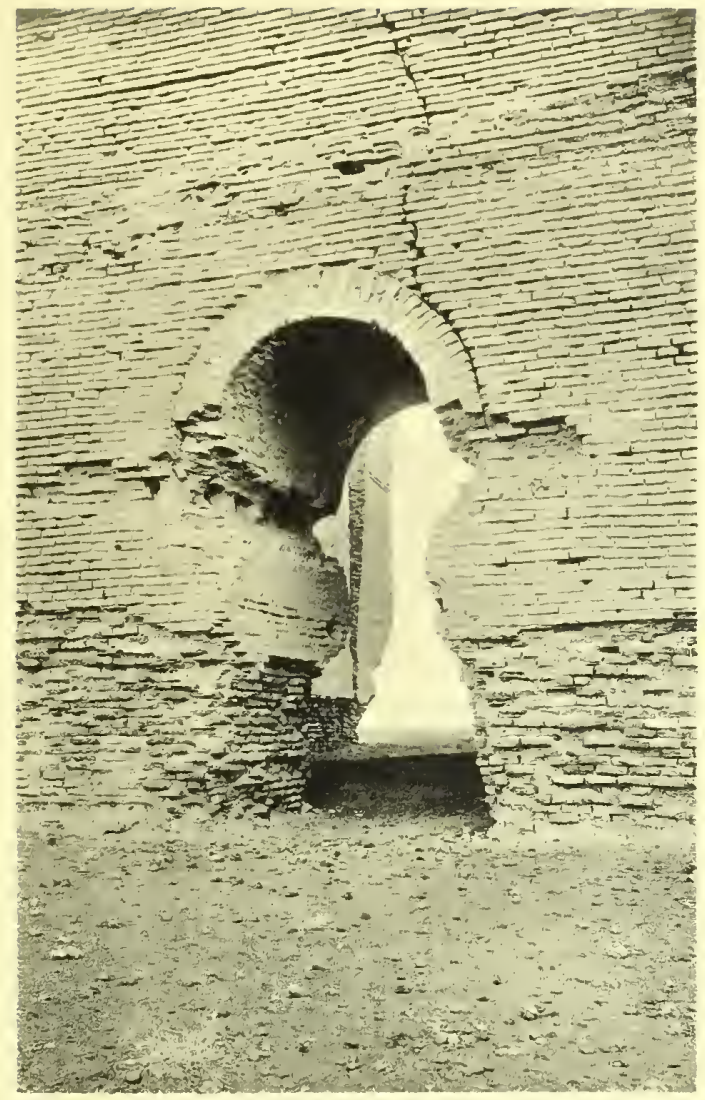

Ṭāq i Kissãu, Tưr der Rückwand

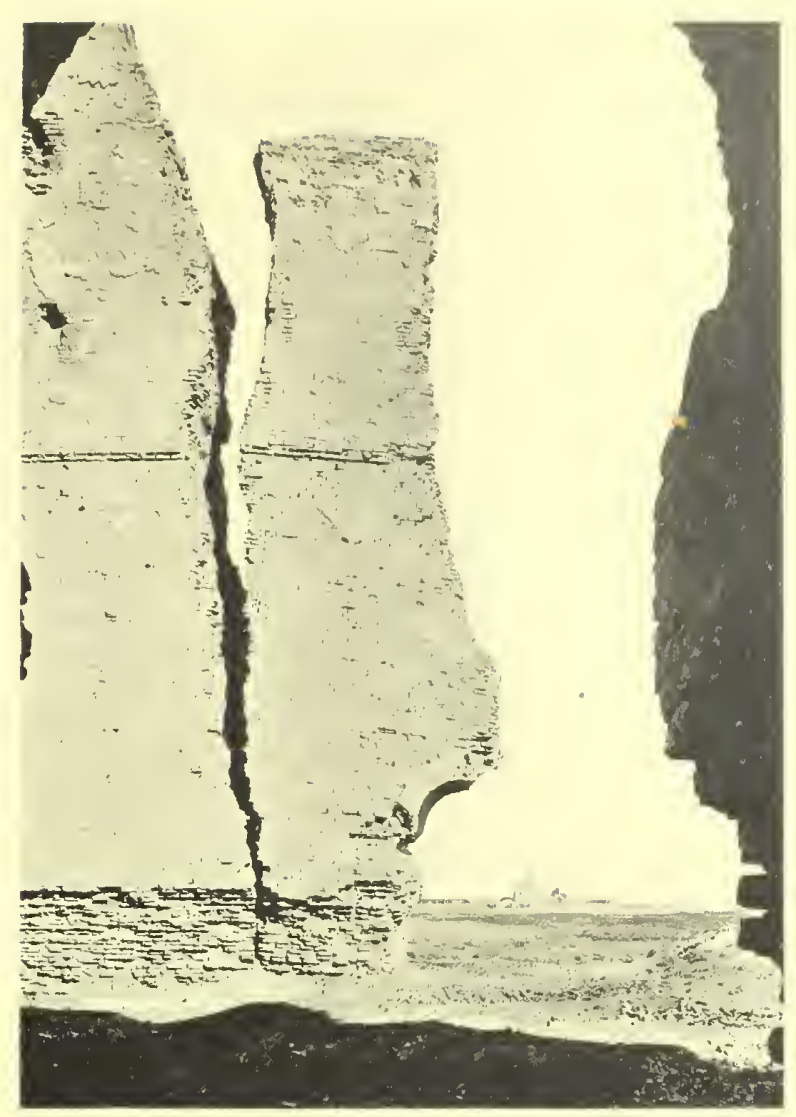

Tạq i Kisrā (1908) Blick durch Seitentür

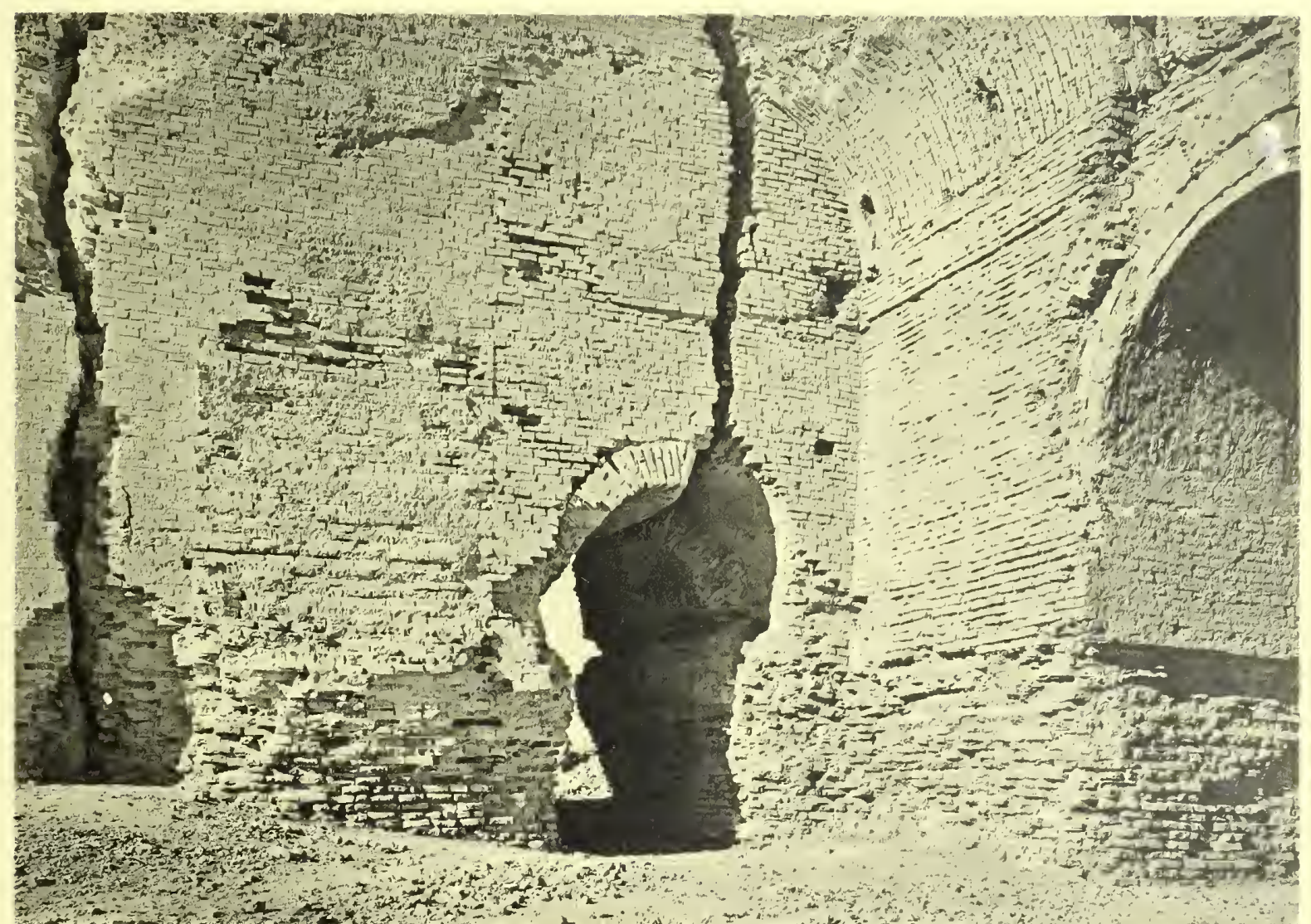

KTESIPHON, Tāq i Kisrā, Seitenraum 



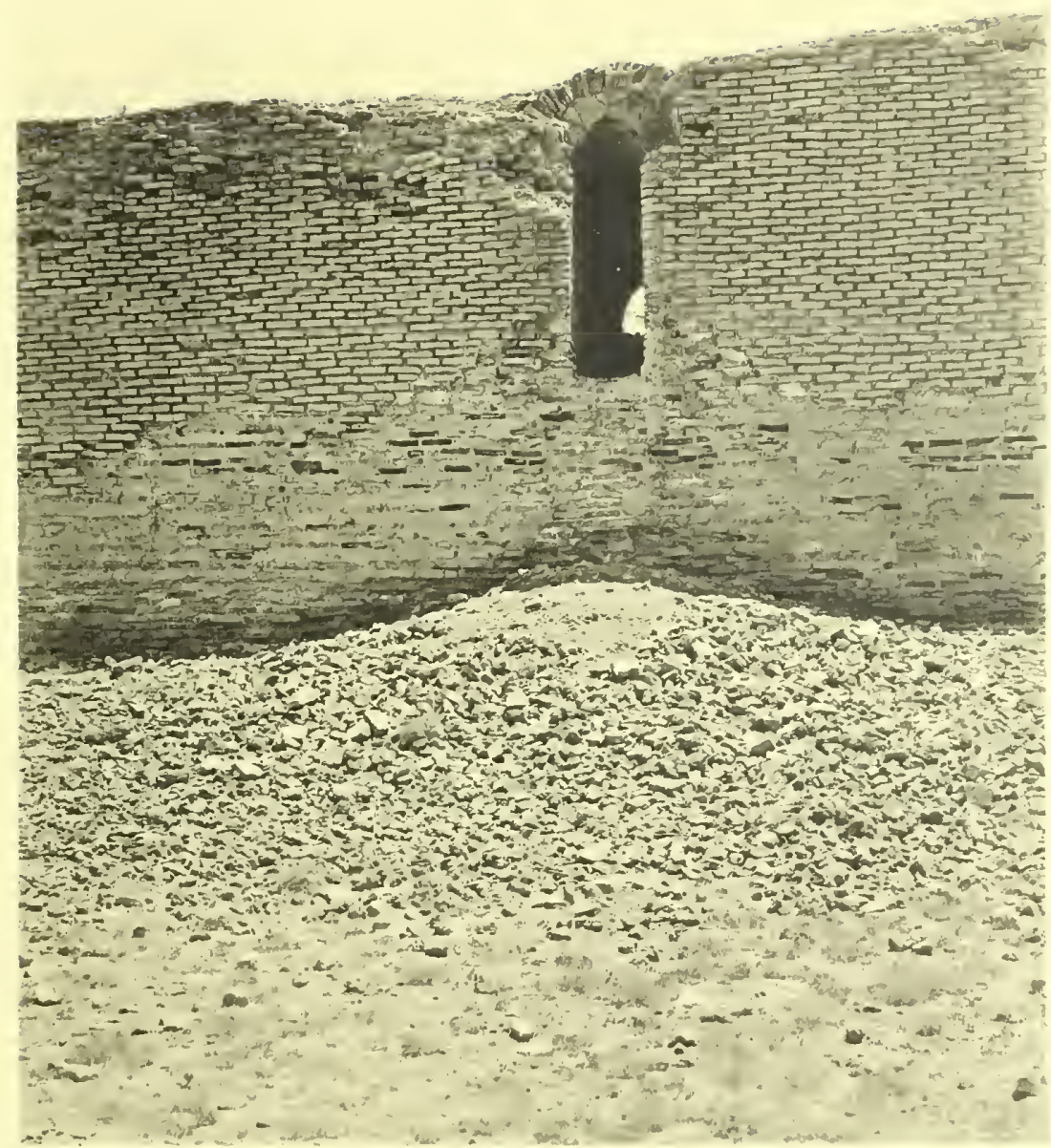

DASTAGERD, Wehrgang der Stadtmauer

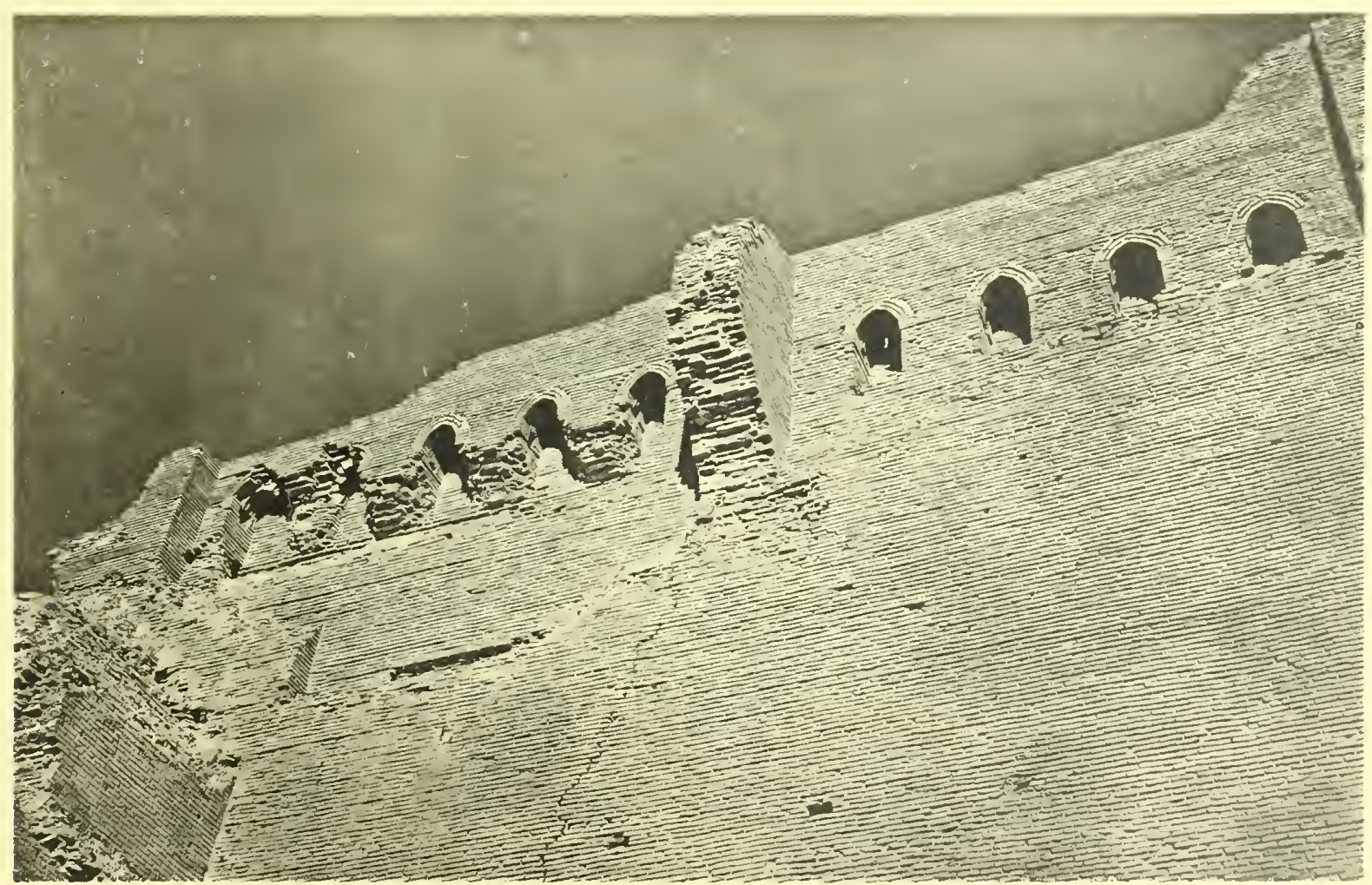

KTESIPHON, Ṭāq i Kisrā, Galerie der Rückseite der Front 


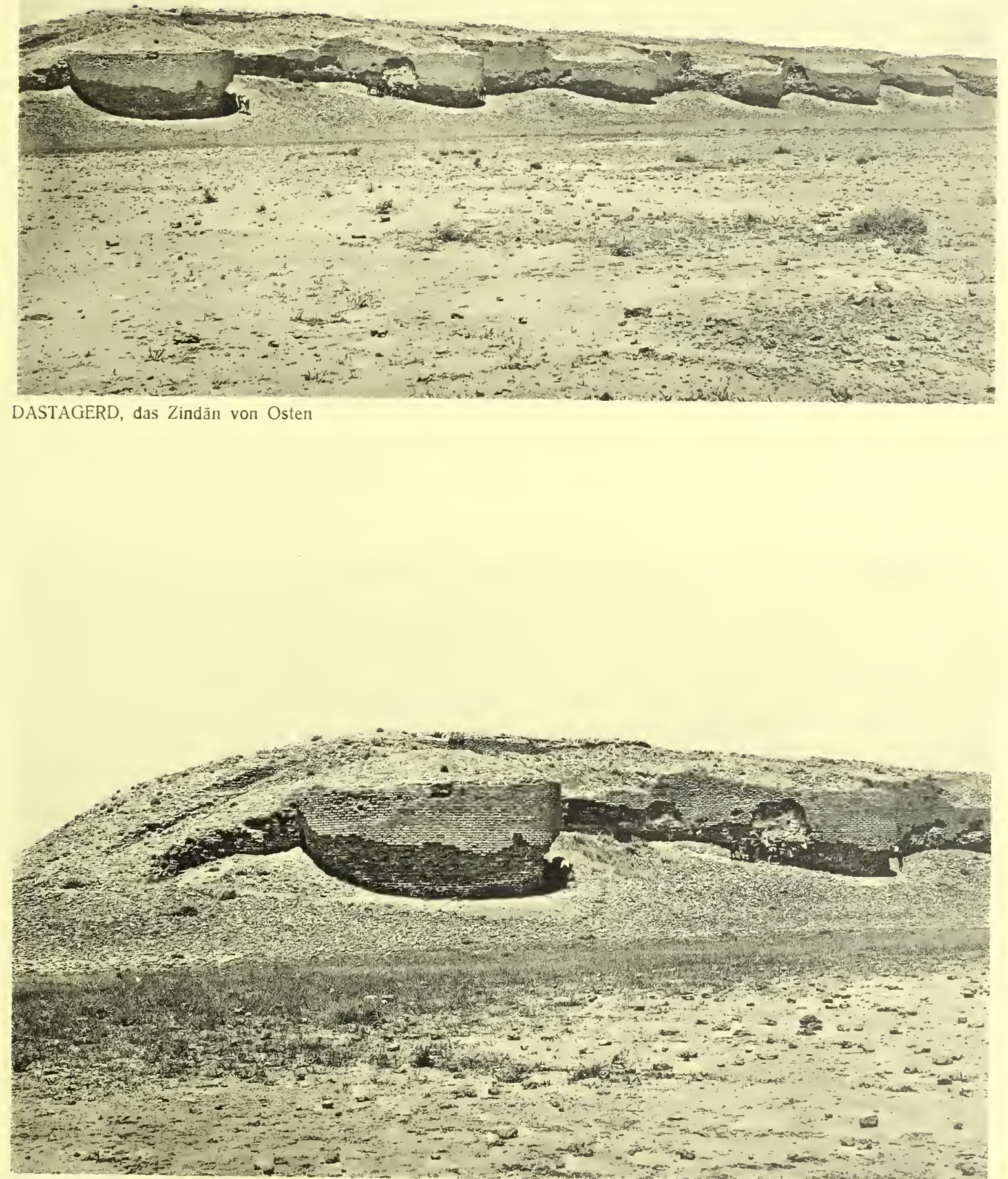

DASTAGERD, das Zindān, suddiche Turrme 



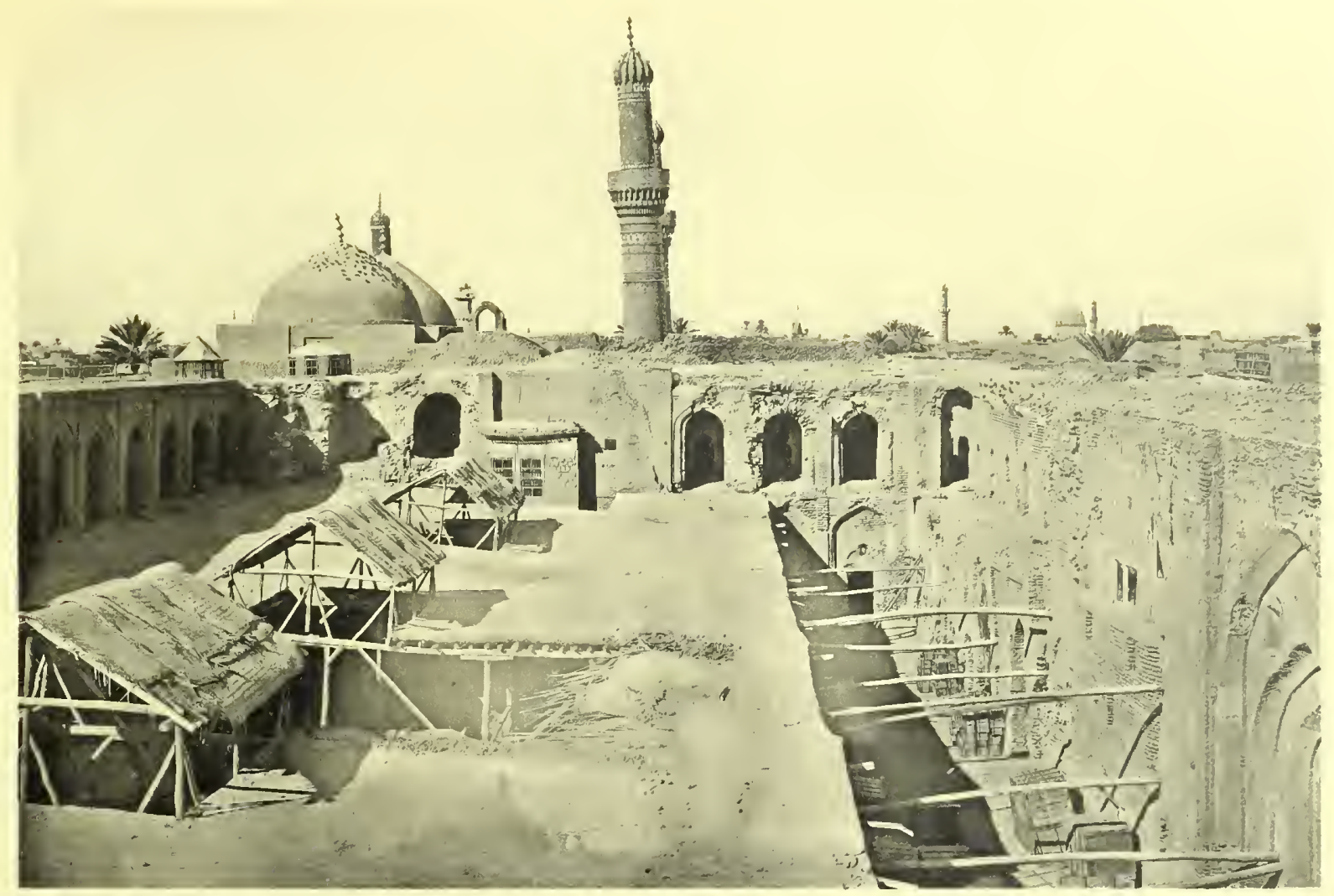

BAGHDAD, die Mustanșiriyyah

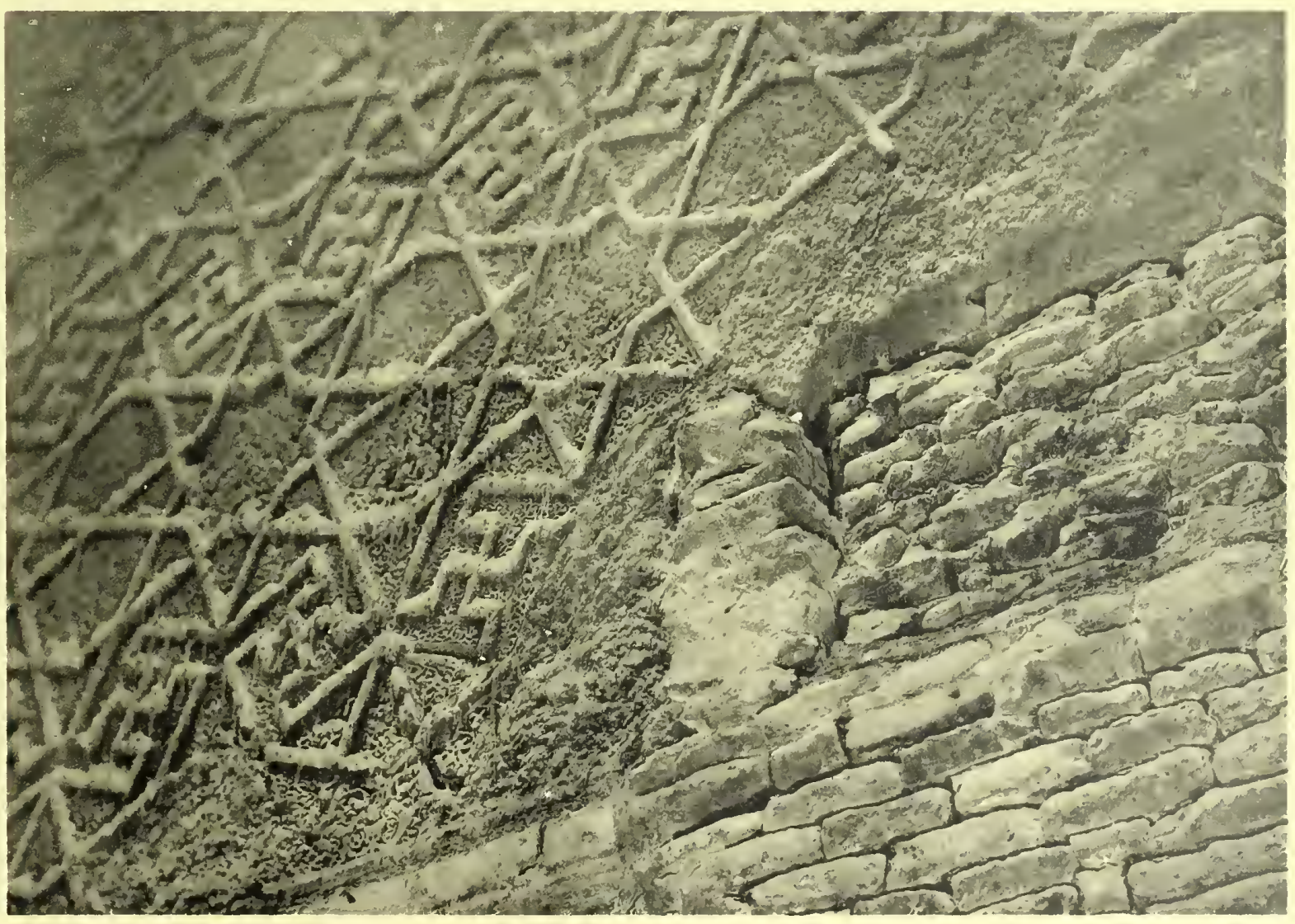

BAGHDAD, Decoration inı nördlichen Īwān der Mustanșiriyyah 


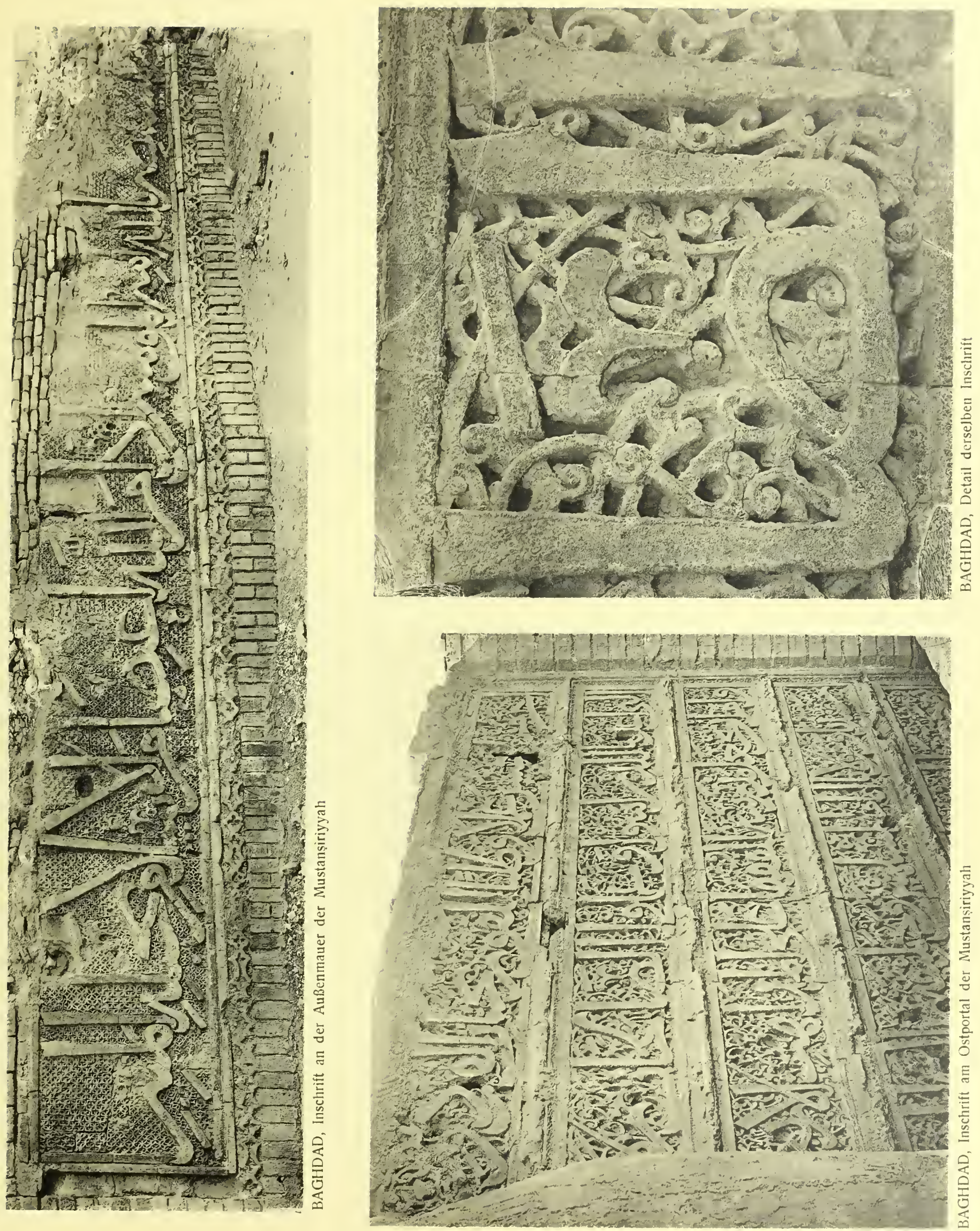



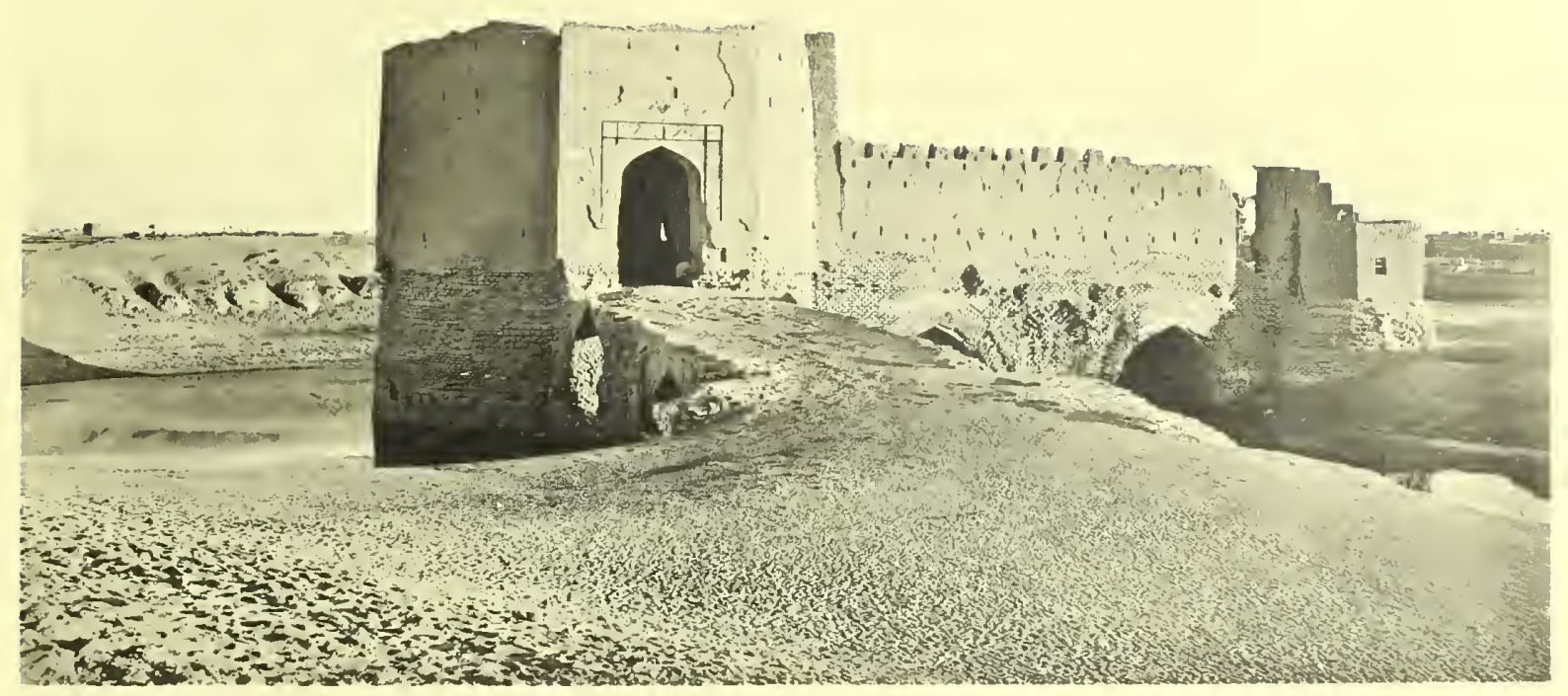

BAGHDAD, Bāb al-wasțănt von außen

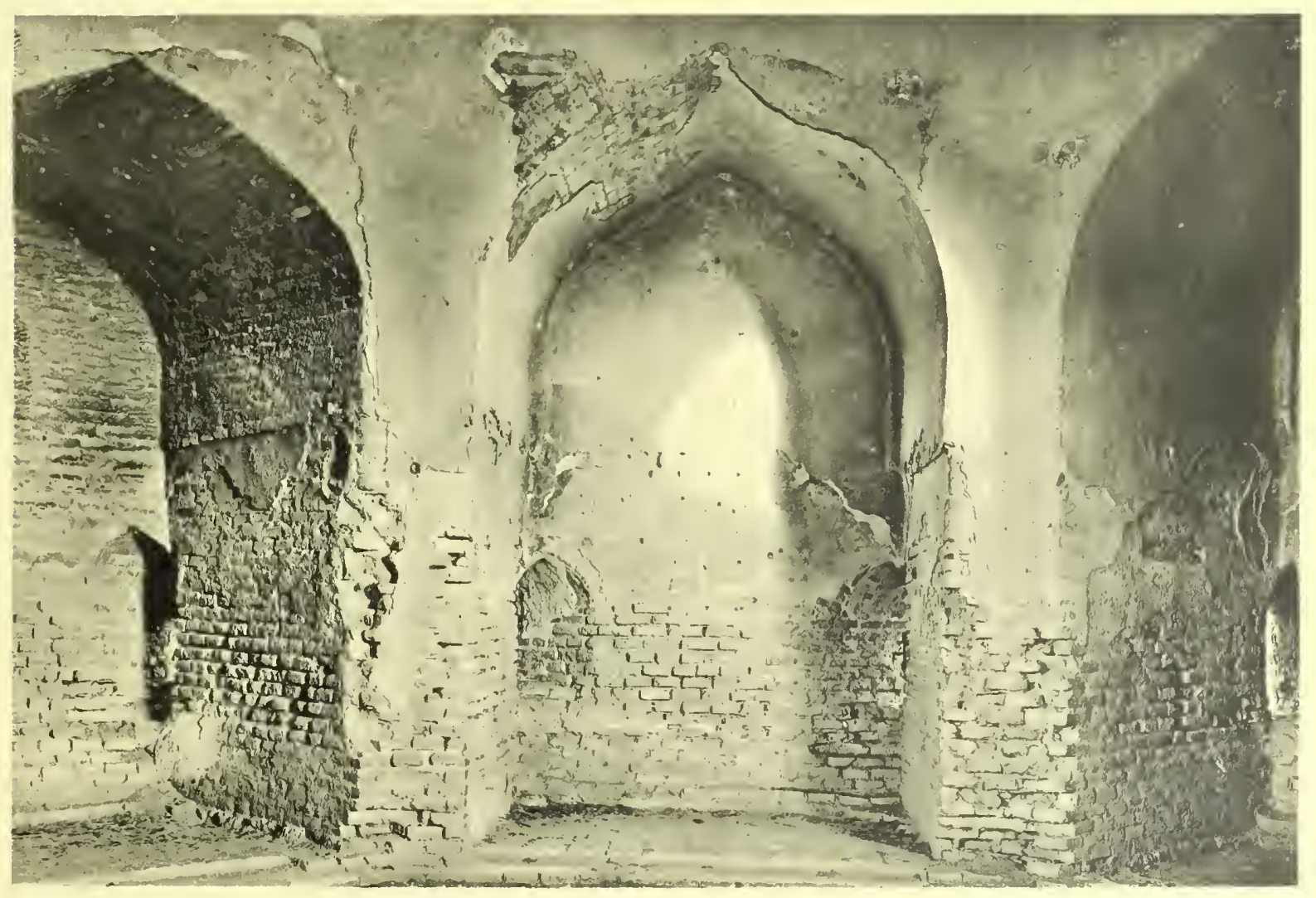

BAGHDAD, Inneres des Bāb al-wasțāni 



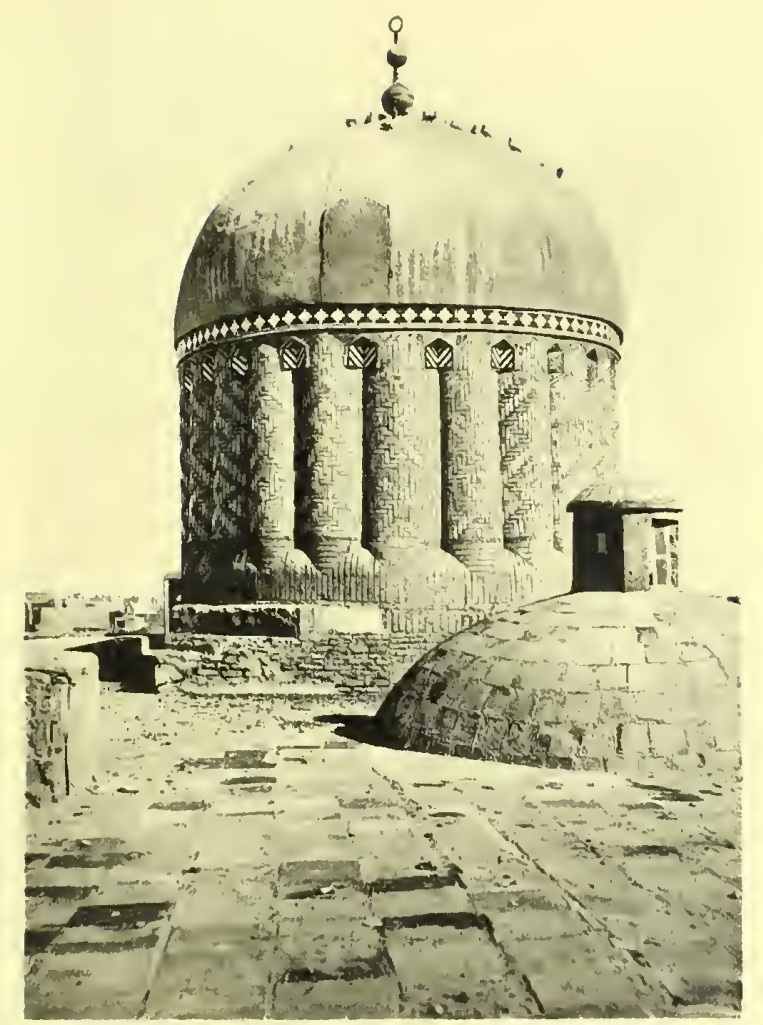

BAGHDAD, Kuppel der Mirdjāniyyah

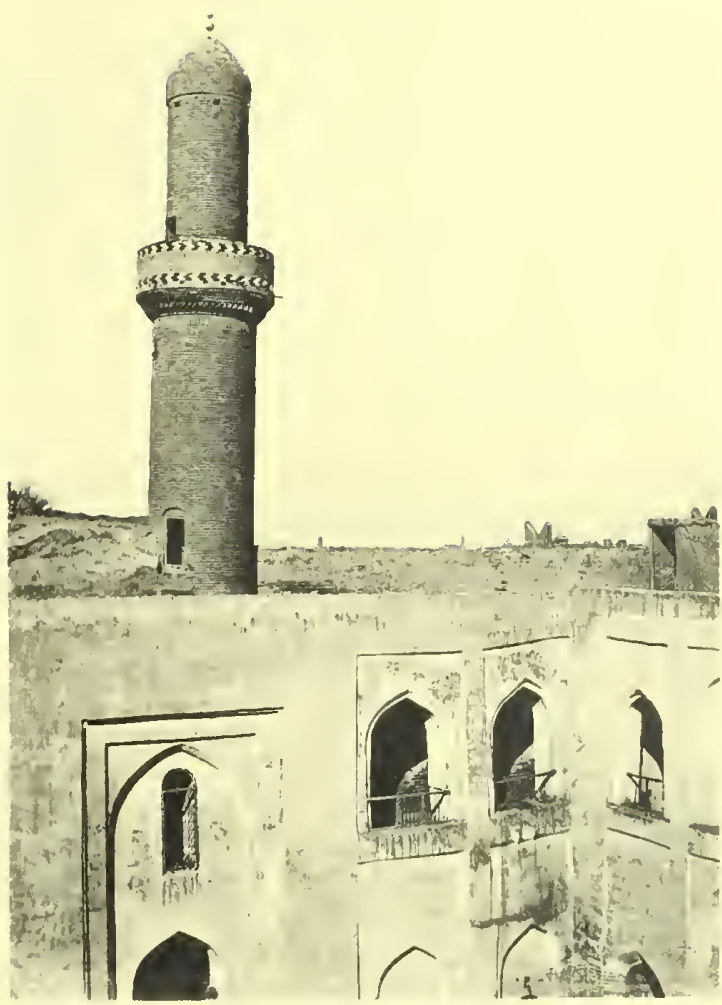

BAGHDAD, Hof und Minaret der Mirdjāniyyah

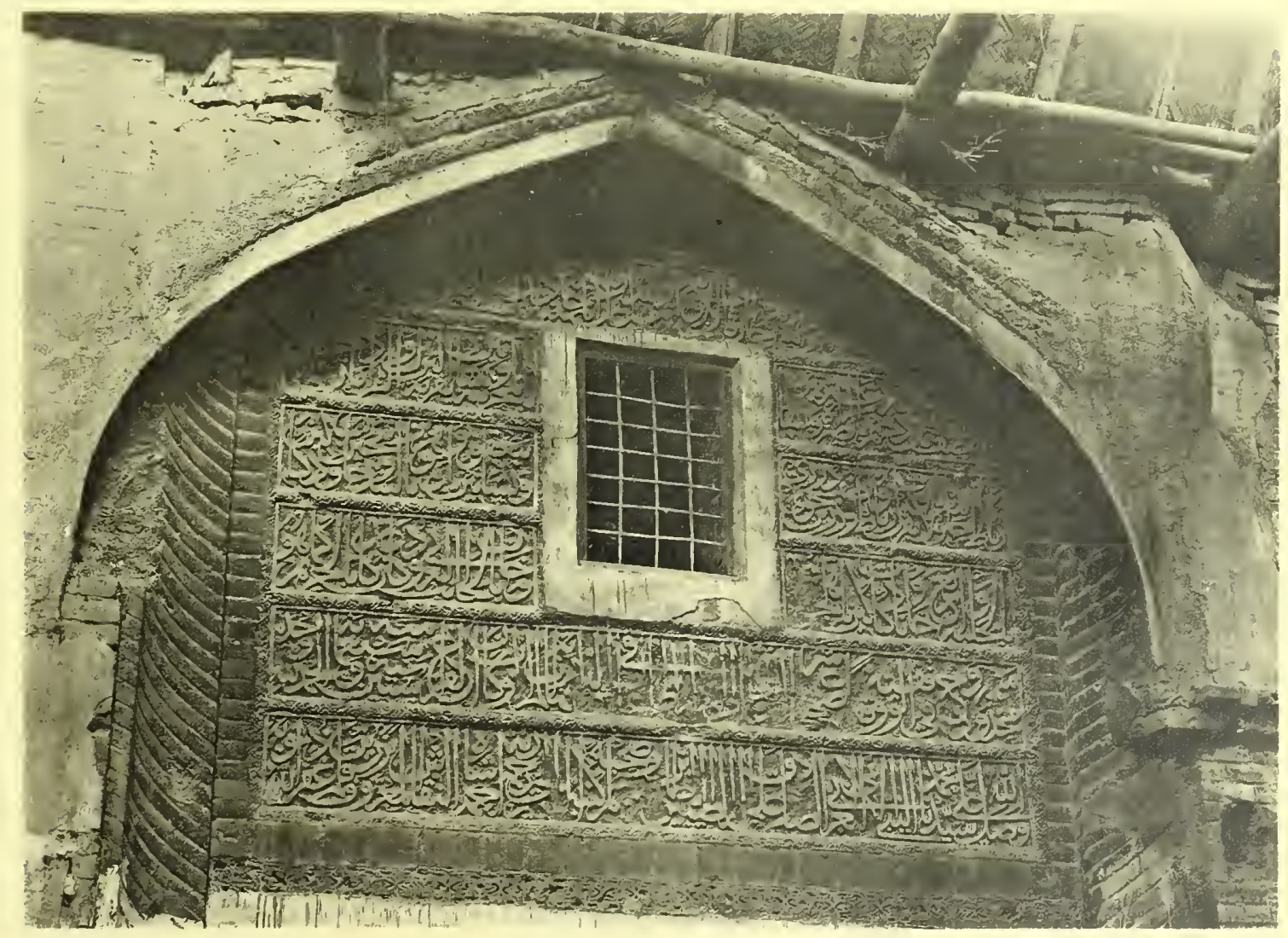

BAGHDAD, Inschrift anı Nordportal des Khān Ortmah 


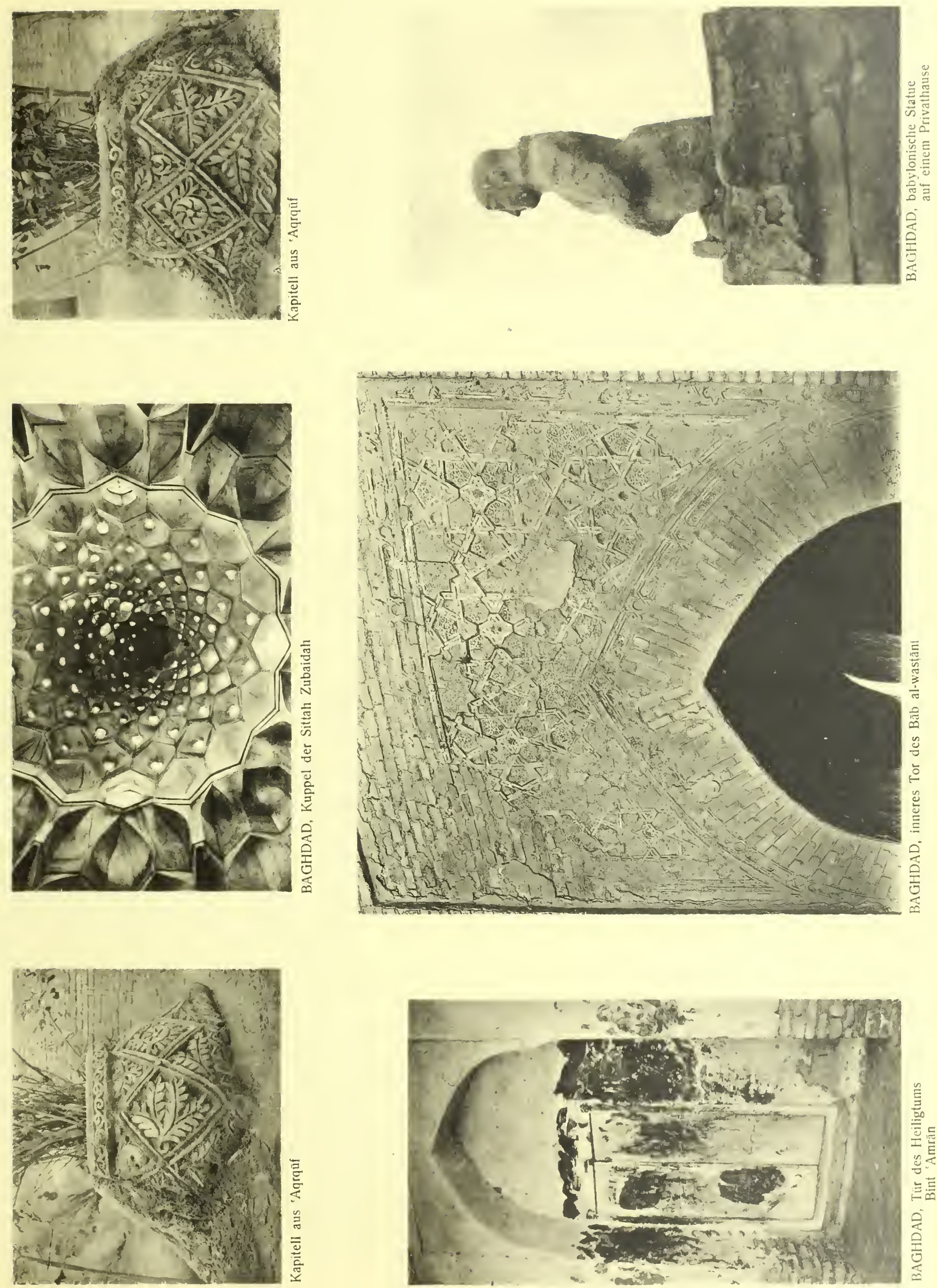



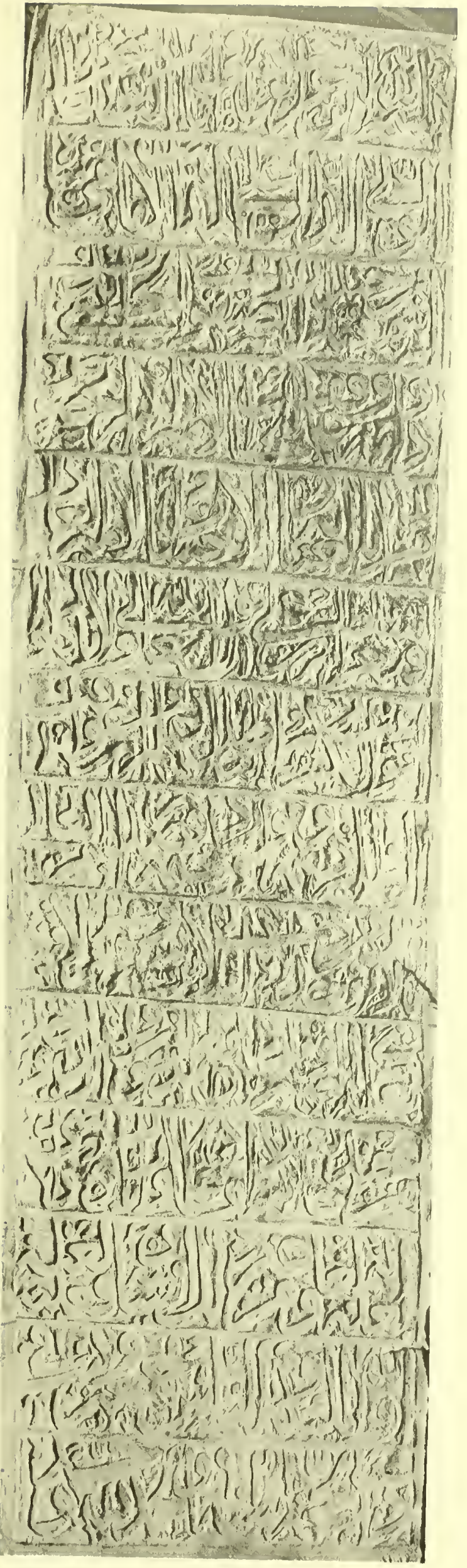

BAGHDAD, Khān Ortmah, Inschrift 5

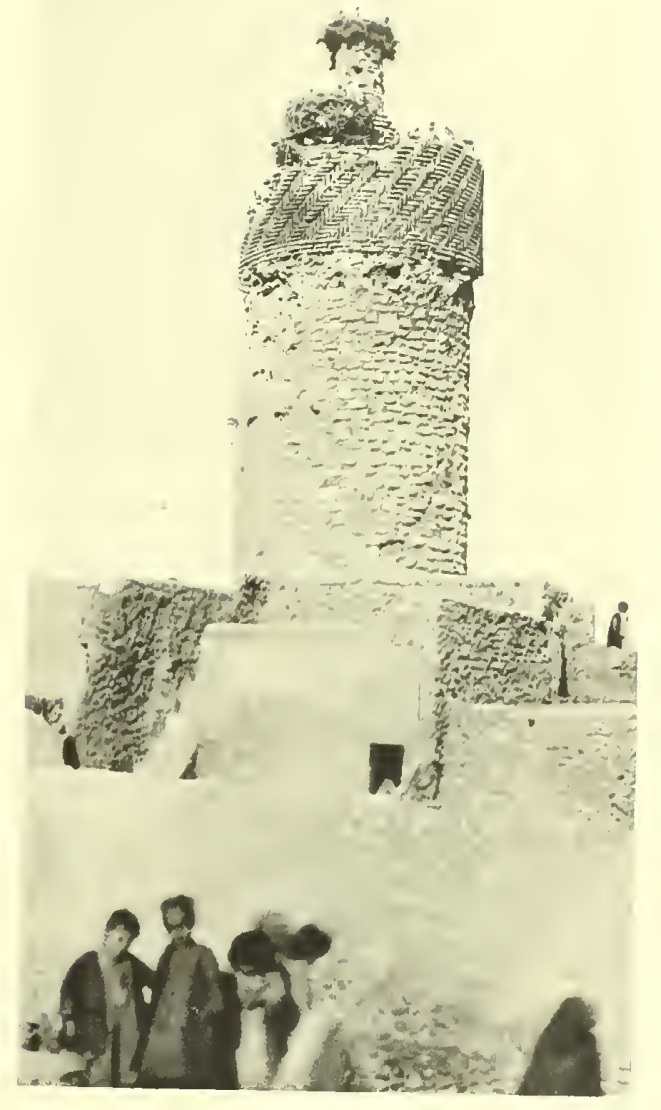

MOSUl, Manărah al-maksūrah

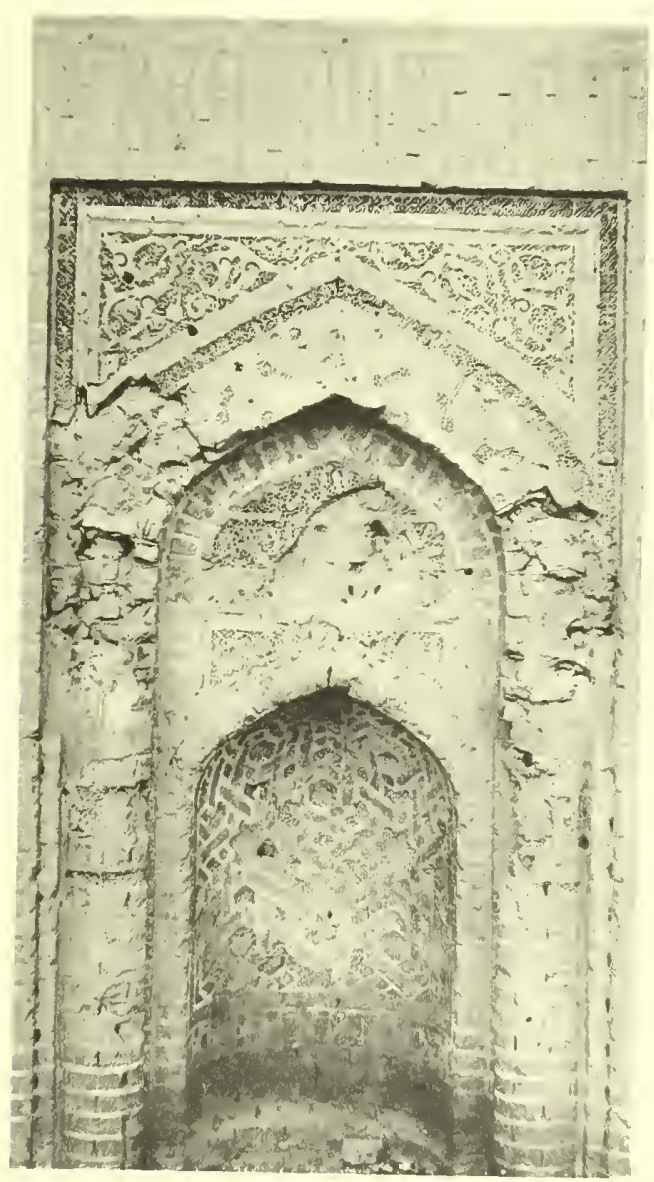

KHĀN KHARNĨNAH, Miḷrāb 



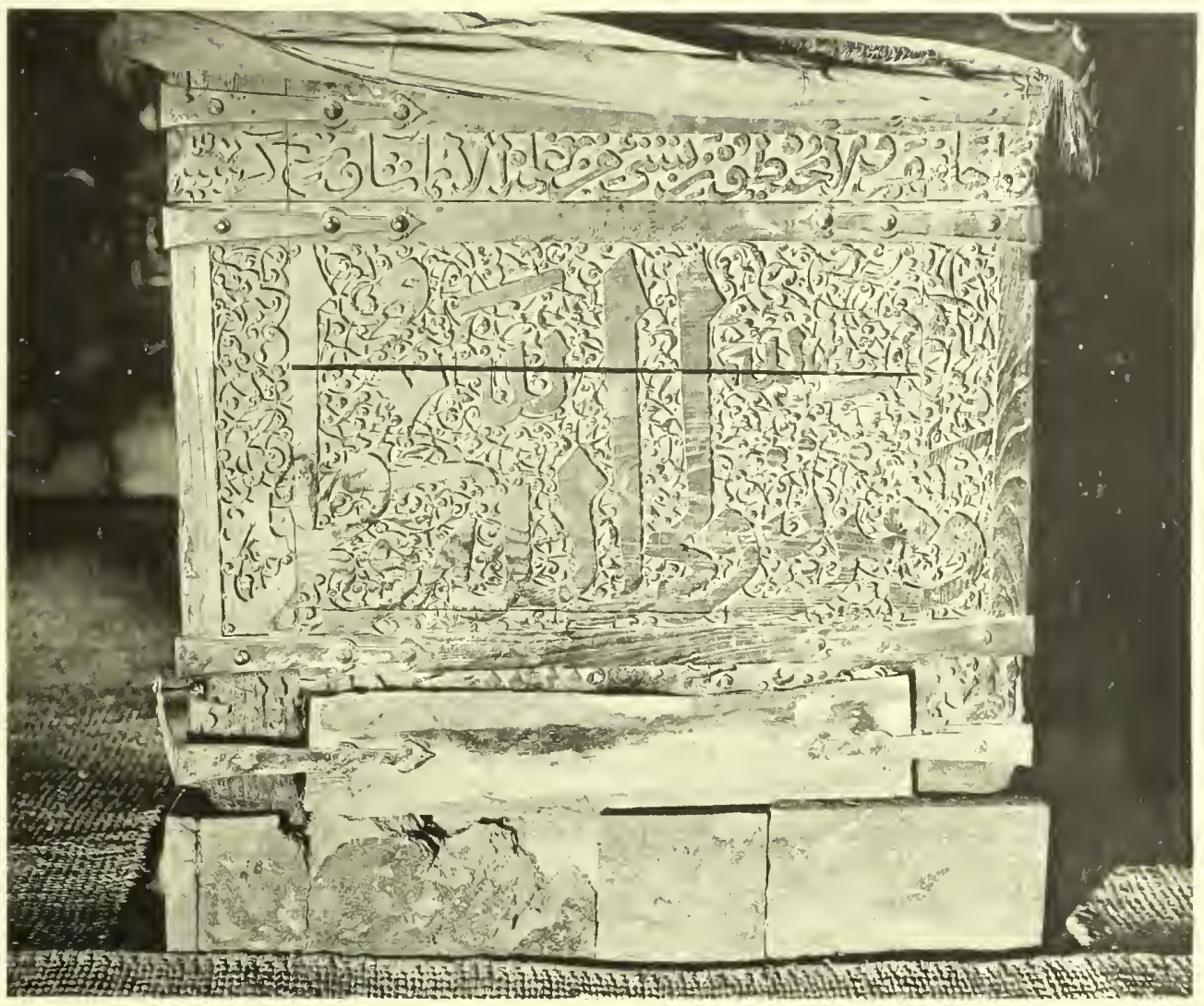

MOSLit, Kenotaph des 'Alin al-din

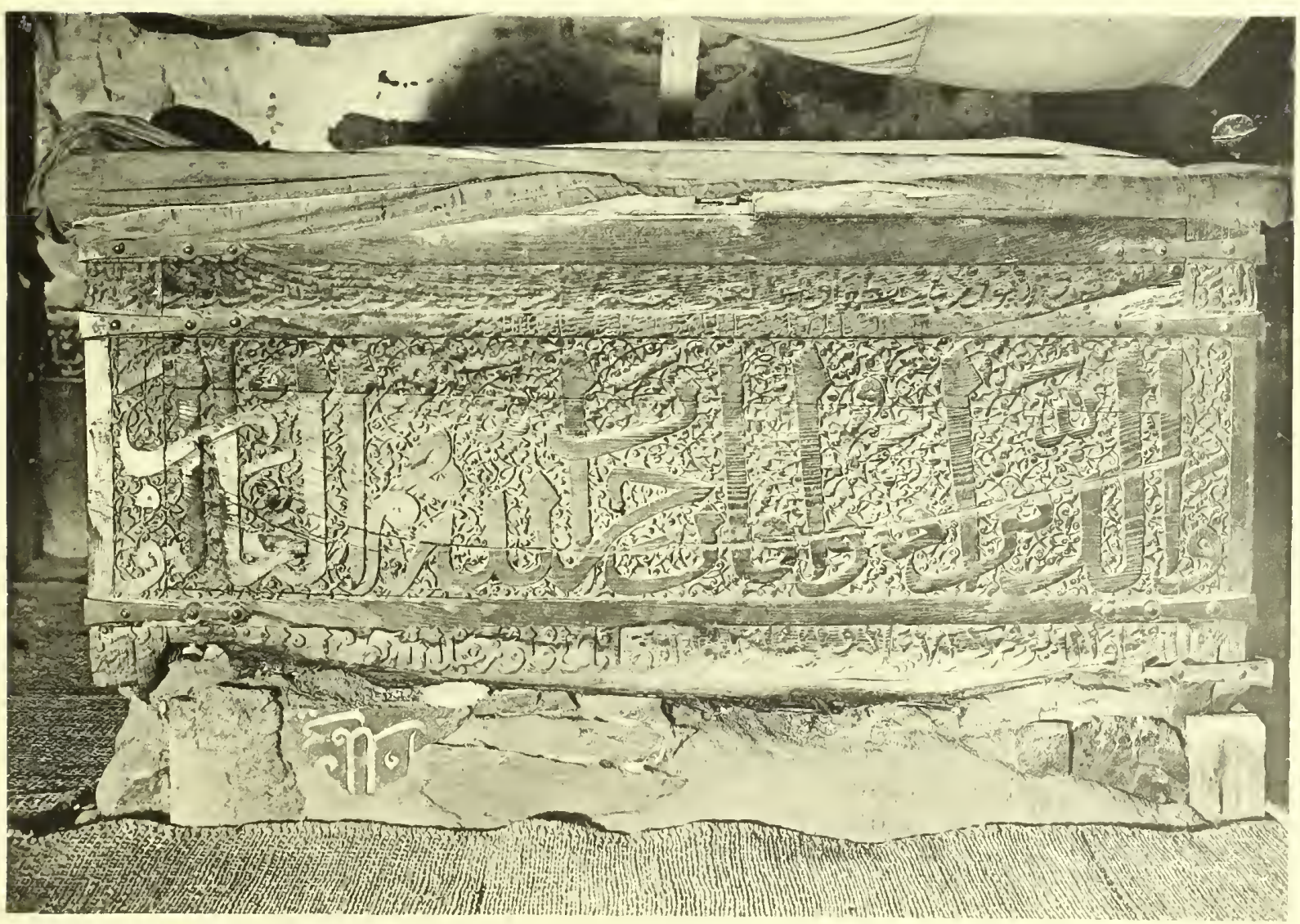

MOSuL, Kenotaplı des 'Aun al-dīn 


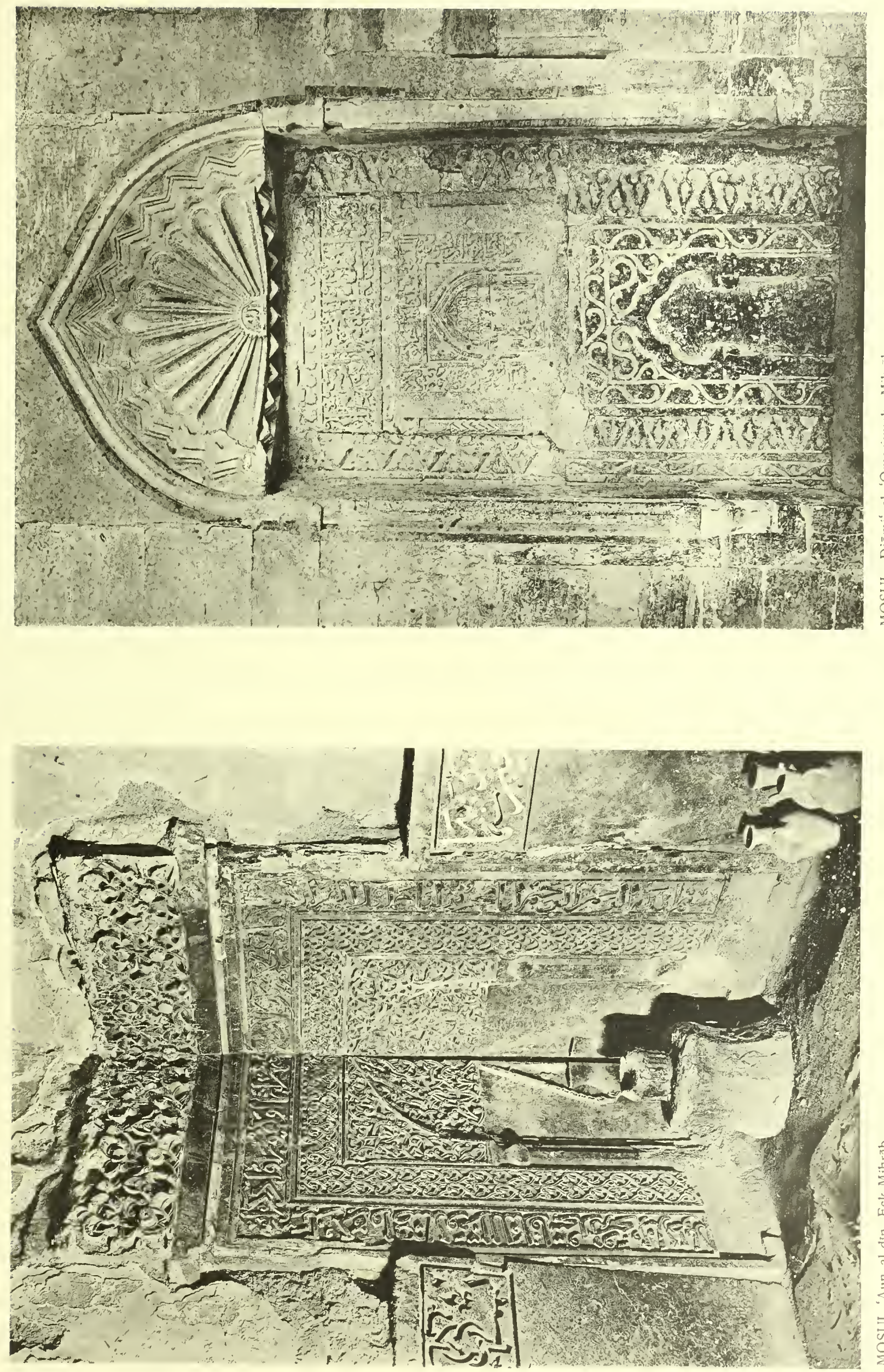


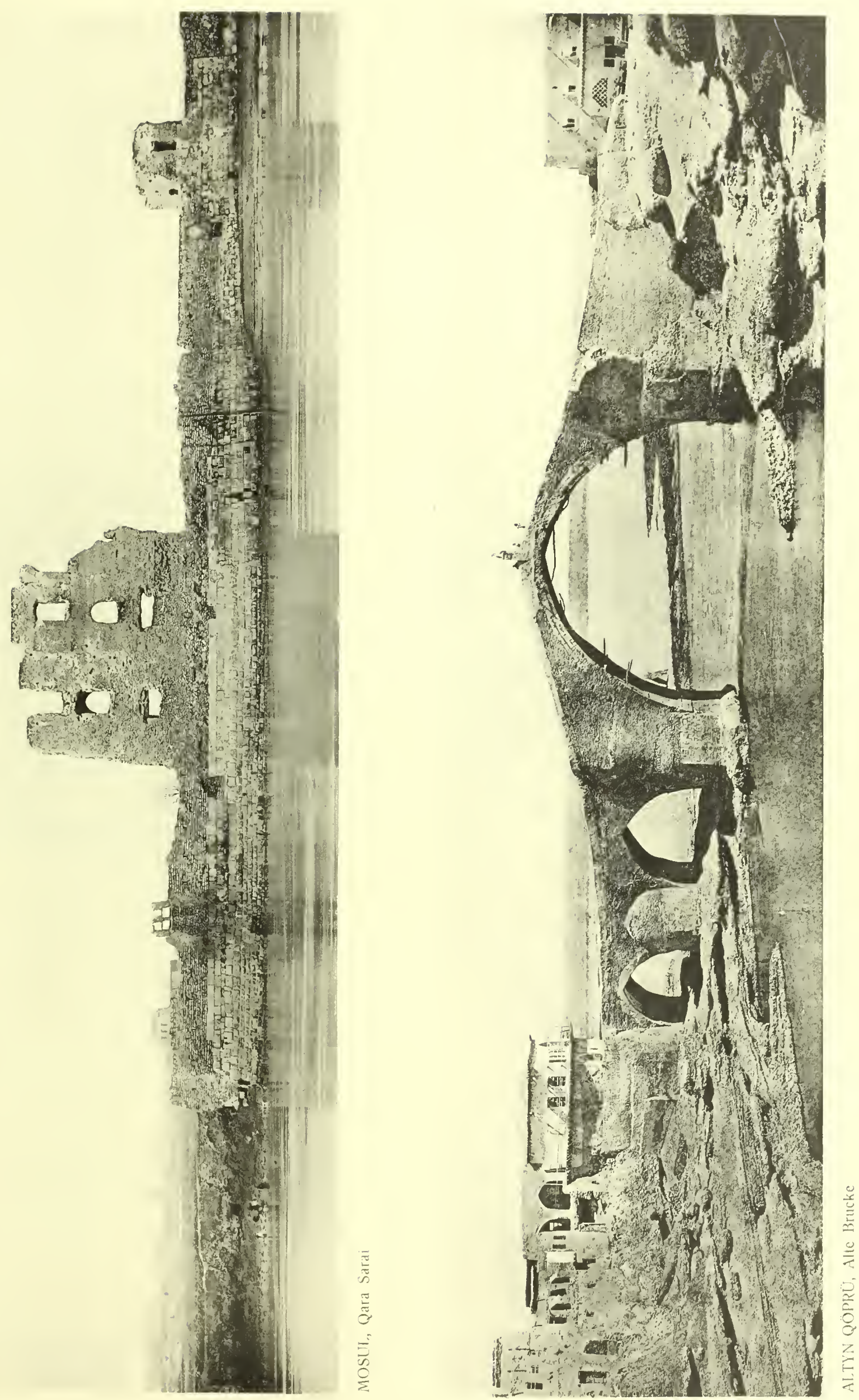


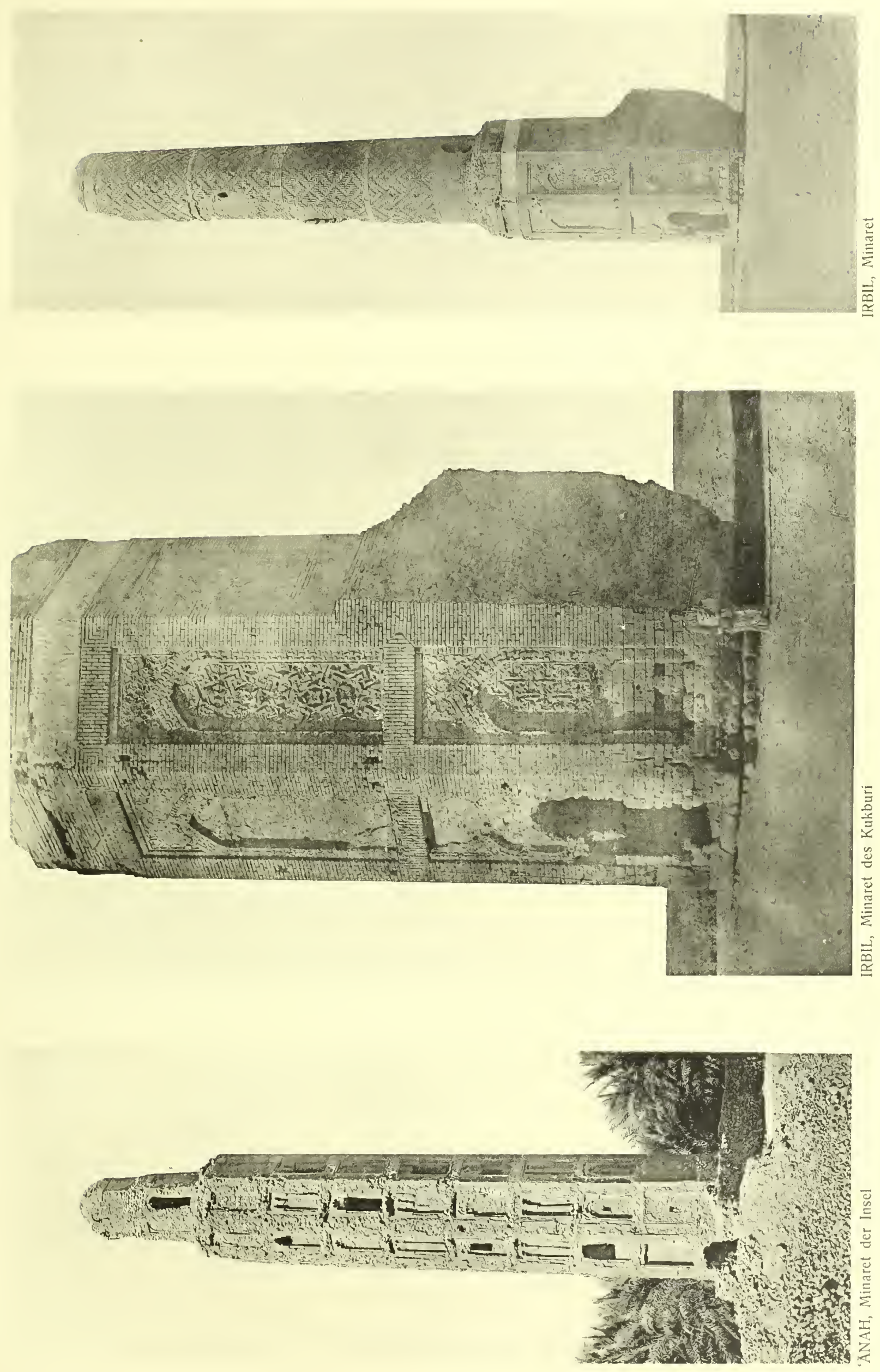



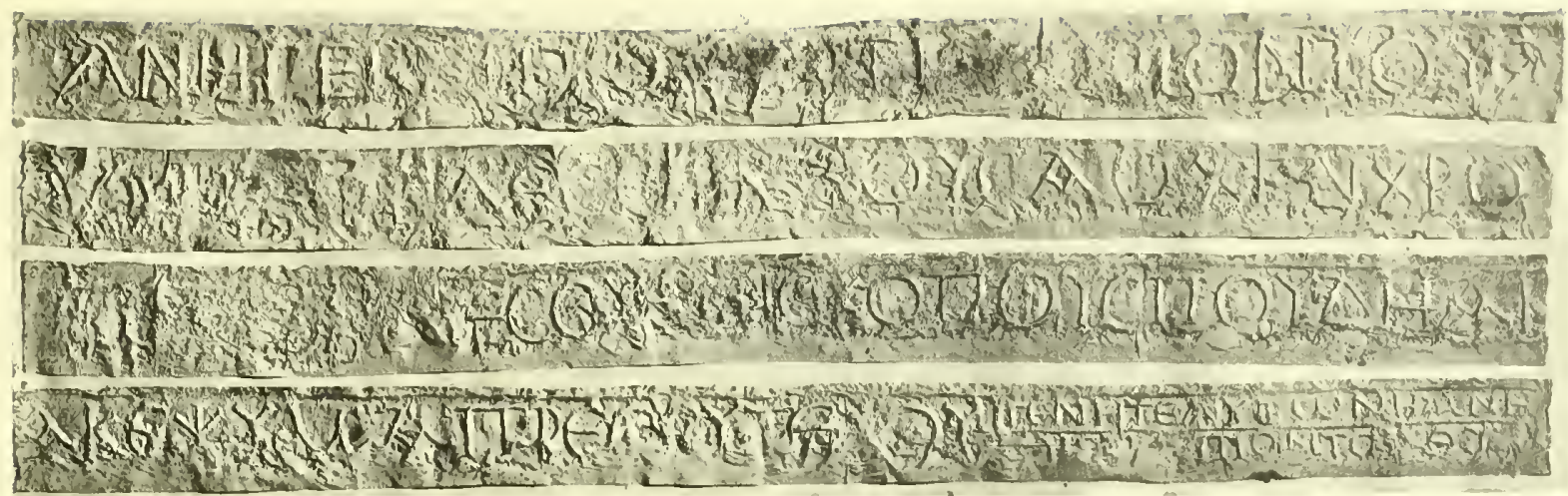

NISIBIS, Abklatsch der Iuschrift

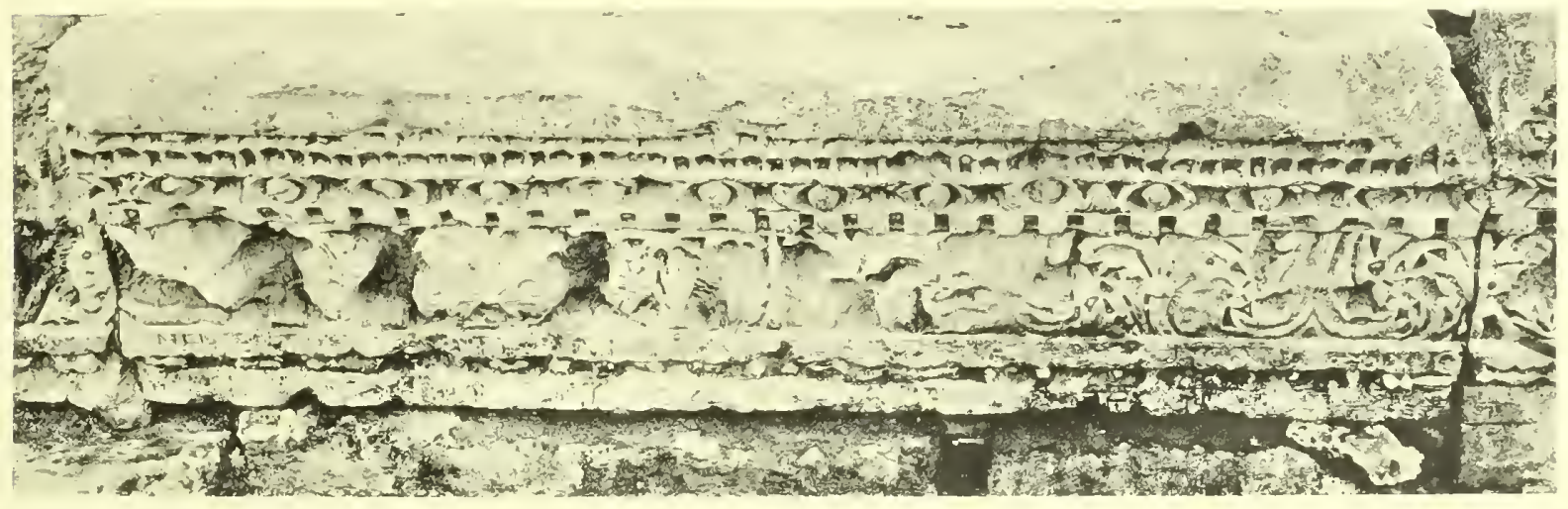

NISIBIS, Gebälk mit Inschrift

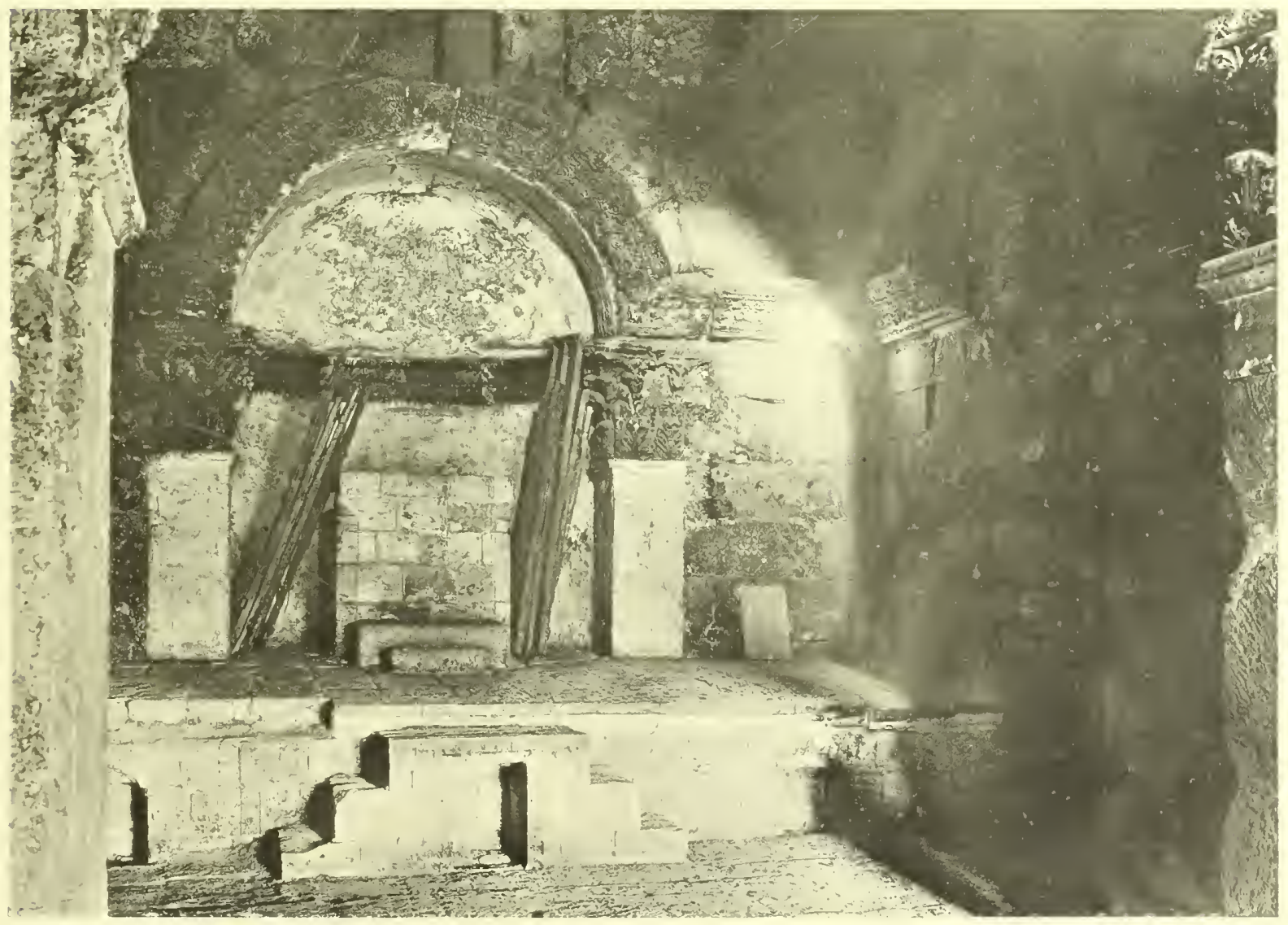

NISIBIS, Mār Ya'qūb, altes Baptisterium 


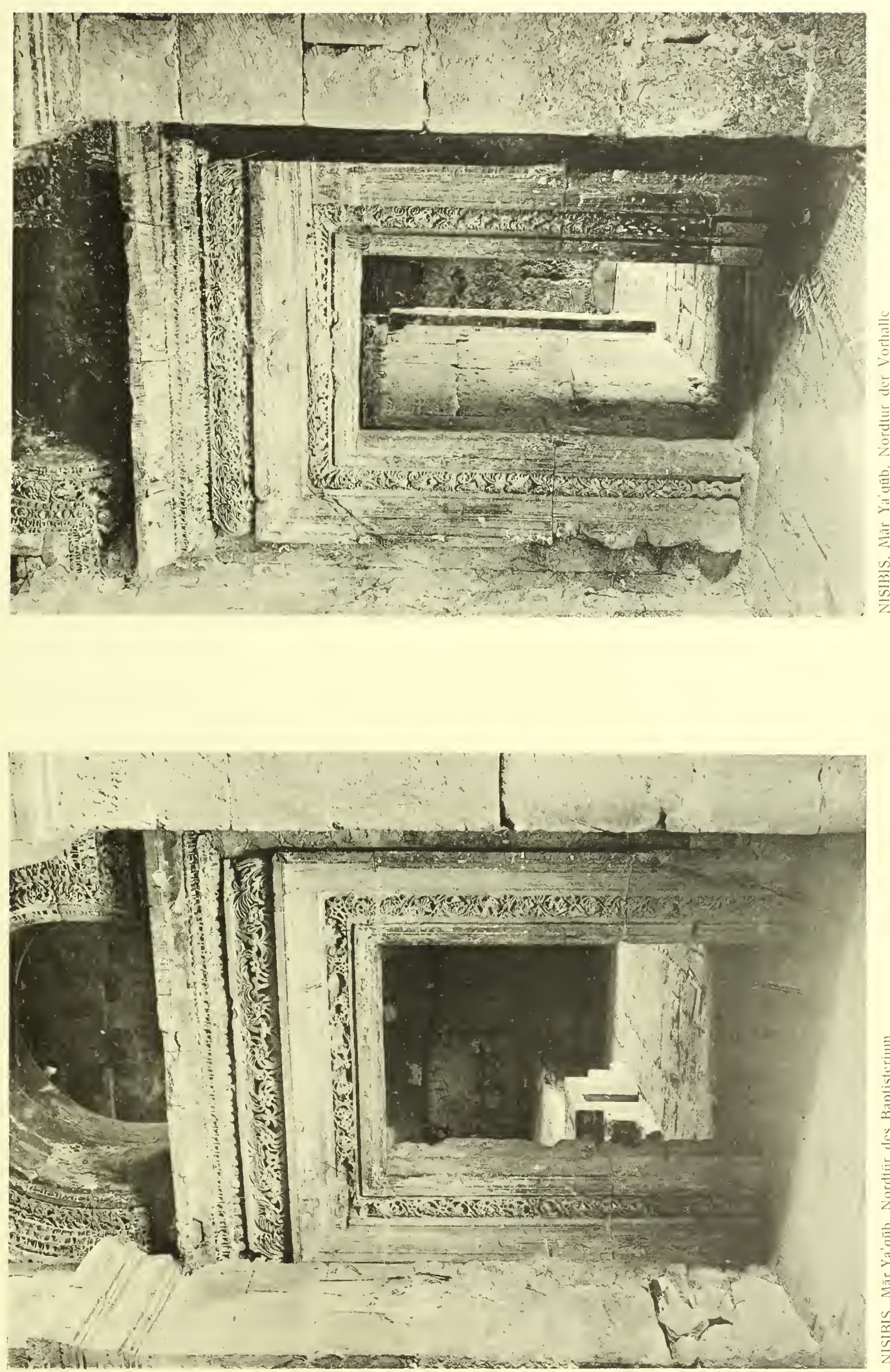


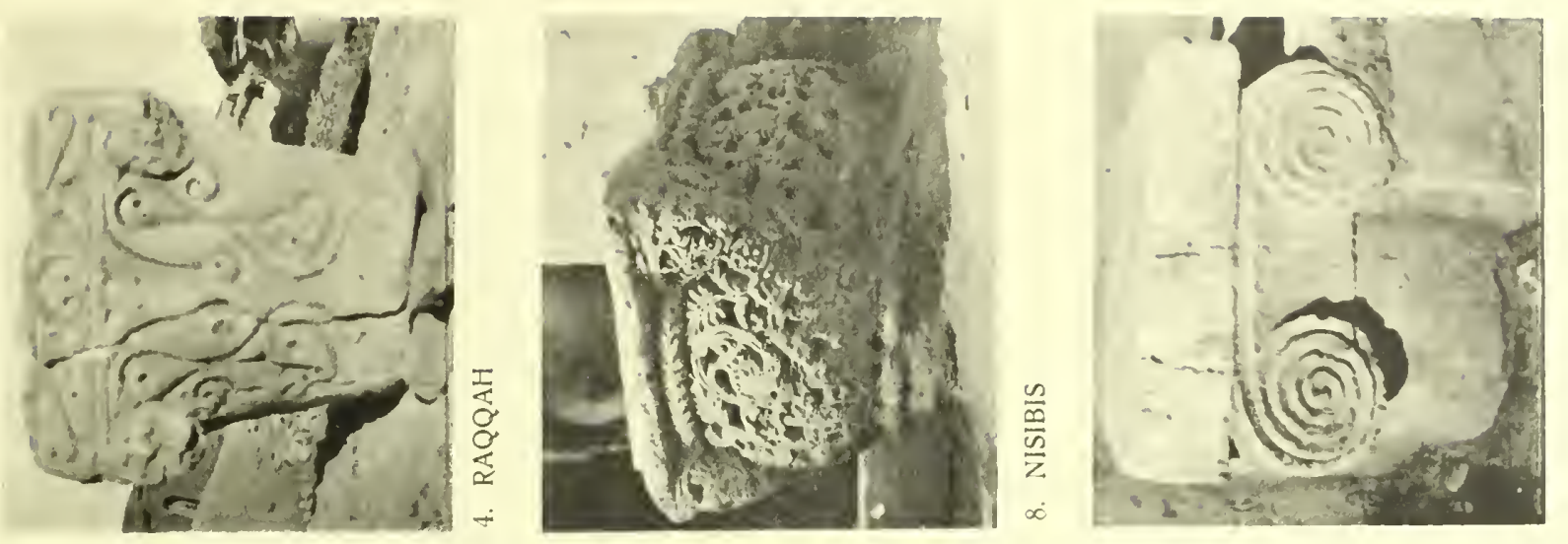

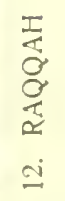
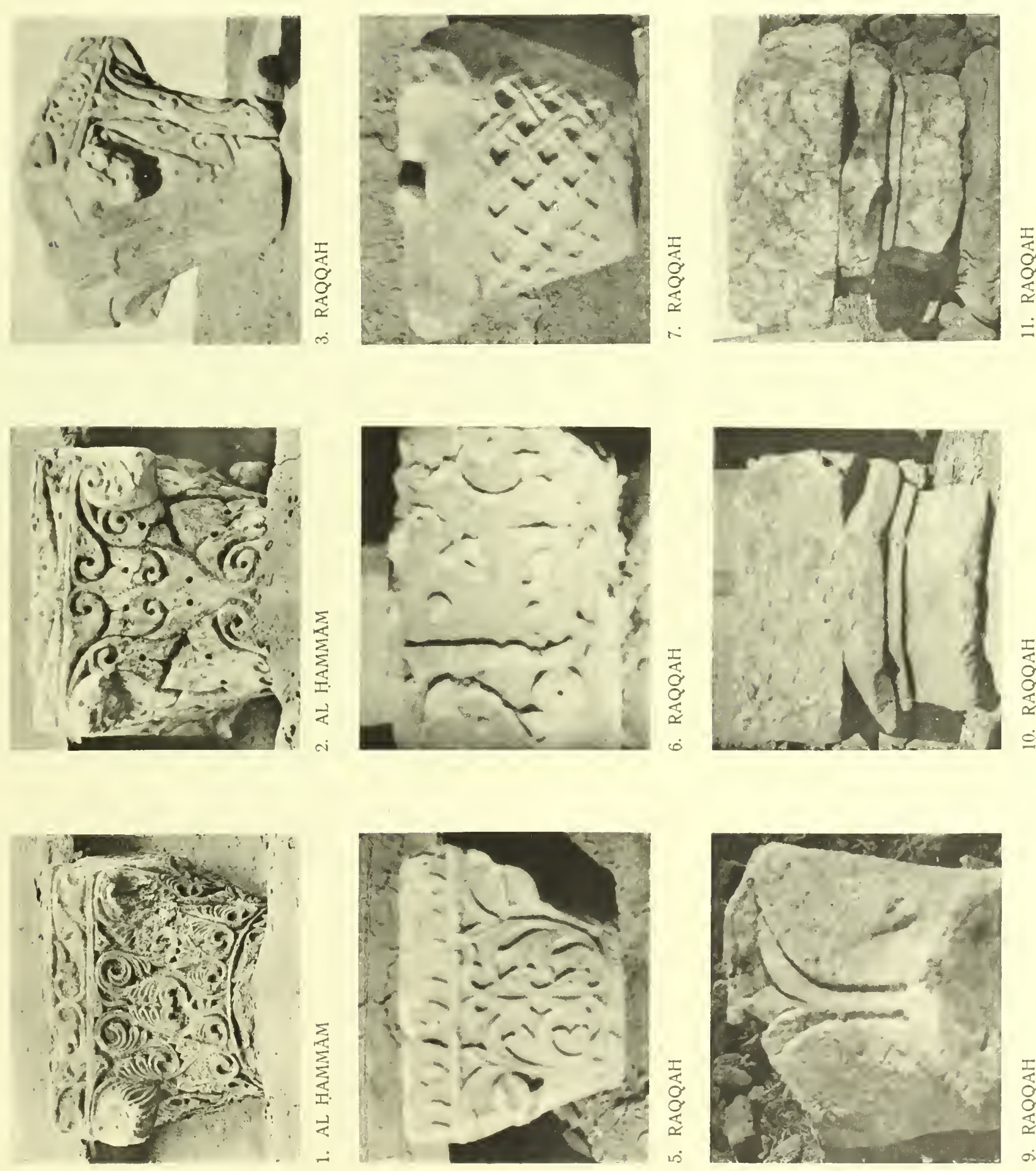

$x$
$z$
8
8
0
0
0
0 



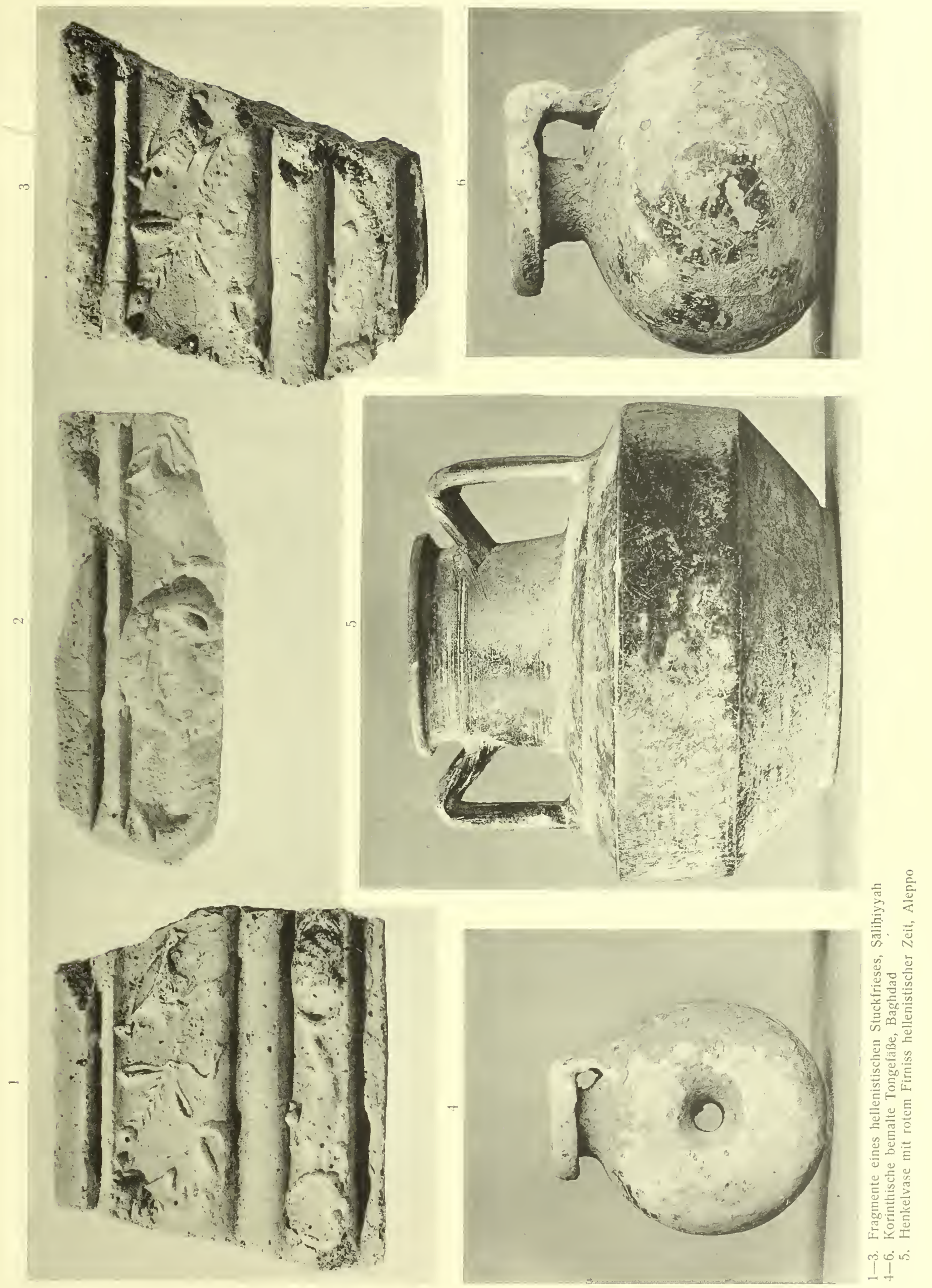




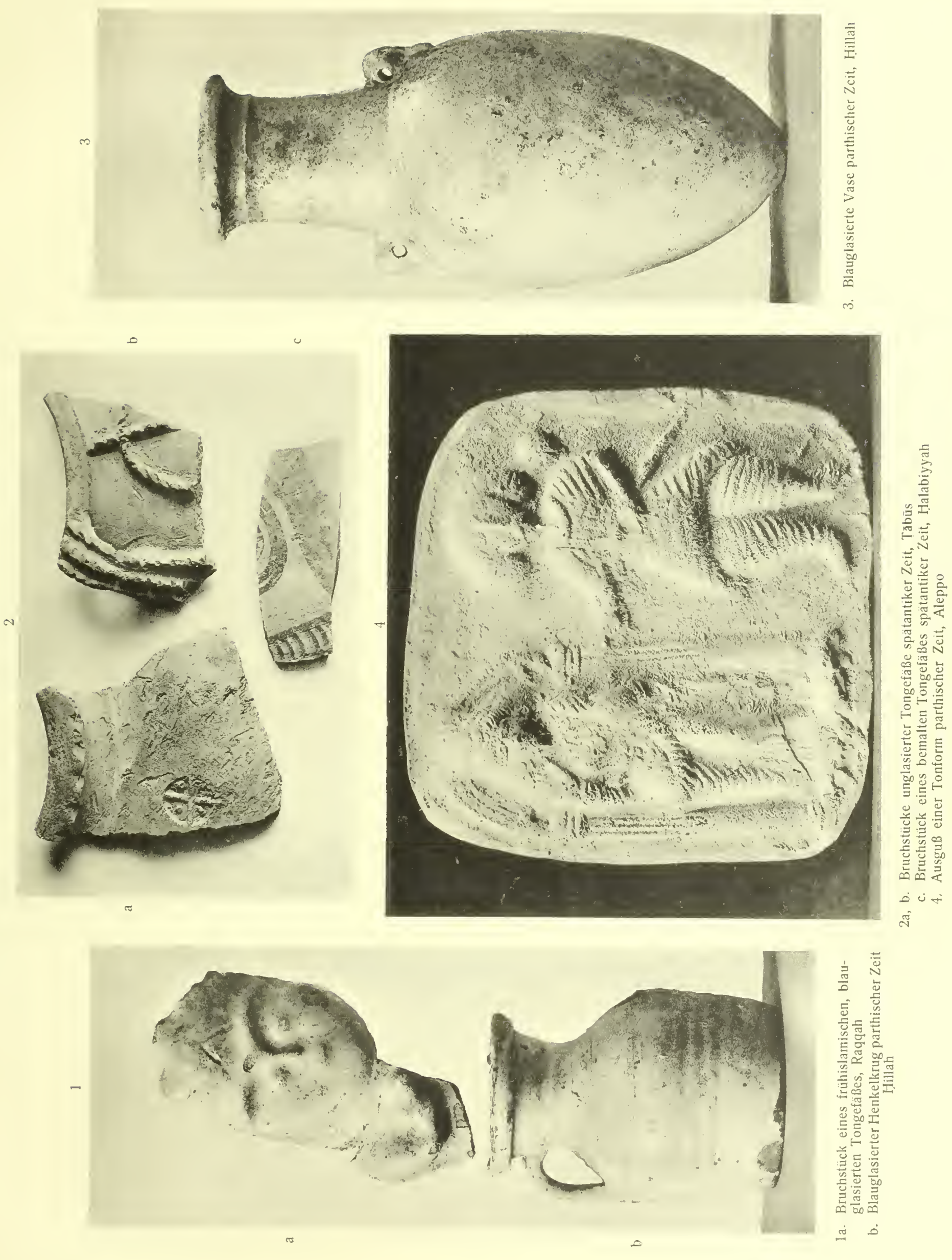


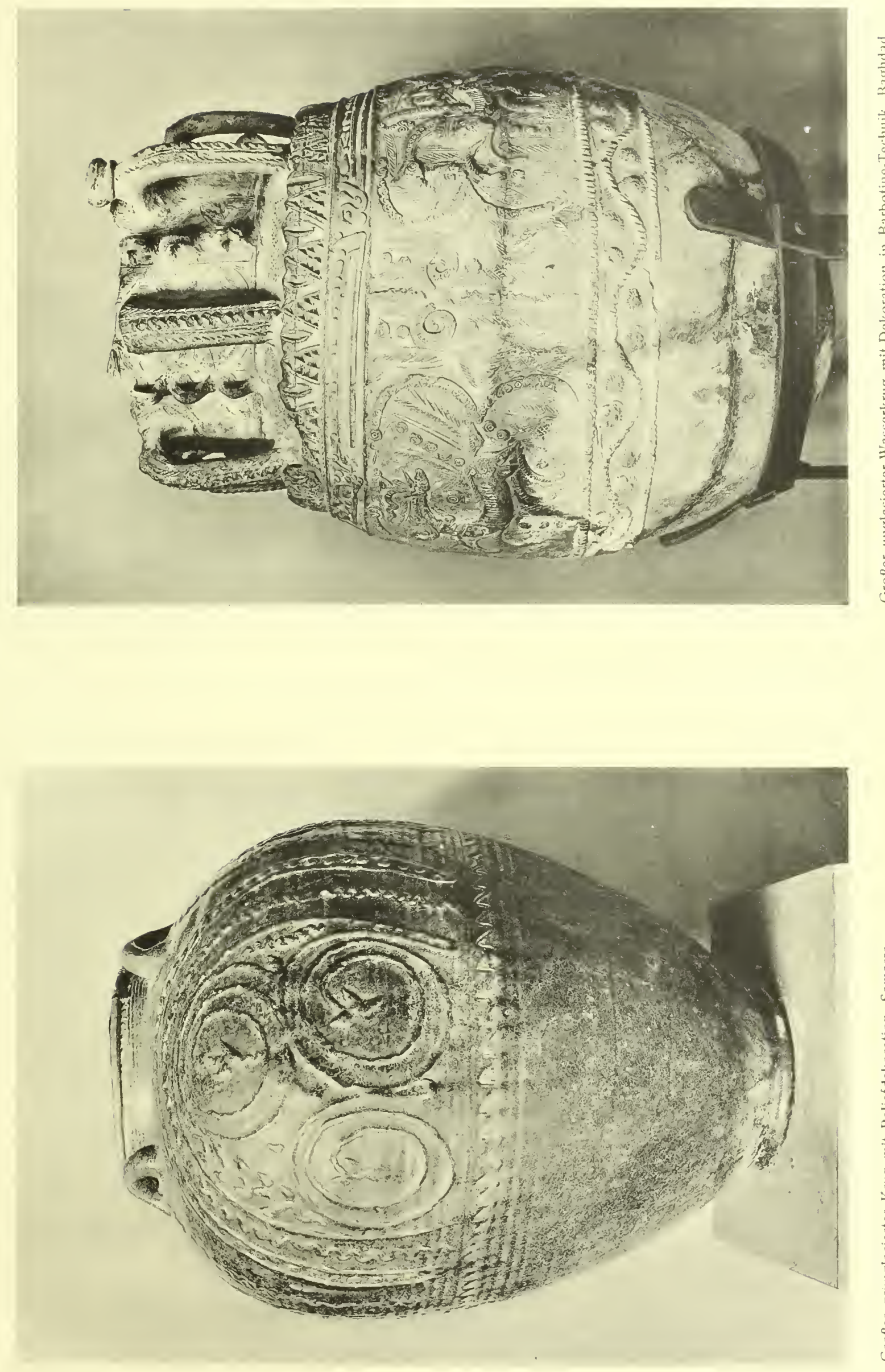


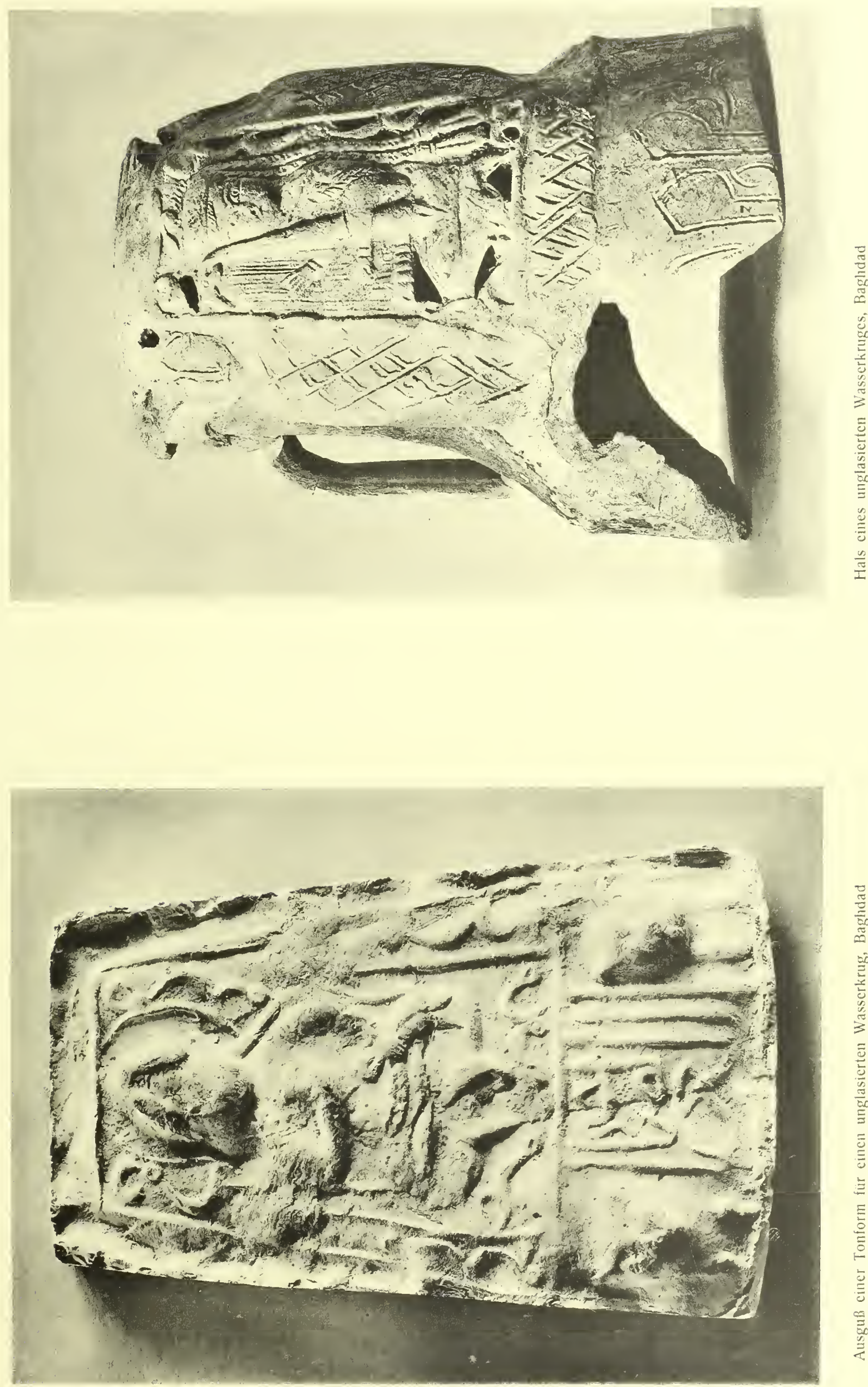

造
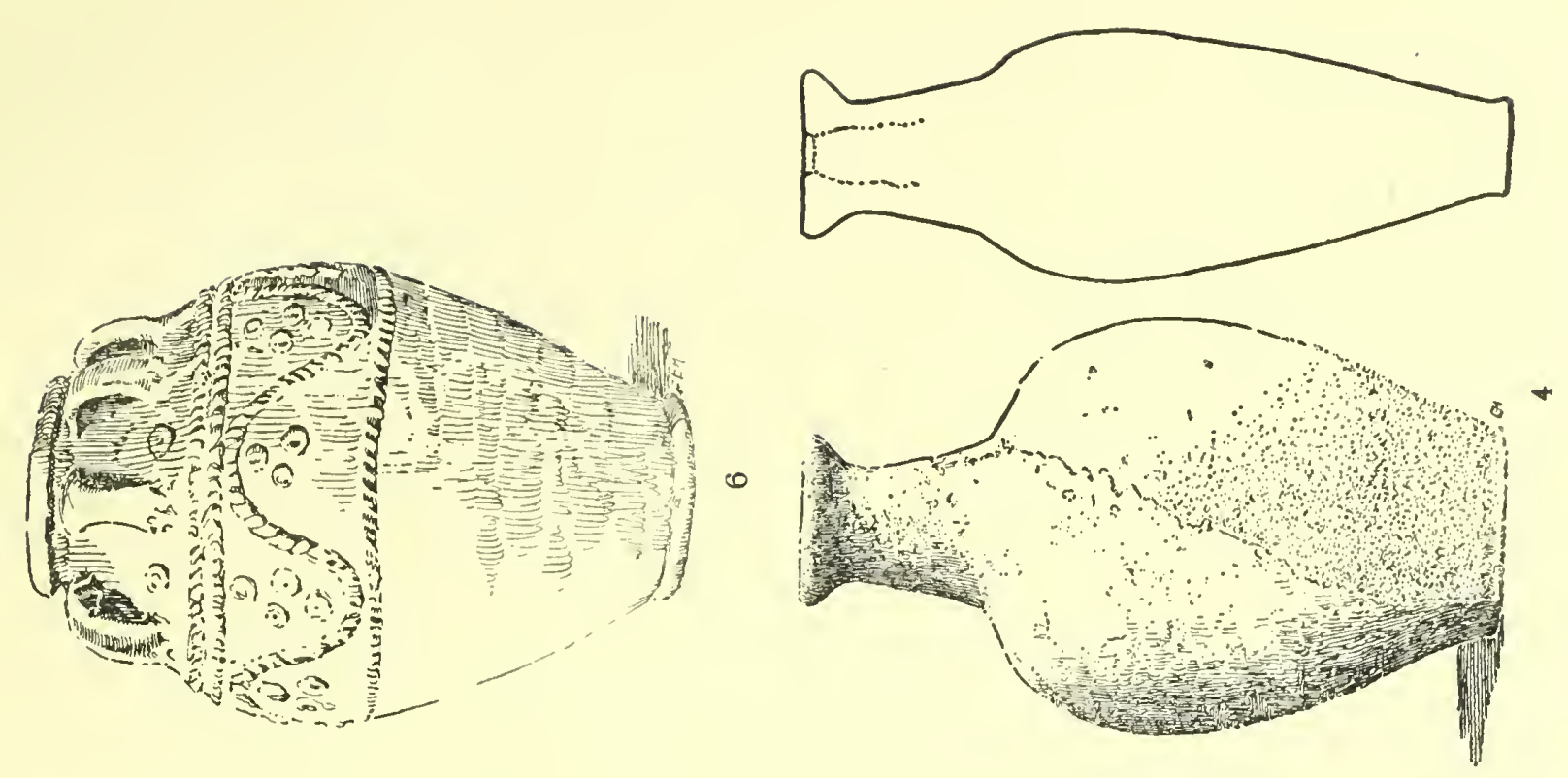

.
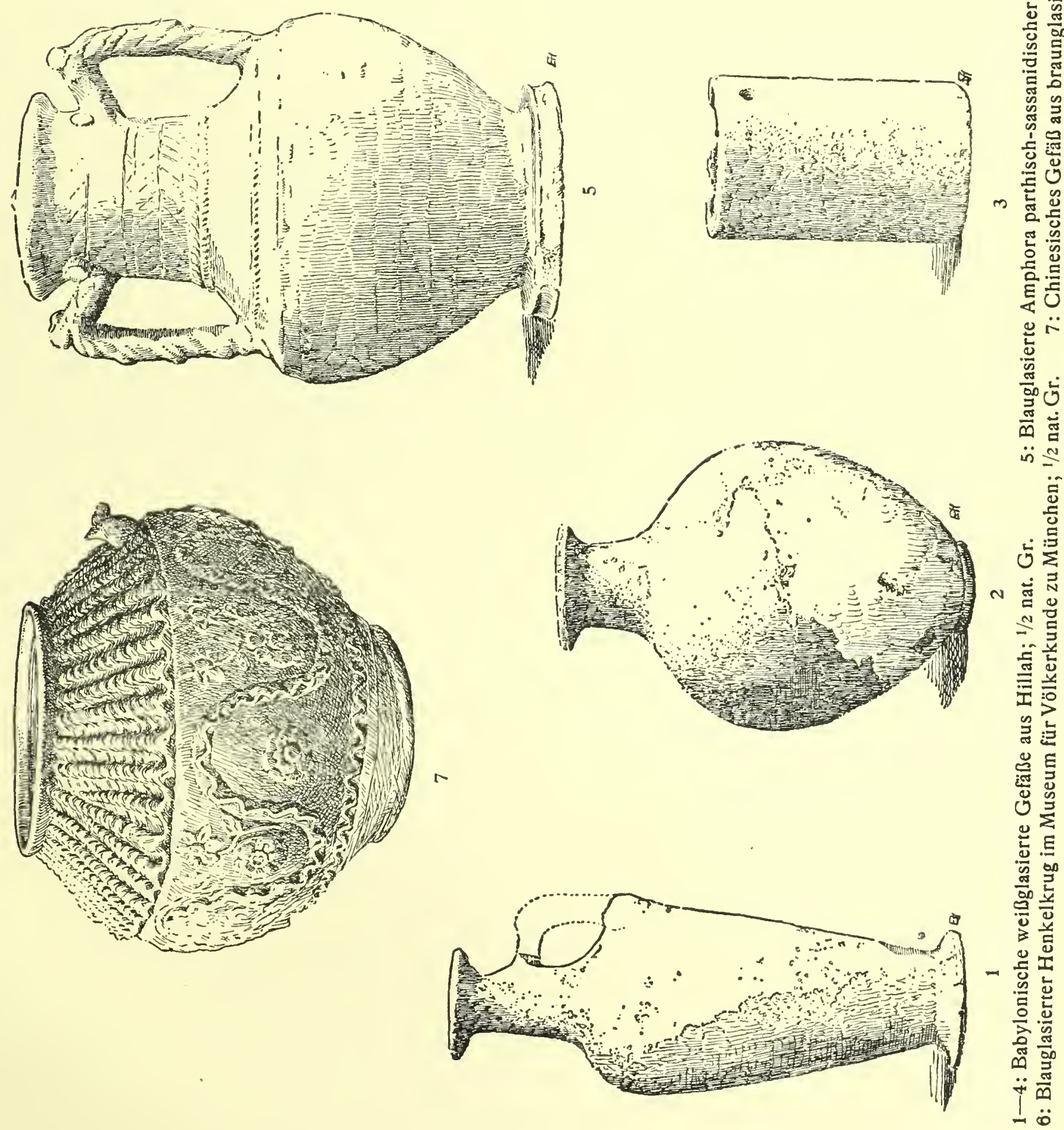

है

苋

总寻

ș

\%

존.

总

栗

要

in 


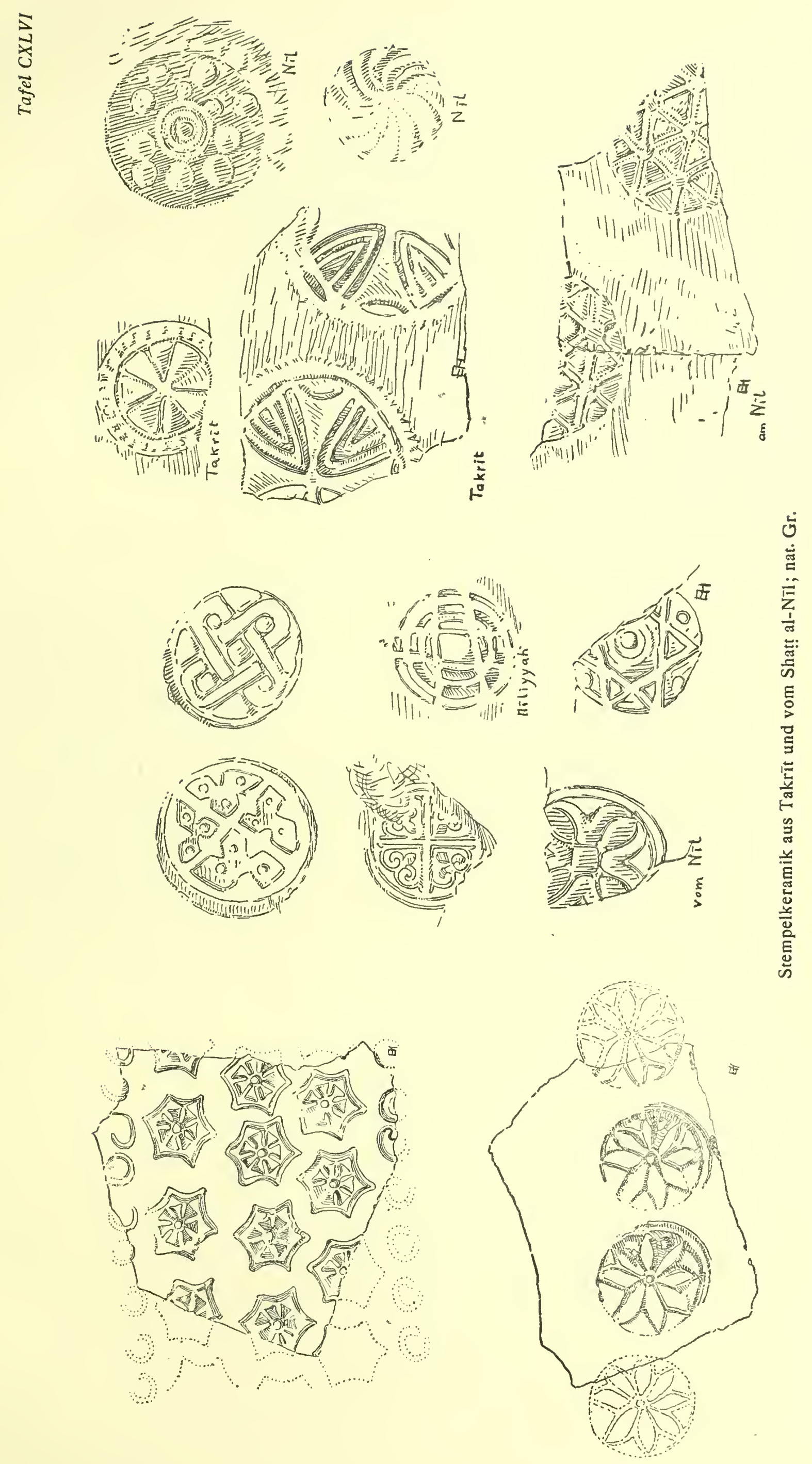



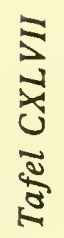

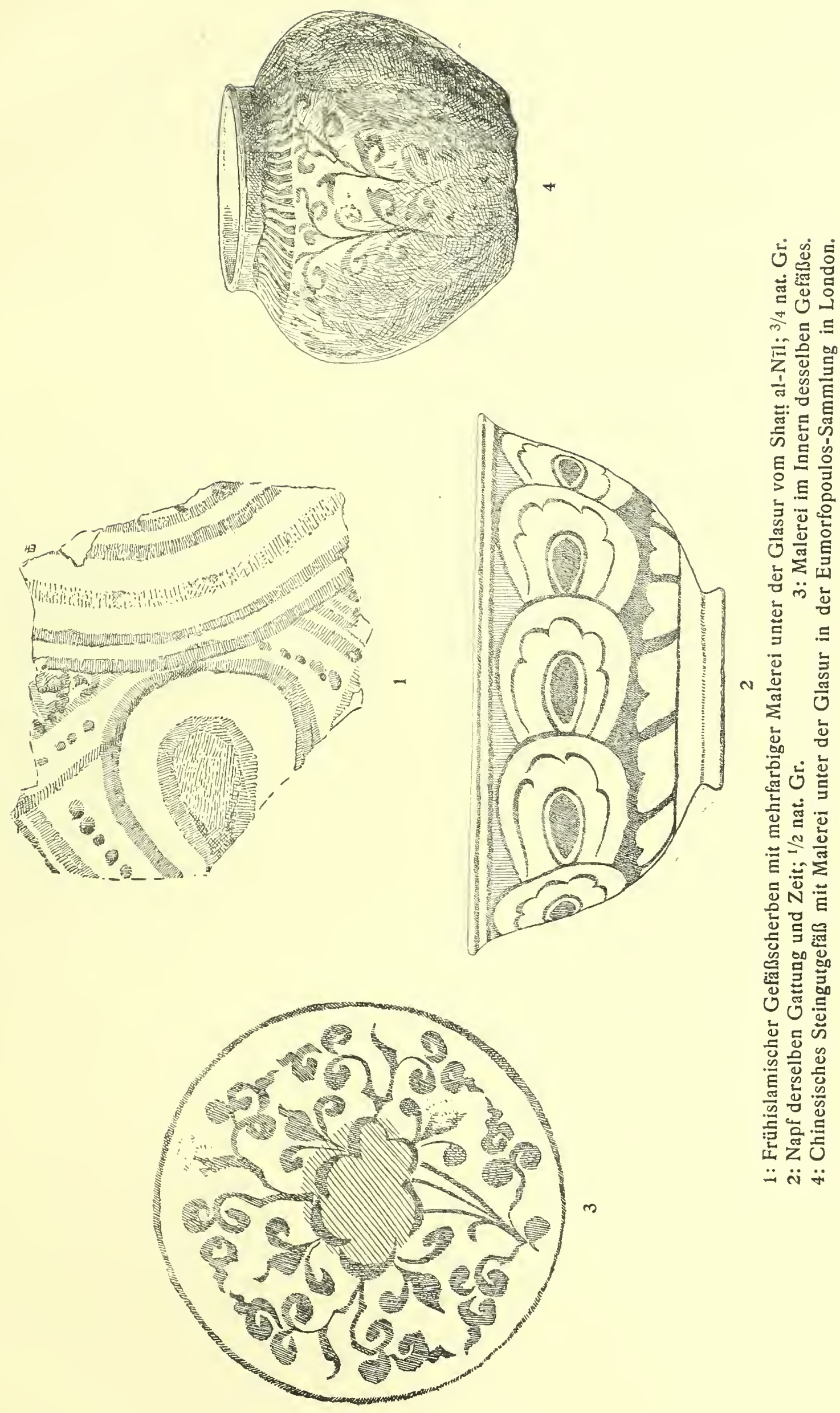







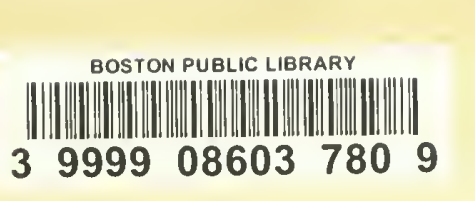


